

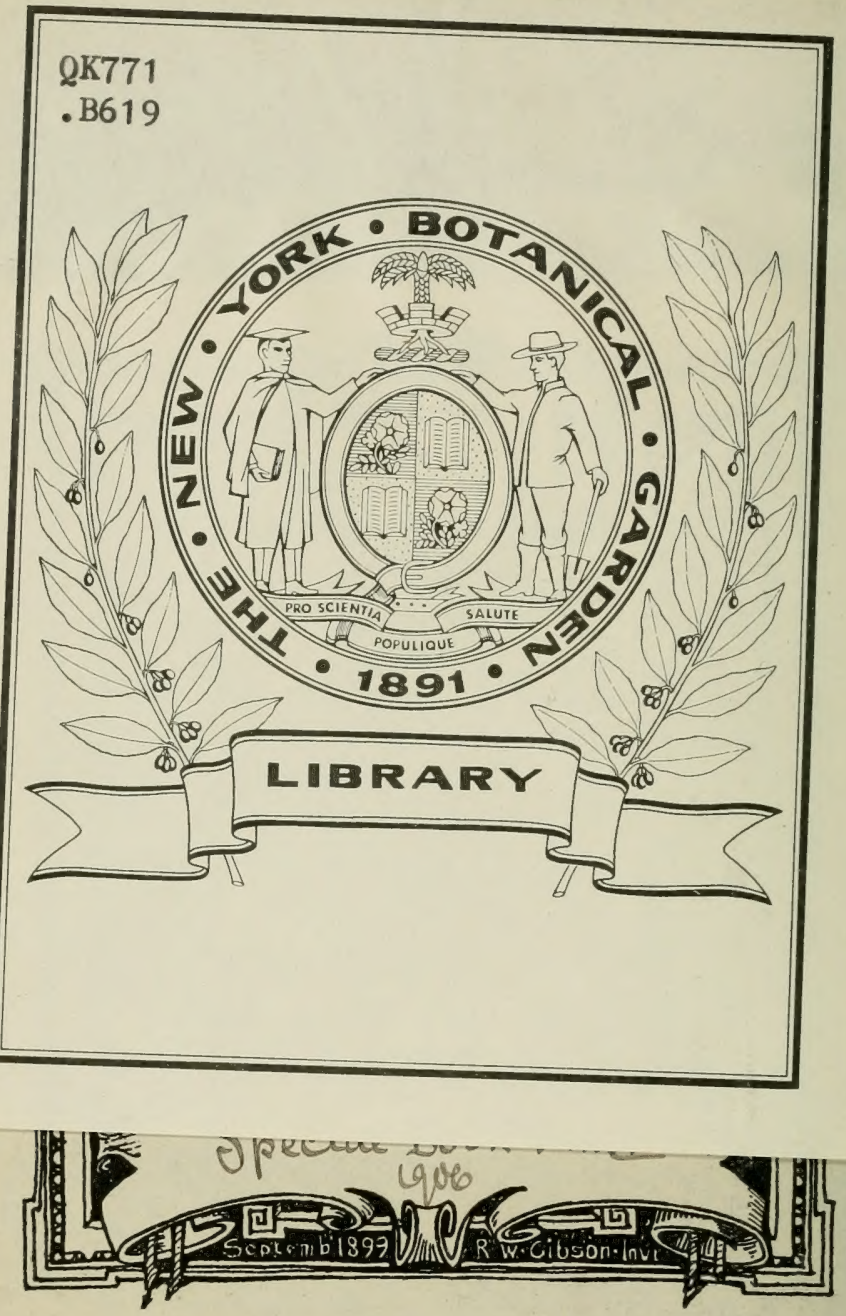

RESPONSE IN THE LIVING AND NON-LIVING 



\section{RESPONSE IN THE LIVING}

\section{ANI) NON-LIVING}

BY

JAGADIS CHUNDER BOSE, M.A.(Cantab.), D.Sc.(Lond.) PROFESSOR, PRESIDENCY COLLEGE, CALCUTTA

\section{LIBRARV \\ NEW YORK \\ BOTANICAL. \\ GAPDIN}

WITH ILLUSTRATIONS

LONGMANS, GREEN, AND CO.

39 PATERNOSTER ROW, LONDON

NEW YORK AND BOMBAY

1902 
.3619

'The real is one: wise men call it variously'

RIG VEDA 
To my Countrymen

This Work is Dedicated 



\section{PREFACE}

IIBRNKY ATPXY YORK

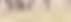

I nave in the present work put in a comnected and a more complete form results, some of which have been published in the following Papers:

'De lia Généralité des Phénomènes Moléculaires produits par l'Electricité sur la matière Inorganique et sur la matière Vivante.' (Travaux du Congrès International de Physique. Paris, 1900.)

'On the Similarity of Effect of Electrical Stimulus on Inorganic and Living Substances.' (Report, Bradford Meeting British Association, 1900.-Electrician.)

'Response of Inorganic Matter to Stimulus.' (Friday Evening Discourse, Royal Institution, May 1901.)

- On Electric Response of Inorganic Substances. Preliminary

Notice.' (Royal Society, June 1901.)

'On Electric Response of Ordinary Plants under Mechanical Stimulus.' (Journal Linnean Society, 1902.) 'Sur la Réponse Electrique dans les Métaux, les 'lissus Animaux et Végétaux.' (Société de Physique, Paris, 1902.)

'On the Electro-Motive Wave accompanying Mechanical Disturbance in Metals in contact with Electrolyte.' (Proceedings Royal Society, vol. 70.)

'On the Strain Theory of Vision and of Photographic Action.' (Journal Royal Photographic Society, vol. xxvi.) 
viii RESPONSE IN THE LIVING AND NON-LIVING

These investigations were commenced in Inclia, and I take this opportunity to express my grateful acknomlerlgments to the Managers of the lioyal Institution. for the facilities offered me to complete them at the Davy-Faraclay Laboratory.

J. C. Bost:

Daty-Faradar Laboratory, loyal Institution, LoNDon: May 1902. 


\title{
CONTENTS
}

\author{
CHAPTER I \\ THE MIECHANICAL RESPONSE OF LIVING SUBSTANCES
}

Mechanical responst-Different kinds of stimuli-Myograph-Characteristics of response-curve : period, amplitude, form-Modification of response-curves

\section{CHAPTER II}

\section{ELECTRIC RESPONSE}

C'onditions for obtaining electric response-Method of injury-C'urrent of injury-Injured end, cuproid: uninjured, zincoid-Current of response in nerve from more excited to less excited-Difficulties of present nomenclature-Electric recorder-Two types of response, positive and negative-Universal applicability of electric mode of response-Electric response a measure of physiological activityElectric response in plants

\section{CHAPTER III}

\section{ELECTRIC RESPONSE IN PLANTS- IIETHOD OF NEGATIVE} VARIATION

Negative rariation - liesponse recorder-Photographic recorder-Compensator-Means of graduating intensity of stimulus-Springtapper and torsional vibrator-Intensity of stimulus dependent on amplitude of vibration-Effectiveness of stimulus dependent on rapidity also. 


\section{CHAPTER IV}

ELECTRIC RESPONSE IN PLANTS-BLOCK METHOD

Method of block-Adrantages of block method-Plant response a physiological phenomenon-Abolition of response by anæsthetics and poisons-Abolition of response when plant is killed by hot water .

\section{CHAPTER V}

PLANT RESPONSE-ON THE EFFECTS OF SINGLE STIMULUS AND OF SUPERPOSED STIMULI

Effect of single stimulus - Superposition of stimuli-Additive effectStaircase effect-Fatigue-No fatigue when sufficient interval between stimuli-Apparent fatigue when stimulation frequency is increased-Fatigue under continuous stimulation

\section{CHAPTER VI}

\section{PLANT RESPONSE-ON DIPHASIC VARIATION}

Diplıasic variation-Positive after-effect and positive response-Radial E.M. variation

\section{CHAPTER VII}

\section{PLANT RESPONSE-ON TJE RELATION BETWEEN} STIMULUS AND RESPONSE

Increased response with increasing stimulus-Apparent diminution of response with excessively strong stimulus 


\section{CHAPTER VIII}

\section{PLANT RESPONSE-ON THE INFLUENCE OF TEMPERATURE}

Effect of very low temperature-Influence of high temperatureDetermination of death-point-Increased response as after-effect of temperature variation-Death of plant and abolition of response by the action of steam . . . . . . .

\section{CHAPTER IX}

PLANT RESPONSE-EFFECT OF AN ESTHETICS AND POISONS

Effect of anæsthetics, a test of vital character of response-Effect of chloroform-Effect of chloral-Effect of formalin-Method in which response is unaffected by variation of resistance-Advantage of block method-Effect of dose . . . . . . .

\section{CHAPTER X}

\section{RESPONSE IN METALS}

Is response found in inorganic substances?-Experiment on tin, block method-Anomalies of existing terminology--Response by method of depression-Response by method of exaltation .

\section{CHAPTER XI}

\section{INORGANIC RESPONSE-MODIFIED APPARATUS TO EXHIBIT} RESPONSE IN METALS

Conditions of obtaining quantitative measurements-Modification of the block method-Vibration cell-Application of stimulusGraduation of the intensity of stimulus-Considerations showing that electric response is due to molecular disturbance-Test experiment-Molecular voltaic cell 


\section{CHAPIER XII}

\section{INORGANIC RESPONSE-RETHOD OF ENSURING CONSISTENT} 1RESULTS

Preparation of wire-Effect of single stimulus . . . . . 100

\section{CHAPTER XIII}

\section{INORGANIC RESPONSE-MOLECULAR MOBILITY :}

ITS INFLUENCE ON RESPONSE

Effects of molecular inertia-Prolongation of period of recovery by overstrain-Molecular model-Reduction of molecular sluggishness attended by quickened recovery and heightened responseEffect of temperat ure-Modification of latent period and period of recovery by the action of chemical reagents-Diphasic variation .

\section{CHAPTER XIV}

INORGANIC RESPONSE-FATIGUE, STARCASE, AND MODIFIED RESPONSE

Fatigue in metals - Fatigue under continuous stimulation-Staircase effect-Reversed responses due to molecular modification in nerve and in metal, and their transformation into normal after continuous stimulation-Increased response after continuous stimulation

\section{CHAPTER XV}

INORGANIC RESPONSE-RELATION BETIVEEN STIMULUS AND RESPONSE-SUPERPOSITION OF STIMULI

Relation between stimuius and response-Magnetic analogue-Increase of response with increasing stimulus-Threshold of response -Superposition of stimuli-Hysteresis . . . . . 


\section{CHAP'TER XVI}

INORGANIC RESPONSE-EFFECT OF CHEMICAL REAGENTS

Action of chemical reagents-Action of stimulants on metals-Action of depressants on metals-Eftect of 'poisons' on metals-Opposite eflect of large and small doses

\section{CHAPTER XVII}

\section{ON THE STIMULUS OF LIGHT AND RETINAL CURRENTS}

Visual impulse : (1) chemical theory; (2) electrical theory-Retinal currents-Normal response positive-Inorganic response under stimulus of light-Typical experiment on the electrical effect induced by light

\section{CHAPIER XVIII}

\section{INORGANIC RESPONSE-INFLUENCE OF VARIOUS CONDI- TIONS ON THE RESPONSE TO STIMULUS OF LIGHT}

Effect of temperature-Effect of increasing length of exposure--Relation between intensity of light and magnitude of response-Afteroscillation-Abnormal effects: (1) preliminary negative twitch: (2) reversal of response; (3) transient positive twitch on cessation of light; (4) decline and reversal-Résumé

\section{CHAPTER XIX}

VISUAL ANALOGUES

Effect of light of short duration-A fter-oscillation-Positive and negative after-images-Binocular alternation of vision-Period of alter. nation modified by physical condition-After-images and their revival-Unconscious visual impression

\section{CHAPTER XX}

GENERAL SURVEY AND CONCLUSION . . 1K1 



\section{ILLUSTRATIONS}

WIG.

PAGE

1. Mechanicat Leter Recorder . . . . . . 3

2. Electric Method of Detecting Nerve Response a . 6

:). Diagram shoting Injured End of Nerve Correspondos to Copper in a Toltatc Element . . . . . 8

4. Electric Tiecorder . . . . . . . . . 11

5. Simultaneous Record of Mechanical and Electrical Responses . . . . . . . 13

(i. Negative Variation in Plants . . . . . 19

7. Photographic Record of Negative Variation in Plants 20

8. Response Recorder . . . . . . . . 21

๑. The Compensator . : . . . . . . . 22

10. The Spring-tapper . . . . . . . . 23

11. The Torsionat Tibrator. . . . . . 24

1:. Response in Plant to Mechanical Tap or Vibration . 25

13. Infiuence of Sudpenness on the Efficinacy of Stimulus 26

14. The Method of Block . . . . . . . 28

15. Response in Plant completely Imaersan under Water 29

16. Uniforil Responses in Plant . . . . . . 36

17. Fusion of Effect under Rapidix Succending Stimuli in Muscle and in Plant . . . . . . . . 36

18. Adpitive Effect of Singly Infafective Stimuli on Plant . . . . . . . . 37

19. 'Statrcase Effect' in Plant . . . . . . 37

20. Appearance of Fatigue in Plant under Shortened Pertod of Rest . . . . . . . . . 
FIG.

21. Fatigue in Celiery . . . . . . . 40

22. Fatigue in CaUliflower-stalk . . . . . . . 41

23. Fatigue From Previods Overstraix . . . . . 41

24. Fatigue under Continuous Stimulation in Celery * 42

25. Effect of Rest in Removal of Fatigue if Prant . . 43

26. Diphasic Vartation in Plant. . . . . . . 46j

27, 28. Abnormal Positive Responses ix Stale Planix transformed into Noryal Negative under Śtrong StimuLATION

29. Radiat E.M. Variation . . . . . . . . 50

30. Curves showing the Relation Becween INTeNsity of Stimulus and Response in MUscle axd Nerve . . 52

31. Increasing Responses to Ifrereasing Stimuli (Taps) in Piants . . . . . . 52

32. Incraasing Responses to Increasing VibRatoxal Stimuli IN PJANTS . . . . . . . . . . . . .

33. Responses to Increasting Stmuld in Fresh and Stale SPHCMENS OF PLANTS . . . . . . 54

31. Apparent Diminution of Response caused by Fatigue UNDER STRONG STIMUJATIO

35). Diminution of Response in Eucharts Liey at Low ThaiPERATURF

36. Records showing the Difference ix the EFFects of Low Temperature oN IVI, HoLly, AND EUCharis LiLY

37. Plant Chamber for Studing the Effect of TemperaTIRE AND ANASTHETICS .

38. Effhct of High Temperature on Plant Response:

39. After-tiffect on the Response due to Temperature VARIATION

40. Records of Responses in Eucharis Lily duriyg Rise axd FAII OF Temperature

41. Curve showing Variaton of Sexsitiveness Durixg a Cycle of Temperature Variation

42. Record of Effect of Steam in Abolition of Response at Death of Plant 
4:3. Effect of Chloroform on Nerve Response . . . 72

44. Effect of Chlorofora on tue Responses of Carrot . 74

4.). Action of Chloral Hydrate on Plant Responses • 75

46. Action of Formalin on Radisil . . . . . . 75

47. Action of Sodium Hrorate in Abolishing the Response in Plant : . . . . . . . . 78

4\%. Stmiulating Action of Poison in Syald Doses in Plants 79

49. The Poisonous Effect of Stronger Dose of Koll . 79

50. Block Method for obtaining Response in Tin . . 83

.)1. Response to Mechanical Stimulation in a Zn-Cu Couple 85

52. Eiectidic Response in Metal by the Method of Relative Depression (Negative Variation) . . . . 88

53. Method of Relative Exaltation . : . . . . 89

54. Various Cases of Positive and Negative Variation . 90

5). Modffications of the Block Method for Exhibiting Electric Response in Metals . . . . . . 93

56. Equal and Opfosite Resfonses given bx Two Ends of THE TVtRE. . . . . . . . . 95

57. Top View of the Vimation Cell. . • . . . 96

58. Tnflutince of Annea ing in the Enhancement of Response in Metals . . . . . . . 101

59. Unifokm Electric Responses in Metals • • . . 102

60. Persistence of Aftei-effect . . . . . . 105

61. Prolongation of Period of Recotery after Orerstrain 106

6:. Molecular Model . . . . . . . . . 107

6:3, 64. Effects of Remotal of Molecular Sluggisiness in Quickened Recovery and Heightened Response in Metals . . . . . . . . 109, 110

65. Effect of Temperature on Response in Metals. . . 111

66. Diphasic Variation in Metals . . . . . . 113

67. Negatme, Diphasic, and Positive Resultant Riesponse in Metals . . . . . . . . . . 115 
wiii RESPONSE IN THE LIVING AND NON-LIITNG

Fin.

PA(i:

68. Conmevods Transformation from Negative to Positive throdgh Ixterdedite Diphasic Response . . . 116

69. Fatigue in Muscle . . . . . . . . . 118

70. Fatigue in Pisitinum . . . . . . . . 118

71. Fattgete in Tin. . . . . . . . . 119

7.2. Appharance of Fatigue def to Shortentag the Period of Recovery . . . . . . . 120

73. Fatigue in Meral under Continuous Strmulation . . 121

74. 'Statrcase' Response in Muscle and in Metal . . 19.2

75. Abnormal Response in Nerve conterted into Normal under Continued Stimulation . . . . . . 124

76, 77. Amnormat Response in Tin and Platinum conterted into Normal uxder Coxtinued Stimulation . . 12.;

78. Gradual Transition from Abnormal to Normal Response in Platinum . . . . . . . 1266

79. Increase of Respoxse ix Nerve after Contixuous STIMUtatio

80, 81. Response in Tin and Platixum Exhanced after Contindous Stmulation . . . . . . 127, 1:28

82. Magnetic Axalogut . . . . . . . 13:

83, 84. Records of Responses to Increasing Stumuli in Trin 134, 135

85. Ineffective: Strmulus becoming Effectite by SuperPOSITION . . . . . . 135

86. Incomplete and Complete Fusion of Effects . . 136

87. Crclic Curvi for Maximum Efencts showing Hrsteresis $1: 37$

89. Action of Poison in Abomishixg Response in Nerte . 139

89. Action of Strmulant ox Tix . . . . . 141

90. Action of Strmulant on Platinum . . . . 14:

91. Depressing Effect of KBr ox Tix . . . . . 143

92. Abolition of Response in Metals bx 'Poison' . . . 1at3

13. 'Molecular Arrest' by the Action of 'Porson' . . 145

9. Opposite Effects of Shall and Large Doses ox the Response in Mrtals . . . . . . . 146

9.). Retinal Rrsponse to Jighti . . . . . . 150 
96. Response of Sensitivi Celi to Light .

97. Trpical Experiment on the E.M. Variation l'roducho BY LIGHT . . . . . . . . . 15t

98. Modification of the Photo-sensitive Celt . . . . 155

99. Responses in Frog's Retina . . . . . . 1566

100. Responses in Sensitive Photo-Cele . . . . . 15\%

101. Effect of Temperature on the Response to Light Strmulus . . . . . . . . . $15 \%$

102. Effect of Duration of Expostre on the Response . . 1.)?

103. Responses of Sensitive Cele to Increasive Intensiticis OF Light . . . . . . . . . 161

104. Rfiation between the Intensity of Light and MagniTUDE OF RESPONSE. . . . . . . . . 16:

105. After-oscillation . . . . . . . . . 1(i:;

106. Transient Positive Increase of Response in the Frog's Rfinta on the Cessation of Lithit . . . . 164

107. Transient Positire Increase of Response in the Sensitive Celí, . . . . . . . 16.5

108. Dechine under the Continuous Action of Light . . 16t;

109. Cfertain After-effects of Light . . . . I fir

110. After-ffFect of Light of Short Duration . . . 17.

111. Stereoscopic Design for the Exhibition of Binocurar Alternation of Vision . . . . . . 17 ;

112. Unffory Responses in Nerve, Plant, axd Metal . . Mit

113. Fatigue in Muscle, Plant, and Metal . . . 1 . . .

114. 'Stalroase' Effect in Muscle, Plant, and Mrtai . . 186 ;

115. Increase of Response after Continuous Stimulation in

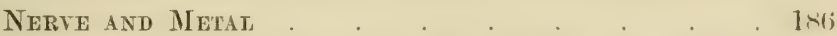

116. Modified Abnormal Response in Nerve and Metat Transformed into Nolmal Response after Continuous Stimulation . . . . . . . . 187

117. Action of the same 'Poison' in the Abotrtion of Response in Nerte, Plant, and Metal 



\section{RESPONSE}

IN THE

\section{LIVING AND NON-LIVING}

\section{CHAPTER I}

THE MECHANICAL RESPONSE OF LIVING SUBSTANCES

Mechanical response-Different kinds of stimuli-Myograph-Characteristics of response-curve:, period, amplitude, form-Modification of response-curves.

ONE of the most striking effects of external distmrbance on certain types of living substance is a visible change of form. Thus, a piece of muscle when pinched contracts. The external disturbance which produced this change is called the stimulus. The body which is thus capable of responding is said to be irritable or (xeitable. A stimulus thus produces a state of excitability which may sometimes be expressed by change of form.

Mechanical response to different kinds of stimuli.This reaction under stimulus is seen even in the lowest organisms; in some of the amohoid rhizopods, for instance. These lumpy protoplasmic bodies, usually elongated while creeping, if mechanically jarred, contract into a spherical form. If, instead of mechanical 
disturbance, we apply salt solution, they again contract, in the same way as before. Similar effects are produced by sudden illumination, or by rise of temperature, or by electric shock. A living substance may thus be put into an excitatory state by either mechanical, chemical, thermal, electrical, or light stimulus. Not only does the point stimulated show the effect of stimulus, but that effect may sometimes be conducted even to a considerable distance. This power of conducting stimulus, though common to all living substances, is present in very different degrees. While in some forms of animal tissue irritation spreads, at a very slow rate, only to points in close neighbourhood, in other forms, as for eximple in nerves, conduction is rery rapid and reaches far.

The visible mode of response by change of form may perhaps be best studied in a piece of muscle. When this is pinched, or an electrical shock is sent through it, it becomes shorter and broader. A responsive twitch is thus produced. The excitatory state then disappears, and the muscle is seen to relax into its normal form.

Mechanical lever recorder.-In the case of contraction of nuscle, the effect is very quick, the twitch takes place in too short a time for detailed obserration by ortinary means. A myographic apparatus is therefore used, by means of which the changes in the muscle are self-recorded. Thus we obtain a history of its change and recovery from the change. The muscle is connected to one end of a writing lever. When the muscle contracts, the tracing point is pulled up in one 
direction, say to the right. The extent of this pull depends on the amount of contraction. A band of paper or a revolving drum-surface moves at a uniform speed at right angles to the direction of motion of the writing lever. When the muscle recovers from the stimulus, it relaxes into its original form, and the writing point traces the recovery as it moves now to the left, regaining its first position. A curve is thus described, the rising portion of which is due to contraction, and the falling portion to relaxation or recovery. The ordinate of the curve represents the intensity of response, and the abscissa the time (fig. 1).

Characteristics of the responsecurve: (I) Period, (2) Amplitude, (3) Form.-Just as a wave of sound is characterised by its (1) period, (2) amplitude, and (3) form, so may these response-curves be distinguished from each other. As regards the period, there is an

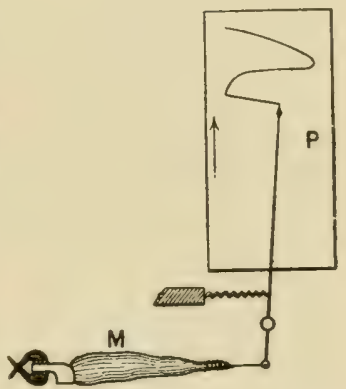

Fig, 1.-Mechanical Lever ReCORDER

The muscle M with the attached bone is securely held at one end, the other end being connected with the writing lever. Under the action of stimu. lus the contracting muscle pulls the lever and moves the tracing point to the right over the travelling recording surface $P$. When the muscle recovers from contrac. tion, the tracing point returns to its original position. See on $\mathrm{P}$ the record of muscle curve.

enormous variation, corresponding to the functional activity of the muscle. For instance, in tortoise it may be as high as a second, whereas in the wing-muscles of many insects it is as small as $\frac{1}{300}$ part of a second. - It is probable that a continuous graduated scale might, as suggested by Hermann, be drawn up in the animal kingdom, from the excessively rapid contraction of 
insects to those of tortoises and hibernating dormice.' 1 Differences in form and amplitude of curve are well illustrated by various muscles of the tortoise. The curve for the muscle of the neck, used for rapid withdrawal of the head on approach of danger, is quite different from that of the pectoral muscle of the same animal, used for its sluggish movements.

Again, progressive changes in the same muscle are well seen in the modifications of form which conserutive muscle-curves gradually undergo. In a dying muscle, for example, the amplitude of succeeding curves is continuously diminished, and the curres themselves are elongated. Numerous illustrations will be seen later, of the effect, in changing the form of the curve, of the increased excitation or depression produced by various agencies.

Thus these response records give us a means of studying the effect of stimulus, and the modification of response, under varying external conditions, advantage being taken of the mechanical contraction produred in the tissue by the stimulus. But there are other kinds of tissue where the excitation produced by stimulus is not exhibited in a visible form. In order to study these we have to use an altogether independent method, the method of electric response.

Biederman, Electro-physiology, p. 59. 


\section{CHAPTER II}

\section{ELECTRIC RESPONSE}

Conditions for obtaining electric response-Method of injury-Current of injury-Injured end, cuproid : uninjured, zincoid-Current of response in nerve from more excited to less excited-Difficulties of present nomenclature-Electric recorder-Two types of response, positive and negative -Universal applicability of electric mode of response-Electric response a measure of physiological activity-Electric response in plants.

UnLike muscle, a length of nerre, when mechanically or electrically excited, does not undergo any visible change. That it is thrown into an excitatory state, and that it conducts the excitatory disturbance, is shown however by the contraction produced in an attached piece of muscle, which serves as an indicator.

But the excitatory effect produced in the nerve by stimulus can also be detected by an electrical method. If an isolated piece of nerve be taken and two contacts be made on its surface by means of non-polarisable electrodes at $\mathrm{A}$ and $\mathrm{B}$, comnection being made with a galvanometer, no current will be observed, as both A and $\mathrm{B}$ are in the same physico-chemical condition. The two points, that is to say, are iso-electric.

If now the nerve be excited by stimulus, similar disturbances will be eroked at both $A$ and $B$. If, further, these disturbances, reaching $\mathrm{A}$ and $\mathrm{B}$ almost simultaneously, cause any electrical change, then, 
similar changes taking place at both points, and there being thus no relative difference between the two, the galvanometer will still indicate no current. This nulleffect is due to the balancing action of $\mathrm{B}$ as against 1 . (See fig. 2, a.)

Conditions for obtaining electric response.-If then we wish to detect the response by means of the galvanometer, one means of doing so will lie in the abolition of this balance, which may be accomplished by making one of the two points, say B, more or less permanently
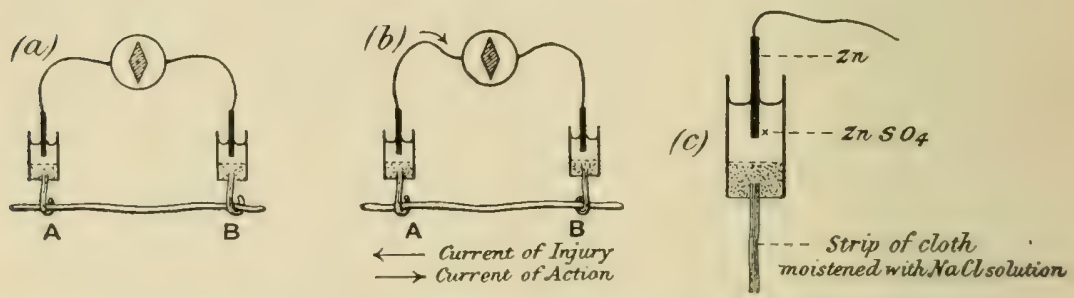

Fig. 2.-Electric Methon of Detecting Nenve Response

(a) Iso-electric contacts; no current in the galvanometer.

(b) The end B injured; current of injury from B to A: stimulation gives rise to an action current from $\mathrm{A}$ to $\mathrm{B}$.

(c) Non-polarisable electrode.

irresponsive. In that case, stimulus will cause greater electrical disturbance at the more responsive point, say $\mathrm{A}$, and this will be shown by the galranometer as a current of response. To make $B$ less responsive we may injure it by means of a cross-sectional cut, a burn, or the action of strong chemical reagents.

Current of injury.--We shall revert to the subject of electric response; meanwhile it is necessary to say a few words regarding the electric disturbance caused by the injury itself. Since the physico-chemical conditions of the uninjured $A$ and the injured $B$ are now no longer the same, it follows 
that their electric conditions have also become different. They are no longer iso-electric. There is thus a more or less permanent or resting difference of electric potential between them. A current-the current of injury-is found to flow in the nerve, from the injured to the uninjured, and in the galvanometer, through the electrolytic contacts from the uninjured to the injured. As long as there is no further disturbance this current of injury remains approximately constant, and is therefore sometimes known as 'the current of rest' (fig. 2, b).

A piece of living tissue, unequally injured at the tro ends, is thus seen to act like a voltaic element, comparable to a copper and zinc couple. As some confusion has arisen, on the question of whether the injured end is like the zinc or copper in such a combination, it will perhaps be well to enter upon this subject in detail.

If we take two rods, of zinc and copper respectively, in metallic contact, and further, if the points $A$ and lis are connected by a strip of cloth $s$ moistened with salt solution, it will be seen that we have a complete voltaic element. A current will now flow from $B$ to $A$ in the metal (fig. 3 , a) and from $A$ to $B$ through the electrolyte $s$. Or instead of connecting $A$ and $B$ by a single strip of cloth $s$, we may connect them by tro strips $s s^{\prime}$, leading to non-polarisable electrodes $\mathrm{E} \mathrm{E}^{\prime}$. The current will then be found just the same as before, i.e. from I) to $A$ in the metallic part, and from $A$ through $s s^{\prime}$ to 1 , the wire $\mathrm{w}$ being interposed, as it were, in the electrolytic part of the circuit. If now a galvanometer be interposed at $o$, the current will flow from $\mathrm{B}$ to $\mathrm{A}$ through the galvanometer, i.e. from right to left. But if we interpose the galvanometer in the electrolytic part of the circuit, that is to say, at $w$, the same current will appear to flow in the opposite direction. In fig. 3, c, the galvanometer is so interposed, and in this case it is to be noticed that when the current in the galvanometer flows from left to right, the metal connected to the left is zinc.

Compare fig. $3, d$, where $A$ B is a piece of nerve of which the $\mathrm{I}$ end is injured. The current in the galvanometer 
through the non-polarisable electrode is from left to right. The uninjured end is therefore comparable to the zinc in a voltaic cell (is zincoid), the injured being copper-like or cuproid. ${ }^{1}$

If the electrical condition of, say, zinc in the voltaic couple (fig. 3, c) undergo any change (and I shall show later that this can be caused by molecular disturbance), then the existing difference of potential between $A$ and $B$ will also undergo variation. If for example the electrical condition of A approach that of $\mathrm{B}$, the potential difference will undergo a
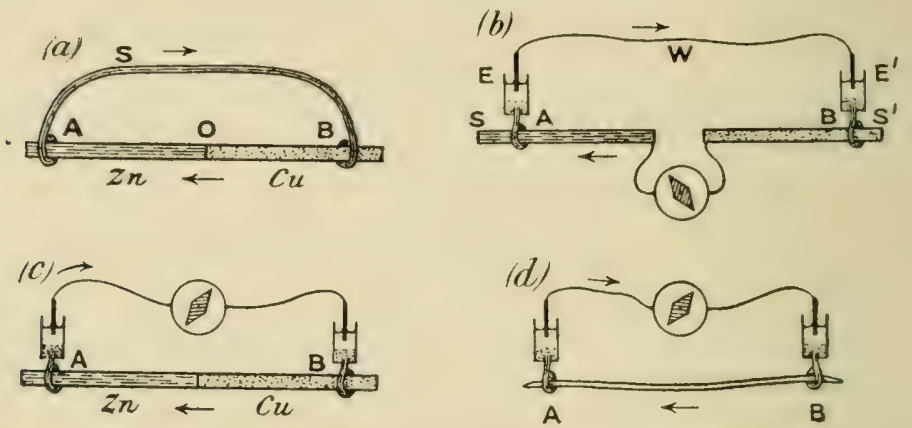

Frg. 3.-Diagram showing the Correspondence between injured (B) and uninjored (A) contacts in Nerve, and Cu and Zn in a Voltaic Element Comparison of $(c)$ and $(d)$ will show that the injured end of $\mathbf{B}$ in $(d)$ corresponds with the $\mathrm{Cu}$ in $(c)$.

diminution, and the current hitherto flowing in the circuit will, as a consequence, display a diminution, or negative variation.

Action current.- WVe have seen that a current of injury-sometimes known as 'current of rest'-flors in a nerve from the injured to the uninjured, and that the injured $\mathbf{B}$ is then less excitable than the uninjured A. If now the nerve be excited, there being a greater

1. In some physiological text-books much wrong inference has been made, based on the supposition that the injured end is zinc-like. 
effect produced at $A$, the existing difference of potential may thus be reduced, with a consequent diminution of the current of injury. During stimulation, therefore, a nerve exhibits a negative variation. We may express this in a different way by saying that a 'current of action' was produced in response to stimulus, and acted in an opposite direction to the current of injury (fig. 2, b). The action current in the nerve is from the relatively more excited to the relatively less excited.

Difficulties of present nomenclature.-We shall deal later with a method by which a responsive current of action is obtained without any antecedent current of injury. 'Negative variation' has then no meaning. Or, again, a current of injury may sometimes undergo a change of direction (see note, p. 12). In view of these considerations it is necessary to have at our disposal other forms of expression by which the direction of the current of response can still be designated. lieeping in touch with the old phraseology, we might then call a current 'negative' that flowed from the more excited to the less excited. Or, bearing in mind the fact that an uninjured contact acts as the zinc in a voltaic couple, we might call it 'zincoid,' and the injured contact ' cuproid.' Stimulation of the uninjured end, approximating it to the condition of the injured, might then be said to induce a cuproid change.

The electric change produced in a normal nerve by stimulation may therefore be expressed by saying that there has been a negative variation, or that there was a current of action from the more excited to the less excited, or that stimulation has produced a cuproid change.

The excitation, or molecular disturbance, produced by a stimulus has thus a concomitant electrical expres- 
sion. As the excitatory state disalpear's with the return of the excitable tissue to its original condition, the current of action will gradually disappear. The movement of the galvanometer needle during excitation of the tissue thus indicates a molecular upset by the stimulus; and the gradual creeping back of the galvanometer deflection exhibits a molecular recovery.

This transitory electrical variation constitutes the 'response, and its intensity varies according to that of the stimulus.

Electric recorder.- We have thus a methorl of obtaining curves of response electrically. After all, it is not essentially very different from the mechanical method. In this case we use a magnetic lever (fig. t, a), the needle of the galvanometer, which is deflected by the electromagnetic pull of the current, generated under the action of stimulus, just as the mechanical lever was deflected by the mechanical pull of the muscle contracting under stimulus.

The accompanying diagram (fig. $4, b$ ) shows how,

1 'The exciting cause is able to produce a particular molecular rearrangement in the nerve; this constitutes the state of excitation and is accompanied by local electrical changes os an ascertained physical concomitant.'

'The excitatory state evoked by stimulus manifests itself in nerve fibres by E.M. changes, and as far as our present linowledge goes by these only. The conception of such an excitable living tissue as nerve implies that of a molecular state which is in stable equilibrium. This equilibrium can be readily upset by an external agency, the stimulus, but the term "stable" expresses the fact that a change in any direction must be succeeded by one of opposite character, this being the return of the living structure to its previous state. Thus the electrical manifestation of the excitatory state is one whose duration depends upon the time during which the external agent is able to upset and retain in a new poise the liring equilibrium, and if this is extremely brief, then the recoil of the tissue causes such manifestation to be itself of very short duration.'-Text-book of Physiology, ed. by Schäfer, ii. 453 . 
under the action of stimulus, the current of rest undergoes a transitory diminution, and how on the cessation of stimulus there is gradual recovery of the tissue, as exhibited in the return of the galvanometer needle to its original position.

Two types of response - positive and negative. - It may here be added that though stimulus in general produces a diminution of current of rest, or a negative variation (e.g. muscles and nerves), yet, in certain cases, there is an increase, or positive variation. This is seen in the response of the retina to light. Again, a tissue which normally gives a negative variation may

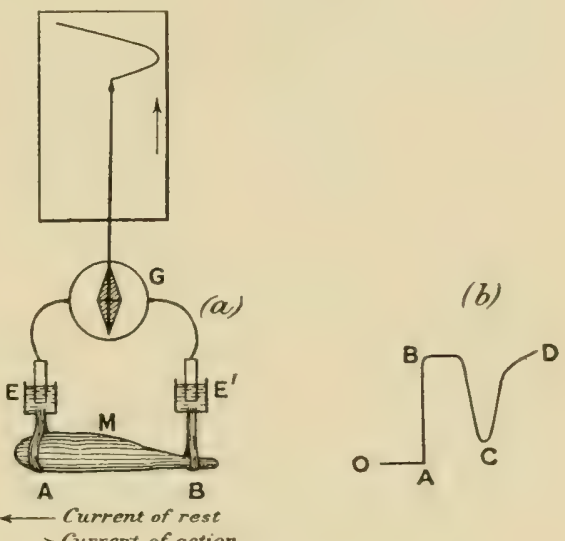

Fig. 4.-Electric Recorder

(a) M muscle; A uninjured, B injured ends. E E' non-polarising electrodes ennnecting $\mathbf{A}$ and B with galvanometer $\mathrm{G}$. Stimulus produces 'negative variation' of current of rest. Index commected with galranometer needle records curve on travelling paper (in practice, moving galvanometer spot of light traces curre on photographic plate). Rising part of curve shows effect of stimulus; descending part, recovery.

(b) $\mathrm{O}$ is the zero position of the galvanometer; injury produces a deflection A B; stimulus diminishes this deflection to $\mathrm{C} ; \mathrm{CD}$ is the recovery.

undergo molecular changes, after which it gives a positive variation. Thus Dr. Waller finds that whereas fresh nerve always gives negative variation, stale nerve sometimes gives positive; and that retina, which when fresh gives positive, when stale, exhibits negative variation. 
The following is a tabular statement of the two types of response:

I. Negative variation.-Action current from more excited to less excited-cuproid change in the excitede.g. fresh muscle and nerve, stale retina.

II. Positive variation.-Action current from less excited to more excited-zincoid change in the excited -e.g. stale nerve, fresh retina. ${ }^{1}$

From this it will be seen that it is the fact of the electrical response of living substances to stimulus that is of essential importance, the sign plus or minus being a minor consideration.

\section{Universal applicability of the electrical mode of} response.-This mode of obtaining electrical response is applicable to all living tissues, and in cases like that of muscle, where mechanical response is also available, it is found that the electrical and mechanical records are practically identical.

The two response-curves seen in the accompanying diagram (fig. $\tilde{y}$ ), and taken from the same muscle by the two methods simultaneously, clearly exhibit this. Thus we see that electrical response can not only take the place of the mechanical record, but has the further

1 I shall here mention briefly one complication that might arise from regarding the current of injury as the current of reference, and designating the response current either positive or negative in relation to it. If this current of injury remained always invariable in direction-that is to say, from the injured to the uninjured-there would be no source of uncertainty. But it is often found, for example in the retina, that the current of injury undergoes a reversal, or is reversed from the beginning. That is to say, the direction is now from the uninjured to the injured, instead of the opposite. C'onfusion is thus very apt to arise. No such misunderstanding can however occur if we call the current of response towards the more excited positive, and towards the less excited negative. 
advantage of being applicable in cases where the latter cannot be used.

\section{Electrical response: A measure of physiological} activity.-These electrical changes are regarderl as physiological, or characteristic of living tissue, for any conditions which enhance physiological activity also, pari passu, increase their intensity. Again, when the tissue is killed by poison, electrical response disappears, the tissue passing into an irresponsive condition. Anæsthetics, like chloroform, gradually diminish, and finally altogether abolish, electrical response.

From these observed factsthat living tissue gives response while a tissue that has been killed does not-it is concluded that the phenomenon of response is peculiar to living organisms. ${ }^{1}$ The response phenomena that we have been studying are therefore considered as due
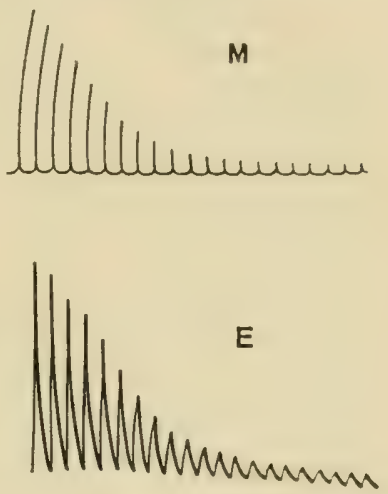

Fig. 5.-Sinultaneous Recorir OF THE MECHANical (M) AND (E) Electrical Responses of THE MIUSCle of Frog. (W.iLLER.)

to some unknown, super-physical 'vital' force and are thus relegated to a region beyond physical inquiry.

1 'The Electrical Sign of Life . . . An isolated muscle gires sign of life by contracting when stimulated. . . An ordinary nerve, normally connected with its terminal organs, gives sign of life by means of muscle, which by direct or reflex path is set in motion when the nerve trunk is stimulated. But such nerve separated from its natural termini, isolated from the rest of the organism, gives no sign of life when excited, either in the shape of chemical or of thermic changes, and it is only by means of an electrical change that we can ascertain whether or no it is alive . . The most general and most delicate sign of life is then the electrical response.'Waller, in Brain, pp. 3 and 4, Spring 1900. 
It may, however, be that this limitation is not justified, and surely, at least until we have explored the whole range of physical action, it cannot be asserted definitely that a particular class of phenomena is by its very nature outside that category.

Electric response in plants.-But before we proceed to the inquiry as to whether these responses are or are not due to some physical property of matter, and are to be met with even in inorganic substances, it will perhaps be advisable to see whether they are not paralleled by phenomena in the transitional world of plants. We shall thus pass from a study of response in highly complex animal tissues to those given under simpler vital conditions.

Electric response has been found by Munck, BurdonSanderson, and others to occur in sensitive plants. But it would be interesting to know whether these responses were confined to plants which exhibit such remarkable mechanical movements, and whether they could not also be obtained from ordinary plants where visible movements are completely absent. In this connection, Kunkel observed electrical changes in association with the injury or flexion of stems of ordinary plants. ${ }^{1} \mathrm{My}$ own attempt, however, was directed, not towards the obtaining of a mere qualitative response, but rather to the determination of whether throughout the whole range of response phenomena a parallelism between animal and regetable could be detected. That is to

1 Funkel thought the electric disturbance to be due to morement of water through the tissue. It will be shown that this explanation is inadequate. 
say, I desired to know, with regard to plants, what was the relation betreen intensity of stimulus and the corresponding response; what were the effects of superposition of stimuli; whether fatigue was present, and in what manner it influenced response; what were the effects of extremes of temperature on the response ; and, lastly, if chemical reagents could exercise any influence in the modification of plant response, as stimulating, anæsthetic, and poisonous drugs have been found to do with nerve and muscle.

If it could be proved that the electric response served as a faithful index of the physiological activity of plants, it would then be possible successfully to attack many problems in plant physiology, the solution of which at present offers many experimental difficulties.

With animal tissues, experiments have to be carried on under many great and unaroidable difficulties. The isolated tissue, for example, is subject to unknown changes inseparable from the rapid approach of death. Plants, howerer, offer a great advantage in this respect, for they maintain their vitality unimpaired during a very great length of time.

In animal tissues, again, the vital conditions themselves are highly complex. Those essential factors which modify response can, therefore, be better determined under the simpler conditions which obtain in vegetable life.

In the succeeding chapters it will be shown that the response phenomena are exhibited not only by plants but by inorganic substances as well, and that the 
responses are modified by various conditions in exactly. the same manner as those of animal tissues. In orler to show how striking are these similarities, I shall for comparison place side by side the responses of animal tissues and those I have obtained with plants and inorganic substances. For the electric response in animal tissues, I shall take the latest and most complete examples from the records made by Dr. Waller.

But before we can obtain satisfactory and conclusive results regarding plant response, many experimental difficulties will have to be surmounted. I shall now describe how this has been accomplished. ${ }^{1}$

1 My assistant $\mathrm{MI}_{\mathrm{l}}$. J. Bull has rendered me very efficient help in these experiments. 


\section{CHAPTER III}

\section{ELECTRIC RESPONSE IN PLANTS-METHOD OF NEGATIVE VARIATION}

Negative variation--Response recorder--Photographic recorder-Compensator-Means of graduating intensity of stimulus-Spring-tapper and torsional vibrator-Intensity of stimulus dependent on amplitude of vibration-Effectiveness of stimulus dependent on rapidity also.

I sinum first proceed to show that an electric response is evoked in plants under stimulation. ${ }^{1}$

In experiments for the exhibition of electric response it is preferable to use a non-electrical form of stimulus, for there is then a certainty that the observed response is entirely due to reaction from stimulus, and not, as might be the case with electric stimulus, to mere escape of stimulating current through the tissue. For this reason, the mechanical form of stimulation is the most suitable.

I find that all parts of the living plant give electric response to a greater or less extent. Some, howerer, give stronger response than others. In favourable cases, we may have an E.M. variation as high as 11 volt.

1 A preliminary account of Electric Response in Plants was given at the end of my paper on 'Electric Response of Inorganic Substances ' read before the Royal Society on June 6, 1901; also at the Friday Evening Discourse, Royal Institution, May 10,1901. A more complete account is given in my paper on 'Electric Response in Ordinary Plants under Mechanical Stimulus' read before the Linnean Society March 20, 1902.

I thank the Royal Society and the Linnean Society for permission to reproduce some of my diagrams published in their Proceedings.-J. C. B. 
It must however be remembered that the response, being a function of physiological activity of the plant, is liable to undergo changes at different seasons of the year. Each plant has its particular season of maximum responsiveness. The leaf-stalk of horse-chestnut, for example, exhibits fairly strong response in spring and summer, but on the approach of autumn it unclergoes diminution. I give here a list of specimens which will be found to exhibit fairly good response:

Root.-Carrot (Daucus Carota), radish (Raphanus sativus).

Stem.-Geranium (Pelargonium), vine (Vitis vinifera).

Leaf-stalk.-Horse-chestnut (Esculus Hippocastanum), turnip (Brassica Napus), cauliflower (Brassica oleracea), celery (Apium yraceolens), Eucharis lily (Eucharis amazonica).

Flower-stalk.-Arum lily (Richardia africana).

Fruit.-Egg-plant (Solanum Melongena).

Negative variation.-Taking the leaf-stalk of turnip we kill an area on its surface, say $\mathrm{B}$, by the application of a few drops of strong potash, the area at $\mathrm{A}$ being left uninjured. A current is now observed to flow, in the stalk, from the injured $B$ to the uninjured $A$, as was found to be the case in the animal tissue. The potential difference depends on the condition of the plant, and the season in which it may have been gathered. In the experiment here described (fig. 6, a) its value was 13 volt.

A sharp tap was now given to the stalk, and a sudden diminution, or negative variation, of current occurred, the resting potential difference being 
decreased by 026 volt. A second and stronger tap produced a second response, causing a greater diminution of P.D. by $\cdot 047$ volt $($ fig. $6, b)$. The accompanying figure is a photographic record of another set of responsecurves (fig. 7). The first three responses are for a given intensity of stimulus, and the next six in response to stimulus nearly twice as strong. It will be noticed that fatigue is exhibited in these responses. Other
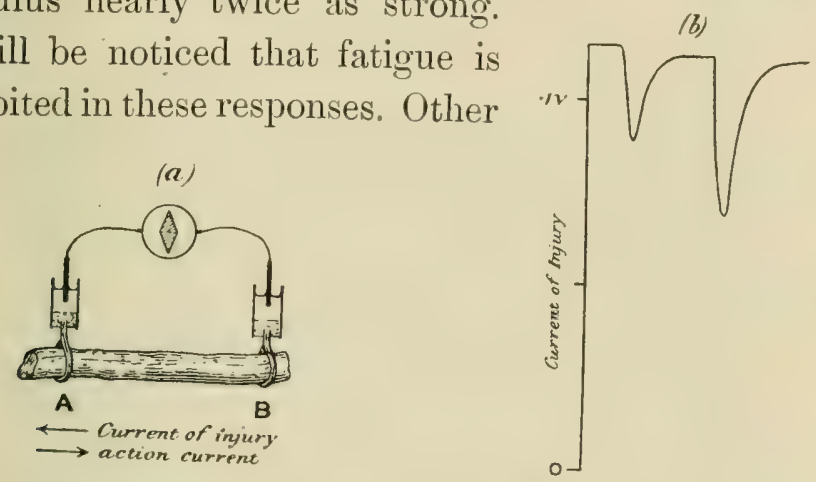

Fig. 6.- (a) Experinent for exhibiting Electric Response in Plants by Method of Negative Variation. (b) Responses in Leaf-stalis of Turnip to Sturuli of Two Successive Taps, the Second being STronger.

$\mathrm{A}$ and $\mathrm{B}$ contacts are about $2 \mathrm{~cm}$. apart, $\mathrm{B}$ being injured. Plant is stimulated by a tap between $A$ and $B$. Stimulus acts on both $A$ and $B$, but owing to

injury of $B$, effect at $A$ is stronger and a negative variation due to differen-
tial action occurs.

experiments will be described in the next chapter which show conclusively that the response was not due to any accidental circumstance but was a direct result of stimulation. But I shall first discuss the experimental arrangements and method of obtaining these graphic records.

Response recorder.-The galvanometer used is a sensitive dead-beat D'Arsonval. The period of complete swing of the coil under experimental conditions is about 11 seconds. A current of $10^{-9}$ ampere produces a 
deflection of $1 \mathrm{~mm}$. at a distance of 1 metre. For a quick and accurate method of obtaining the records, I devised the following form of response recorder. The curves are obtained directly, by tracing the excursion of the galvanometer spot of light on a revolving drum (fig. 8). The drum, on which is wrapped the paper for receiving the record, is driven by clockwork. Different speeds of revolution can be given to it by adjustment of

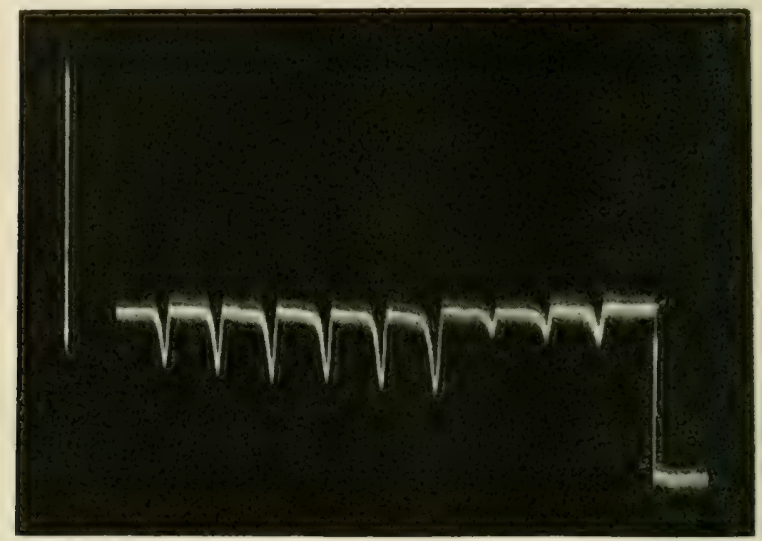

Fig. 7.-Record of Responses in Plant (Leaf-stalk of Caultflotwer) by Method of Negative Variation

The first three records are for stimulus intensity 1 ; the next six are for intensity twice as strong; the successive responses exhibit fatigue. The vertical line to the left represents ' 1 volt. The record is to be read from right to left.

the clock-governor, or by changing the size of the drivingwheel. The galvanometer spot is thrown down on the drum by the inclined mirror M. The galranometer deflection takes place at right angles to the motion of the paper. A stylographic pen attached to a carrier rests on the writing surface. The carrier slictes over a rod parallel to the drum. As has been said before, the galvanometer deflection takes place parallel to the drum, and 
as long as the plant rests unstimulated, the pen, remaining coincident with the stationary galvanometer spot on the revolving paper, describes a straight line. If, on stimulation, we trace the resulting excursion of the spot of light, by moving the carrier which holds the pen, the rising portion of the response-curve will be obtained. The galvanometer spot will then return more or less gradually to its original position, and that part of the curve which is traced during the process constitutes the recovery. The ordinate in these curves represents the E.M. variation, and the abscissa the time.

We can calibrate the value of the deflection by applying a

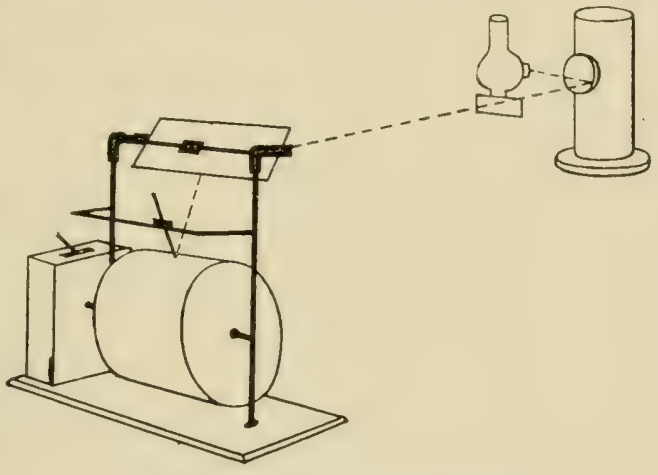

Fig, 8,-Response Recorder

known E.M.F. to the circuit from a compensator, and noting the deflection which results. The speed of the clock is previously adjusted so that the recording surface moves exactly through, say, one inch a minute. Of course this speed can be increased to suit the particular experiment, and in some it is as high as six inches a minute. In this simple manner very accurate records may be made. It has the additional advantage that one is able at once to see whether the specimen is suitable for the purpose of investigation. A large number of records might be taken by this means in a comparatively short time. 
Photographic recorder.-Or the records may be made photographically. A clockwork arrangement moves a photographic plate at a known uniform rate, and a curve is traced on the plate by the moving spot of light. All the records that will be given are accurate reproductions of those obtained by one of these two methods. Photographic records are reproduced in white against a black background.

Compensator.-As the responses are on variation of current of injury, and as the current of injury may be

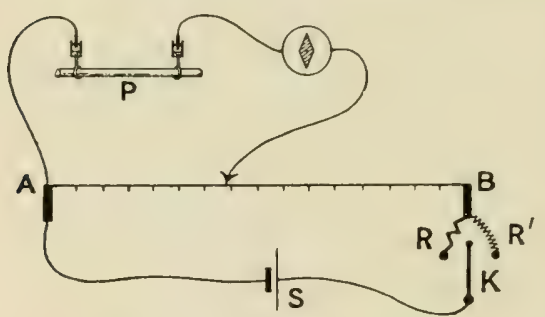

Fig. 9.-The Compensator

$A B$ is a stretched wire with added resistances $R$ and $\mathrm{R}^{\prime}$. $\mathrm{S}$ is a storage cell. When the key $\mathrm{K}$ is turned to the right one scale division= -001 volt, when turned to the left one scale division $={ }^{*} 01$ volt. $P$ is the plant. strong, and throw the spot of light beyond the recording surface, a potentiometer balancing arrangement may be used (fig. 9), by which the P.D.due to injury is exactly compensated ; E.M. variations produced by stimulus are then taken in the usual manner. This compensating arrangement is also helpful, as has been said before, for calibrating the E.M. value of the deflection.

Means of graduating the intensity of stimulus. - One of the necessities in connection with quantitative measurements is to be certain that the intensity of successive stimuli is (1) constant, or (2) capable of gradual increase by known amounts. No two taps given by the hand can be made exactly alike. I have therefore devised the two following methods of stimulation, which have been found to act satisfactorily. 
The spring-tapper.-This consists (fig. 10) of the spring proper (s), the attached rod (R) carrying at its end the tapping-head (T). A projecting rod-the lifter (L)-passes through $\mathrm{S}$ R. It is provided with a screwthread, by means of which its length, projecting downwards, is regulated. This fact, as we shall see, is made to determine the height of the stroke. (c) is a cogwheel. As one of the spokes of the cogwheel is rotated past (L), the spring is lifted and released, and ( $\mathrm{T}$ ) delivers a sharp tap. The height of the lift, and therefore the intensity of the stroke, is measured by means of a

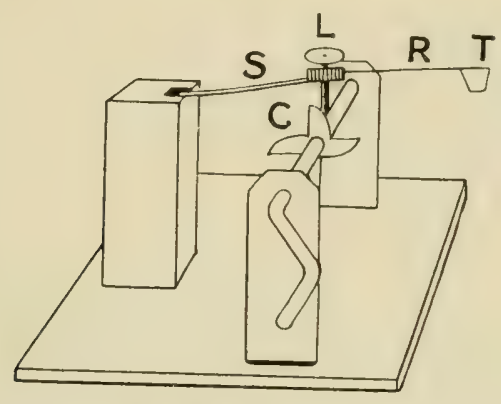

Fit. 10,-The SPring-tapper

graduated scale. We can increase the intensity of the stroke through a wide range (1) by increasing the projecting length of the lifter, and (2) by shortening the length of spring by a sliding catch. We may give isolated single taps or superpose a series in rapid succession according as the wheel is rotated slow or fast. The only disadvantage of the tapping method of stimulation is that in long-continued experiment the point struck is liable to be injured. The vibrational mode of stimulation to be presently described labours under no such disadvantage. 
The electric tapper.--Instead of the simple mechanical tapper, an electromagnetic tapper may be used.

Vibrational stimulus. - I find that torsional ribration affords mother very effective method of stimulation (fig. 11). The plant-stalk may be fixed in a rice (v), the free ends being held in tubes $\left(c^{\prime} c^{\prime}\right)$, provided with three clamping jaws. A rapid torsional vibration ${ }^{1}$ may now be imparted to the stalk by means of the handle (i). The amplitude of vibration, which determines the intensity of stimulus, can be accurately measured by
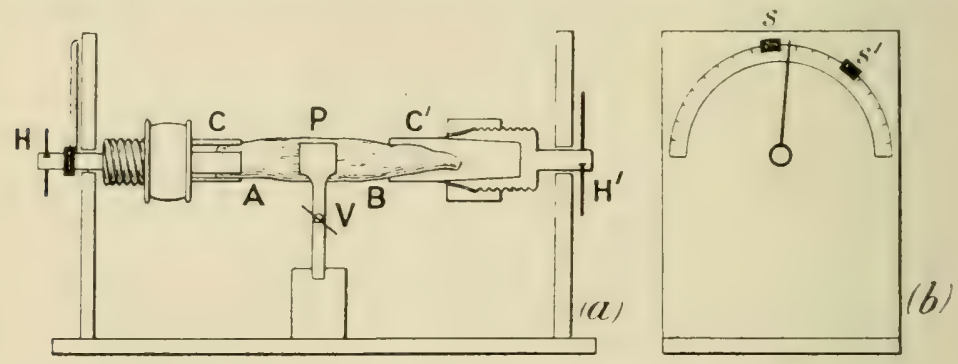

Fig. 11.-The Torsional Vibrator

Plant $\mathrm{P}$ is securely held by a vice $\mathrm{V}$. The two ends are clamped by holders $\mathrm{CC}^{\prime}$. By means of handles $\mathrm{H} \mathrm{H}^{\prime}$, torsional vibration may be imparted to either the end $A$ or end $B$ of the plant. The end view $(b)$ shows how the amplitude of vibration is predetermined by means of movable stops S $\mathrm{S}^{\prime}$.

the graduated circle. The amplitude of ribration may be predetermined by means of the sliding stops ( $\mathrm{s}^{\prime}$ ).

Intensity of stimulus dependent on amplitude of vibration.-I shall now describe an experiment which shows that torsional vibration is as effective as stimulation by taps, and that its stimulating intensity increases, length of stalk being constant, with amplitude of

$\therefore$ By this is meant a rapid to-and-fro or complete vibration. In order that successive responses should be uniform it is essential that there should be no resultant twist, i.e. the plant at the end of ribration should be in exactly the same condition as at the beginning. 
vibration. It is of course obrious that if the length of the specimen be doubled, the ribration, in order to produce the same effect, must be through twice the angle. I took a leaf-stalk of turnip and fixed it in the torsional ribrator. I then took record of responses to two successive taps, the intensity of one being nearly double that of the other. Haring done this, I applied to the same stalk two successive torsional vibrations of $45^{\circ}$ and $67^{\circ}$ respectively. These successive responses

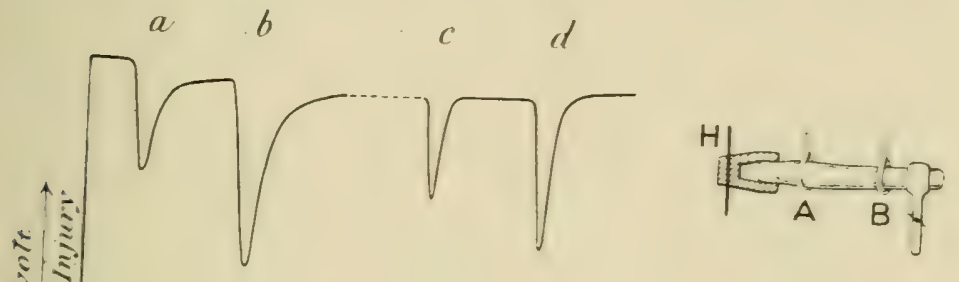

Fig. 12.-Pesponse in Plant to Mechamical Tap or Vibration The end $\mathrm{B}$ is injured. A tap was giren between $\mathrm{A}$ and $\mathrm{B}$ and this gave the response-curve $a$. A stronger tap gare the response $b$. By means of the handle $\mathrm{H}$, a torsional vibration of $45^{\circ}$ was now imparted, this gave the response $c$. Vibration through $67^{\circ}$ gare $\lambda$.

to taps and torsional ribrations are given in fig. 12, and from them it will be seen that these two modes of stimulation may be used indifferently, with equal effect. The ribrational method has the adrantage orer tapping, that, while with the latter the stimulus is somewhat localised, with ribration the tissue subjected to stimulus is uniformly stimulated throughout its length.

\section{Effectiveness of stimulus dependent on rapidity also.} In order that successive stimuli may be equally effective 
another point has to be borne in mind. In all cases of stimulation of living tissue it is found that the effectiveness of a stimulus to arouse response depends on the rapidity of the onset of the disturbance. It is thus found that the stimulus of the 'break' induction shock, on a muscle for example, is more effective, by reason

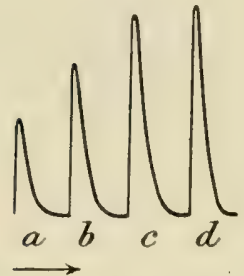

Fig. 13.-INFLUENCE of Soddenness on THE Efficiency of Strimolos

The curves $a, b, c, d$, are responses to vibrations of the same amplitude, $30^{\circ}$. In a the vibration was very slow; in $b$ it was less slow ; it was rapid in $c$, and very rapid in $d$. of its greater rapidity, than the 'make' shock. So also with the torsional vibrations of plants, I find response depending on the quickness with which the vibration is effected. I give below records of successive stimuli, given by vibrations through the same amplitude, but delivered with increasing rapidity (fig. 13).

Thus if we wish to maintain the effective intensity of stimulus constant we must meet two conditions: (1) The amplitude of ribration must be kept the same. This is done by means of the graduated circle. (2) The vibration period must be kept the same. With a little practice, this requirement is easily fulfilled.

The uniformity of stimulation which is thus attained solves the great difficulty of obtaining reliable quantitative values, by whose means alone can rigorous demonstration of the phenomena we are studying become possible. 


\section{CHAPTER IV}

\section{ELECTRIC RESPONSE IN PLANTS-BLOCK METHOD}

Method of block-Advantages of block method-Plant response a physiological phenomenon-Abolition of response by anæsthetics and poisons -Abolition of response when plant is killed by hot water.

I sHaLl now proceed to describe another and independent method which I devised for obtaining plant response. It has the advantage of offering us a complementary means of verifying the results found by the method of negative variation. As it is also, in itself, for reasons which will be shown later, a more perfect mode of inquiry, it enables us to investigate problems which would otherwise have been difficult to attempt.

When electrolytic contacts are made on the uninjured surfaces of the stalk at $\mathrm{A}$ and $\mathrm{B}$, the two points, being practically similar in every way, are iso-electric, and little or no current will flow in the galvanometer. If now the whole stalk be uniformly stimulated, and if both ends $\mathrm{A}$ and $\mathrm{B}$ be equally excited at the same moment, it is clear that there will still be no responsive current, owing to balancing action at the two ends. This difficulty as regards the obtaining of response was overcome in the method of negative variation, where the excitability of one end was depressed by chemical reagents or injury, or abolished by excessive tempera- 
ture. On stimulating the stalk there was produced a greater excitation at $\Lambda$ than at $B$, and a current of action was then observed to flow in the stalk from the more excited A to the less excited B (fig. 6).

But we can cause this differential action to become evident by another means. For example, if we produce a block, by clamping at $\mathrm{C}$ between $\mathrm{A}$ and $\mathrm{B}$ (fig. 14, a),

(a)

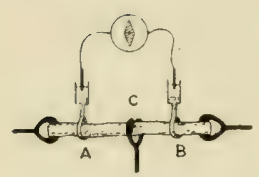

Current of response uhen $A$ is stimulated $\rightarrow$ Current of response when $B$ is stimulated $\leftarrow$ (b)

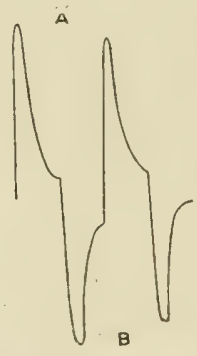

Fig, 14.-The Method of Block.

(a) The plant is clamped at C, between $\mathrm{A}$ and $B$.

(b) Responses obtained by alternately stimulating the two ends. Stimulation of A produces upward response; of B gives downward response. so that the disturbance made at $\mathrm{A}$ by tapping or vibration is prevented from reaching $\mathrm{B}$, we shall then have A thrown into a relatively greater excitatory condition than $\mathrm{B}$. It will now be found that a current of action flows in the stalk from A to $B$, that is to say, from the excited to the less excited. When the $\mathbf{B}$ end is stimulated, there will be a reverse current (fig. 14, b).

We have in this method a great advantage over that of negative variation, for we can always verify any set of results by making corroborative reversal experiments.

By the method of injury again, one end is made initially abnormal, i.e. different from the condition which it maintains when intact. Further, inevitable changes will proceed unequally at the injured and uninjured ends, and the conditions of the experiment may thus undergo unknown variations. But by the 
block method which has just been described, there is no injury, the plant is normal throughout, and any physiological change (which in plants will be exceedingly small during the time of the experiment) will affect it as a whole.

\section{Plant response a physiological or} vital response.-I now proceed to a demonstration of the fact that whatever be the mechanism by which they are brought about, these plant responses are physiological in their character. As the investigations described in the next few chapters will show, they furnish an accurate index of physiological activity. For it will be found that, other things being equal, whatever tends to exalt or depress the vitality of the plant tends also to increase or diminish its electric response. These E.M. effects are well marked, and attain considerable value, rising sometimes, as has been said before, to as much as 11 volt or more. They are proportional to the intensity of stimulus.

It need hardly be added that special precautions are taken to avoid shifting of contacts. Variation

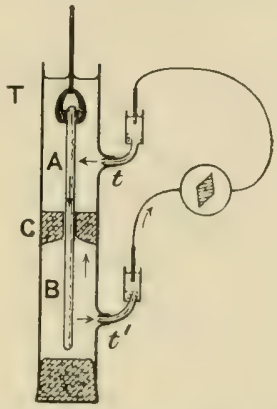

FIG. 15.--RESPONSE IN Plant (Froli the Stimolated A to UnSTIMULATED B) COMPLETELT IMMERSED under Water

The leaf-stalk is clamped securcly in the middle with the cork $\mathrm{C}$, inside the tube $\mathrm{T}$, which is filled with water, the plant being completely immersed. Moistened threads in connection with the two non-polarisable electrodes are led to the side tubes $t t^{\prime}$. One end of the stalk is held in ebonite forceps and vibrated. A current of response is found to flow in the stalk from the excited $\mathrm{A}$ to the unexcited $\mathbf{B}$, and outside, through the liquid, from $B$ to $A$ A portion of this current, flowing through the side tubes $t t^{\prime}$, produces deflection in the galvanometer. of contact, however, could not in any case account for repeated transient responses to repeated stimuli, when contact is made on iso-electric surfaces. Nor could it 
in any way explain the reversible nature of these responses, when $\mathrm{A}$ and $\mathrm{B}$ are stimulated alternately. These responses are obtained in the plants even when completely immersed in water, as in the experimental arrangement (fig. 15). It will be seen that in this case, where there could be no possibility of shifting of contact, or variation of surface, there is still the usual current of response.

I shall describe here a few crucial experiments only, in proof of the physiological character of electric response. The test applied by physiologists, in order to discriminate as to the physiological nature of response, consists in finding out whether the response is diminished or abolished by the action of anæsthetics, poisons, and excessively high temperature, which are known to depress or destroy vitality.

I shall therefore apply these same tests to plant responses.

Effect of anæsthetics and poisons.-Ordinary anæsthetics, like chloroform, and poisons, like mercuric chloride, are known to produce a profound depression or abolish all signs of response in the living tissue. For the purpose of experiment, I took two groups of stalks, with leaves attached, exactly similar to each other in every respect. In order that the leaf-stalks might absorb chloroform I dipped their cut ends in chloroform-water, a certain amount of which they absorbed, the process being helped by the transpiration from the leaves. The second group of stalks was placed simply in water, in order to serve for control experiment. The narcotic action of rhloroform, finally 
culminating in death, soon became visually evident. The leaves began to droop, a peculiar death-discolouration began to spread from the mid rib along the venation of the leaves. Another peculiarity was also observed. The aphides feeding on the leaves died even before the appearance of the discoloured patches, whereas on the leaves of the stalks placed in water these little creatures maintained their accustomed activity, nor did any discolouration occur. In order to study the effect of poison, another set was placed in water containing a small quantity of mercuric chloride. The leaves here underwent the same change of appearance, and the aphides met with the same untimely fate, as in the case of those subjected to the action of chloroform. There was hardly any visible change in the appearance of the stalks themselves, which were to all outer seeming as living as ever, indications of death being apparent only on the leaf surfaces. I give below the results of several sets of experiments, from which it would appear that whereas there was strong normal response in the group of stalks kept in water, there was practically a total abolition of all response in those anæsthetised or poisoned.

\section{Experiments on the effect of anæsthetics and poisons.}

A batch of ten leaf-stalks of plane-tree was placed with the cut ends in water, and leaves in air; an equal number was immersed in chloroform-water; a third batch was placed in 5 per cent. solution of mercuric chloride.

Similarly a batch of three horse-chestnut leaf-stalks was put in water, another batch in chloroform-water, and a third batch in mercuric chloride solution. 


\section{Jueaf-stalik of Plane-tree}

The stimulus applied was a single vibration of $90^{\circ}$.

A. After 24 hours in water

[All leaves standing up and fresh - aphides alive]

\begin{tabular}{|c|c|}
\hline \multicolumn{2}{|c|}{ Electric respon } \\
\hline (1)....2 21 & dns. \\
\hline (2)......31 & , \\
\hline (3) $\ldots \ldots .26$ & " \\
\hline (4) .....15 & " \\
\hline (5)....17 & $"$ \\
\hline (6).....23 & " \\
\hline (7).....30 & " \\
\hline (8).....27 & ", \\
\hline (9) $\ldots \ldots 29$ & $"$ \\
\hline$(10) \ldots \ldots .17$ & , \\
\hline
\end{tabular}

Mean response $23 \cdot 6$
B. After 24 hours in chloroform-water

C. After 24 hours in mercuric chloride

[Leaves began to [Leaves began to droop droop in 1 hour and in 4 hours. Deep disbent overin 3 hours colouration along the -aphides dead]

Electric response

(1).....1 dn.

(2) $\ldots . .1$,

(3) .....2,

(4) .....

(5) $\ldots . .1$,

(6) ......1.5,

(7) ....2,

(8) ...... ,

(9) ...1 ,

(10) .... 5,

Mean 1 veins. A phides dead]

Electric response

(1)..... $0 . \mathrm{dn}$.

(2)..... 25,

(3) ..... 25,

(4) ......0

(5) $\ldots .25$.25

(6) $\ldots \ldots \cdot 25$,

(7) ......0

(8)..... 25,

(9) ..... 25,

$(10) \ldots . .5$,

Mean 15

II. Leaf-stali of Horse-chestedt

\begin{tabular}{|c|c|c|}
\hline $\begin{array}{l}\text { (1) } \ldots . .15 \text { dns, } \\
(2) \ldots \ldots 17 \quad ", \\
(3) \ldots \ldots 10 \quad "\end{array}$ & $\begin{array}{l}(1) \ldots . .5 \mathrm{dn} . \\
(2) \ldots \ldots .5, \\
(3) \ldots \ldots 0,\end{array}$ & $\begin{array}{l}\text { (1) } \ldots . .00 \mathrm{dn} \text {. } \\
\text { (2) } \ldots . .00 \text {, } \\
(3) \ldots . .00 \text {, }\end{array}$ \\
\hline Mean 14 & Mean '3 & Mean 0 \\
\hline
\end{tabular}

These results conclusively prove the physiological nature of the response.

I shall in a succeeding chapter give a continuous series of response-curves showing how, owing to progressive death from the action of poison, the responses undergo steady diminution till they are completely abolished.

Effect of high temperature.-It is well known that plants are killed when subjected to high temperatures. I took a stalk, and, using the block method, with torsional 
vibration as the stimulus, obtained strong responses at both ends $\mathrm{A}$ and $\mathrm{B}$. I then immersed the same stalk for a short time in hot water at about $65^{\circ} \mathrm{C}$, and again stimulated it as before. But at neither A nor B could any response now be evoked. As all the external conditions were the same in the first and second parts of this experiment, the only difference being that in one the stalk was alive and in the other killed, we have here further and conclusive proof of the physiological character of electric response in plants.

The same facts may be demonstrated in a still more striking manner by first obtaining two similar but opposite responses in a fresh stalk, at $A$ and $\mathrm{B}$, and then killing one half, say B, by immersing only that half of the stalk in hot water. The stalk is replaced in the apparatus, and it is now found that whereas the $\mathrm{A}$ half gives strong response, the end $\mathrm{B}$ gives none.

In the experiments on negative variation, it was tacitly assumed that the variation is due to a differential action, stimulus producing a greater excitation at the uninjured than at the injured end. The block method enables us to test the correctness of this assumption. The $\mathrm{B}$ end of the stalk is injured or killed by a few drops of strong potash, the other end being uninjured. There is a clamp between $\mathrm{A}$ and $\mathrm{B}$. The end $\mathrm{A}$ is stimulated and a strong response is obtained. The end $\mathrm{B}$ is now stimulated, and there is little or no response. The block is now removed and the plant stimulated throughout its length. Though the stimulus now acts on both ends, yet, owing to the irresponsive condition of $\mathrm{B}$, there is a resultant response, which from its direction is found 
34 RESPONSE IN THE LIVING AND NON LIVING to be due to the responsive action of $\mathrm{A}$. This would not have been the case if the end $\mathrm{B}$ had been uninjured. We have thus experimentally verified the assumption that in the same tissue an uninjured portion will be thrown into a greater excitatory state than an injured, by the action of the same stimulus. 


\section{CHAPTER V}

PLANT RESPONSE-ON THE EFFEC'TS OF SINGLE STIMULUS AND OF SUPERPOSED STIMULI

Effect of single stimulus - Superposition of stimuli - Additive effectStaircase effect-Fatigue-No fatigue when sufficient interval between stimuli-Apparent fatigue when stimulation frequency is increasedFatigue under continuous stimulation.

Effect of single stimulus.-In a muscle a single stimulus gives rise to a single twitch which may be recorded either mechanically or electrically. If there is no fatigue, the successive responses to uniform stimuli are exactly similar. Muscle when strongly stimulated often exhibits fatigue, and successive responses therefore become feebler and feebler. In nerves, however, there is practically no fatigue and successive records are alike. Similarly, in plants, we shall find some exhibiting marked fatigue and others very little.

Superposition of stimuli.-If instead of a single stimulus a succession of stimuli be superposed, it happens that a second shock is received before recovery from the first has taken place. Individual effects will then become more or less fused. When the frequency is sufficiently increased, the intermittent effects are fused, and we find an almost unbroken curve. When for example the muscle attains its maximum contraction (corresponding to the frequency and strength of stimuli) it 
is thrown into a state of complete tetanus, in which it appears to be held rigid. If the rapidity be not sufficient for this, we have the jagged curve of incomplete tetanus. If there is not much fatigue, the upper part

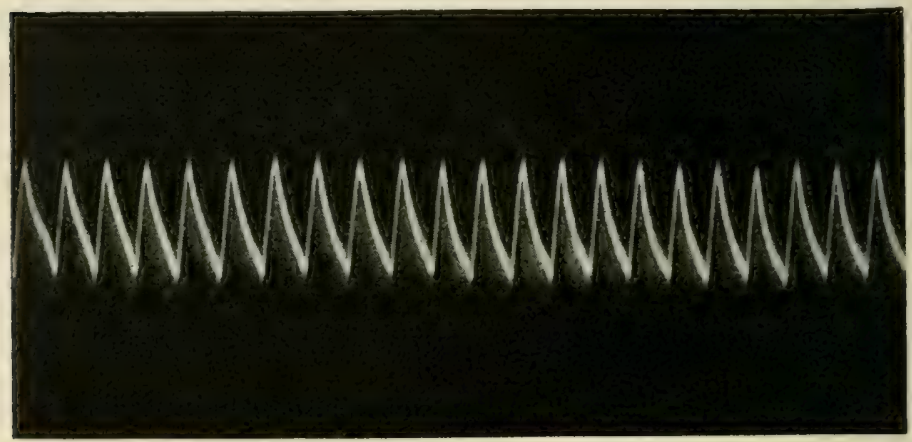

Fig. 16.-Uniforir Responses (RAdish)

of the tetanic curve is approximately horizontal, but in cases where fatigue sets in quickly, the fact is shown by the rapid decline of the curve. With regard to all these points we find strict parallels in plant response.

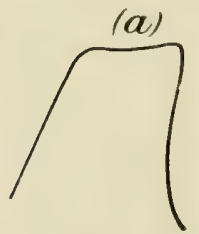

Fig. 17.-Fusion of Effect of Rapiduy Sticceeding Strmuli

$(a)$ in muscle; $(b)$ in carrot.

In cases where there is no fatigue, the successive responses are identical (fig.

16). With superposition of stimuli we have fusion of effects, analogous to the tetanus of muscle (fig. 17). And lastly, the influence of fatigue in plants is to produce a modification of response-curve exactly similar to that of muscle (see below). One effect of superposition of stimuli may be mentioned here. 
Additive effect.-It is found in animal responses that there is a minimum intensity of stimulus, below which no response can be evoked. But even a sub-minimal

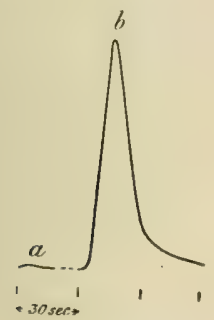

Fig. 18.-Additive Effect

(a) A single stimulus of $3^{\circ}$ vibration produced little or no effect, but the same stimulus when rapidly super. posed thirty times, produced the large effect $(b)$. (Leaf-stalk of turnip.) stimulus will, though singly ineffective, become effective by the summation of several. In plants, too, we obtain a similar effect, i.e. the summation of single ineffective stimuli produces effective response (fig. 18).

Staircase effect.-Animal tissues sometimes exhibit what is known as the 'staircase effect,' that is to say, the heights of successive responses are gradually increased, though the stimuli are maintained constant. This is exhibited typically by cardiac muscle, though it is not unknown even in nerve. The cause is obscure, but it seems to depend on the condition of the tissue. It appears as if the molecular sluggishness of tissue were in these cases only gradually removed under stimulation, and the increased effects were due to increased molecular mobility. Whatever be the explanation, I have sometimes observed the same staircase effect in plants (fig. 19).

Fatigue.-It is assumed that in living substances like muscle, fatigue is caused by the break down or 
dissimilation of tissue by stimulus. And till this waste is repaired by the process of building-up or assimilation, the functional activity of the tissue will remain below par. There may also be an accumulation of the products of dissimilation- 'the fatigue stuffs'-and these latter may act as poisons or chemical depressants.

In an animal it is supposed that the nutritive blood supply performs the two-fold task of bringing material for assimilation and removing the fatigue products, thus causing the disappearance of fatigue. This explanation, however, is shown to be insufficient by the fact that an excised bloodless muscle recovers from fatigue after a short period of rest. It is obvious that here the fatigue has been removed by means other than that of renewed assimilation and remoral of fatigue products by the circulating blood. It may therefore be instructive to study certain phases of fatigue exhibited under simpler conditions in vegetable tissue, where the constructive processes are in abeyance, and there is no active circulation for the removal of fatigue products.

It has been said before that the E.M. variation caused by stimulus is the concomitant of a disturbance of the molecules of the responsive tissues from their normal equilibrium, and that the curve of recovery exhibits the restoration of the tissue to equilibrium.

No fatigue when sufficient interval between successive stimuli.-We may thus gather from a study of the response-curve some indication of the molecular distortion experienced by the excited tissue. Let us first take the case of an experiment whose record is given 
in fig. 20, $a$. It will be seen from that curve that one minute after the application of stimulus there is a complete recovery of the tissue; the molecular condition is exactly the same at the end of recovery as in the beginning of stimulation. The second and succeeding response-curves therefore are exactly similar to the first, provided a sufficient interval has been allowed in each case for complete recovery. There is, in such a case, no diminution in intensity of response, that is to say, no fatigue.

We have an exactly parallel case in muscles. ' In muscle with normal circulation and nutrition there is always an interval between each pair of stimuli, in which the height of twitch does not diminish even after protracted excitation, and no fatigue appears.' ${ }^{1}$

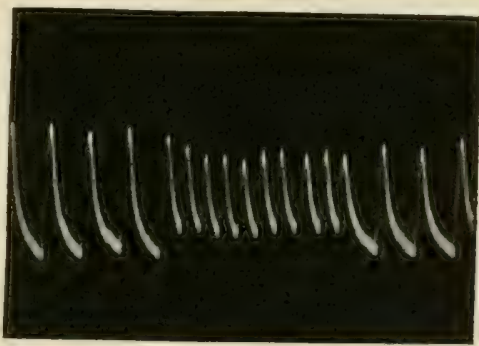

(a)

(c)

Fig. 20.-Record showing Dimindtion of Response when Sufficient Trye is yot Allowed for Full Recovery

In $(a)$ stimuli were applied at intervals of one minute; in $(b)$ the intervals were reduced to half a minute; this caused a diminution of response. In $(c)$ the original rhythm is restored, and the response is found to be enhanced. (Radish.)

Apparent fatigue when stimulation frequency increased.-If the rhythm of stimulation frequency be now changed, and made quicker, certain remarkable modifications will appear in the response-curves. In fig. 20, the first part shows the responses at one minute interval, by which time the individual recovery was complete.

The rhythm was now changed to intervals of half

1 Biedermann, Electro-physiology, p. 86. 
a minute, instead of one, while the stimuli were maintained at the same intensity as before. It will be noticed (fig. 20, b) that these responses appear much feebler than the first set, in spite of the equality of stimulus. An inspection of the figure may perhaps throw some light on the subject. It will be seen that when greater frequency of stimulation was introduced, the tissue had not yet had time to effect complete recovery from previous strain. The molecular swing

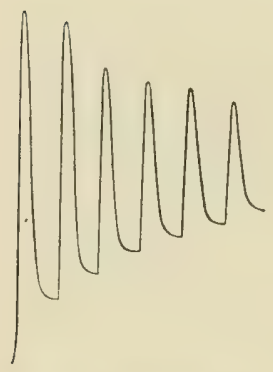

Fit. 21.-F.titie IN Celery

Vibration of $30^{\circ}$ at inter. vals of lialf a minute. towards equilibrium had not yet abated, when the new stimulus, with its opposing impulse, was received. There is thus a diminution of height in the resultant response. The original rhythm of one minute was now restored, and the succeeding curves (fig. 20, c) at once show increased response. An analogous instance may be cited in the case of muscle response, where "the height of twitch diminishes more rapidly in proportion as the excitation interval is shorter.' 1

From what has just been said it would appear that one of the causes of diminution of response, or fatigue, is the residual strain. This is clearly seen in fig. 21, in a record which I obtained with celerystalk. It will be noticed there that, owing to the imperfect molecular recovery during the time allowed, the succeeding heights of the responses have undersone a continuous diminution. Fig. 22 gives a

I Biedermann, loc. cit. 
photographic record of fatigue in the leaf-stalk of cauliflower.

It is evident that residual strain, other things being equal, will be greater if the stimuli have been excessive. This is well seen in fig. 23, where the set of first three curves A is for stimulus intensity of $45^{\circ}$ vibration, and the second set $\mathrm{B}$, with an . augmented response, for stimulus intensity of $90^{\circ}$ vibration. On reverting in $\mathrm{c}$ to stimulus intensity of $45^{\circ}$, the responses are seen to have undergone a great diminution as compared with the first set A. Here is seen

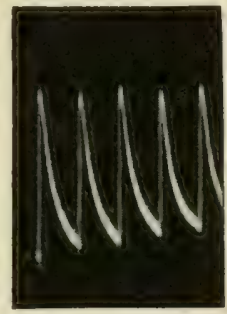

Fig. 22. - FATigUE iN LEAF-STALK OF CAULIF LOWEI:

Stimulus : $30^{\circ}$ vibration at intervals of one minute.

marked fatigue, the result of orerstrain from excessive stimulation.

If this fatigue be really due to residual strain effect, then, as strain disappears with time, we may expect the

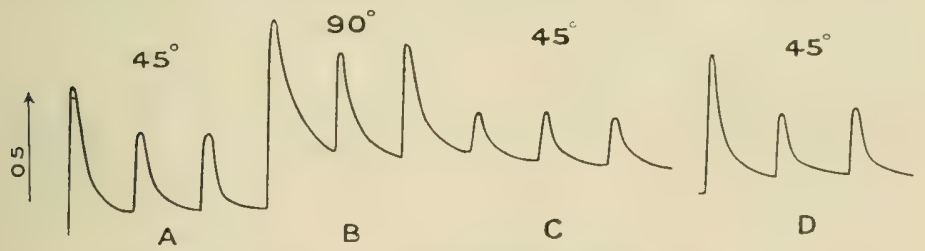

Fig. 23.-Effect of Overstrain in Prodecing Fatigué

Successive stimuli applied at intervals of one minute. The intensity of stimulus in $\mathrm{C}$ is the same as that of $\mathrm{A}$, but response is feebler owing to previous over-stimulation. Fatigue is to a great extent removed after fifteen minutes' rest, and the responses in $\mathrm{D}$ are stronger than those in $\mathrm{C}$. The vertical line between arrows represents ${ }^{\circ} 05$ volt. (Turnip leaf-stalk.)

responses to regain their former height after a period of rest. In order to verify this, therefore, I renewed the stimulation (at intensity $45^{\circ}$ ) after fifteen minutes. It 
will at once be seen from record $\mathrm{D}$ how far the fatigue had been removed.

One peculiarity that will be noticed in these curves is that, owing to the presence of comparatively little residual strain, the first response of each set is relatively large. The succeeding responses are approximately equal where the residual strains are similar. The first response of $\Lambda$ shows this because it had had long previous rest. The first of $\mathrm{B}$ shows it because we are
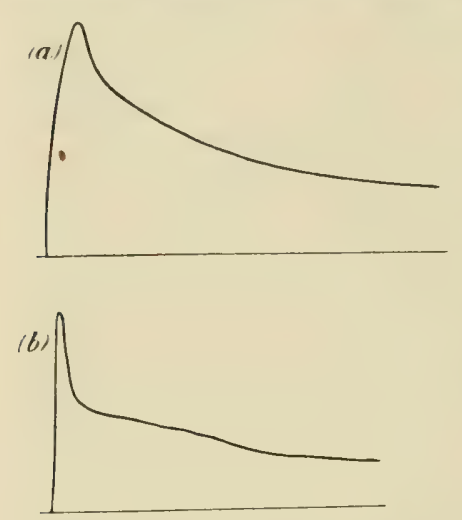

Fig. 24.-Rapid Fatigue under Contindous Strud lation in (a) Moscle; (b) in Leaf-STalk of Celeny there passing for the first time to increased stimulation. The first of $\mathrm{c}$ does not show it, because there is now a strong residual strain. D again shows it because the strain has been removed by fifteen minutes' rest.

Fatigue under continuous stimulation.-The effect of fatigue is exhibited in marked degree when a tissue is subjected to continuous stimulation. In cases where there is marked fatigue, as for instance in certain muscles, the top of the tetanic curve undergoes rapid decline. A similar effect is obtained also with plants (fig. 24).

The effect of rest in producing molecular recovery, and hence in the removal of fatigue, is well illustrated in the following set of photographic records (fig. 25). The first shows the curve obtained with a fresh plant. 
The effect is seen to be very large. Two minutes were allowed for recovery, and then stimulation was repeated during another two minutes. The response in this case is seen to be decidedly smaller. A third case is somewhat similar to the second. A period of rest of five minutes was now allowed, and the curve obtained

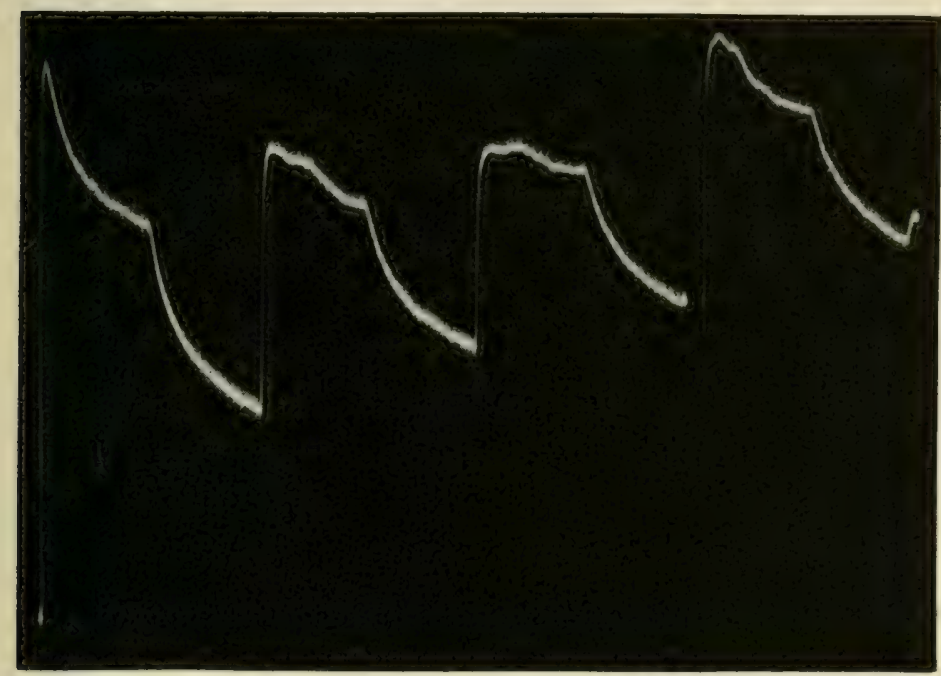

Fig. 25.-Effect of Contindods Vibration (Throdgh 50 ) in Carrot

In the first three records, two minutes' stimulation is followed by two minutes' recovery. The last record was taken after the specimen had a rest of five minutes. The response, owing to removal of fatigue by rest, is stronger.

subsequently, owing to partial removal of residual strain, is found to exhibit greater response.

The results thus arrived at, under the simple conditions of vegetable life, free as they are from all possible complications and uncertainties, may perhaps throw some light on the obscure phenomena of fatigue in animal tissues. 


\section{CHAPTER VI}

\section{PLANT RESPONSE-ON DIPHASIC VARIATION}

Diphasic variation-Positive after-effect and positive responseRadial E.M. variation.

Whes a plant is stimulated at any point, a molecular disturbance-the excitatory wave-is propagated outwards from the point of its initiation.

Diphasic variation.-This wave of molecular disturbance is attended by a wave of electrical disturbance. (U'sually speaking, the electrical relation between disturbed and less disturbed is that of copper to zinc.) It takes some time for a disturbance to travel from one point to another, and its intensity may undergo a diminution as it receles further from its point of origin. Suppose a disturbance originated at $\mathrm{C}$; if two points are taken near each other, as $\mathrm{A}$ and $\mathrm{B}$, the disturbance will reach them almost at the same time, and with the same intensity. The electric disturbance will be the same in both. The effect produced at A and $B$ will balance each other and there will be no resultant current.

By killing or otherwise reducing the sensibility of $\mathrm{B}$ as is done in the method of injury, there is no response at $\mathrm{B}$, and we obtain the unbalanced response, due to disturbance at $\mathbf{A}$; the same effect is obtained by putting 
a clamp between $\mathrm{A}$ and $\mathrm{B}$, so that the disturbance may not reach B. But we may get response even without injury or block. If we have the contacts at $A$ and $\mathrm{B}$, and if we give a tap nearer A than B (fig. 26, a), then we have (1) the disturbance reaching $\mathrm{A}$ earlier than B. (2) The disturbance reaching $\Lambda$ is much stronger than at $\mathrm{B}$. The disturbance at $\mathrm{B}$ may be so comparatively feeble as to be negligible.

It will thus be seen that we might obtain responses even without injury or block, in cases where the disturbance is enfeebled in reaching a distant point. In such a case on giving a tap near $\mathrm{A}$ a responsive current would be produced in one direction, and in the opposite direction when the tap is given near B (fig. 26, b). Theoretically, then, we might find a neutral point between $\mathrm{A}$ and $\mathrm{B}$, so that, on originating the disturbance there, the waves of disturbance would reach $\mathrm{A}$ and $\mathrm{B}$ at the same instant and with the same intensity. If, further, the rate of recovery be the same for both points, then the electric disturbances produced at $\mathrm{A}$ and $\mathrm{B}$ will continue to balance each other, and the galvanometer will show no current. On taking a cylindrical root of radish I have sometimes succeeded in finding a neutral point, which, being disturbed, did not give rise to any resultant current. But disturbing a point to the right or to the left gave rise to opposite currents.

It is, however, difficult to obtain an absolutely cylindrical specimen, as it always tapers in one direction. The conductivity towards the tip of the root is not exactly the same as that in the ascending direction. It 
is therefore difficult to fix an absolutely neutral point, but a point may be found which approaches this very nearly, and on stimulating the stalk near this, a very interesting diphasic variation has been observed. In a specimen of cauliflower-stalk, (1) stimulus was applied very much nearer $\mathrm{A}$ than $\mathrm{B}$ (the feeble disturbance reaching $\mathrm{B}$ was negligible). The resulting response was upward and the recovery took place in about sixty seconds.

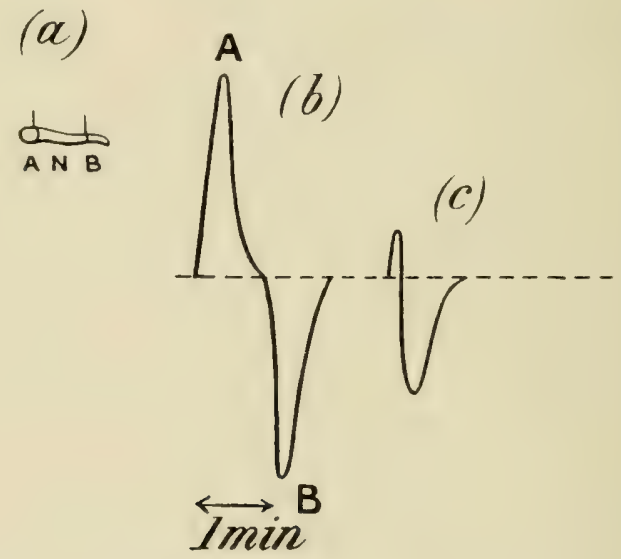

Fig. 26.--Diaphasic Variation

(2) Stimulus was next applied near B. The resulting response was now downward (fig. 26, $b$ ).

(3) The stimulus was now applied near the approximately neutral point $\mathrm{N}$. In this case, owing to a slight difference in the rates of propagation in the two directions, a very interesting diphasic variation was produced (fig. 26, c). From the record it will be seen that the disturbance arrived earlier at $\mathrm{A}$ than at $\mathrm{B}$. This produced an upward response. But during the 
subsidence of the disturbance at $\mathrm{A}$, the wave reached $\mathrm{B}$. The effect of this was to produce a current in the opposite direction. This apparently hastened the recovery of a (from 60 seconds to 12 seconds). The excitation of a now disappeared, and the second phase of response, that due to excitation of $\mathrm{B}$, was fully displayed.

Positive after-effect.-If we regard the response due to excitation of $\mathrm{A}$ as negative, the later effect on $\mathrm{B}$ would appear as a subsequent positive variation.

In the response of nerve, for example, where contacts are made at two surfaces, injured and uninjured, there is sometimes observed, first a negative variation, and then a positive after-effect. This may sometimes at least be due to the proximal uninjured contact first giving the usual negative rariation, and the more distant contact of injury giving rise, later, to the opposite, that is to say, apparently positive, response. There is always a chance of an after-effect due to this cause, unless (1) the injured end be completely killed and rendered quite irresponsive, or (2) there be an effective block between $\mathrm{A}$ and $\mathrm{B}$, so that the disturbance due to stimulus can only act on one, and not on the other.

I have found cases where, even when there was a perfect block, a positive after-effect occurred. It would thus appear that if molecular distortion from stimulus give rise to a negative variation, then during the process of molecular recovery there may be overshooting of the equilibrium position, which may be exhibited as a positive variation. 
Positive variation.-The responses given by muscle or nerve are, normally speaking, negative. But that of retina is positive. The sign of response, however, is apt to be reversed if there be any molecular modification of the tissue from changes of external circumstances. Thus it is often found that nerve in a stale condition gives positive, instead of the normal negative variation, and stale retina often gives negative, instead of the usual positive.

Curiously enough, I have on many occasions found exactly parallel instances in the response of plants.

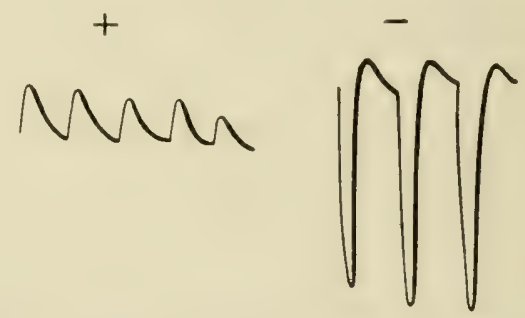

Fig. 27.-Abnomiral Positive Responses in Stale Leaf-stalk of Tornip converted into Norval Negative under Strong Stimolation ${ }^{1}$

The relative intensities of stimuli in the two cases are in the ratio of $1: 7$.

Plants when fresh, as stated, give negative responses as a rule. But when somewhat faded they sometimes give rise to positive response. Again, just as in the modified nerve the abnormal positive response gives place to the normal negative under strong and longcontinued stimulation, so also in the modified plant the abnormal positive response passes into negative

1 For general purposes it is immaterial whether the responses are recorded up or down. For convenience of inspection they are in general recorded up. But in cases where it is necessary to discriminate the sign of response, positive response will be recorded up, and negative down. 
(fig. 27) under strong stimulation. I was able in some cases to trace this process of gradual reversal, by continuously increasing the intensity of stimulus. It was then found that as the stimulus was increased, the positive at a certain point underwent a reversal into the normal negative response (fig. 28 ).

The plant thus gives a reversed response under abnormal conditions of staleness. I hare sometimes

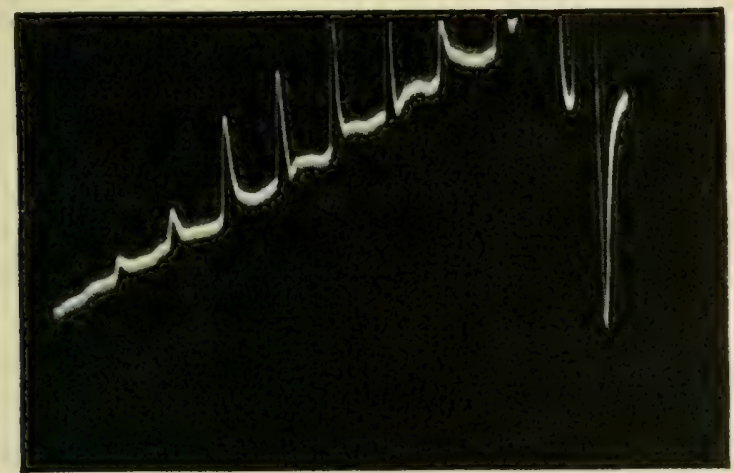

Fig, 28.-Abxornat Positive passing into Normal Negative in a Stale Specimex of Leaf-stalk of Cadliflower

Stimulus was gradually increased from 1 to 10 , by means of spring-tapper. When the stimulus intensity was 10 , the response became reversed into normal negative. (Parts of 8 and 9 are out of the plate.)

found similar reversal of response when the plant is subjected to the abnomal conditions of excessively high or low temperature.

Radial E.M. variation.-We hare seen that a current of response flows in the plant from the relatively more to the relatirely less excited. A theoretically important experiment is the following: A thick stem of plant stalk was taken and a hole bored so as to make one contact with the interior of the tissue, the other being 
on the surface. After a while the current of injury was found to disappear. On exciting the stem by taps or torsional vibration, a responsive current was observed

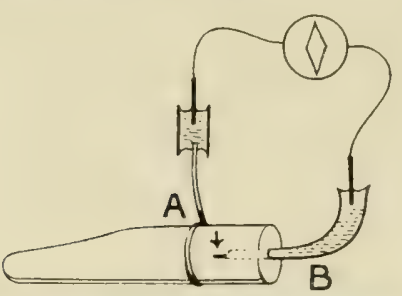

Fig. 29.-Radial E.M. Variation which flowed inwards from the more disturbed outer surface to the shielded core inside (fig. 29). Hence it is seen that when a wave of disturbance is propagated along the plant, there is a concomitant wave of radial E.M. variation. The swaying of a tree by the wind would thus appear to give rise to a radial E.M.F. 


\section{CHAPTER VII}

PLANT RESPONSE-ON THE RELATION BETWELN STIIULUS AND RESPONSE

Increased response with increasing stinulus--Apparent dinimution of response with excessively strong stimulus.

As already said, in the living tissue, molecular disturbance induced by stimulus is accompanied by an electric disturbance, which gradually disappears with the return of the disturbed molerules to their position of equilibrim. The greater the molecular distortion produced by the stimulus, the greater is the electric rariation produced. The electric response is thus an outward expression of a molecular disturbance produced by an external agency, the stimulus.

Curve of relation between stimulus and response.-In the curve showing the relation between stimnlus and response in nerve and muscle, it is found that the molecular effect as exhibited either by contraction or E.M. variation in muscle, or simply by E.I. variation in nerve, is at first slight. In the second part, there is a rapidly increasing effect with increased stimulus. Finally, a tendency shows itself to approach a limit of response. Thus we find the curre at first slightly convex, then straight and ascending, and lastly, concare to the abscissa (fig. 30).

In muscle the limit of response is reached much sooner than in nerve. As will be seen, the range of variation of stimulus in these curves is not very 
great. When the stimulus is carried beyond moderate limits, the response. oring to fatigue or other causes, may sometimes undergo an artual diminution.

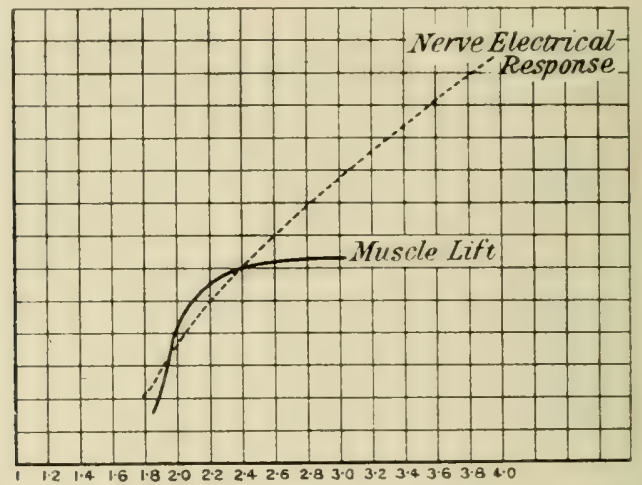

Fig. 30.-Conves showing the Relation between the Intensiti of Strmolus and Response

Abscisse indicate increasing intensity of stimulus. Ordinates indicate magnitude of response. (Waller.)

I have obtained very interesting results, with reference to the relation between stimulus and response,

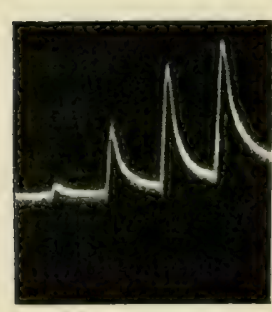

FIG. 31

Taps of increasing strength $1: 2: 3: 4$ producing increased response in leafstalls of turnip.
I when experimenting with plants. These results are suggestive of various types of response met with in animal tissues.

1. In order to obtain the simplest type of effects, not complicated by secondary phenomena, one has to choose specimens which exhibit little fatigue. Having procured these, I undertook two series of experiments. In the first $(1)$ the stimulus was applied by means of the spring-tapper, and in the second $(B)$ by torsional vibration. 
(A) The first stimulus was given by a fall of the lever through $h$, the serond through $2 h$, and so on. The response-curves clearly show increasing effect with increased stimulus (fig. 31).

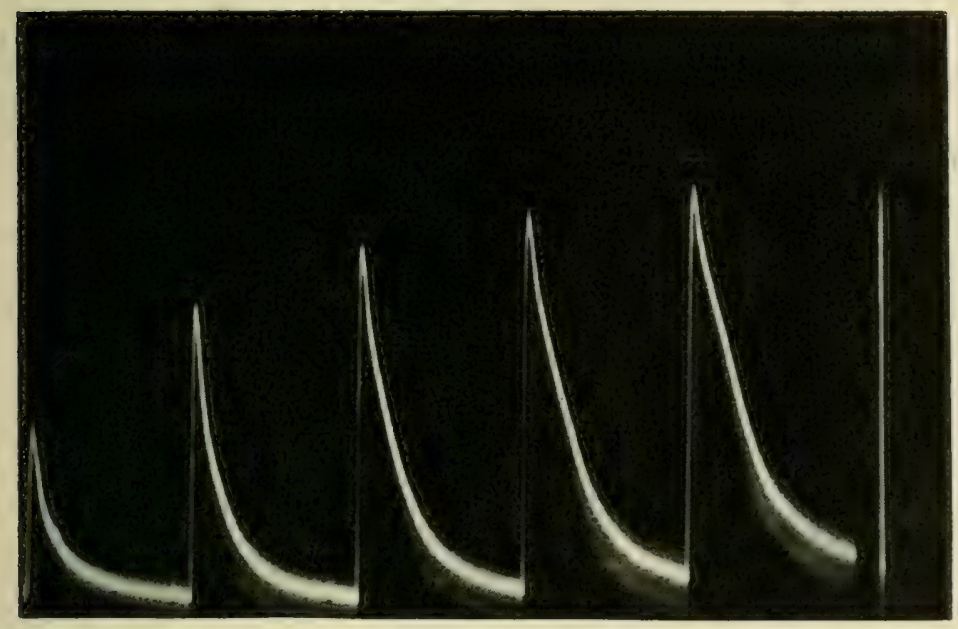

$2 \frac{1}{2}^{\circ}$

$5^{\circ}$

$7 \frac{1}{2}$ ?

$10^{3}$

$12 \frac{1}{2}^{\circ}$

Fig. 32.-increased Resposse with Increasing Vibrational Stimelt (C.ADLIFLOWER-STALK)

Stimuli applied at intervals of three minutes. Vertical line $=\cdot 1$ volt.

(B) 1. The vibrational stimulus was increased from $2.5^{\circ}$ to $5^{\circ}$ to $7.5^{\circ}$ to $10^{\circ}$ to $12.5^{\circ}$ in amplitude. It will be observed how the intensity of response tends to approach a limit (fig. 32).

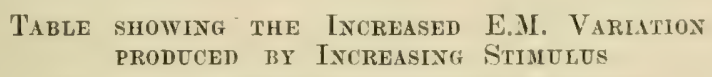

Angle of Vibration

E.M.I?

\begin{tabular}{|l|l|}
$2 \cdot 5^{\circ}$ & 044 volt \\
$50^{\circ}$ & $\cdot 075$, \\
$7 \cdot 5^{\circ}$ & 090, \\
$10^{\circ}$ & $\cdot 100$, \\
$12 \cdot 5^{\circ}$ & $\cdot 106, "$ \\
\hline
\end{tabular}


2. The next figure shows how little variation is produced with low ralue of stimulus, but with increasing stimulus the response undergoes a rapid increase, after which it tends to approach a limit (fig. 33, a).

3. As an extreme instance of the case just cited, I have often come across a curious phenomenon. T)ring the gradual increase of the stimulus from a low value there woukt the apparently no response. But.

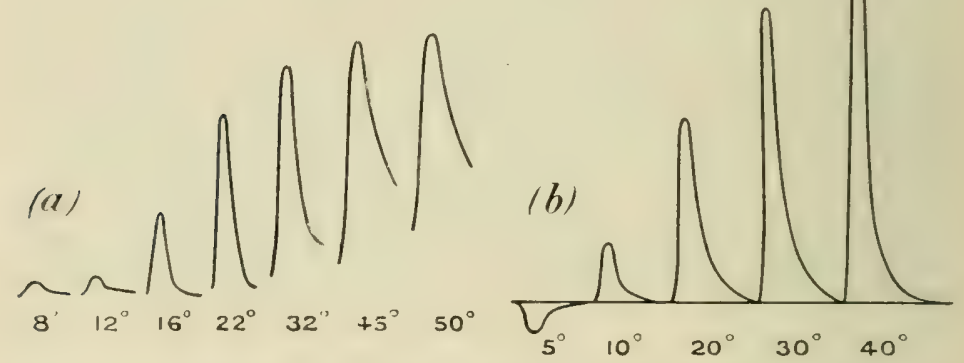

Fig. 33.-Responses to Increasing Stinuli produced by Increasixg Angle of Vibration

(a) Record with a specimen of fresh radish. Stimuli applied at interrals of two minutes. The record is taken for one minute.

(b) Record for stale radish. There is a reversed response for the feeble stimulus of $5^{\circ}$ ribration.

when a critical value was reached a maximum response would suddenly occur, and would not be exceeded when the stinulus was further increased. Here we have a parallel to what is known in animal physiology as the 'all or none' principle. With the cardiac muscle, for example, there is a certain minimal intensity which is effective in producing response, but further increase of stimulus produces no increase in response.

4. From an inspection of the recorts of responses 
which are given, it will be seen that the slope of a curve which shows the relation of stimulus to response will at first be slight, the curve will then ascend rapidly, and at high values of stimulus tend to become horizontal. The curve as a whole becomes, first slightly convex to the abscissa, then straight and ascending, and lastly roncare. I far more pronounced convexity in the first part is shown in some cases, especially when the specimen is stale. This is due to the fact that under these circumstances response is apt to begin with an actual reversal of sign, the plant under feebler than a certain critical intensity of stimulus piving positive, instead of the normal newative, response (fig. 33, l).

Diminution of response with excessively strong stimulus.-It is found that in animal tissues there is sometimes an actual dininution of response with exressive increase of stimulus. Thus Waller finds, in working with retina, that as the intensity of light stimulus is gradually increased, the response at first increases, and then sometimes undergoes a diminution. This phenomenon is unfortunately complicated by fatigue, itself regarded as obscure. It is therefore difficult to say whether the diminution of response is clue to fatigue or to some reversing action of an excessively strong stimulus.

From fig. 33, l, above, it is seen that there was an actual reversal of response in the lower portion of the curve. It is therefore not improbable that there may be more than one point of reversal.

In physical phenomena we are, howerer, arcquainted with numerous instances of reversals. For example, 
a common effect of magnetisation is to produce an elongation of an iron rod. But Bidwell finds that as the magnetising force is pushed to an extreme, at a rertain point elongation ceases and is succeeded, with further increase of magnetising force, by an actual contraction. Again a photographic plate, when exposed continuously to light, gives at first a negative image. Still longer exposure produces a positire. Then again we have a negative. There is thus produced a series of recurrent reversals. In photographic prints of flasher of lightning, two kinds of images are observed, one, the positive-when the lightning discharge is moderately intense-and the other, negative, the so-called 'dark lightning -due to the reversal action of an intensely strong discharge.

In studying the changes of conductivity produced in metallic particles by the stimulus of Hertzian radiation, I have often noticed that whereas feeble radiation produces one effect, strong radiation produces the opposite. Again, under the continuous action of electric radiation, I have frequently found recurrent reversals. ${ }^{1}$

\section{Diminution of response under strong stimulus traced}

to fatigue. - But there are instances in plant response where the diminution effert can be definitely traced to fatigue. The records of these cases are extremely suggestive as to the mamer in which the diminution is brought about. The accompanying figures (fig. $3 t$ ) give records of responses to increasing stimulus. They were made with specimens of cauliflower-stalks, one of which $(a)$ showed little fatigue, while in the other (I)

' See 'On Electric Touch,' Proc. Roy. Soc. Aug. 1900. 
fatigue was present. It will be seen that the curves obtained by joining the apices of the successive single responses are very similar.

In one case there is no fatigue, the recovery from each stimulus being complete. Every response in the
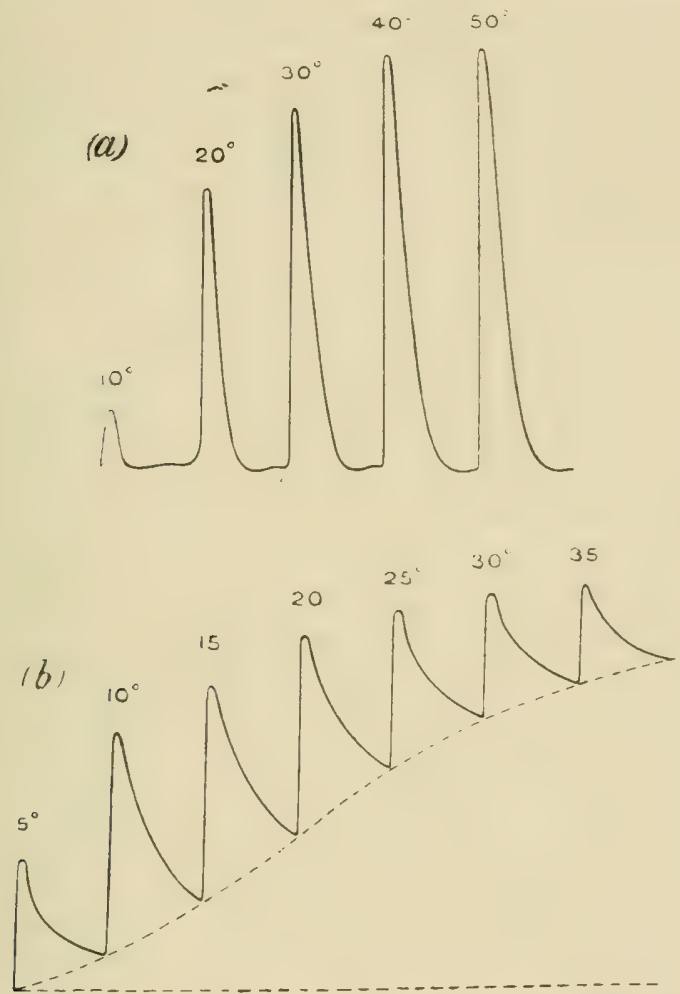

Fig. 34.-Responses to Increasing Stimolus obtained with Two Specimens of Stalk of Cadulflower

In (a) fatigue is absent, in $(b)$ it is present.

series therefore starts from a position of perfect equilibrium, and the height of the single responses increases with increasing stimulation. But in the second case, 
the strain is not completely removed after any single stimulation of the series. That recovery is partial is seen by the gradual shifting of the base line upwards. In the former case the base line is horizontal and represents a condition of complete equilibrium. Nor, horever, the base line, or line of modified equilibrium, is tilted upwards. Thus even in this case if we measure the heights of successive responses from the line of absolute equilibrium, they will be found to increase with increasing stimulus. (Ordinarily, however, we make no allowance for the shifting of the base line, measuring response rather from the place of its previous recovery, or from the point of modified equilibrium. Judged in this way, the responses undergo an apparent diminution. 


\section{CHAPTER VIII}

\section{PLANT RESPONST-ON THE INFLUENCE OF TEMPERATURE}

Effect of very low temperature-Influence of high temperature-Determination of death-point-Increased response as after-effect of temperature variation-Death of plant and abolition of response by the action of steam.

For every plant there in a range of temperature most favourable to its vital actirity. Alove this optimum, the vital activity diminishes, till a maximum is reached, when it ceases altogether, and if this point be maintained for a long time the plant is apt to be killed. Similarly, the vital activity is diminished if the temperature be lowered below the optimum, and again, at a minimum point it ceases, while below this minimum the plant may be killed. We may regard these maximum and minimum temperatures as the death-points. Some plants can resist these extremes better than others. Length of exposure, it should howerer be remembered, is also a determining factor in the question as to whether or not the plant shall survive unfarourable conclitions of temperature Thus we have hardy plants, and plants that are affected by excessive rariations of temperature. Within the characteristic power of the species, there may be, again, a certain anount of inclivichal difference. These facts being known, I was anxious to deter- 
mine whether the undoubted changes induced by tenperature in the vital activity of plants would affect electrical response.

Effect of very low temperature. - As regards the influence of very low temperature, I harl opportunities of studying the question on the sudden appearance of frost. In the previons week, when the temperature was about $10^{\circ} \mathrm{C}$., I had obtained strong electric response in radishes whose value varied from 0.5 to $\cdot 1$ volt. But two or three days later, as the effect of the frost, I found electric response to have practically disappeared. A few radishes were, however, fomd somewhat resistant, but the electric response had, even in these cases, fallen from the arerage value of $07.5 \mathrm{~V}$. muler normal temperature to $003 \mathrm{~V}$. after the frost. That is to say, the average sensitiveness had been recluced to about $2_{2}^{1}$ th. On warming the frost-bitten radish to $20^{\circ} \mathrm{C}$. there was an appreciable revival, as shown by increase in response. In specimens where the effect of frost had been very great, i.e. in those which showed little or no electric response, warming did not restore responsiveness. From this it would appear that frost killed some, which could not be subsequently revived, whereas others were only reAnced to a rondition of torpidity, from which there was revival on warming.

I now tried the effect of artificial lowering of temperature on various plants. A plant which is rery easily affected by cold is a certain species of Eucharis lily. I first obtained responses with the leaf-stalk of this lily at the ordinary temperature of the room 
$\left(17^{\circ} \mathrm{C}\right.$.). I then placed it for fifteell minutes in a cooling rhamber, temperature $-2^{\circ} \mathrm{C}$. f for only ten minutes, after which, on trying to obtain response, it was found to hare practically disappeared. I now warmed the plant by immersing it for awhile in water at $2\left(0^{\circ} \mathrm{C}\right.$.. and this produced a revival of the response (fig. 35). If the plant be subjected to low temperature for too long a time, there is then no subsequent revival.

I obtained a similar marked diminution of response with the flower-stalk of Arum lily, on lowering the temperature to zero.

My next attempt was to compare the sensibility of different plants to the effect of lowered temperatures. For this purpose I chose three specimens: (1) Eucharis lily ;

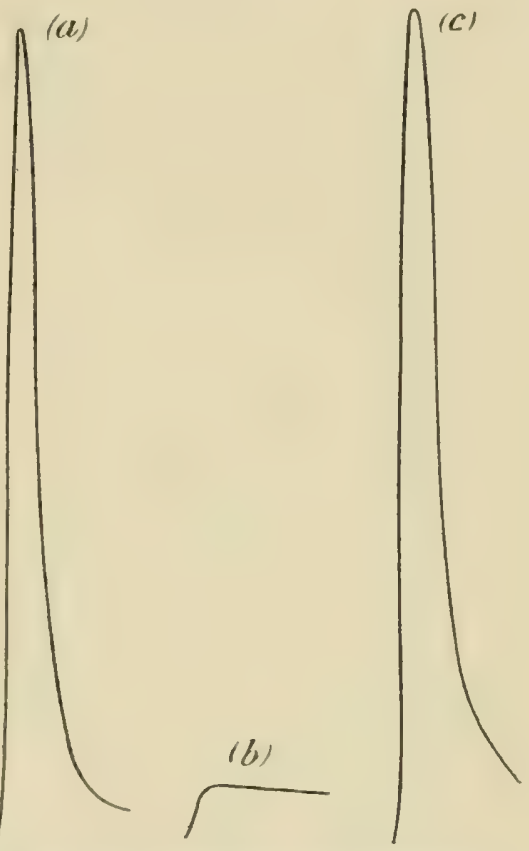

Fig. 35.- Dinisction of Resingen in Eucharis by Lowering of Temperature (a) Normal response at $17^{\circ} \mathrm{C}$.

(b) The response almost disappears when plantis subjected to -2 C. for fifteen minutes. (c) Revival of response on warming to $20^{\circ} \mathrm{C}$.

Iry; and (3) Holly. I took their normal response at $17^{\circ} \mathrm{C}$, and found that, generally speaking, they attained a fairly constant value after the third or fourth response. After taking these records of normal response, I placed the specimens in an ice-chamber, 
temperature $0^{\circ}$ C'., for twenty-fom hours, and afterwards took their records once more at the ordinary temperature of the room. From these it will be seen that while the responsiveness of Eucharis lily, known to be susceptible to the effect of cold, harl entirely disappeared, that of the hardier plants, Holly and Iry, showed very little change (fig. 36).

Another very curious eflect that I have noticerl is that when a plant approaches its death-point by reason of excessively high or low temperature, not only is its general responsiveness diminished almost to zero, but even the slight response occasiomally becomes reverser.
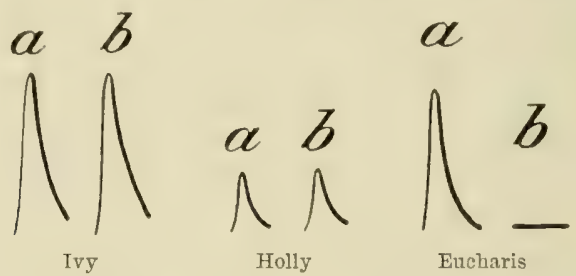

Fig. 36.-Aiter-effect of Cold on Ivy, Holdx, and Edcharis Litiy a. The normal response; $b$. Response after subjection to freezing temperature for twenty-four hours.

Influence of high temperature, and determination of death-point.-I next tried to find out whether a rise of temperature produced a depression of response, and whether the response disappeared at a maximum temperature-the temperature of death-point. For this purpose I took a batch of six radishes and obtained from them responses at gradually increasing temperatures. These specimens were obtained late in the season, and their electric responsiveness was much lower than those obtained earlier. The plant, previously kept for five minutes in water at a definite temperature 
(say $17^{\circ} \mathrm{C}$.), was mounted in the vibration apparatus and responses observed. The plant was then dismounted, and replaced in the water-bath at a higher temperature (say $30^{\circ}$ C.) again, for five minutes. A second set of responses was now taken. In this way observations were made with each specimen till the temperature at which response almost or altogether ceased was reached. I give below a table of results obtained with six specimens of radish, from which it would appear that response begins to be abolished in these cases at temperatures varying from $53^{\circ}$ to $55^{\circ} \mathrm{C}$.

\section{Table showing Effect of High Temperature in}

\section{Abolishing Response}

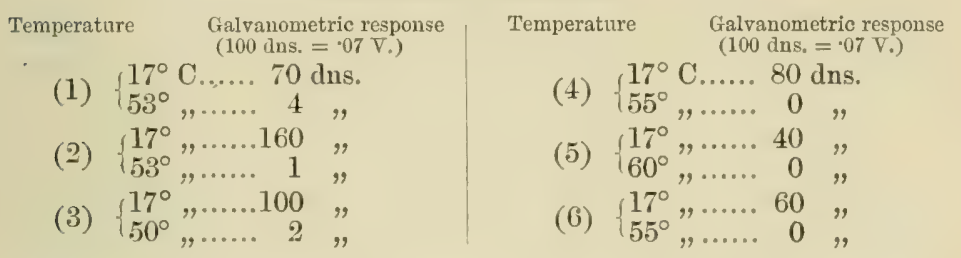

Electric heating.-The experiments just described were, however, rather troublesome, inasmuch as, in order to produce each variation of temperature, the specimen had to be taken ont of the apparatus, warmed, and remounted. I therefore introduced a modification by which this difficulty was obriated. The specimen was now enclosed in a glass chamber (fig. 37), which also contained a spiral of German-silver wire, through which electric currents could be sent, for the purpose of heating the chamber. By rarying the intensity of the current, the temperature could be regulated at will. The specimen chosen for experiment was the leaf-stalk of celery. It was kept at each given temperature for 
ten mimutes, and two records were taken during that time. It was then raised by $10^{\circ} \mathrm{C}$, and the same process

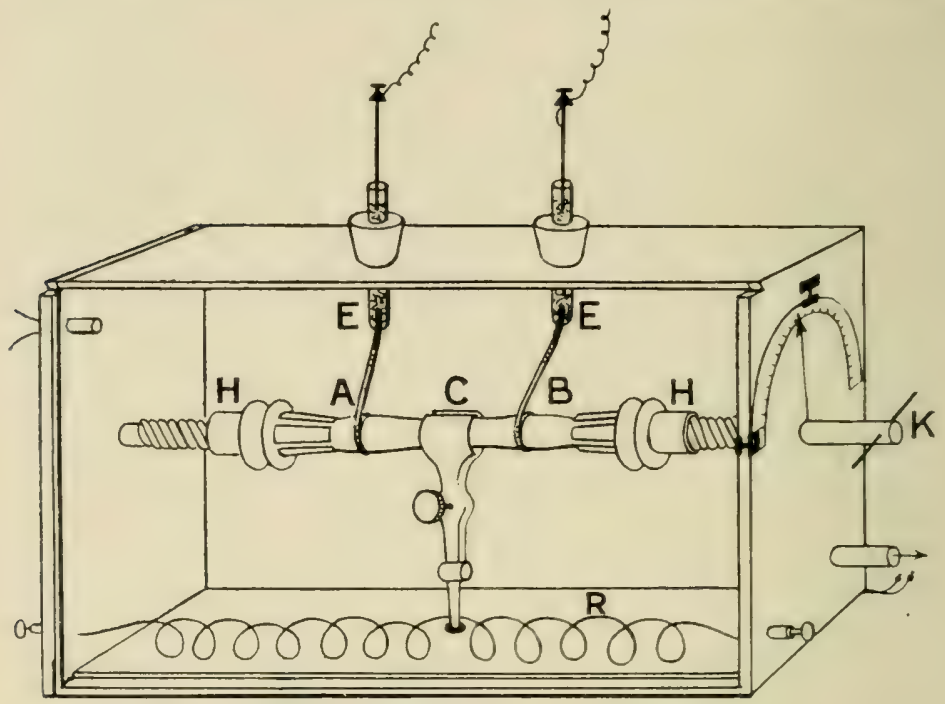

Fig. 37.-The Glass Chamber containing the Pulaxt

Amplitude of vibration which determines the intensity of stimulus is measured by the graduated circle seen to the right. Temperature is regulated by the electric heating coil R. For experiments on action of anæsthetics, vapour of chloroform is blown in through the side tube.

was repeated. It will be noticed from the record (fig. 38) that in this particular case, as the temperature

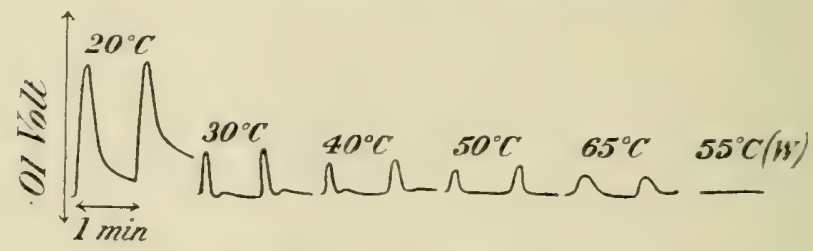

Fig. 38.-Effect of Temperature on Response

The response was abolished at the hot-water temperature of $55^{\circ} \mathrm{C}$.

rose from $20^{\circ} \mathrm{C}$. to $30^{\circ} \mathrm{C}$, there was a marked diminution of response. At the same time, in this case at 
least, recovery was quicker. At $20^{\circ} \mathrm{C}$, for example, the response was 21 dns., and the recovery was not complete in the course of a minute. At $30^{\circ} \mathrm{C}$, however, the response had been reduced to 7.5 divisions, but there was almost complete recovery in twelve seconds. As the temperature was gradually increased, a continuous decrease of response occurred. This diminution of response with increased temperature appears to be universal, but the quickening of recovery may he true of individual cases only.

'Table showing Diminution of Response with Ixcreasing Temphrature

( 01 Volt $=35$ divisions)

Temperature Response
$20^{\circ} \ldots \ldots \ldots 21$
$30^{\circ} \ldots \ldots \ldots .7 \cdot 5$
$40^{\circ} \ldots \ldots \ldots .5 \cdot 5$

Temperature $\quad$ Response
$50^{\circ} \ldots \ldots \ldots$
$65^{\circ} \ldots \ldots \ldots$.

In radishes response disappeared completely at $55^{\circ} \mathrm{C}$, but with celery, heated in the mammer described, I could not obtain its entire abolition at $60^{\circ} \mathrm{C}$. or even higher. A noticeable circumstance, however, was the prolongation of the period of recovery at these high temperatures. I soon understood the reason of this apparent anomaly. The method adopted in the present case was that of dry heating, whereas the previous experiments had been carried on by the use of hot water. It is well known that one can stand a temperature of $100^{\circ} \mathrm{C}$. without ill efferts in the hot-air chamber of a Turkish bath, while immersion in water at $100^{\circ} \mathrm{C}$. would be fatal.

In order to find out whether subjection to hot water would kill the celery-stalk, I took it out and placed it 
for five minutes in water at 550 C. This, as will be seen from the record taken afterwards, effectively killed the plant (fig. 38, w).

\section{Increased sensitiveness as after-effect of temperature} variation.-A very curions effect of temperature variation is the marked increase of sensitiveness which often
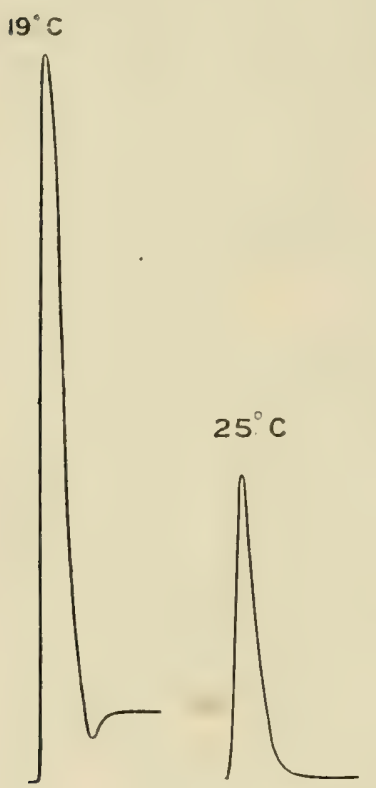

$30^{\circ} \mathrm{C}$

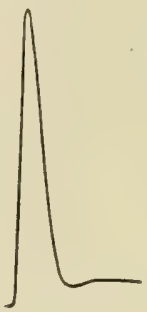

$50^{\circ} \mathrm{C}$

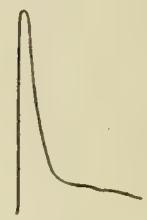

$\longleftarrow$ Temperature

falliny

$30^{\circ} \mathrm{C}$

Temperature rising $\longrightarrow$

$50^{\circ} \mathrm{C}$

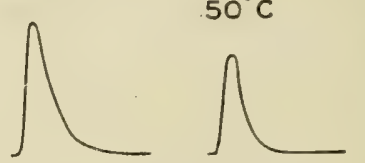

$70^{\circ} \mathrm{C}$

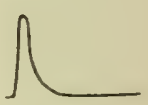

Fig. 39.--Effect of Rising and Faluing Temperature on the Response of Scotch Kalie

appear's as its after-effect. I noticed this first in a series of observations where records were taken during the rise of temperature and continued while the temperature was falling (fig. 39). The temperature was adjusterl by electric: heating. It was found that the responses were markedly enhanced during cooling, as 
compared with responses given at the same temperatures while warming (see table). Temperature variation thus seems to have a stimulating effect on response, by increasing molecular molility in some way. The second

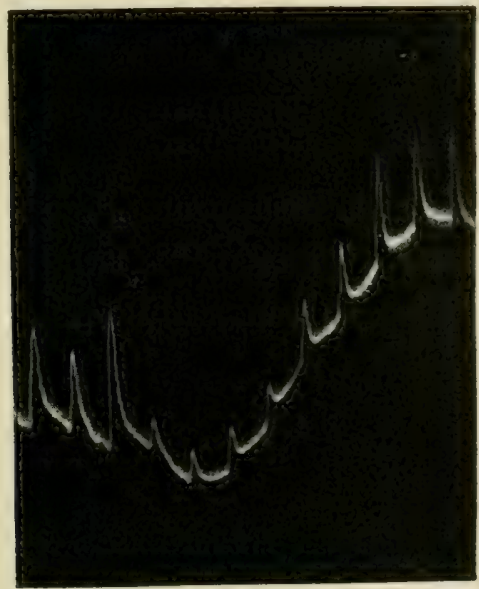

Fig. 40. - Reconts of Responses in Eucharis Lilu dotixa Rise añ Fall of Temperature

Stimulus constant, applied at intervals of one minute. The temperature of plant-chamber gradually rose on starting current in the heating coil; on breaking current, the temperature fell gradually. Temperature corresponding to each record is given below.

Temperature rising: (1) $20^{\circ}$, (2) $20^{\circ}$, (3) $22^{\circ}$, (4) $38^{\circ}$, (5) $53^{\circ},(6) 68^{\circ},(7) 65^{\circ}$. Temperature falling: (8) $60^{\circ}$, (9) $51^{\circ}$, (10) $45^{\circ}$, (11) $40^{\circ}$, (12) $38^{\circ}$.

record (fig. 10 ) shows the rariation of response in Eucharis lily (1) during the rise, and (2) during the fall

Table showing the Variation of Response ix Scoteh Kate DURING the Rise and Fall of Temperature

Temperature

Response

Response

[Temperature rising]| [Temperature falling]

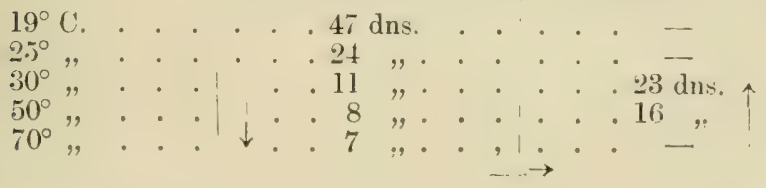


of temperature. Fig. 41 gives a curve of variation of response dming the rise and fall of temperature.

Point of temperature maximum.-We have seen how, in cases of lowered temperature, response is abolished earlier in plants like Eucharis, which are affected by cold, than in the hardier plants such as Holly and Ivy. Plants again are unequally affected as regards the upper range. In the case of Scotch kale, for instance, response disappears after ten minutes of water temperature of about 55 5 ., but with Eucharis fairly marked response can still be obtained after such

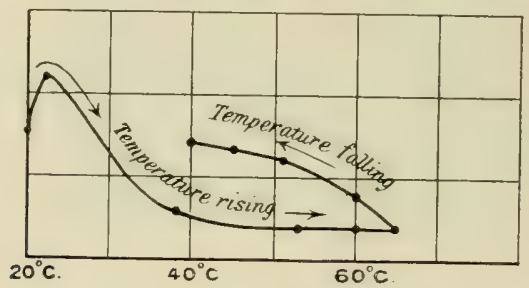

Fig. 41.-Corve showing Variation of Response in Eucharis with the Rise and Fall of Temperature

immersion and does not disappear till it has been subjected for ten minutes to hot water, at a temperature of $65^{\circ} \mathrm{C}$. or even higher. The reason of this great power of resistance to heat is probably found in the fact that the Eucharis is a tropical plant, and is grown, in this country, in hot-houses where a comparatively high temperature is maintained.

The effect of steam.-I next wished to obtain a continuous record by which the effects of suddenly increased temperatures, culminating in the death of the plant, might be marle evident. For this purpose I mounted the plant in the glass chamber, into which steam 
rould be introduced. I had rhosen a specinen which gave regular response. On the introduction of steam, with the consequent sudden increase of temperature, there was a transitory angmentation of excitalility. But this quickly disappeared, and in fire minutes the plant was eflectively killed, as will be seen graphically illustrated in the record (fig. 42).

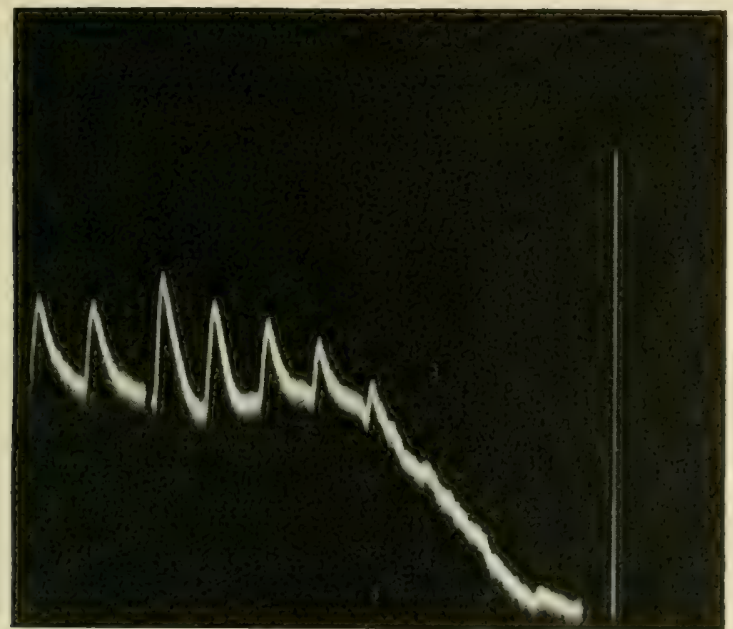

Before $\uparrow$ After

Fig. 42.-- Effect of Steati in Kulung Response

The two records to the left exhibit normal response at $17^{\circ} \mathrm{C}$. Sudden warming by steam produced at first an increase of response, but five minutes' exposure to steam killed the plant (carrot) and abolished the response.

Vibrational stimulus of $30^{\circ}$ applied at intervals of one minute; vertical line $=\cdot 1$ volt.

It will thus be seen that those modifications of vital achivity which are produced in plants by temperature+ rariation can he very accurately cauced hy electric: response. Indeed it may be said that there is no other method by which the moment of cessation of vitality can he so satisfactorily distinguished. Ordinarily, we 
are able to judge that a plant has died, only after various indirect effects of death, such as withering, have begun to appear. But in the electric response we have an immediate indication of the arrest of vitality, and we are therehy enabled to determine the death-point, which it is impossible to do by any other means.

It may be mentioned here that the explanation sugrested hy Kunkel, of the response lexing due to movement of water in the plant, is inadequate. For in that "ase we should expect a definite stimulation to be under all ronditions followerl by a definite eler:tric response, whose intensity and sign should remain invariable. But we find, insteat, the response to hes profoundly modified by any influence which aflects the vitality of the plant. For instance, the response is at its maximum at an optimum temperature. a rise of a few regrees producing a profomd depression; the response disappears at the maximm and minimum temperatures, and is revived when brought back to the optimum. Anastheties and poisons abolish the response. Again, we have the response undergoing an actual reversal when the tissue is stale. All these facts show that mere movement of water could not be the effective cause of plant response. 


\section{CHAPTER IX}

\section{PLANT RESPONSE-EFHECT OF ANESTHETICS AND POISONS}

Effect of anesthetics, a test of vital character of response--Effect of chlnioform-Effect of chloral-Effect of formalin-Method in which response is unaffected by rariation of resistance-Advantage of block method-Effect of dose.

THe most important test by which vital phenomena are distinguished is the influence on response of nareotics and poisons. For example, a nelve when narcotiserl by chloroform exhibits a diminishing response as the action of the amesthetic proceeds. (See below, fig. 43.) Similarly, various poisons have the eflect of permanently abolishing all response. Thus a nerve is killed by strong alkalis and strong acids. I lave already shown how plants whirh previously gave strong response dicl not, after application of an anesthetic ol poison, give any response at all. In these ases it was the last stage only that rould be olsserved. - But it appeared important to be able to trace the growing effect of anasthetisation or poisoning throughout the process. There were, however, two conditions which it at first appeared difficult to meet. First it was necessary to find a specimen which would normally exhibit no fatigue, and give rise for a long time to a uniform series 


\section{RESPONSE IN THE LIVING AND NON-LIVING}

of response. The immediate changes marle in the response, in consequence of the application of chemical reagents, could then be demonstrated in a striking manner. And with a little trouble, specinens can be secured in which perfect regularity of response is found. The record given in fig. 16, obtained with a specimen of radish, shows how possible it is to secure plants in which response is absolutely regular. I subjected this to uniform stimulation at intervals of one minute, during half an hour, without deterting the least variation

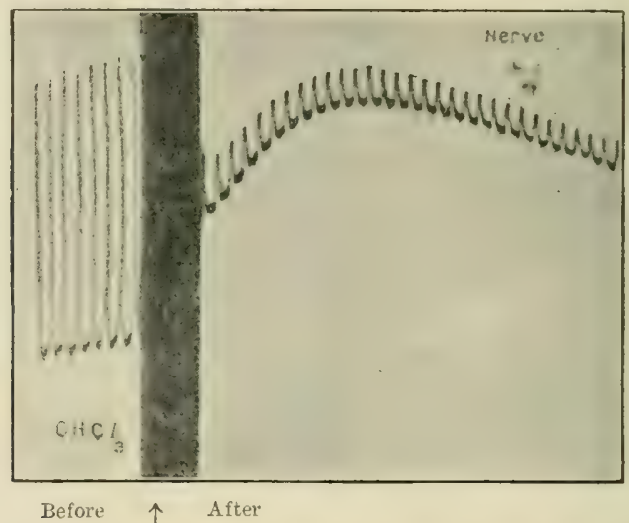

Fig. 43.-Effect of Chiloroforir on Nerte Respoxse (Waller)

in the responses. But it is of course easier to find others in which the responses as a whole may be taken as regular, though there may be slight rhythmic fluctuations. And eren in these cases the effect of reagents is too marked and sudden to escajue notice.

For the obtaining of constant and strong response I found the best materials to be carrot and radish, selected individuals from which gave most satisfactory results. The carrots were at their best in August and September, 
after which their sensitiveness rapidly declined. Later, being obliged to seek for other specimens, I c:ame upon radish, which gave good results in the early part of Norember; but the setting-in of the frost had a prejudicial effect on its responsiveness. Tess perfect than these, but still serviceable, are the leaf-stalks of turnip and cauliflower. In these the successive responses as a whole may be regarded as regular, though a curious altemation is sometimes noticed. which, howerer, has a resularity of its own.

My second misgiving was as to whether the action of reagents would be sufficiently rapid to display itself within the time linit of a photorraphic record. This would of course depend in turn upon the rapidity with which the tissues of the plint could alsorb the reagent and be affected by it. It was a surprise to me to find that, with good specimens, the effect was manifested in the course of so short a time as a minute or so.

Effect of chloroform.-In studying the eflect of rhemical reagents in plants. the methor is precisely similar to that employed with nerve; that is to say, where vapour of chloroform is used, it is blown into the plant chamber. In cases of liquid reacents, they are applied on the points of contant $A$ and band their close neighbourhood. The mode of experiment was (1) to obtain a series of normal responses to uniform stimuli, applied at regular intervals of time, say one minute, the record being taken the while on a photographic plate. $(\stackrel{\cdot}{-)}$ Without intermpting this procedure, the anasthetic agent. vapour of chloroform, was blown into the closed chamber containing the piant. 
It will be seen how rapilly chloroform produces depression of response (fig. 44), and how the effect grows with time. In these experiments with plants, the same curious shifting of the zero line is sometimes noticed as in nerve when subjected similarly to the action of reagents. This is a point of minor importance, the

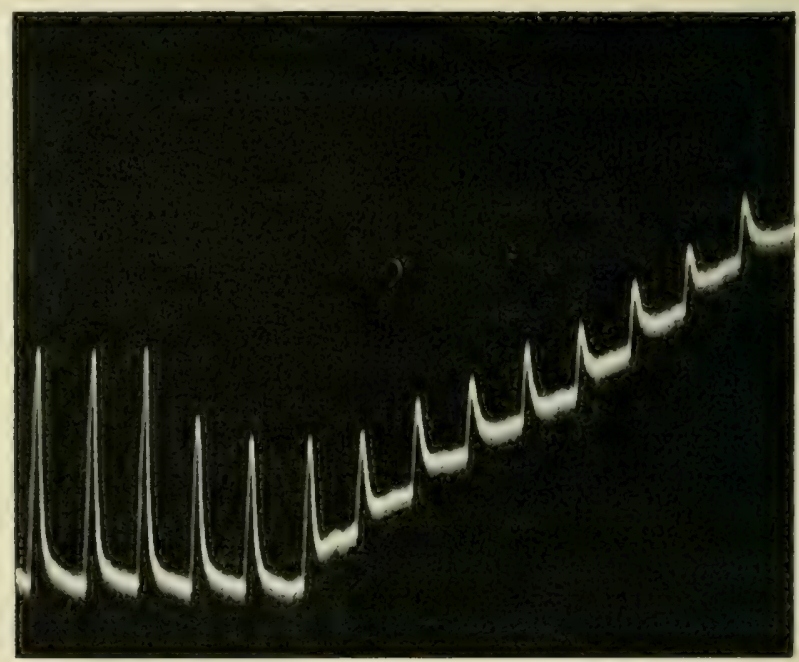

- Before $\uparrow$ After

Frc. 44.-Effect of Chlorofordr ox Respoxses of Carrot Stimuli of $25^{\circ}$ vibration at intervals of one minute.

eusential point to be notired being that the responses are rapidly reduced.

Effects of chloral and formalin.-I wive below (figs. $45,46)$ two sets of records, one for the reagent chloral and the other for formalin. The reagents were applied in the form of a solution on the tissue at the two leading contacts, and the contiguous surface. The rhythmic fluctuation in the normal response shown in fig. 45 is interesting. The abrupt decline, within a 
minute of the application of chloral, is also extremely well marked.

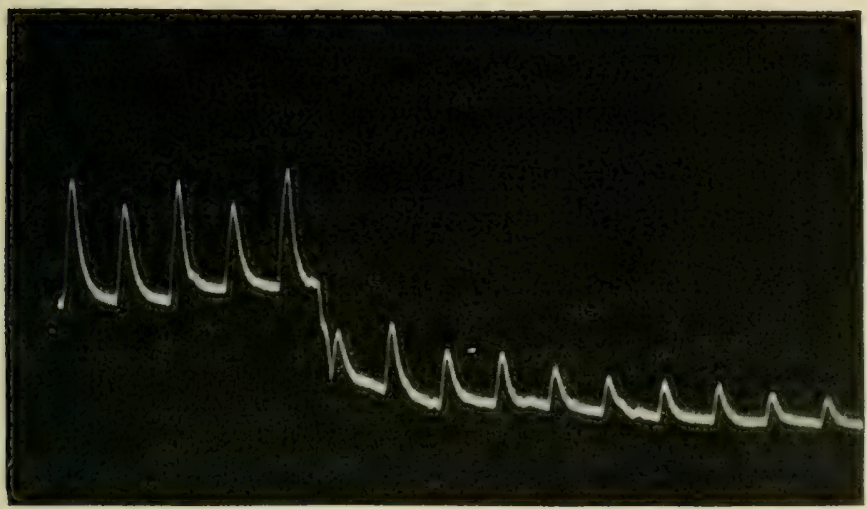

Before $\uparrow$ After

Fig. 45.-Action of Chlotil Hydrate on the Responsfes of Leaf-statik of CAultflower

Vibration of $25^{\circ}$ at intervals of one minute.

Response unaffected by variation of resistance.-In order to bring out rlearly the main phenomena, I have postponed till now the consideration of a point of some

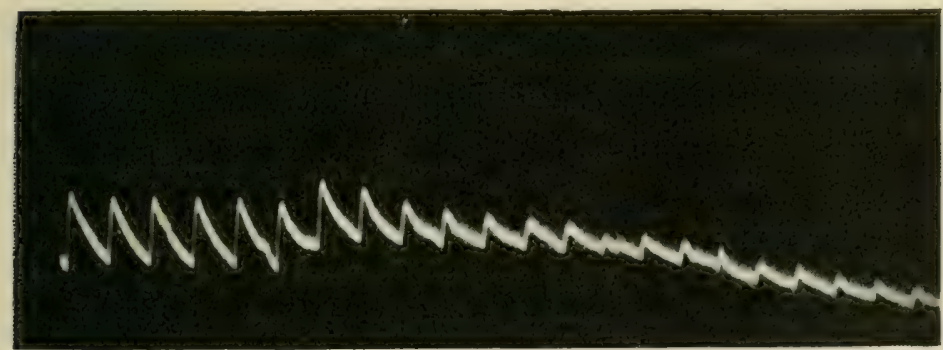

Before $\uparrow$ After

Fig. 46.-Action of Formatin (Radish)

difficulty. To determine the influence of a reacrent in modifying the excitability of the tissue, we rely upon its effect in exalting or depressing the responsive F...M. 
variation. We read this effect by means of galvanometric deflections. And if the resistance of the circuit remained constant, then an increase of galvanometer deffection would accurately indicate a heightened or depressed E.M. response, due to greater or less excitability of tissue caused by the reagent. But, by the introduction of the chemical reagent, the resistance of the tissue may mulergo change, and owing to this ('ause, modification of response as read by the galvanometer may be produced without any E.M. rariation. The observed variation of response may thus be partly owing to some unknown change of resistance, as well as to that of the E.M. variation in response to stimulus.

IVe may however discriminate as to how much of the olserved change is due to variation of resistance hy comparing the deflections produced in the galranometer by the action of a definite small E.MI.F. before and after the introduction of the reagent. If the reflections be the same in both cases. we know that the resistance has not varied. If there have been any change, the variation of deflection will show the amount, and we can make allowance accordingly.

I have howerer adopted another method, by which all necessity of correction is obriated, and the galvanometric reflections simply give E.M. variations, maffected by any change in the resistance of the tissue. This is done by interposing a rery large and constant resistance in the external circuit and thereby making other resistances negligible. An example will make this point clear. Taking a carrot as the regetable tissue, I found its resistance plus the resistance of the non- 
polarisable electrode equal to 20,000 ohms. The introduction of a chemical reagent reduced it to 19,000 ohms. The resistance of the galvanometer is equal to 1,000 ohms. The high external resistance was $1,000,000$ olmms. The variation of resistance produced in the circuit would therefore be $1,000 \mathrm{in}(1,000,000+$ $19,000+1,000)$ or one part in 1,020. Therefore the variation of galvanometric leflection due to change of resistance would be less than one part in a thousand (cf. fig. 49).

The advantage of the block method.-In these investigations I have used the block method, instead of that of negative variation, and I may here draw attention to the advantages which it offers. In the method of negative variation, one contact heing injured, the chemical reagents act on injured and uninjured unequally, and it is conceivable that by this unequal action the resting rifference of potential may be altered. But the intensity of response in the method of injury depends on this resting difference. It is thus hypothetically possible that on the method of negative variation there might be changes in the responses caused by variation of the resting difference, and not necessarily due to the stimulating or depressing effect of the reagent on the tissue.

But by the block method the two contacts are made with uninjured surfaces, and the effect of reagents on both is similar. Thus no advantage is given to one contact over the other. The changes now detected in response are therefore due to no adventitions circumstance, but to the reagent itself. If further verification 
be desired as to the effect of the reagent, we "an obtain it hy alternate stimulation of the $A$ and $B$ ends. Both ends will then show the given change. I give below a record of responses given hy two ends of leafstalk of turnip, stimulated alternately in the manner describerl. The stalk used was slightly conical, and owing to this diflerence between the $\mathrm{A}$ and $\mathrm{B}$ ends the responses given by one end were slightly different from those given by the other. though the stimuli were

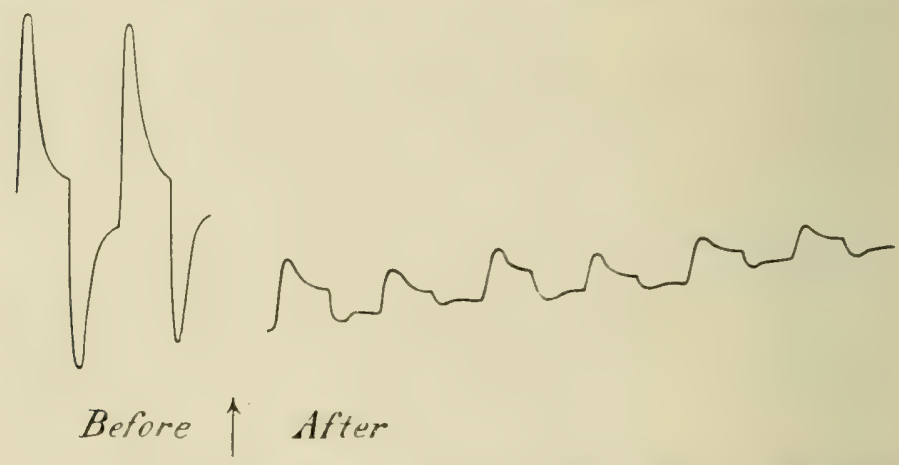

Fig. 47.-Abolition of Response at both A and B Exds by tine Action of $\mathrm{NaOH}$

Stimuli of $30^{\circ}$ vibration were applied at intervals of one minute to $\mathrm{A}$ and $\mathrm{B}$ alternately: Response was completely abolished twenty-four minutes after application of $\mathrm{NaOH}$.

equal. A few drops of 10 per cent. solution of $\mathrm{TaOH}$ was applied to both the ends. It will be seen how quickly this reagent abolished the response of both ends (fig. 47).

Effect of dose.-It is sonetimes found that while a reagent acts as a poison when given in large quantities, it may act as a stimulant in small doses. Of the two following recolds fig. 48 shows the slight stimulating 


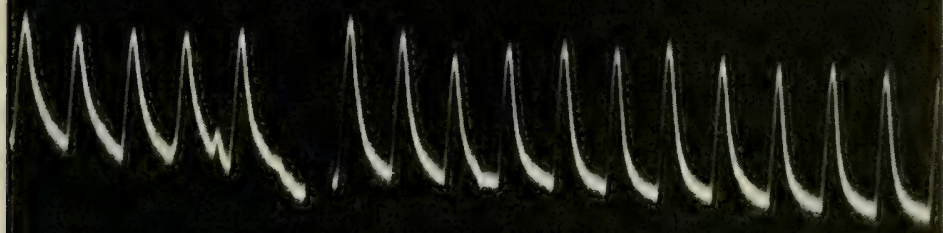

Before $\uparrow \quad$ After

Fig. 48.-Stimolating Action of veri dilute KOH

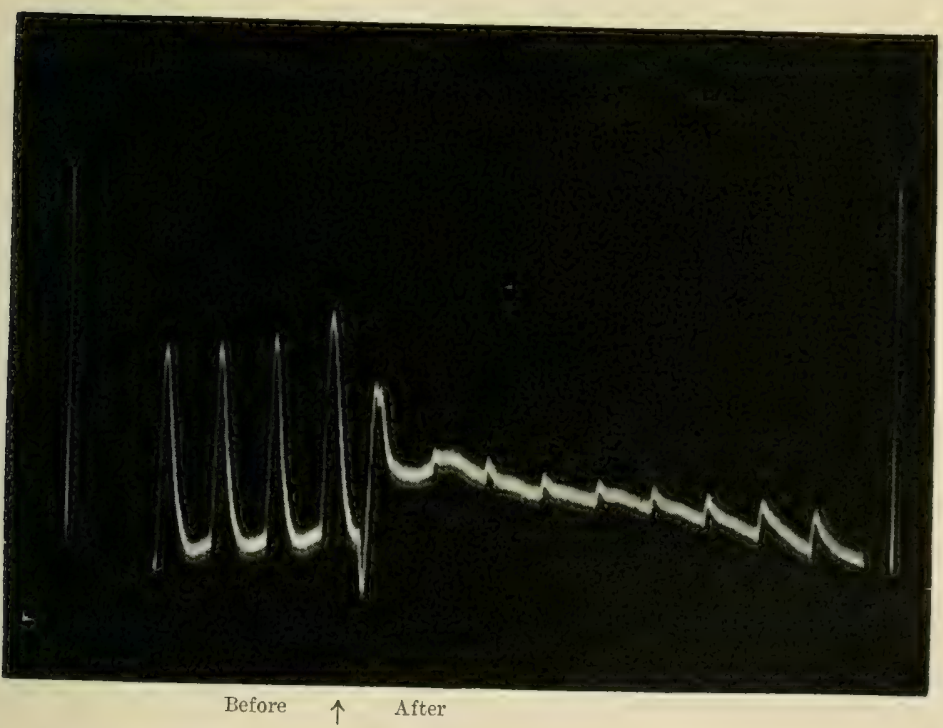

Fig. 49.-Neariy conplete Amolition of Response by strong KoH The two vertical lines are galvanometer deflections due to 1 volt, before and after the application of reagent. It will be noticed that the total resistance
remains unchanged. 
effect of very dilute $\mathrm{K}(\mathrm{)H}$, and fig. 49 exhilhits nearly complete abolition of response by the action of the same reagent when given in stronger doses.

So we see that, judged by the final criterion of the effect produced by anæsthetics and poisons, the plant response fulfils the test of vital phenomenon. In previous chapters we have found that in the matter of response by negative variation, of the presence or absence of fatigue, of the relation between stimulus and response, of modification of response by high and low temperatures, and even in the matter of occasional abnormal variations such as positive response in a modified tissue, they were strictly correspondent to similar phenomena in animal tissues. The remaining test, of the influence of chemical reagents, having now been applied, a complete parallelism may be held to have been established between plant response on the one hand, and that of animal tissue on the other. 


\section{CHAPTER X}

\section{RESPONSE IN METALS}

Is response found in inorganic substances?-Experiment on tin, block method-Anomalies of existing terminology-Response by method of depression-Response by method of exaltation.

WE have now seen that the electrical sign of life is not confined to animals, but is also found in plants. And we have seen how electrical response serves as an index to the vital activity of the plant, how with the arrest of this vital activity electrical response is also arrested temporarily, as in the case amongst others of anrsthetic action, and permanently, for instance under the action of poisons. Thus living tissues-both animal and vegetable-may pass from a responsive to an irresponsive condition, from which latter there may or may not be subsequent revival.

Hitherto, as already said, electrical response in animals has been regarded as a purely phỹsiological phenomenon. We have proved by various tests that response in plants is of the same character. And we have seen that by physiological phenomena are generally understood those of which no physical explanation can be offered, they being supposed to be clue to the play of some unknown vital force existing in living substances and giving rise to electric response to stimulation as one of its manifestations. 
Is response found in inorganic substances? '- It is now for us, however, to examine into the alleged superphysical character of these phenomena by stimulating inoroanic substances and discovering whether they do or do not give rise to the same electrical mode of response which was supposed to be the special ('haracteristic of living substances. Tre shall nse the same apparatus and the same mode of stimulation as those employed in obtaining plant response, merely sulstituting, for the stalk of "l plant, a metallic wire, say' tin' (fig. 50). Any other metal could be used instead of tin.

Experiment on tin, block method.-Let us then take a piece of tin wire ${ }^{2}$ from which all strains have been previously removed by annealing, and hold it clamper in the middle at $c$. If the strains have been successfully removed $A$ and $B$ will be found iso-electric, and no current will pass through the galvanometer. If $A$ and $B$ are not exactly similar, there will be a slight current. But this will not materially affect the results to be described presently, the slight existing current merely adding itself algebraically to the current of response.

If we now stimulate the end A by taps, or better

1 Following another line of inquiry I obtained response to electric stimulus in inorganic substances using the method of conductivity variation (see 'De la Généralité des Phénomènes Moléculaires Produits par l'Electricité sur la Matière Inorganique et sur la Matière Tivante,' Tracaux du Congres International de Physique, Paris, 1900; and also 'On Similarities of Effect of Electric Stimulus on Inorganic and Living Substances,' British Assuciation 1900. See Electrician). To bring out the parallelism in all details between the inorganic and living response, I have in the following chapters used the method of electro-motive variation employed by physiologists.

${ }_{2} \mathrm{By}$ 'tin' is meant an alloy of tin and lead used as electric fuse. 
still hy torsional vibration, a transitory 'current of action' will be found to flow in the wire from $B$ to $A$, from the unstimulater to the stimulated, and in the galvanometer from the stimulated to the unstimulated. Stimulation of B will give rise to a current in an opposite direction.

Experiment to exhibit the balancing effect.-If the wire has been carefully ammealed, the molecular condition of its different portions is found to be approximately the same. If such a wire he held at the "balancing

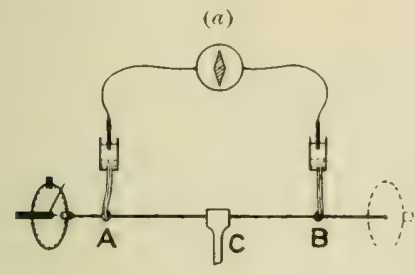

(b)

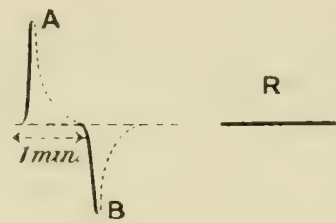

Fig. 50. - Eilectric Response in Metalus

(a) Method of block; (b) Equal and opposite responses when the ends $\mathbf{A}$ and $B$ are stimulated; the dotted portions of the curves show recovery;

(c) Balancing effect when both the ends are stimulated simultaneously.

point' (which is at or near the middle) by the clamp, and a quick vibration, say, of $900^{\circ}$ be given to $\mathrm{A}$, an upward deflection will be produced; if a vibration of $90^{\circ}$ be wiren to $\mathrm{B}$, there will he an equal downward deflection. If now both the ends $A$ and $B$ are vibrated simultaneously, the responsive E.M. variation at the two ends will continuously balance each other and the galvanometer spot will remain quiescent (fic..) $0, \mathrm{~A}, \mathrm{~B}, \mathrm{R}$ ). This balance will be still maintained when the block is removed and the wire is vilnated as a whole. It is to be remembered that with the length of wire constant, 
the intensity of stimulus increases with the amplitude of vibration. Again, keeping the amplitude constant, the intensity of stimulus is increased by shortening the wire. Hence it will be seen that if the clamp be shifted from the balancing point towards $A$, simultaneous vibration of $\mathrm{A}$ and $\mathrm{B}$ through $90^{\circ}$ will now give a resultant upward deflection, showing that the A response is now relatively stronger. Thus keeping the rest of the circuit untouched, merely moving the clamp from the left, past the balancing point to the right, we get either a positive, or zero, or negative, resultant effect.

In tin the current of response is from the less to the more excited point. In the retina also, we found the current of action flowing from the less stimulated to the more stimulated, and as that is known as a positive response, we shall consider the normal response of tin to be in like manner positive.

Just as the response of retina or nerve, under certain molecular conditions, undergoes reversal, the positive being then converted into negative, and negative into positive, so it will be shown that the response in metallic wires under certain conditions is found to undergo reversal.

Anomalies of present terminology.-When there is no current of injury, a particular current of response can hardly be called a negative, or positive, variation. Such nomenclature is purely arbitrary, and leads, as will be shown, to much confusion. A more definite terminology, free from misunderstanding, would be, as already said, to regard the current towards the more stimulated as positive, and that towards the less stimulated, in tissue or wire, as negative.

The stimulated end of tin, say the end A, thus becomes 
zincoid, i.e. the current through the electrolyte (non-polarisable electrodes with interposed galvanometer) is from $\mathrm{A}$ to $\mathrm{B}$, and through the wire, from the less stimulated $\mathrm{B}$ to the more stimulated A. Conversely, when B is stimulated, the action current flows round the circuit in an opposite direction. This positive is the most usual form of response, but there are cases where the response is negative.

In order to show that normally speaking a stimulated wire becomes zincoid, and also to show once more the anomalies into which we may fall by adopting no more definite terminology than that of negative variation, I have devised the following experiment (fig. 51). Let us take a bar, one half of which is zine and the other half copper, clamped in the middle, so that a disturbance produced at one end may not reach the other; the two ends are connected to a galvanometer through non-polarisable electrodes. The current through the electrolyte (non-polarisable electrodes and interposed galvanometer) will then

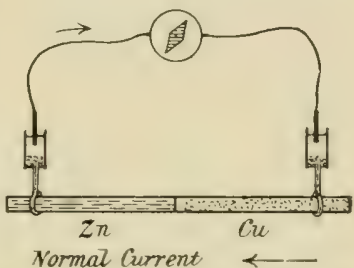

Fig. 51. - Corrent of Response tomards the Stimelated Exid

Hence when $\mathrm{Cu}$ stimulated: action current $\rightarrow$, normal E.MI.F. diminished $(\cdot 85-\cdot 009) \mathrm{V}$.

When Zn stimulated : action current $\leftarrow$, normal E.MI.F. increased $(\cdot 85+\cdot 013) \mathrm{V}$.

flow from left to right. We must remember that metals under stimulation generally become, in an electrical sense, more zinc-like. On vibrating the copper end (inasmuch as copper would then become more zinc-like) the difference of potential between zine and copper ought to be diminished, and the current flowing in the circuit would therefore be lessened. But vibration of the zinc end ought to increase the potential difference, and there ought to be then an increase of current during stimulation of zinc.

In the particular experiment of fig. 51, the E.M.F. between the zinc and copper ends was found to be 85 volt. This was balanced by a potentiometer arrangement, so that the galvanometer spot came to zero. On vibrating the zinc wire, a deflection of 33 dns. was obtained, in a direction which 
showed an increase of E.M.F. On stopping the vibration, the spot of light came back to zero. On now vibrating the copper wire, a deflection of 23 dns. was obtained in an opposite direction, showing a diminution of E.M.F. This transitory responsive variation disappeared on the cessation of disturbance.

By disturbing the balance of the potentiometer, the galvanometer deflection due to a known increase of E.II.F. was found from which the absolute E.M. variation caused by disturbance of copper or zine was determined.

It was thus found that stimulation of zinc had increased the P.D. by fifteen parts in 1,000 , whereas stimulation of copper had decreased it by eleven parts in 1,000. According to the old terminology, the response due to stimulation of zinc would have been regarded as positive variation, that of copper negative. The responses however are not essentially opposite in character, the action current in the bar being in both cases towards the more excited. For this reason it would be preferable, as already said, to employ the terms positive and negative in the sense I have suggested, i.e. positive, when the current in the acted substance is towards the more excited, and negative, when towards the less excited. The method of block is, as I have already shown, the most perfect for the study of these responses.

In the experiment fig. 50 , if the block is abolished and the wire is struck in the middle, a wave of molecular disturbance will reach $A$ and $B$. The mechanical and the attendant electrical disturbance will at these points reach a maximum and then gradually subside. The resultant effert in the galvanometer will be due to $\mathrm{E}_{\mathrm{A}}-\mathrm{E}_{\mathrm{B}}$ when $\mathrm{E}_{\mathrm{A}}$ and $\mathrm{E}_{\mathrm{B}}$ are the electrical variations produced at $\Delta$ and $\mathrm{B}$ by the stimulus. The electric changes at $\Lambda$ and 13 will continuously balance each other, and the resultant effect on the galvanometer will be zero: $(a)$ if 
the exciting disturbance reaches $\mathrm{A}$ and $\mathrm{B}$ at the same time and with the same intensity; (b) if the molecular condition is similar at the two points; and (c) if the rate of rise and subsidence of excitation is the same at the two points. In order that a resultant effect may be exhibited in the galvanometer, matters have to be so arranged that the disturbance may reach one point, say $A$, and not $\mathrm{B}$, and vice versa. This was accomplished by means of a clamp, in the method of block. Again a resultant differential action may be obtained even when the disturbance reaches both $\mathrm{A}$ and $\mathrm{B}$, if the electrical excitability of one point is exalted or depressed by physical or chemical means. We shall in Chap. XTI study in cletail the effect of chemical reagents in producing the enhancement or depression of excitability. There are thus two other means of obtaining a resultant effect-(2) by the method of relative depression, (3) by the method of relative exaltation.

Electric response by method of depression.-We may thus by reducing or abolishing the excitability of one end by means of suitable rhemical reagents (so-called method of injury) obtain response in metals without a block. The entire length of the wire may then be stimulated and a resultant response will be produced, owing to the difference between the excitability of the two ends. A piece of tin wire is taken, and one normal contact is made at A (strip of cloth moistened with water, or very dilute salt solution). The excitability of $\mathrm{B}$ is depressed by a few drops of strong potash or oxalic acid. By the application of the latter there will be a small P.D. between $\mathrm{A}$ and $\mathrm{B}$; this will simply 
produce a displacement of zero. By means of a potentiometer the galvanometer spot may be brought back to the original position. The shifting of the zero will not affect the general result. The effect of mechanical stimulus is to produce a transient electromotive response, which will be superposed algebraically on the existing P.D. The deflection will take place from the modified zero to which the spot returns during recovery. On now stimulating the wire as a whole by, say, torsional vibration, the current of response will be
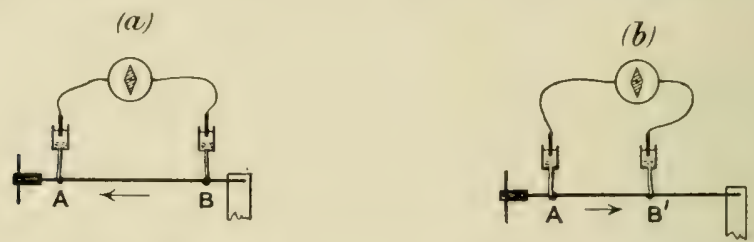

Fig. 52.-Response by Method of Depression (Without Block)

When the wire is stimulated as a whole the current of response is towards the more excitable.

In $(a) \mathrm{A}$ is a normal contact, $\mathrm{B}$ has been depressed by oxalic acid; current of response is towards the more excitable $\mathrm{A}$.

In (b) the same wire is used, only $\mathbf{A}$ is depressed by oxalic acid and a normal contact is made at a fresh point $\mathrm{B}^{\prime}$, a little to the left of $\mathrm{B}$ in $(a)$. Current of response is now from $\mathrm{A}$ towards the more excitable $\mathrm{B}^{\prime}$.

found towards the more excitable, i.e. from $B$ to $A$ (fig. 52, $a$ ).

A corroborative reversal experiment may next be made on the same piece of wire. The normal contact, through water or salt solution, is now made at $\mathbf{B}^{\prime}$, a little to the left of $B$. The excitability of $A$ is now depressed by oxalic acid. On stimulation of the whole wire, the current of response will now be found to flow in an opposite direction-i.e. from A to $\mathrm{B}^{\prime}$-but still from the relatively less to the relatively more excitable (fig. 52, b). 
From these experiments it will be seen how in one identical piece of wire the responsive current flows now in one direction and then in the other, in absolute conformity with theoretical considerations.

Method of exaltation.-A still more striking corroboration of these results may, however, be obtained by the

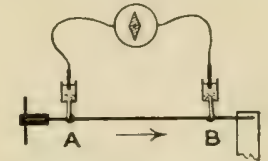

Fig. 53.-Method of Exaltation

The contact $\mathrm{B}$ is made more excitable by chemical stimulant $\left(\mathrm{Na}_{2} \mathrm{CO}_{3}\right)$. The current of response is towards the more excitable $B$.

converse process of relative exaltation of the responsiveness of one contact. This may be accomplished by touching one contact, say $\mathrm{B}$, with a reagent which like $\mathrm{Na}_{2} \mathrm{CO}_{3}$ exalts the electric excitability. On stimulation of the wire, the current of response is towards the more excitable B (fig. 53).

I give four records (fig. jt) which will clearly exhibit the responses as obtained by the methods of relative depression or exaltation. In $(a) \mathrm{B}$ is touched with the excitant $\mathrm{Na}_{2} \mathrm{CO}_{3}$, a permanent current flows from $\mathrm{A}$ to $\mathrm{B}$, response to stimulus is in the same direction as the permanent current (positive variation). In (b) B is touched with a trace of the depressant oxalic acid, the permanent current is in the same direction as before, but the current of response is in the opposite direction (negative variation). In $(c) \mathrm{B}$ is touched with dilute $\mathrm{KHO}$, the response is exhibited by a positive rariation. In $(d) \mathrm{B}$ is touched with strong KHO, the response is now exhibited by a negative variation. The last two results, apparently anomalous, are due to the fact, which will be demonstrated later, 
that $\mathrm{KHO}$ in minute quantities is an excitant, while in large quantities it is a depressant.

We have thus seen that we may obtain response (1) by block method, (2) by the method of injury, or relative depression of responsiveness of one contact,
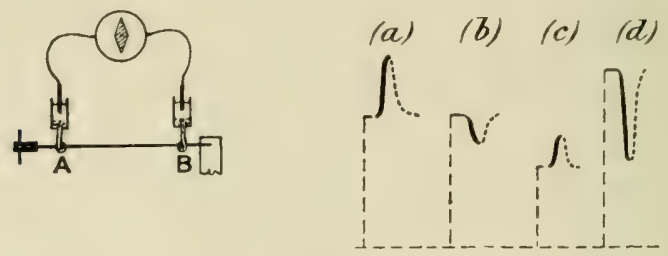

FIG. 54

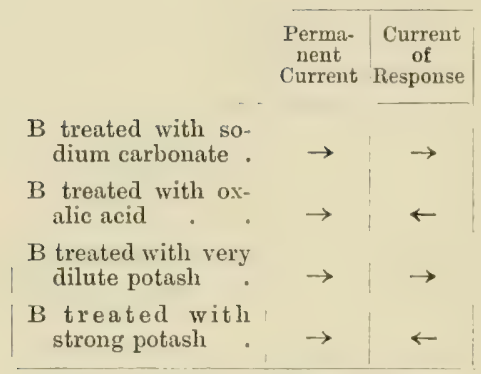

Current of response is always towards the more excitable point. (a) Response when B is treated with sodium carbonate.-An apparent positive variation.

(b) Response when B is treated with oxalic acid.-An apparent negative variation.

(c) Response when $\mathbf{B}$ is treated with very dilute potash.-Positive variation.

(d) Response when $\mathrm{B}$ is treated with strong potash.- Negative rariation.

The response is up when $B$ is more excitable, and down when $A$ is more excitable.

Lines thus ..... indicate deflection due to permanent current.

and (3) by the method of relative exaltation of responsiveness of one contact. In all these cases alike we obtain a consistent action current, which in tin is normally positive, or towards the relatively more excited. 


\section{CHAPTER XI}

INORGANIC RESPONSE-MODIFIED APPARATUS TO EXHIBIT

\section{RESPONSE IN METALS}

Conditions of obtaining quantitative measurements-Modification of the block method-Vibration cell-Application of stimulus-Graduation of the intensity of stimulus-Considerations showing that electric response is due to molecular disturbance-Test experiment-Molecular roltaic cell.

WE have already seen that metals respond to stimulus by E.M. variation, just as do animal and vegetable tissues. We have yet to see whether the similarity extends to this point only, or goes still further, whether the response-curves of living and in organic are alike, and whether the inorganic responsecurve is modified, as living response was found to be, by the influence of external agencies. If so, are the modifications similar? What are the effects of superposition of stimuli? Is there fatigue? If there be, in what way does it affect the curves? And lastly, is the response of metals exalted or depressed by the action of chemical reagents?

Conditions of obtaining quantitative measurements.-. In order to carry out these investigations, it is necessary to remove all sources of uncertainty, and obtain quantitative measurements. Many difficulties at first presented themselves in the course of this attempt, but they were 
completely removed by the adoption of the following experimental modification. In the simple arrangement for qualitative demonstration of response in metals previously described, successive experiments will not give results which are strictly comparable (1) unless the resistance of the circuit be maintained constant. This would necessitate the adoption of some plan for keeping the electrolytic contacts at $\mathrm{A}$ and $\mathrm{B}$ absolutely invariable. There should then be no chance of any shifting or variation of contact. (2) There must also be some means of applying successive stimuli of equal intensity. (3) And for certain further experiments it will be necessary to have some way of gradually increasing or decreasing the stimuli in a definite manner.

Modification of the block method.-By consideration of the following experimental molifications of the block methor (fig. 5j), it will be found easy to construct a perfected form of apparatus, in which all these conditions are fully met. The essentials to be kept in mind were the introduction of a complete block midway in the wire, so that the disturbance of one half should be prevented from reaching the other, and the making of a perfect electrolytic contact for the electrodes leading to the galvanometer.

Starting from the simple arrangement previously described where a straight wire is clamped in the middle (fig. 55, a), we next arrive at $(b)$. Here the wire $\mathrm{A} \mathrm{B}$ is placed in a $\mathrm{U}$ tube and clamped in the middle hy a tightly fitting cork. Melted paraffin wax is poured to a certain depth in the bend of the tube. The two 
limbs of the tube are now filled with water, till the ends $\mathrm{A}$ and $\mathrm{B}$ are completely immersed. Comnection is made with the non-polarisable electrodes by the side tubes. Vibration may be imparted to either A or в by means of ebonite clip holders seen at the upper ends $\mathrm{A}$ B of the wire.
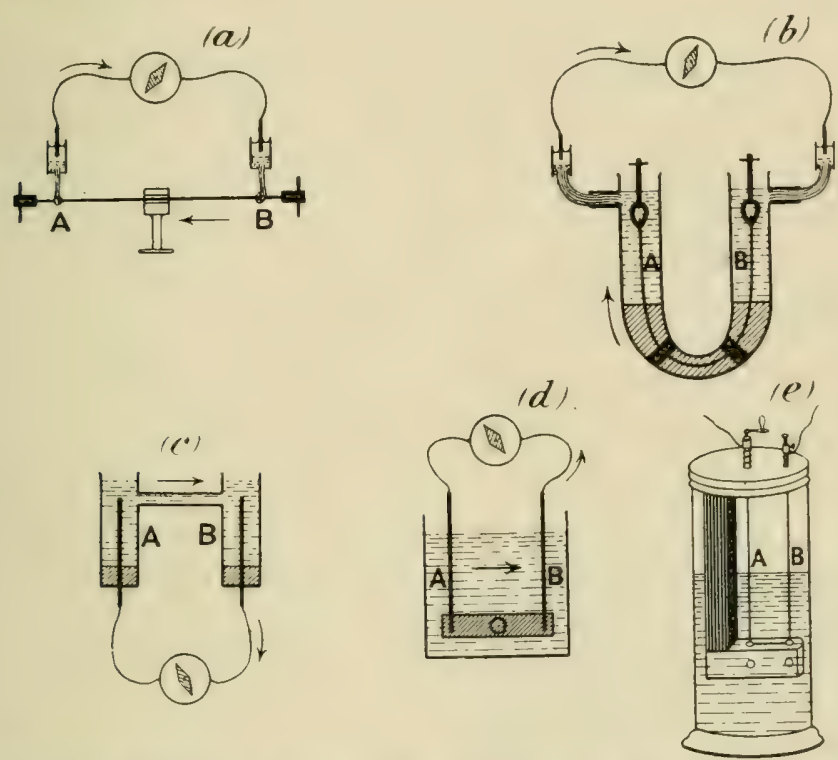

Fig. 55.-Successive Modifications of the Block Method from the

'Straight Wire' (a) to 'Cell Form' (e)

When A is excited, current of response in the wire is from less excited B to more excited A. Note that though the current of response is constant in direction, the galvanometer deflection in $(d)$ will be opposite to that in $(b)$.

It will be seen that the two limbs of the tube filled with water serve the purpose of the strip of moistened cloth used in the last experiment to make electric connections with the leading-out electrodes-with the advantage that we have here no chance of any shifting of contact or variation of surface, the contact between 
the wire and the surrounding liquid being perfect and invariable.

On now vibrating the end $\mathrm{A}$ of the tin wire by means of the ebonite clip holder, a current will be found to flow from B to A through the wire-that is to say, towards the excited-and from $\mathrm{A}$ to $\mathrm{B}$ in the galvanometer.

The next modification $(c)$ is to transfer the galvanometer from the electrolytic to the metallic part of the circuit, that is to say, it is interposed in a gap made by cutting the wire $\mathrm{A} \mathrm{B}$, the upper part of the circuit being directly connected by the electrolyte. Tibration of A will now give rise to a current of response which flows in the metallic part of the circuit with the interposed galvanometer from B to $A$. We see that though the direction of the current in this is the same as in the last case, yet the galvanometer deflection is now reversed, for the evident reason that we have it interposed in the metallic and not in the electrolytic part of the cireuit.

The next arrangement $(d)$ consists simply of the preceding placed upside down. Here $\mathrm{A}$ and $\mathrm{B}$ are held parallel to each other in an electrolytic bath (water). Merhanical ribration may now be applied to A without affecting $\mathrm{B}$, and vice versa.

The actual apparatus, of which this is a diagrammatic representation, is seen in (e).

Two pieces, from the same specimen of wire, are clamped separately at their lower ends by means of ebonite screws, in an L-shaped piece of ebonite. The wires are fixed at their upper ends to two electrodes- 
leading to the galvanometer-and kept moderately and uniformly stretched by spiral springs. The handle, by which a torsional vibration is imparted to the wire, may be slipped over either electrode. The amplitude of ribration is measured by means of a graduated circle.

It will be seen from these arrangements :

(1) That the cell depicted in $(e)$ is essentially the same as that in $(a)$.

(2) That the wires in the cell being immersed to a definite depth in the electrolyte there is always a perfect and invariable contar ${ }^{2}$ between the wire and the electrolyte. The difficulty as regards variation of contact is thus eliminated.

(3) That as the wires $A$ and $B$ are clamped separately below, we may impart a sudden molecular disturbance to either A or B by giving a quick to-and-fro (torsional) vibration round the vertical wire, as axis, by means of the handle. As the wire $\mathrm{A}$ is separate from $\mathrm{B}$, disturbance of one will not affect the other. Vibration of A produces a current in one direction, vibration of $\mathrm{B}$ in the opposite direstion. Thus we have means

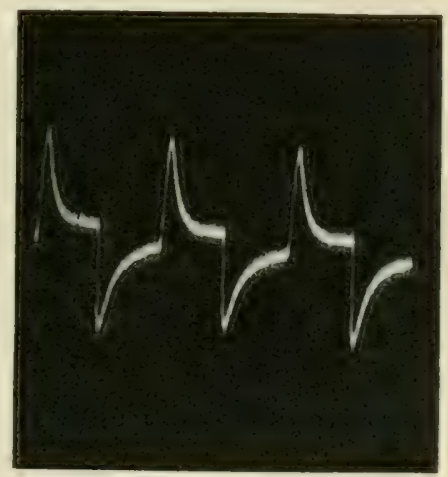

Firi, 56.-EQtal ani Opposite ReSPONSES EXHibited BY A AND $B$ of verifying every experiment by obtaining corroborative and reversed effects. When the two wires have been brought to exactly the same molecular condition by the 
processes of amealing or stretching, the effects obtained on subjecting $\mathbf{A}$ or $\mathbf{B}$ to any given stimulus are always equal (fig. 56).

Usually I interpose an external resistance rarying from one to five megohms according to the sensitiveness of the wire. The resistance of the electrolyte in the cell is thus relatively small, and the galvanometer deflections are proportional to the E.M. variations. It is always advisable to have a high external resistance, as by this means one is not only able to keep the deflections within the scale, but one is not troubled by slight accidental disturbances.

Graduation of intensity of stimulus.-If now a rapid torsional viluration be given to A or B, an E.M. variation

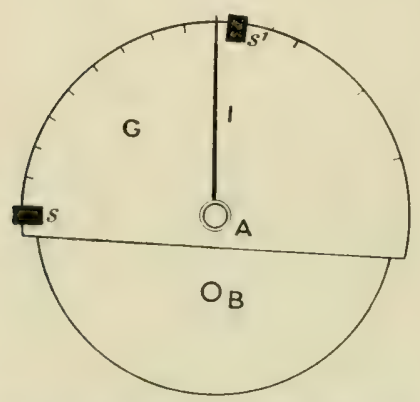

Fig. 57.- Top View of THE Vibration CeLL

The amplitude of vibration is determined by means of movable stops $\mathrm{S} \mathrm{S}^{\prime}$, fixed to the edge of the graduated circle $G$. The index arm I plays between the stops. (The second index arm, connected with $B$, and the second circle are not shown.) will be induced. If the amplitude of vibration be kept constant, successive responses - in substances which, like tin, show no fatigue-will be found to be absolutely identical. But as 'the amplitude of vibration' is increased, response will also become enhanced (see Chap. XV).

Amplitude of vibration is measured by means of the graduated circle (fig. 57). A projecting index, in comnection with the vibration-head, plays between fixed and sliding stops (s and $s^{\prime}$ ), one at the zero point of the scale, and the other moral)le. 
The amplitude of a given vibration can thus be predetermined by the adjustment of the sliding stop. In this way we can obtain either uniform or definitely graduated stimuli.

Considerations showing that electric response is due to molecular disturbance.-The electromotive variation varies with the substance. With superposition of stimuli, a relatively high value is obtained in tin, amounting sometimes to nearly half a volt, whereas in silver the electromotive variation is only about 01 of this value. The intensity of the response, howerer, does not depend on the chemical activity of the substance, for the electromotive variation in the relatively chemically inactive tin is greater than that of zinc. Again, the sign of response, positive or negative, is sometimes modified by the molecular condition of the wire (see Chap. XII).

As regards the electrolyte, dilute $\mathrm{NaCl}$ solution, dilute solution of bichromate of potash \&e. are normal in their action, that is to say, the electric response in such electrolytes is practically the same as with water. Ordinarily I use tap-water as the electrolyte. Zinc wires in $\mathrm{ZnSO}_{4}$ solution give responses similar in character to those given by, for example, Pt or $\mathrm{Sn}$ in water.

Test experiment.-It may be urged that the E.MI. effect is due in some way (1) to the friction of the vibrating wire against the liquid; or (2) to sone unknown surface action, at the point in the wire of the contact of liquid and air surfaces. This second objection has already been completely met in experi- 
mental morlification, fig. 5j, b, where the wire was shown to give response when kept completely immersed in water, variation of surface being thus entirely eliminated.

Both these questions may, howerer, be subjected to a definite and final test. When the wire to be acted on is clamped below, and ribration is imparted to it, a strong molecular disturbance is produced. If now it be carefully released from the clamp, and the wire rotated backwards and forwards, there could be little molecular disturbance, but the liquid friction and surface variation, if any, would remain. The effect of any slight disturbance outstanding owing to shaking of the wire would be relatively very small.

We can thus determine the effect of liquid friction and surface action by repeating an experiment with and without clanping. In a tin wire cell, with interposed external resistance equal to one million ohms, the wire A was subjected to a series of vibrations through $180^{\circ}$, and a deflection of 210 divisions was obtained. A corresponding negative deflection resulted on ribrating the wire 13. Now A was released from the clamp, so that it could be rotated backwards and formards in the water by means of the handle. On vibrating the wire A no measurable deflection was produced, thus showing that neither water friction nor surface rariation had anything to do with the electric action. The vibration of the still clamped $\mathrm{B}$ gave rise to the normal strong deflection.

As all the rest of the circuit was kept absolutely the same in the two different sets of experiments, these 
results conclusively prove that the responsive electromotive variation is solely due to the molecular disturbance produced by mechanical ribration in the acted wire.

A new and theoretically interesting molecular roltaic cell may thus be made, in which the two elements consist of the same metal. Molecular disturbance is in this case the main source of energy. A cell once made may be kept in working order for some time by pouring in a little vaseline to prevent evaporation of the liquid.

It will be shown further, in succeeding chapters, by numerous instances, that any conditions which increase molecular mobility will also increase intensity of response, and converwely that any conditions having the reverse effect will depress response. 


\section{CHAPTER XII}

WORGANIC RESPONSE - METHODS OF ENSLRING CONSISTENT RESUITS

Preparation of wire-Effect of single stimulus.

I sHALL now proceed to describe in detail the responsecurves obtained with metals. The E.M. rariations resulting from stimulus range, as has been said, from - $t$ volt to $\cdot 01$ of that value, according to the metal employed. And as these are molecular phenomena, the effect will also depend on the molecular condition of the wire.

Preparation of wire.-In order to have our results thoroughly consistent, it is necessary to bring the wire itself into a normal condition for experiment. The very fact of mounting it in the cell strains it, and the after-effect of this strain may cause irregularities in the response.

For the purpose of bringing the, wire to this normal state, one or all of the following devices may be used with advantage. (1) The wires obtained are usually wound on spools. It is, therefore, advisable to straighten any given length, before mounting, by holding it stretched, and rubbing it up and down with a piece of cloth. On washing with water, they are now ready for mounting in the cell. 
()ㅡ The cell is usually filled with tap-water, and a period of rest after making up, generally speaking, improves the sensitiveness. These expedients are ordinarily sufficient, but it occasionally happens that the wire has got into an abnormal condition.

In this case it will be found helpful (3) to have recourse to the process of annealing: For if response be a molecular phenomenon, then anything that increases molecular mobility will also increase its

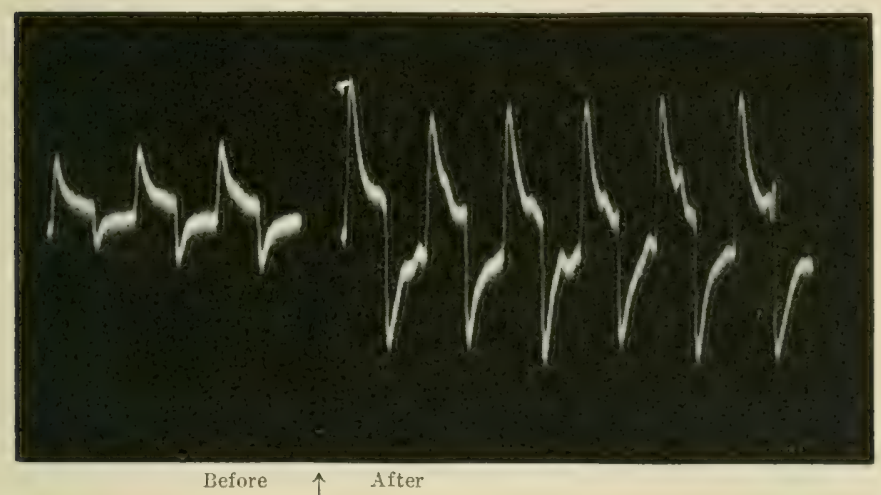

Fig. 58.-Effect of Annealing on increasing the Response of botil A ant B Wires (Tix)

Stimuli (vibration of $160^{\circ}$ ) applied at intervals of one minute.

intensity. Ilence we may expect annealing to enhance lesponsiveness. This inference will be seen rerified in the record given in fig. 58. In the case under consideration, the convenient method employed was by pouring hot water into the cell, and allowing it to stand and cool slowly. The first three pairs of responses were taken by stimulating $A$ and $B$ alternately, on mounting in the cell, which was filled with water. Hot water was then substituted, and the cell was 
allowed to cool down to its original temperature. The six following pairs of responses were then taken. That this beneficial effect of ammealing was not due to any accidental circunstance will be seen from the fact that both wires have their sensitiveness equally enhanced.

(4) In addition to this mode of amnealing, both wires may be short-circuited and vibrated for a time. Lastly (j) slight stretching in situ will also sometimes be found beneficial. For this purpose I have a screw arrangement.

By one or all of these methods, with a little practice, it is always possible to bring the wires to a normal condition. The responses subsequently obtained become extraordinarily consistent. There is therefore no reason why perfect results should not be arrived at.

Effect of single stimulus.-The accompanying figure (fig. 59) gives a series, each of which is the response-

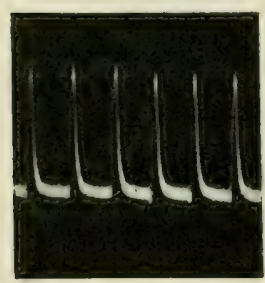

Fic. 59.-Uxifonir RespoNses IN TIN curve for a single stimalus of uniform intensity, the amplitude of vibration being kept constant. The perfect regularity of responses will be noticed in this figure. The wire after a long period of rest may be in an abnormal condition, but after a short period of stimulation the responses become extremely regular, as may be noticed in this figure. Tin is, usually speaking, almost indefatigable, and I have often obtained several hundreds of successive responses showing practically no fatigue. In the figure it will be noticel that the rising portion 
of the curve is somewhat steep, and the recovery convex to the abscissa, the fall being relatively rapid in its first, and less rapid in its later, parts. As the electric variation is the concomitant effect of molecular disturbance-a temporary upset of the molecular equilibrium-on the cessation of the external stimulus, the excitatory state, and its expression in electric variation, disappear with the return of the molecules to their condition of equilibrium. This process is seen clearly in the curve of recovery.

Different metals exhibit different periods of recovery, and this again is modified by any influence which affects the molecular condition.

That the excitatory state persists for a time eren on the cessation of stimulus can be independently shown by keeping the galvanometer circuit open during the application of stimulus, and completing it at various short intervals after the cessation, when a persisting electrical effect, diminishing rapidly with time, will be apparent. The rate of recovery immediately on the ressation of stimulus is rather rapicl, but traces of strain persist for a short time. 


\section{CHAPTER XIII}

INORGANIC RESPONSE-MOLECULAR MOBILITY :

ITS INFLUENCE ON RESPONSE

Effects of molecular inertia-Prolongation of period of recovery by orerstrain-Molecular model-Reduction of molecular sluggishness attended by quickened recovery and heightened response-Effect of temperature -Modification of latent period and period of recovery by the action of chemical reagents-Diphasic variation.

WE have seen that the stimulation of matter causes an electric variation, and that the acted substance gradually recovers from the effect of stimulus. We shall next study how the form of response-curres is modified by various agencies.

In order to study these effects we must use, in practice, a highty sensitive galvanometer as the recorder of E.M. variations. This necessitates the use of an instrument with a comparatively long period of swing of needle, or of suspended coil (as in a D'Arsonval). Owing to inertia of the recording galvanometer, howerer, there is a lag produced in the records of E.M. changes. But this can be distinguished from the effect of the molecular inertia of the substance itself by comparing two successive records taken with the same instrument, in one of which the latter effect is relatively absent, and in the other present. We wish, for example, to find out 
whether the E.M. effect of mechanical stimulus is instantaneous, or, again, whether the effect clisappear's immediately. We first take a galvanometer record of the sudden introduction and cessation of an E.M.F. on the circuit containing the vibration-cell (fig. 60, $a$ ). WTe then take a record of the E.M. effect produced by a stimulus caused by a single torsional vibration. In order to make the conditions of the two experiments as similar as possible, the disturbing E.M.F., from a potentiometer, is previously adjusted to give a deflection nearly equal to that caused by stimulus.

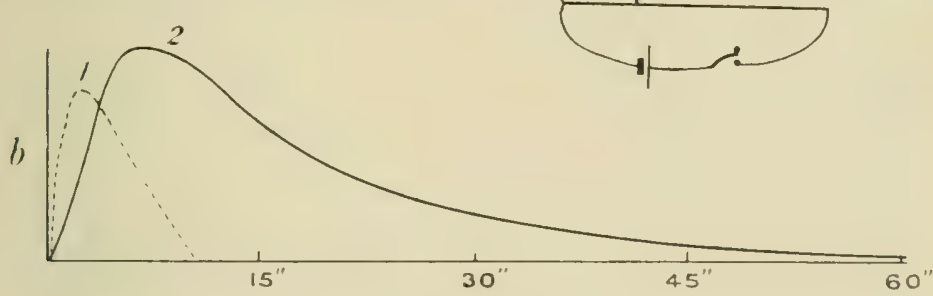

FIG. 60

(a) Arrangement for applying a short-lived E.M.F.

(b) Difference in the periods of recovery: (1) from instantaneous E.M.F.; and (2) that caused by mechanical stimulus.

The torsional vibration was accomplished in a quarter of a second, and the contact with the potentiometer (ircuit was also made for the same length of time.

The record was then taken as follows. The recording drum had a fast speed of six inches in a minute, one of the small subdivisions representing a second. The battery contact in the main potentiometer circuit was made for a quarter of a second as just mentioned and a record taken of the effect of a short-lived E.M.F. 
on the circuit containing the cell. (2) A record was next taken of the E.M. variation produced in the cell by a single stimulus. It will be seen on comprarison of the two records that the maximum effect took place relatively later in the case of mechanical stimulus, and that whereas the galvanometer recovery in the former case took place in 11 seconds, the recovery in the latter was not complete till after 60 seconds (fig. 60 , l). This shows that it takes some time for the effect of stimulus to attain its maximum, and that the effect does not disappear till after the lapse of a certain interval. The time of recovery from strain depends on the intensity of stimulus. It takes a longer time to recover from a stronger stimulus. But, other things being equal, successive recovery periods from successive stimulations of equal intensity are, generally speaking, the same.

We may now study the influence of any change in external conditions by observing the modifications it produces in the normal curve.

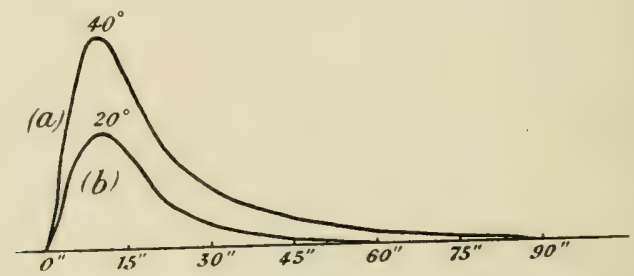

Fig. 61.-Prolongation of Peniod of Recovery after Overstrain

Recovery is complete in $60^{\prime \prime}$ when the stimulus is due to $20^{\circ}$ vibration. But with stronger stimulus of $40^{\circ}$ vibration, the period of recovery is prolonged to $90^{\prime \prime}$.

Prolongation of period of recovery by overstrain.The pair of records given in fig. 61 shows how 
recovery is delayed, as the effect of overstrain. Curve (a) is for a single stimulus due to a vibration of amplitude $20^{\circ}$, and curve $(b)$ for a stimulus of $40^{\circ}$ amplitude of vibration. It will be noticed how relatively prolonged is the recovery in the latter case.

Molecular Model.-We have seen that the elertric response is an outward expression of the molecular disturbance produced by the action of the stimulus. The rising part of the responsecurve thus exhibits the effect of molecular upset, and the falling part, or recovery, the restoration to equilibrium. The mechanical model (fig. 62) will help us to visualise many complex response phenomena. The mo-

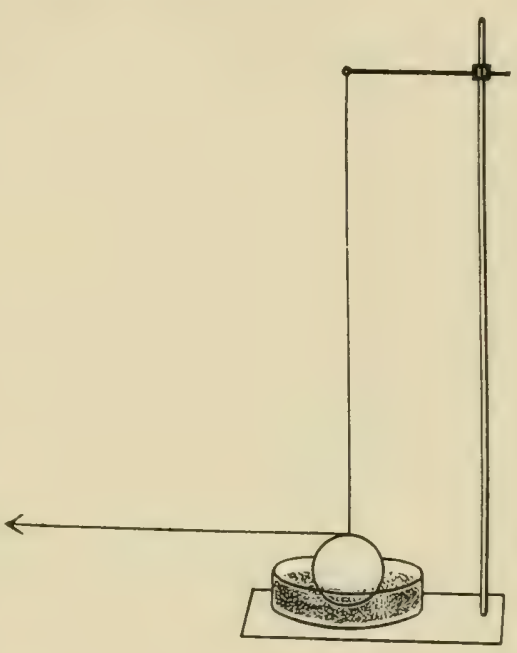
lecular model consists

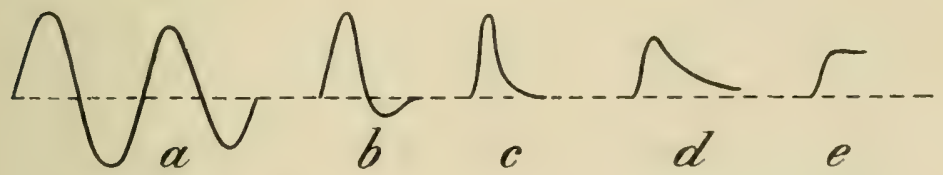

Fig. 62.-Monel showing the Effect of Friction

of a torsional pendulum-a wire with a dependent sphere. By the stimulus of a blow there is produced a torsional vibration - a response followed by recorery. The writing lever attached to the pendulum records 
the response-curves. The form of these curves, stimulus remaining constant, will be modified by friction; the less the friction, the greater is the mobility. The friction may be varied by more or less raising a vessel of sand touching the pendulum. By varying the friction the following curves were obtained.

(a) When there is little friction we get an afteroscillation, to which we have the corresponding phenomenon in the retinal after-oscillation (compare fig. 10.j).

$(b$ and $c)$ If the friction is increased, there is a damping of oscillation. In (c) we get recovery-curves similar to those found in nerre, muscle, plant, and metal.

(d) If the friction is still further increased the maximum is reached much later, as will be seen in the increasing slant of the rising part of the curve; the height of response is diminished and the period of recovery very much prolonged by partial molecular arrest. The curve $(d)$ is very similar to the "molecular' arrest " curve obtained by small dose of chemical reagents which act as 'poison' on living tissue or on metals (compare fig. 93, a).

(e) When the molecular mobility is further decreased there is no recovery (compare fig. $93, b$ ).

Still further increase of friction completely arrests the molecular pendulum, and there is no response.

From what has been said, it will be seen that if in any way the friction is diminished or mobility increased the response will be enhanced. This is well exemplified in the heightened response after ammealing (fig. .j8) and after preliminary vibration (figs. 81, 82). 
Possibly comected with this may be the increased responses exhibited by the action of stimulants (figs. 89, $90)$.

Reduction of molecular sluggishness attended (I) by quickened recovery.-Sometimes, after a cell has been resting for too long a period, especially on cold days, the wire gets into a sluggish condition, and the period of recovery is thereby prolonged. But successive vibrations gradually remore this inertness, and recorery is then hastened. This is shown in the accompanying curves, fig. 63 , where $(a)$ exhibits only rery partial

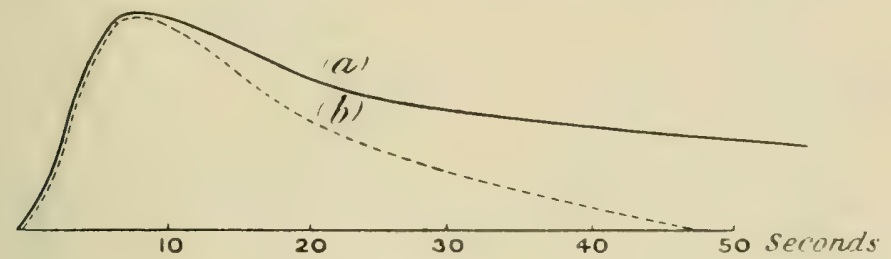

Fig. 63

(a) Slow recovery of a wire in a sluggish condition.

(b) Quickened recovery in the same wire after a few vibrations.

recovery even after the expiration of 60 seconds, whereas when a few vibrations had been given recovery was entirely completed in 47 seconds (b). There was here little change in the height of response.

Or (2) by heightened response. - The removal of sluggishness by vibration, resulting in increased molecular mobility, is in other instances attended by increase in the height of response, as will be seen from the two sets of records which follow (fig. 6t). Cold, due to prevailing frosty weather, had made the wires in the cell somewhat lethargic. The records in $(a)$ were 
the first taken on the day of the experiment. The amplitudes of vibration were $45^{\circ}, 90^{\circ}$, and $135^{\circ}$. In $(b)$ are given the records of the next series, which are in every case greater than those of $(a)$. This shows that previous vibration, by conferring increased mobility, had heightened the response. In this case, removal of molecular sluggishness is attended by greater intensity of response, without much change in the period of recovery. In commection with this it must be remembered that
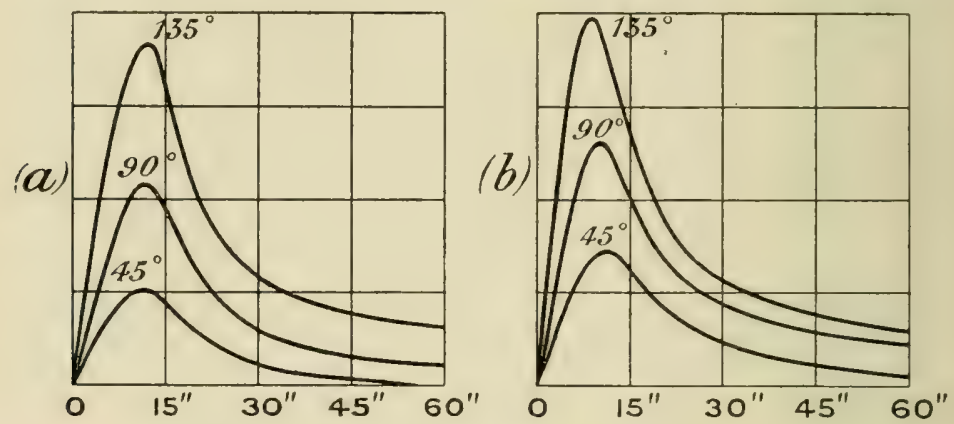

FIG. 64

(a) Three sets of responses for $45^{\circ}, 90^{\circ}$, and $135^{\circ}$ vibration in a sluggish wire.

(b) The next three sets of responses in the same wire; increased mobility conferred by previous vibration has heightened the response.

greater strain consequent on heightened response has a general tendency to a prolongation of the period of recovery.

It is thus seen that when the wire is in a sluggish conclition, successive vibrations confer increased molecular mobility, which finds expression in quickened recovery or heightened response.

Effect of temperature.-Similar considerations lead us to expect that a moderate rise of temperature will be conducive to increase of response. This is exhibited in 
the next series of records. The wire at the low temperature of $5^{\circ} \mathrm{C}$. happened to be in a sluggish condition, and the responses to vibrations of $45^{\circ}$ to $90^{\circ}$ in amplitude were feeb]e. Tepid water at $30^{\circ} \mathrm{C}$. was now substituted for the cold water in the cell, and the responses under-

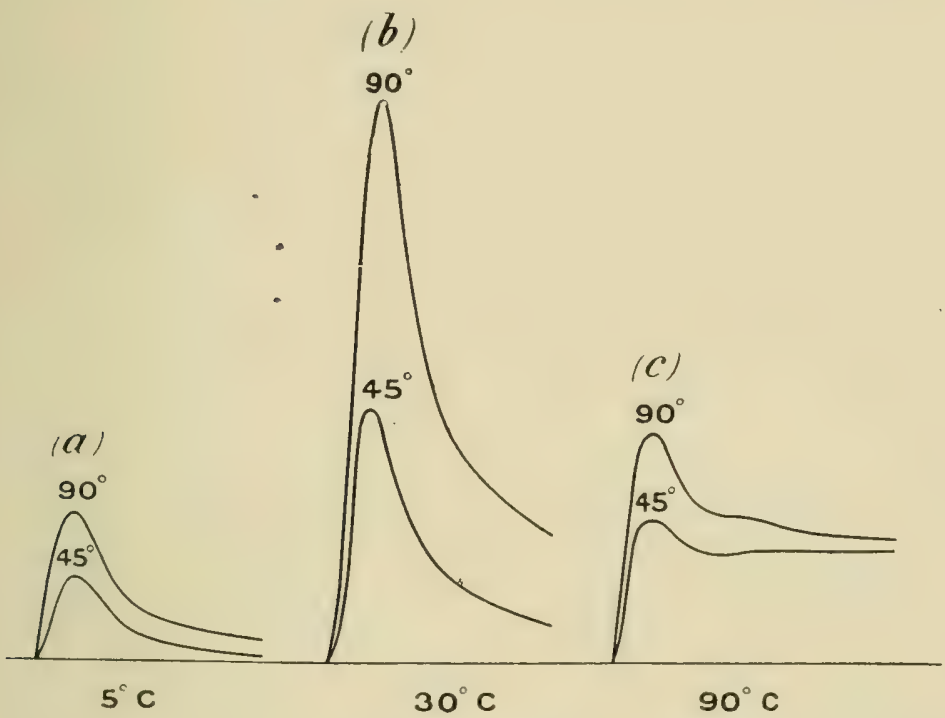

Fig. 65.-Responses of a Wire to Amplitudes of Vibration $45^{\circ}$ and $90^{\circ}$

(a) Responses when the wire was in a sluggish condition at temperature of $5^{\circ} \mathrm{C}$.

(b) Enhanced response at $30^{\circ} \mathrm{C}$.

(c) Diminution of response at $90^{\circ} \mathrm{C}$.

went a remarkable enhancement. But the excessive molecular disturbance caused by the high temperature of $90^{\circ} \mathrm{C}$. produced a great diminution of response (fig. 65 ).

Diphasic variation. - It has alrealy been said that if two points $\mathrm{A}$ and $\mathrm{B}$ are in the same physico-chemical condition, then a given stimulus will give rise to similar excitatory electric effects at the two points. It the 
galvanometer deflection is ' " the excitation of $\mathrm{B}$ will give rise to a downward deflection. When the two points are simultaneously excited the electric variation at the two points will rontinuously balance each other. Under such conditions there will be no resultant deflection. But if the intensity of stimulation of one point is relatively stronger, then the balance will be disturbed, and a resultant deflection produced whose sign and magnitude can be found independently by the algebraical summation of the individual effects of $\mathbf{A}$ and $\mathbf{B}$.

It has also been shown that a balancing point for the block, which is approximately near the middle of the wire, may be found so that the vibrations of $A$ and B through the same amplitude produce equal and opposite deflection. Simultaneous vibration of both will give no resultant current; when the blork is abolisherl and the wire is vibrated as a whole, there will still be no resultant, inasmuch as similar excitations are produced at $\Lambda$ and $B$.

After obtaining the balance, if we apply an exciting reagent like $\mathrm{Na}_{2} \mathrm{CO}_{3}$ at one point, and a depressing reagent like $\mathrm{KBr}$ at the other, the responses will now become unequal, the more excitable point giving a stronger deflection. We can, howerer, make the two deflections equal by increasing the amplitude of vibration of the less sensitive point. The two deflections may thus be rendered equal and opposite, but the time relations-the latent period, the time rate for attaining the maximum excitation and recovery from that effect-will no longer be the same in the two cases. There would therefore 
be no continuous balance, and we obtain instead a very interesting diphasic record. I give below an exact reproduction of the response-curves of $A$ and $B$ recorded on a fast-moring drum. It will be remembered that one point was touched with $\mathrm{Na}_{2} \mathrm{CO}_{3}$ and the other with

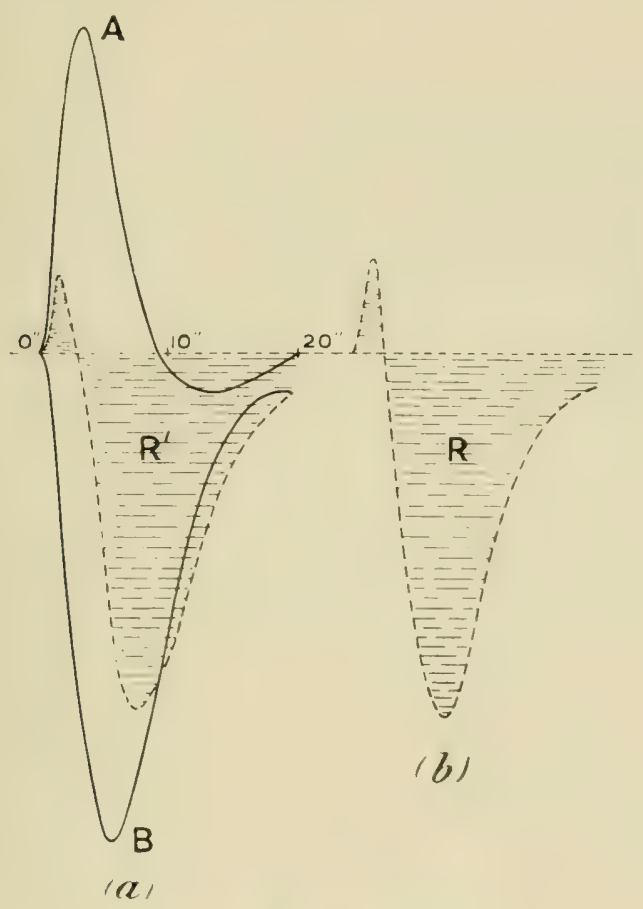

Fig. 66.-Diphasic Variation

a) Records of $A$ and $B$ obtained separately. $R^{\prime}$ is the resultant by algebraical summation. (b) Diphasic record obtained by simultaneous stimulation of $\mathrm{A}$ and $\mathrm{B}$.

$\mathrm{KBr}$. By suitably increasing the amplitude of vibration of the less sensitive, the two deflections were rentered approximately equal. The records of $\mathrm{A}$ and $\mathrm{B}$ were at first taken separately (fig. $66, a$ ). It will be noticed that the maximum deflection of $\mathrm{A}$ was attained relatively 
much earlier than that of $\mathrm{B}$. The resultant curve $\mathrm{R}^{\prime}$ was obtained by summation.

After taking the records of $A$ and $B$ separately, a record of resultant effect $\mathrm{R}$ due to simultaneous vibration of $\mathrm{A}$ and $\mathrm{B}$ was next taken. It gave the curious two-phased response - positive effect followed by negative after-ribration, practically similar to the resultant curve $\mathrm{R}^{\prime}$ (fig. $66, b$ ).

The positive portion of the curve is due to $\mathrm{A}$ effect and the negative to $\mathrm{B}$. If by. any means, say by either increasing the amplitude of vibration of $\mathrm{A}$ or increasing its sensiticeness, the response of $\mathrm{A}$ is rery greatly enhanced, then the positive effect would be predominant and the negative effect would become inconspicuous. When the two constituent responses are of the same order of magnitude, we shall have a positive response followed by a negative after-vibration ; the first twitch will belong to the one which responds earlier. If the response of $\mathrm{A}$ is rery much reduced, then the positive effect will be reduced to a mere twitch and the negative effect will become predominant.

I give a series of records, fig. 67 , in which these three principal types are well exhibited, the two contacts having been rendered unequally excitable by solutions of the two reagents $\mathrm{KBr}$ and $\mathrm{Na}_{2} \mathrm{CO}_{3}$. $\mathrm{A}$ and $\mathrm{B}$ were vibrated simultaneously and records taken. (a) First, the relative response of $\mathrm{B}$ (downward) is increased by increasing its amplitude of vibration. The amplitude of vibration of $\Delta$ was throughout maintained constant. The negative or downward response is now very conspicuous, there being only a mere preliminary indication 
of the positive effect. (b) The amplitude of ribration of $B$ is now slightly redured, and we obtain the diphasic effect. (c) The intensity of vibration of $\mathrm{B}$ is diminished still further, and the negatire effect is seen reduced to a slight downard after-ribration, the positive up)-curve being now very prominent (fig. 67).

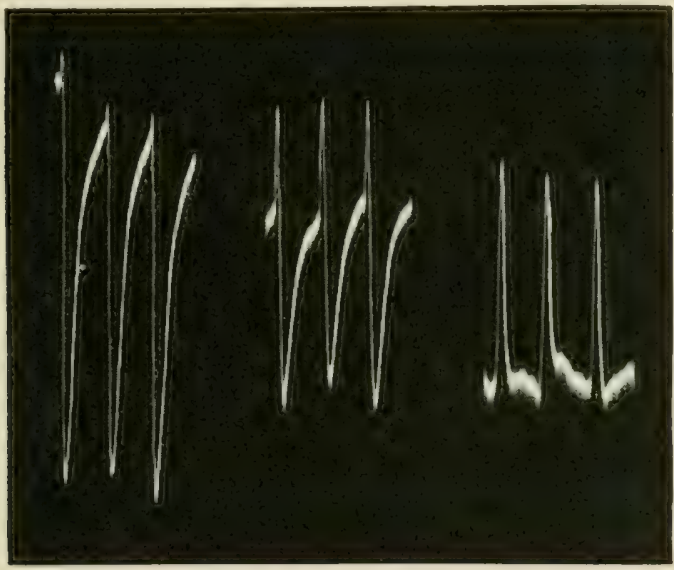

(ii)

(b)

(c)

Fia. 67.-Negative, Diphasic, and Positive Resultant Response

Continuous transformation from negative to positive I have shown the three phases of transformation, the intensity of one of the constituent responses being varied by altering the intensity of disturbance.

In the following record (fig. 68) I succeeded in obtaining a continuous transformation from positive to negative phase by a continuous change in the relative sensitiveness of the two contacts.

I found that traces of after-effect due to the application of $\mathrm{Ta}_{2} \mathrm{CO}_{3}$ remain for a time. If the reagent is previously applied to an area and the traces of the 
carbonate then washed off, the increased sensitiveness conferred disappears gradually. Again, if we apply $\mathrm{Na}_{2} \mathrm{CO}_{3}$ solution to a fresh point, the sensitiveness gradually increases. There is another further interesting point to be noticed: the beginning of response is earlier when the application of $\mathrm{Na}_{2} \mathrm{CO}_{3}$ is fresh.

We have thus a wire held at one end, and successive miform vibrations at intervals of one minute imparted

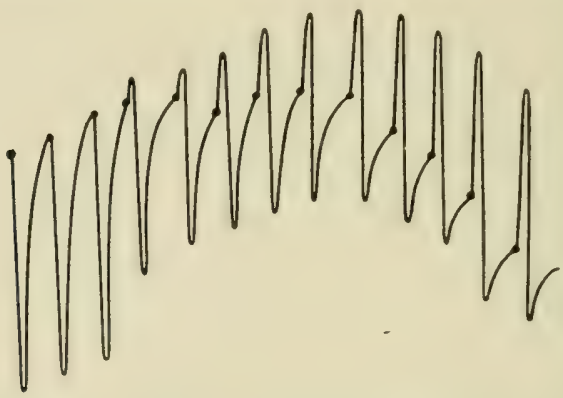

Fig. 68.-Contrnuods Transformation from Negative to Positive throdgh Intermediate Diphasic Response

Thick dots represent the times of application of successive stimuli.

to the wire as a whole, by means of a vibration head on the other end.

Owing to the after-effect of previous apllication of $\mathrm{Na}_{2} \mathrm{CO}_{3}$ the sensitiveness of $\mathrm{B}$ is at the beginning great, hence the three resultant responses at the beginning are negative or downward.

Dilute solution of $\mathrm{Na}_{2} \mathrm{CO}_{3}$ is next applied to $\mathrm{A}$. The response of $\mathrm{A}(u p)$ ) begins earlier and rontinues to srow stronger and stronger. Hence, after this application, the response shows a preliminary positive twitch of $\mathrm{A}$ followed by negative deflection of $B$. The positive grows 
continuously. At the fifth response the two phases, positive and negative, become equal, after that the positive becomes very prominent, the negative being reduced as a feeble after-vibration.

It need only be added here that the diphasic variations as exhibited by metals are in erery way counterparts of similar phenomena observed in animal tissues. 


\section{CHAPTER XIV}

INORGANIC RESPONSE-FATIGLE, STAIRCASL, IND MODIFLU RESPONSE

Fatigue in metals-Fatigue under continuous stimulation-Staircase effect - Reversed responses due to molecular modification in nerre and metal, and their transformation into normal after continuous stimulation-Increased response after continuous stimulation.

Fatigue.-In some metals, as in muscle and in plant. we find instances of that propressive dininution of response which is known as fatigue (fig. (i?)). The accompanying record shows this in platinum (fig. To). It has been said that tin is practically indefatigable. We must, however, remember that this is a question of degree

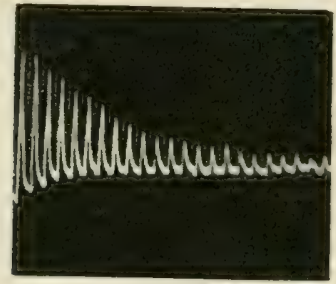

Fig. 69.-Fatigue in Muscle (WALLER)

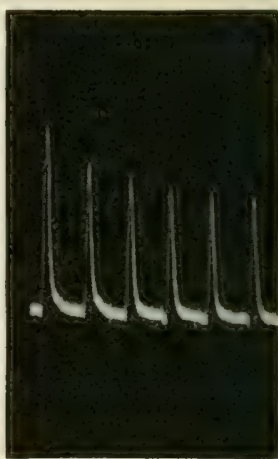

FIG。70.-FATIGUE IN Platinedi

only. Tothing is absolutely indefitigable. The exhibition of fatigue depends on various conditions. Even in tin, then, I obtained the characteristic fatigue-curve with a specinnen which had been in continuous use for 
many days (fig. 71). While discussing the subject of fatigue in plants, I have adduced considerations which showed that the residual effect of strain was one of the main causes for the production of fatigue. This conclusion receives independent support from the records obtained with metals.

In this connection the important fact is that the various typical fatigue effects exhibited in living substances are exactly re-

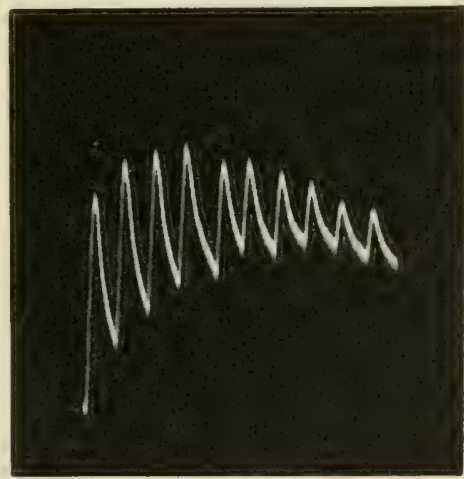

Fig. 71.-FAtigut shown BX Tix WIRE WHICH HAD BEEN CONTINUOCSLY STIMULATEA FOR SEVER. DAYS produced in metals, where there can be question neither of fatigne-product producing fatigne effects, nor of those constructire processes by which they might be remored. We have seen, both in muscles and in plants, that if sufficient time for complete recovery be allowed between each pair of stimuli, the heights of snccessive responses are the same, and there is no apparent fatigue (see page 39). But the height of response diminishes ats the excitation interval is shortened. We find the same thing in metals. Below is given a record taken with tin (fig. 72 ). Throughout the experiment the amplitude of viluation was maintained constant, hut 11 (11) the interval between conser'utive stinuli was $1^{\prime}$, while in (b) this was reduced to $30^{\prime \prime}$. A diminution of height immediately occurs. (On restoring the original rhythm as in (c), the responses revert to their first large value. 
Thus we see that when the wire has not completely recovered, its responses, owing to residual strain, undergo diminution. Height of response is thus decreased by incomplete recovery. If then sufficient time be not allowed for perfect recovery, we can mulerstand how, under certain circumstances, the resichual strain would progressively increase with repetition of stimulus, and thus there would be a progressive diminution of height

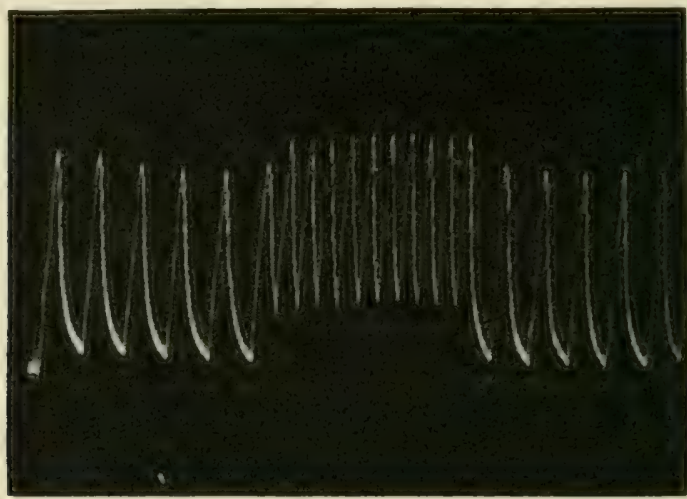

(a)

(b)

(c)

Fig. 72.-Dininution of Response due to Shottening the Peniod of RECOVERY

The stimulus is maintained constant. In $(a)$ the interval between two successive stimuli is one minute, in (b) it is half a minute, and in $(c)$ it is again one minute. The response in $(b)$ is feebler than in either $(a)$ or $(c)$.

of response or fatigue. Again, we saw in the last chapter that increase of strain necessitates a longer period of recovery. Thus the longer a wire is stimulated, the more and more overstrained it becomes, and it therefore requires a gradual prolongation of the interval between the successive stimuli, if recorery is to be complete. This interval, however, being maintained constant, the recovery periods virtually undergo a gradual reduction, and successive recoveries become 
more and more incomplete. These considerations may be found to afford an insight into the progressive diminution of response in fatigued substances.

Fatigue under continuous stimulation.-Fatigue is perhaps best shown under continuous stimulation. For example, in muscles, when fresh and not fatigued, the top of the tetanic: curve is horizontal, or may even be ascending, but with long-continued stimulation the curve declines. The rapidity of this decline depends on the nature of the muscle and its previous condition.

In metals I have found exactly parallel instances. In tin, so little liable to fatigue, the top of the curve is horizontal or ascending; or it maly exhibit a slight decline. But

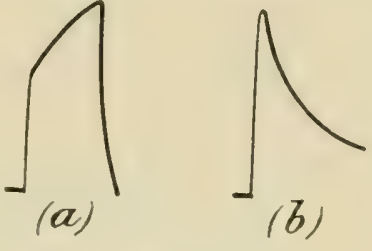

FIG. 73

(a The top of response-curve under continuous stimulation in tin is horizontal or ascending as in figure. (b) In platinum there is rapid decline owing to fatigue.

the record with platinum shows the rapid dercline due to fatigue (fig. 73 ).

Taking any of these instances, say that in which fatigne is most prominent, it is fomd that short period of rest restores the original intensity of response. This affords additional proof of the fact that fatigne is due to overstrain, and that this strain, with its sign of attendant fatigue, disappears with time.

Staircase effect.-We shall now discusis an effect which appears to be the dirert opposite of fatigute. This is the curious phenomenon knom to physiologists as 'the staircase' effect, in which successive miform stimuli produce a series of increasing responses. This 
is seen muler particular conditions in the response of certain muscles (fig. 7t, a). It is also olsserved sometimes even in nerve, which otherwise, generally speaking, gives miform responses. Of this effect, no satisfactory theory has as yet been offered. It is in direct contratdiction to that theory which supposes that each stimulus is followed hy discimilation or break-down of the tissue, reduring its function below par. For in these cases the supposed clissimilation is followed not hy a decrease but by an increase of functional activity. This 'staircase effect' I have shown to be occasionally exhibited by plants. I have also found it in metals. In WWM

(a)

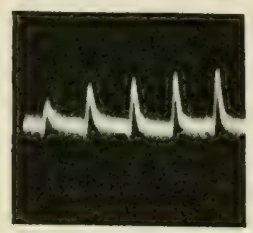

(b)

Fig. 74.-'Staircase' Efrect

(a) in muscle (after Engelmann). (b) in metal. the last chapter we have seen that a wire often falls. especially after lesting for a long time, into a state of comparative sluggishmess. and that this molecular inertness then gradually gives place to increased mobility under stimulation. As a consequence, an increased response is thus obtained. I give in fig. 7 t. l. a series of responses to uniform stimili, exhibited by platinum which had been at rest for some time. This effect is rery clearly shown here. So we see that in a substance which has previously heen in a shogish condition, stimulation anfers increased mobility. Response thus reaches a maximum, but continned stimulation may afterwards produce overstrain, and the subsequent responses may then show a derline. This consideration will explain rertain types of responses 
exhibited by muscles, where the first part of the series exhibits a stailatse increase followed hy declining responses of fatigue.

\section{Reversed response due to molecular modification and} its transformation into normal after continuous stimulation

(I) in nerve.-Reference has already heen made to the fact that a nerve which, when fresh, exhibited the normal negative response, will often, if kept for some time in preservative saline, molergo a molecular modification, after which it gives a positive variation. Thus while the response given hy fresh nerve is nomal or negative, a stale nerve gives modified. i.e. reversed or positive, response. This peculiar modification does not always occur, yet is too frequent to be considered abnormal. Again, when such a nerve is suljected to tetanisation or continuous stimulation, this modified response tends once more to become normal.

It is found that not only tetanisation, but also $\mathrm{CO}_{2}$ has the power of (onverting the modified response into normal. Hence it has heen sugoested that the ronrerrion under tetanisation of modified response to mormal, in stale nerve, is due to a hypothetionl evolution of $\mathrm{C}^{\prime} \mathrm{O}_{2}$ in the nerve during stimulation. ${ }^{1}$

(2) In metals. - I have, however, met with exactly parallel phenomena in metalis, where, owing to some molecular modification, the responses became reversed, and where, under continuons stimulation, thongh here

I 'Considering that we have no previous evidence of any chemical or' physical change in tetanised nerve, it seems to me not worth while pausing to deal with the criticism that it is not $\mathrm{CO}_{2}$, but "something else" that has given the result.'- Waller, Animal Electricity, 1. 59. That this phenomenon is nevertheless capable of physical explanation will be shown presently. 
there could be no possibility of the evolution of $\mathrm{CO}_{2}$, they tended again to become normal.

If after mounting a wire in a cell filled with water, it he set aside for too long a time, I have sometimes moticed that it undergoes a rertain modification, owing to which its response reases to be normal and becomes leversed in sign. I have obtained this effect with various metals, for instance lead and tin, and even with the chemically inactive substance-platinum. .

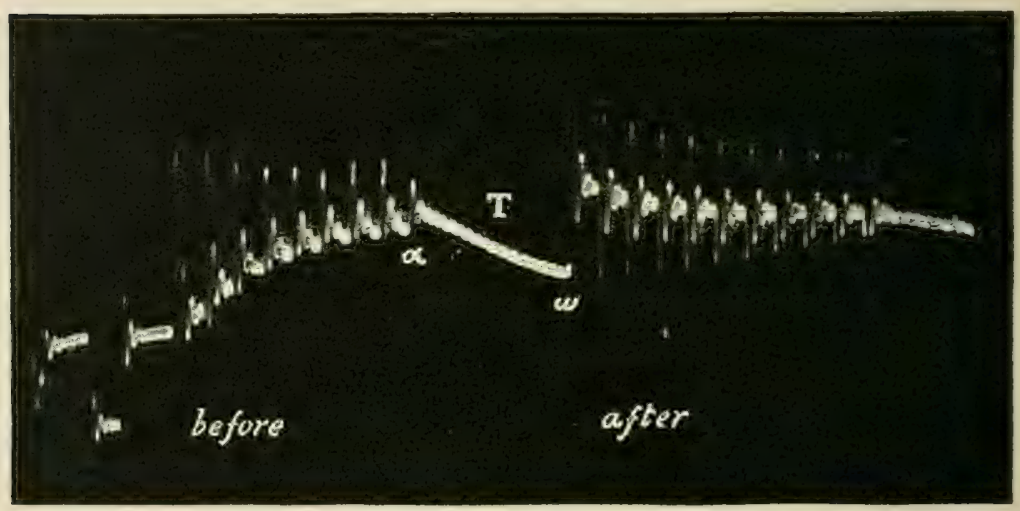

Fig. 75.-Abnormal Positive (cy) Response in Nerve converted into Nordal (down) Response after Contindous Stimulation T (Wallen)

The galvanometer is not dead-beat, and shows after-oscillation.

The subject will be made clearer if we first follow in detail the phenomenon exhibited hy modified nerve, giving this alnommal response. The normal responses in nerve are usually represented by 'down' and the reversed abnormal responses by ' up' curves. In the modified nerve, then, the abnomal responses are "up' instead of the normal 'down.' 'The record of such abmonal response in the modified nerve is shown in fig. 7.). It will be noticed that in this, the successive 
responses are mulergoing a diminution, or tencling towards the normal. After continuous stimulation or tetanisation $(\mathrm{T})$, it will be seen that the abnormal or ' up' responses are converted into normal or 'down.'

I shall now give a record which will exhibit an exactly similar transformation from the albnomal to normal response after continuous stimulation. Here the normal responses are represented by 'up' and the abnormal by 'down' curves. This record was given

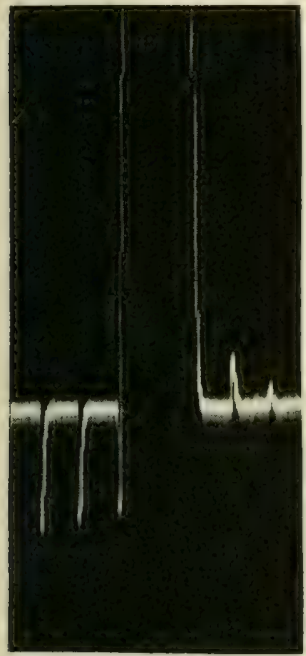

Before $T$ After FIG. 76 by a tin wire, which had been molecularly modified (fig. 76 ). We have at first the abnormal

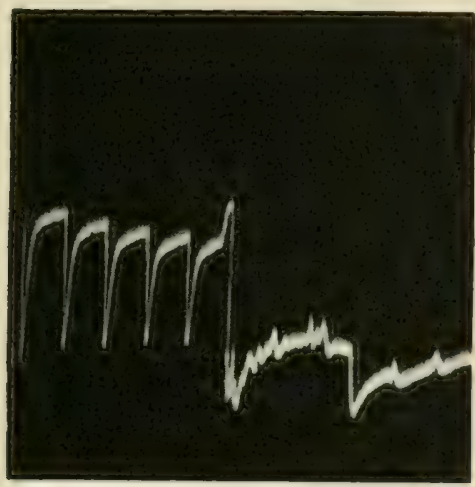

Before
$\mathrm{T}$

FIG. 77

Abnormal 'down' response in tin (fig. 76) and in platinum (fig. 77) transformed into normal ' up ' response, after continuous stimulation, $\mathrm{T}$.

responses; successive responses are undergoing a diminution or tending towards the normal; after continuous stimulation (T), the subsequent responses are seen to have hecome normal. Another recorl, obtained with platinum, shows the same phenomenon (fig. 75 ).

On placing the three sets of records-nerve, tin, and 
platinum--side ly side, it will be seen how essentially similar they are in every respect. ${ }^{1}$

This reversion to normal is seen to have appeared in a pronounced manner after rapidly continuous stimulation, in process of which the modified molecular condition must in some way have reverted to the normal.

Being desirous to trace this change gradually taking place, I took a platinum wire cell giving modified responses, and obtained a series of records of effects of

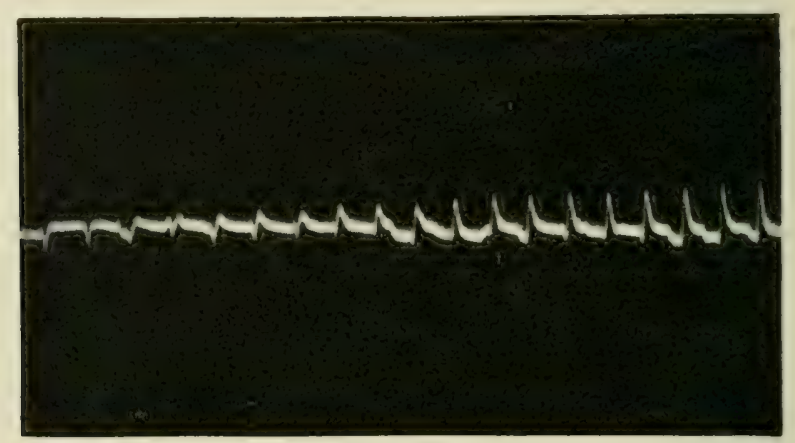

Fig. 78.-The Gradual Transtion from Abnormal to Normal Respoxse in Platinum

The transition will be seen to have commenced at the third and ended at the seventh, counting from the left.

individual stimuli continued for a long time. In this series, the points of transition from modified response to normal will be clearly seen (fig. 78).

1 In order to explain the phenomena of electric response, some physiologists assume that the negative response is due to a process of dissimilation, or breakdown, and the positive to a process of assimilation, or building up, of the tissue. The modified or positive response in nerve is thus held to be due to assimilation : after continuous stimulation, this process is supposed to be transformed into one of dissimilation, with the attendant negative response.

How arbitrary and unnecessary such assumptions are will become evident, when the abnormal and normal responses, and their transformation from one to the other, are found repeated in all details in metals, where there can be no question of the processes of assimilation or dissimilation. 
Increased response after continuous stimulation. We have seen that responses to uniform stimuli sometimes show a staircase increase, apparently owing to the gradual removal of molecular sluggishness. Possibly analogous to this is the increase of response in nerve after continuous stimulation or tetanisation, observed.

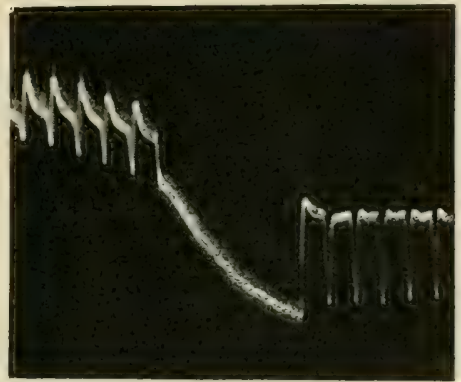

$\mathrm{T}$

Fig. 79.-The Noraral Response $a$ iN Nerve Enhanced to $b$ after Contindods Stimolation T (WaLler)

The normal response in nerve is recorded ' down.' by Waller (fig. 79). Like the staircase effect, this

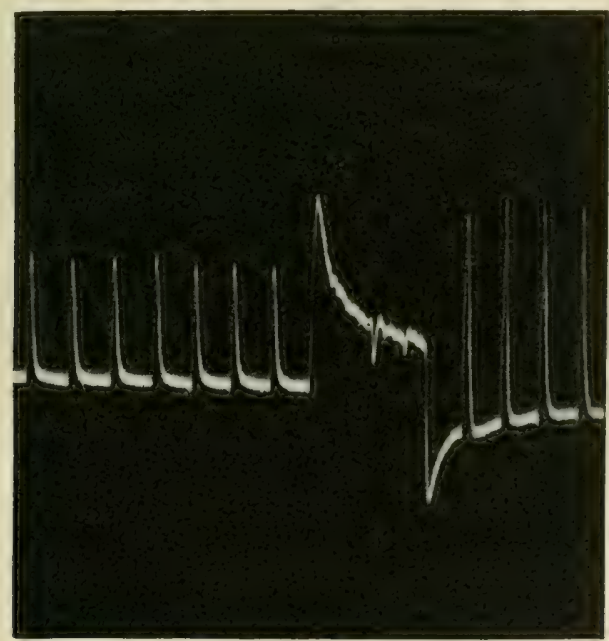

Before

T

After

Fig. 80.-Enhanced Response in Platinum after Cont inuous Stiuutation T

contravenes the commonly accepted theory of the dissimilation of tissue by stimulus, and the consequent depression of response. It is sugoested by Waller that 
this increase of response after tetanisation may be due to the hypothetical evolution of $\mathrm{CO}_{2}$ to which allusion has previously been made.

But there is an exact correspondence between this phenomenon and that exhibited by metals under similar conditions. I give here two sets of records (figs. 80, 81), one obtained with platinmm and the

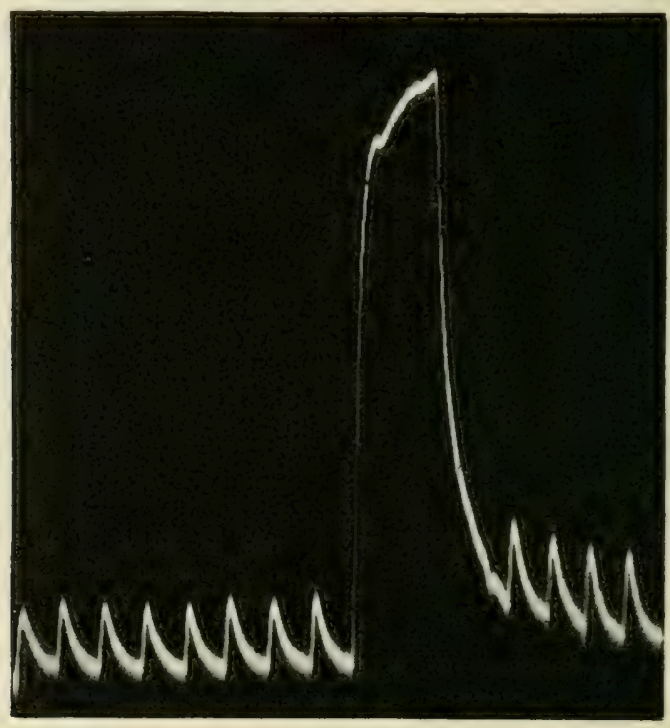

Before

$\mathrm{T}$

After

Fig. 81. - Enhanced Respojise in Tin after Continuous Stimolit on 'T

other with tin, which demonstrate how the response is enhanced after continuous stimulation in a mammer exactly similar to that noticed in the case of nerve.

The explanation which has been suggested with regard to the staircase effect-increased molecular molbility due to removal of sluggishness by repeater stimulation-would appear to be applicable in this case 
also. It would appear, then, that in all the phenomena which we have studied under the heads of 'staircase' effect, increase of response after continuous stimulation, and fatigue, there is a similarity between the observations made upon the response of muscle and nerve on the one hand, and that of metals on the other. Even in their abnormalities we have seen an agreement.

But amongst these phenomena themselves, though at first sight so diverse, there is some kind of continuity. Calling all normal response positive, for the sake of convenience, we observe its gradual modification, corresponding to changes in the molecular condition of the substance.

Begimning with that case in which molecular modification is extreme, we find a maximum rariation of response from the normal, that is to say, to neyative.

Continued stimulation, however, brings back the molecular condition to normal, as evidenced by the progressive lessening of the negative response, culminating in reversion to the normal positie?. This is equally true of nerve and metal.

In the next class of phenomena, the modification of molecular condition is not so great. It now exhibits itself merely as a relative inertness, and the responses, though positive, are feeble. Under continued stimulation, they increase in the same direction as in the last case, that is to say, from less positive to more positive, being the reverse of fatigue. This is evidenced alike by the staircase effect and by the increase of response after tetanisation, seen not only in nerve but also in platinum and tin. 
The substance may next be in what we call the normal condition. Sureessive uniform stimuli now eroke uniform and equal positive responses, that is to say, there is no fatigue. But after intense or longcontinned stimulation, the sulstance is orerstrained. The responses now undergo a change from positive to less positive; fatigue, that is to say, appears.

Again, under very much prolonged stimulation the response may decline to zero. or even undergo a reversal to neyative, a phenomenom which we shall find instanced in the reversed response of retina under the longcontinued stimulus of light.

We must then recognise that a substance may exist in various molecular contitions. whether clue to internal changes or to the action of stimulus. The responses give us indications of these comditions. A romplete cycle of molecular modifications can be traced. from the abnormal negative to the nomal positive, and then again to negative seen in rerersal under continuous stimulation. 


\section{CHAPTER XT}

INOR(iANE: RESPONSE-RELATION BETWELA STLILLC ANI RESPONSE-SUPERPOSITION OF STIMULA

lielation between stimulus and response- Magnetic analogue-Incrense of response with increasing stimulus-Threshold of response-Superposition of stimuli-Hysteresis.

Relation between stimulus and response.- We hare seen what extremely nuifom responses are given ly tin, when the intensity of stimulus is maintained comstant. Hence it is obvious that these phenomena are not acridental, but governed by definite laws. This farct becomes still more erident when we discover how invariably response is increased by increasing the intensity of stimulus.

Electrical response is due, as we have seen, to a molecular disturbance. the stimulus ansing a distortion from a position of equilibrium. In dealing with the subjert of the relation between the disturbing force and the moler nlar effect it produces, it may be instruretire to consider certain analogous physical phenomena in which molecular deflections are also produced by a distorting force.

Magnetic analogue.--Let us consider the effect that a mannetising force produres on a bar of soft ilon. It is knowi that each molecule in such a bar is an 
individual magnet. The bar at a whole, nevertheless, exhibits no external magnetisation. This is held to be che

the far't that the molecular magnets are tumed either in haphazard directions or in closed chains, and there is therefore no resultant polarity. But when the bar is subjected to a magnetising force by means, say, of a solenoid carrying electrical current, the individual molecules are elastically deflected, so that all the molecular magnets tend to place themselves along the lines of magnetising force. All the north poles thus point more or less one way, and the south poles the other. The stronger the magnetising force, the nearer to the molecules approach to a perfect aligmment, and the greater is the indured magnetisation of the bar.

The intensity of this induced magnetisation may be measured by noting the deflection it produres on a freely suspended magnet in a magnetometer.

The force which produces that molecular defiertion, to which the magnetisation of the bar is immediately due,

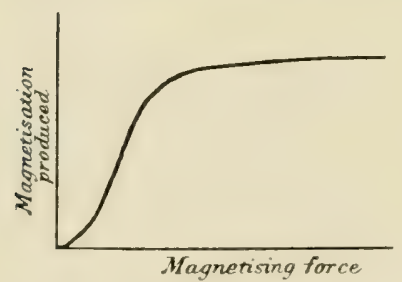

Fig. 82.-Curve of Magnetisation

is the magnetising current flowing round the solenoid. The magnetisation, or the molecular effect, is measured by the deflection of the magnetometer. We may express the relation between cause and effect by a curre in which the abscissa represents the magnetising ('urrent, and the ordinate the magnetisation produced (fig. 82 ).

In such a curve we may roughly distinguish three parts. In the first, where the force is feeble, the mole- 
cular cleflection is slight. In the next, the curve is rapidly ascencling, i.e. a small variation of impressed force produces a relatively large molecular effect. And lastly, a limit is reached, as seen in the third part, where increasing force produces very little further effect. In this rause-and-effect curve, the first part is slightly convex to the abscissa, the second straight and ascending, and the third concave.

Increase of response with increasing stimulus.-We shall find in dealing with the relation between the stimulus and the molecular effect-i.e. the responsesomething very similar.

On gradually increasing the intensity of stimulus, which may be done, as already stated, by increasing the amplitude of ribration, it will be found that, beginning with feeble stimulation, this increase is at first slight, then more pronounced, and lastly shows a tenclency to approach a limit. In all this we have a perfect parallel to rorresponding phenomena in animal and vegetable response. We saw that the proper investigation of this subject. was much complicated, in the case of anmal and regetable tissues, by the appearance of fatigue. The comparatively indefatigable nature of tin causes it to offer great adrantages in the pursuit of this inquiry. I give below two series of records made with tin. The first record, fig. 83 , is for increasing amplitudes from $5^{\circ}$ to $40^{\circ}$ by steps of $5^{\circ}$. The stimuli are imparted at intervals of one minute. It will be noticed that whereas the recovery is complete in one minute when the stimulus is moderate, it is not quite complete when the stimulus is stronger. The 
134 RESPOVSE IN THE LIVING AND NON-LIVING recovery from the eflect of stronger stimulus is mores prolonged. Owing to want of amplete recorery, the

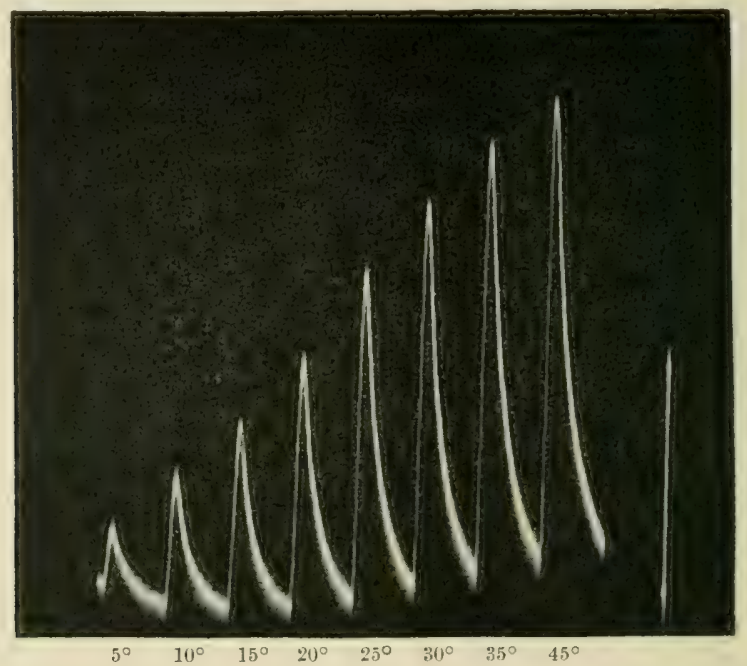

Fici, 83.-Records of Responses in Tix with Increasixg Stinuli, AupliTUDES OF Vibration Froj $5^{\circ}$ to $40^{\circ}$

The vertical line to the right represents ' 1 volt.

base line is tilted slightly umard. This slight displarement of the zero line does not materially affect the result, provided the shifting is slight.

Table showing the Increasing Electric Response due to Increasing Amplitude of Vibration

\begin{tabular}{|cc}
\hline Vibration amplitude & E.M. variatio \\
$5^{\circ}$ & .024 volt \\
$10^{\circ}$ & .057 \\
$20^{\circ}$ & $\cdot 111$, \\
$25^{\circ}$ & $\cdot 143$, \\
$30^{\circ}$ & $\cdot 170 \quad "$ \\
$35^{\circ}$ & $.187 \quad "$ \\
$40^{\circ}$ & $.204 \quad "$
\end{tabular}

The next figure (fig. St) gives record of responses 
through a wider range. For accurate quantitative measurements it is preferalsle to wait till the recovery is complete. We may accomplish this within the limiter space of the recording photographic plate by making the record for one minute; during the rest of recovery, the clockwork moving the plate is stopped and the galvanometer spot of light is cut off. Thus the

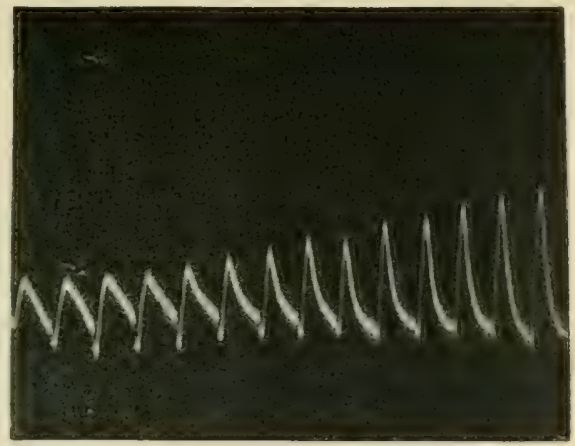

Fia. 84.-A Second Set of Reconds with a Diffenent Speciuen of Tin

The amplitudes of vibration are increased by steps of $10^{\circ}$, from $20^{\circ}$ to $160^{\circ}$. (The deflections are reduced by interposing $₫$ high external resistance.)

next record starts fin a point of completed recovery, which will be noticed as a bright spot at the begiming of each curve. With stimulation of high intensity, a

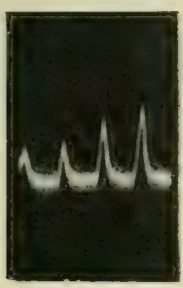

Fig. 85. - Effect of SuperposiTION ON TiN

A single stimulus produces the feeble effect shown in the first response. Superposition of $5,9,13$ such stimuli produce the succeeding stronger responses. tendency will be noticed for the responses to approach a limit.

Threshold of response.--There is a minimum intensity of stimulus below which there is hardly any visible response. We may regard this point as the threshold of response. Though apparently ineflective, the subliminal stimuli produce some latent effect, which may be demonstrated by their adclitive action. The 
record in fig. 85 shows how individually feeble stimuli become markedly effective by superposition.

Superposition of stimuli.--The additive effect of succeeding stimuli will be seen from the above. The fusion of effect will be incomplete if the frequency of stimulation be not sufficiently great; but it will tend to be more

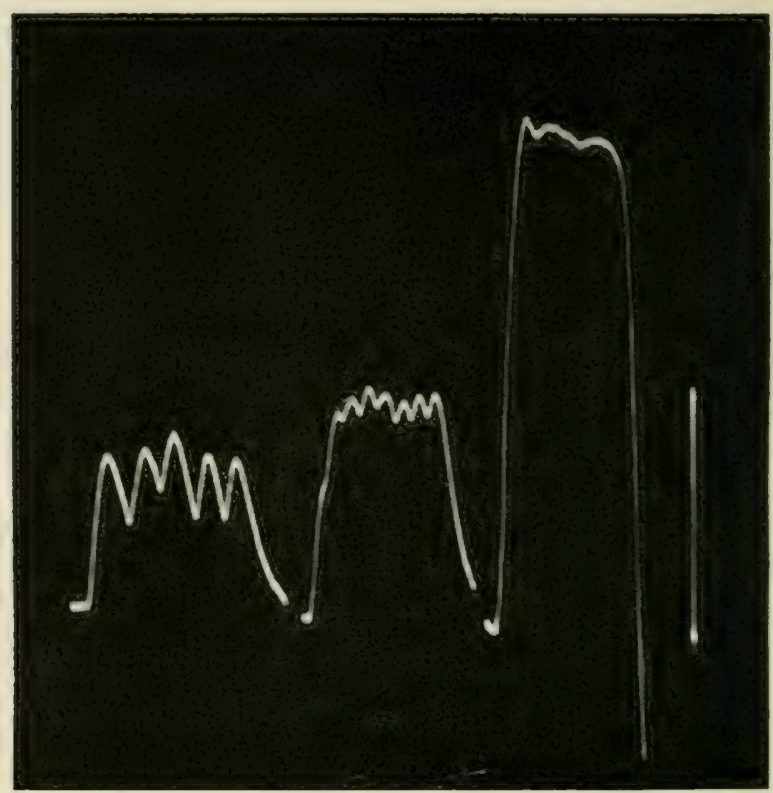

Fig. 86. -Incomplete and Conplete Fusion of Effect in Tix

As the frequency of stimulation is increased the fusion becomes more and more complete. Vertical line to the right represents 1 volt.

complete with higher frequency of stimulation (fig. 86). We have here a parallel case to the complete and inromplete tetanus of muscles, under similar conditions.

By the addition of these rapidly succeeding stimuli, a maximum effect is produced, and further stimulation adds nothing to this. The effect is balanced by a force 
of restitution. The response-curve thus rises to its maximum, after which the deflection is held as it were rigid, so long as the vibration is kept up.

It was found that increasing intensities of single stimuli produced correspondingly increased responses. The same is true also of groups of stimuli. The maximum

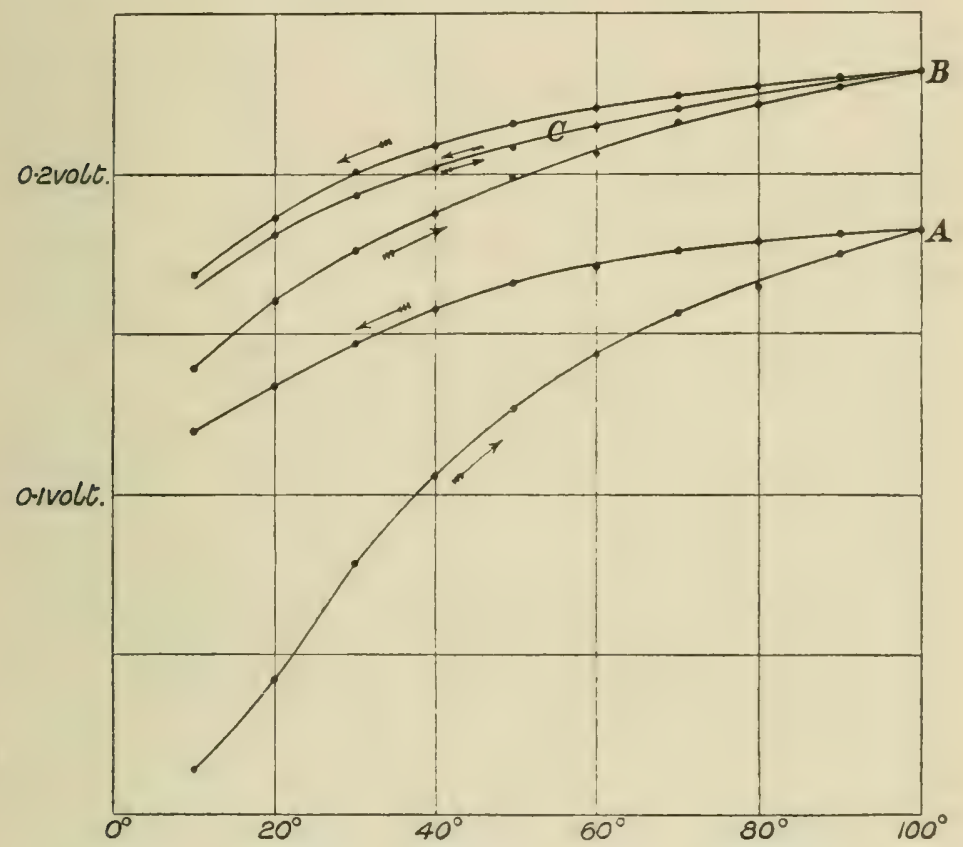

Fig. 87.-Cychic Corve for Maximum Effects shotwing Hysteresis

effect produced by superposition of stimuli increases with the intensity of the constituent stimuli.

Hysteresis.-Allusion has already been made to the increased responsiveness conferred by preliminary stimulation (see p. 127). Teing (lesirous of finding out in what manner this is brought about, I took a series 
of observations for an entire cycle, that is to say, at series of observations were taken for maximum effects, starting from amplitude of vibration of $10^{\circ}$ and ending in 101$)^{\circ}$, and backwards from $100^{\circ}$ to $10^{\circ}$. Effect of hysteresis is very clearly seen (see 1 , fig. 85) ; there is a considerable diverwence between the formard and return curves, the return curve being higher. On repeating the cycle several times, the divergence is found rery much reduced, the wire on the whole is found to assume a mole constant sensitireness. In this steacly condition, enerally speaking, the sensitiveness for smaller amplitude of vibration is found to be greater than at the rery begimning, but the reverse is the case for stronger intensity of stimulation.

Effect of annealing.-I repeated the experiment with the same wire, after pouring hot water into the cell and allowing it to cool to the old temperature. From the cyclic curve (B, fig. ST) it will be seen (1) that the sensitiveness has become rery much enhanced; (2) that there is relatively less diveronce between the forward and return curves. Even this divergence practically disappeared at the third cycle, when the forward and backrard curves coincided (c, fig. S7). The above results show in what manner the excitability of the wire is enhanced by purely physical means.

It is rery curious to notice that addition of $\mathrm{Na}_{2} \mathrm{C}()_{3}$ solution (see ('hap). XV-Action of Stimulants) produces enhancement of responsive power similar to that prodnced by annealing; that is to say, not only is there a great increase of sensitiveness, but there is also a reduction of hysteresis. 


\section{CHAPTER XVI}

\section{INORGANIC RESPONSE-EFFECT OF CHENICAL REAGENT}

Action of chemical reagents-Action of stimulants on metals-Action of dépressants on metals-Effect of 'poisons' on metals-Opposite eflect of large and small doses.

Wr: have seen that the ultinate ariterion of the phyiolowical character of electric response is held to he its abolition when the sulhstance is subjected to those chemical reagents which act as poisons.

Action of chemical reagents.-- () t these leagents. wonne are universal in their action, amonest which strong solutions of acids and alkalis, and salts like merouric

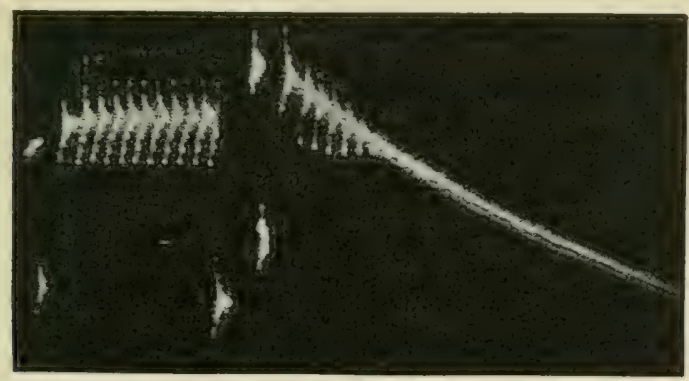

Before

$\uparrow$

After

Fig. 88. - Action of Potson in Abolishing Response in Nerve (Walleer)

'hloride, may be cited. These act as powerful toxir agents, killing the living tissue, and causing elertric response to disappear. (See fig. 88.) It must, however, he remembered that there are again specific poisons 
which may affect one kind of tissue and not others. Poisons in general may be regarded as extreme cases of depressants. As an example of those which produre moderate physiological depression, potassium bromide may be mentioned, and this also diminishes electric. response. There are other chemical reagents, on the other hand, which produce the opposite effect of increasing the excitability and causing a corresponding exaltation of electric response.

Ve shall now proceed to inquire whether the response of inorganic hodies is affected by chemical reagents, so that their excitability is exalted by some, and depressed or abolished by others. Should it prove to be so, the last test will have been fulfilled, and that parallelism which has been already demonstrated throughout a wide range of phenomena, between the electric response of animal tissues on the one hand, and that of plants and metals on the other, will be completely established.

Action of stimulants on metals.-We shall first study the stimulating action of rarious chemical reagents. The method of procedure is tr, take a series of normal responses to miform stimuli, the electrolyte being water. The chemical reagent whose effect is to be observed is now added in small quantity to the water in the cell, and a seconrl series of responses taken, using the same stimulus as before. Generally speaking, the influence of the reagent is manifested in a short period, but there may be occasional instances where the eflect takes some time to develop fully. We must remember that by the introluction of the chemical reagent some change may 
be produced in the internal resistance of the cell. The effect of this on the deflection is eliminated by interposing a very high external resistance (from one to five megohms) in comparison with which the internal resistance of the cell is negligible. The fact that the introduction of the reagent did not produce any variation in the total resistance of the circuit was demonstrated

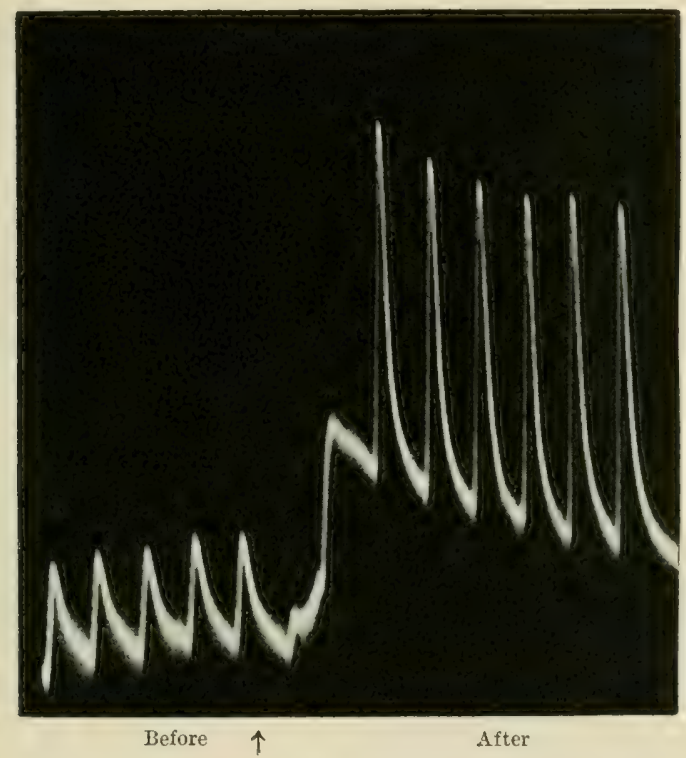

Fig. 89.-Stmulating Action of $\mathrm{Na}_{2} \mathrm{CO}_{3}$ on Tix

by taking two deflections, due to a definite fraction of a volt, before and after the introduction of the reagent. These deflections were found equal.

I first give a record of the stimulating action of sodium carbonate on tin, which will become evilent by a comparison of the responses before and atter the introduction of $\mathrm{Na}_{2} \mathrm{CO}_{3}$ (fig. 89). The next reenrd 
shows the effect of the same reagent on platinum (fig. 90 ).

Action of depressants. - C'ertain other leagents, again, produce an opposite effect. That is to say, they diminish the intensity of response. The record given on the next page (fig. (1) shows the depressing action of 10 per cent. solution of $\mathrm{KBr}$ on tin.

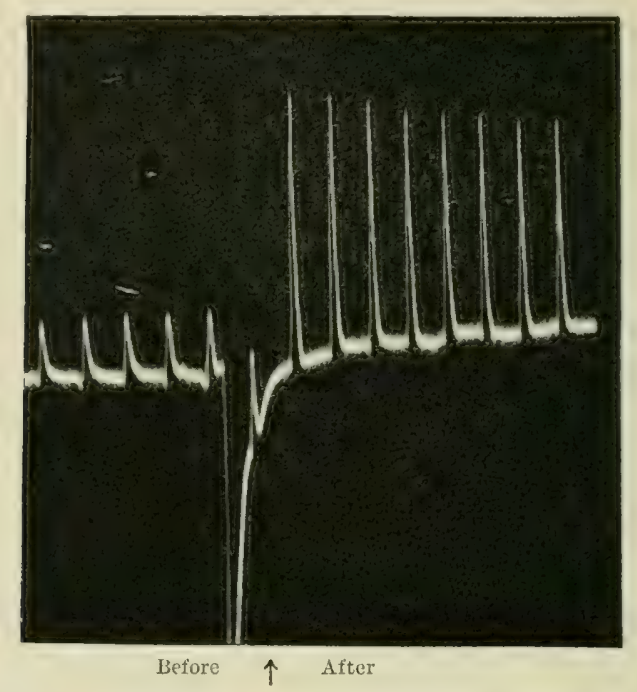

Fig. 90.-Stmolating Action of $\mathrm{Na}_{2} \mathrm{CO}_{3}$ on Platinumi

Effect of 'poison:- -Tiving tissues are killed, and their electric responses are at the same time abolished by the aretion of poisons. It is very curious that rarious chemical reagents are similarly effective in killing the response of metals. I give below a record (fig. 92) to show how oxalic acid abolishes the response. The depressive effect of this reagent is so great that a strength of one part in 10,000 is often sufficient to produce complete 
abolition. Another notable point with reference to the action of this reagent is the persistence of after-efferet.

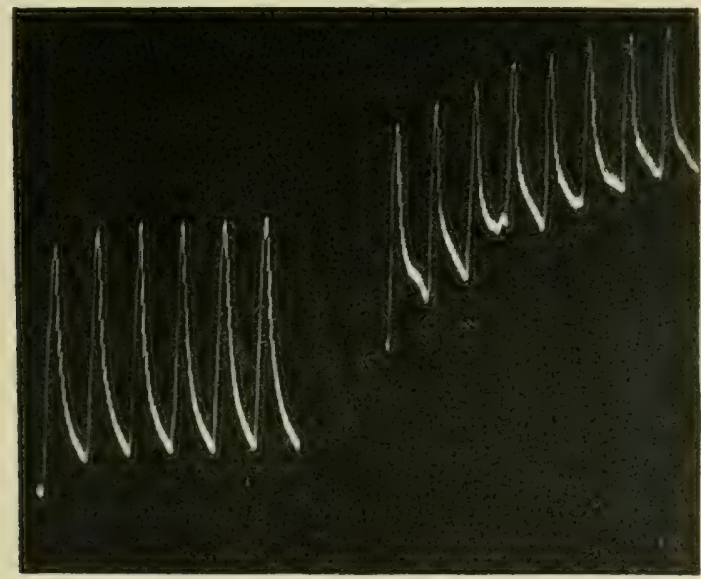

Before $\uparrow$ After

Fit. 91.-Depressing Effect of KBr (10 per Cent.) on the Resionse of TIN

This will be clearly seen from an arcount of the following experiment. The two wires $\mathrm{A}$ and $\mathrm{B}$, in the cell filled with water. were found to give equal responses. The wires were now lifted off; and one wire $\mathrm{B}$ was touched with dilute oxalic acid. All traces of acid were next removed by rubbing the wire with cloth under a stream of water. On replacing the wire in the

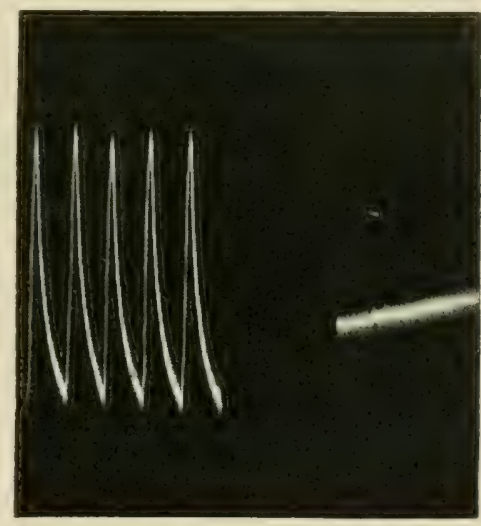

Before

$\uparrow$ After

Fis. 92.-Abolition of Response by Oxalic AcIo cell, A gave the usial response, whereas that of $B$ 
was found to be abolished. The depression produced is so great and passes in so deep that I have often failed (1) revive the response, even after rubbing the wire with emery paper, by which the molecular layer on the sur. face must have been removed.

We have seen in the molerular model (fig. $62, d, c^{\prime}$ ) how the attainment of maximum is delayed, the response diminished, and the recovery prolonged or arrested by increase of friction or reduction of molecular mobility.

It would appear as if the reagents which act as poisons produced some kind of molecular arrest. The following records seem to lend support to this riew. If the oxalic acid is applied in large quantities, the abolition of response is complete. But on carefully adding just the proper amount I find that the first stimulus evokes a responsive electric twitch, which is less than the normal, and the period of recovery is very much prolonged from the normal one minute before, to five minutes after, the application of the reagent (fig. 93, a). In another record the arrest is more pronounced, i.e. there is now no recovery (fig. 93, b). Tote also that the maximum is attained much later. Stimuli applied after the arrest produce no effect, as if the molecular merhanism berame, as it were, rlogged or locked up.

In comection with this it is interesting to note that the effect of veratrine poison on muscle is somewhat similar. This reagent not only diminishes the excitibility, but causes a very great prolongation of the period of recovery. 
In connection with the action of chemical reagents the following points are noteworthy.

(1) The effect of these reagents is not only to increase or diminish the height of the response-curve, but also to modify the time relations. By the action of some

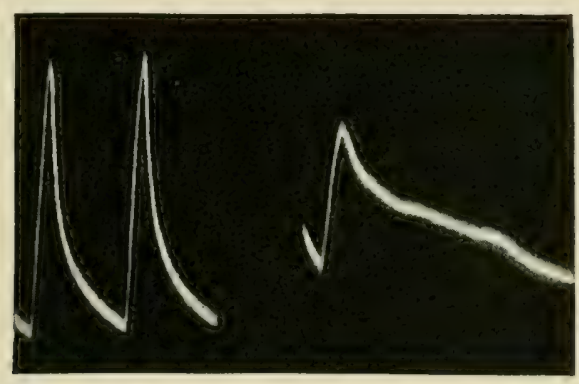

(a)

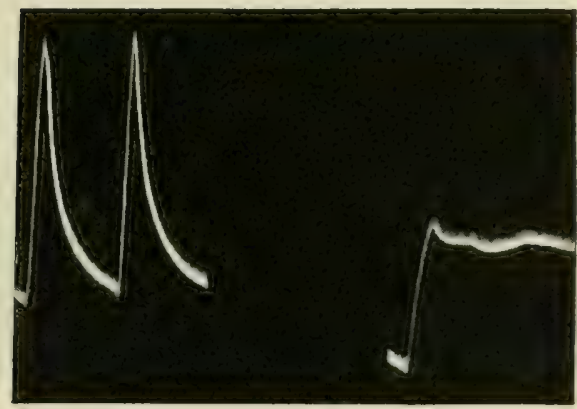

(b)

Fig. 93.- 'Molecular Arrest' by the Action of 'Poison'

In each, curves to the left show the normal response, curve to the right shows the effect of poison. In $(a)$ the arrest is evidenced by prolongation of period of recovery. In $(b)$ there is no recovery.

the latent period is diminished, others produce a prolongation of the period of recovery. Some curious effects produced by the change of time relations have been noticed in the account given of diphasic variation (see p. 113). 
(2) The effect produced by a chemical reagent depends to some extent on the previous condition of the wire.

(3) A certain time is required for the full development of the effect. With some reagents the full effect takes place almost instantaneously, while with others the effect takes place slowly. Again the effect may with time reach a maximum, after which there may be a slight decline.

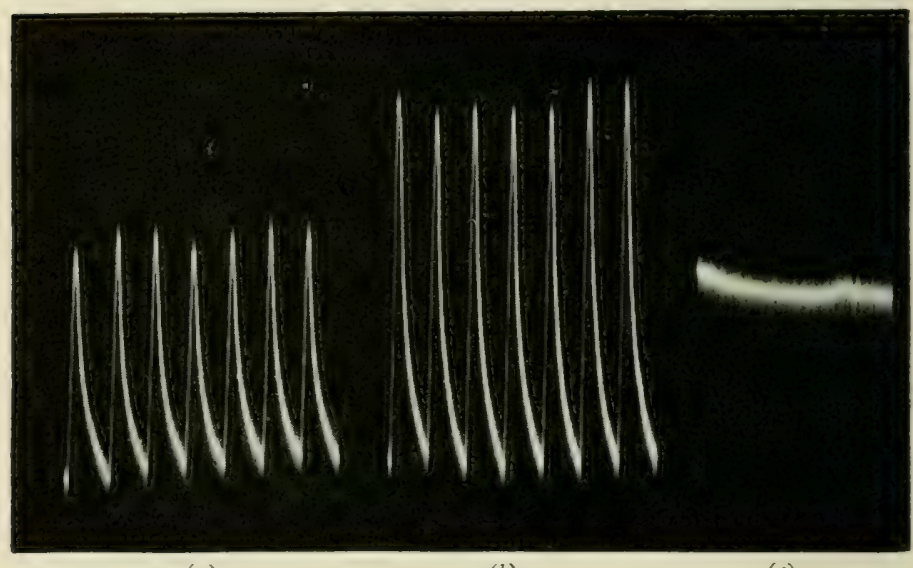

(a)

(b)

(c)

Fig. 94.-Opposite Effects of Suall and Large Doses (Tin)

$(a)$ is the normal response; $(b)$ is the stimulating action of small dose of potash ( 3 parts in 1,000$) ;(c)$ is the abolition of response with a stronger dose ( 3 parts in 100$)$.

(4) The after-effects of the reagents may be transitory or persistent; that is to say, in some cases the removal of the reagent causes the responses to revert to the normal, while in others the effect persists even after the removal of all traces of the reagent.

Opposite effects of large and small doses.-There remains a very curious phenomenon, known not only 
to students of physiological response but also known in medical practice, namely that of the opposite effects produced by the same reagent when given in large or in small doses. Here, too, we have the same phenomena reproduced in an extraordinary manner in inorganic response. The same reagent which becomes a 'poison' in large quantities may act as a stimulant when applied in small doses. This is seen in record fig. 94, in which (a) gives the normal responses in water' $\mathrm{KHO}$ solution was now added so as to make thestrength three parts in 1,000 , and $(b)$ shows the consequent enhancement of response. A further quantity of $\mathrm{KHO}$ ) was added so as to increase the strength to three parts in 100 . This caused a complete abolition $(c)$ of response.

It will thus be seen that as in the case of animal tissues and of plants, so also in metals, the electrical responses are exalted by the action of stimulants, lowered by depressants, and completely aloolished by certain other reagents. The parallelism will thus be found complete in every detail between the phenomena of response in the organic and the inorganic. 


\section{CHAPTER XTII}

\section{ON THE STIMULUS OF LIGHT AND RETINAT, CURRENTS}

Visual impulse: (1) chemical theory; (2) electrical theory - Retinal currents-Normal response positive-Inorganic response under stimulus of light-Typical experiment on the electrical effect induced by light.

TuE effect of the stimulus of light on the retina is perceiver in the hrain as a visual sensation. The process by which the ether-wave disturbance causes this risual impulse is still very olscure. Tro theories may be advanced in explanation.

(I) Chemical theory.-According to the first, or (hemical, theory, it is supposed that certain risual sub)stances in the retina are affected by light, and that vision originates from the metabolic changes produced in these risual substances. It is also supposed that the metabolic changes consist of two phases, the upward, constructive, or anabolic phase, and the downward, destructive, or katabolic phase. Tarious visual sul)stances hy their anabolic or katabolic changes are supposed to produce the variations of sensation of light and colour. This theory, as will be seen, is very complex, and there are certain ohstacles in the way of its acceptance. It is, for instance, difficult to see how this very quirk risual process could be due to a comparatively slow chemical action, consisting of 
the destructive breaking-down of the tissue, followed by its renovation. Some support was at first given to this chemical theory by the bleaching action of light on the visual purple present in the retina, but it has been found that the presence or alssence of visual purple could not be essential to vision, and that its function, when present, is of only secondary importance. For it is well known that in the most sensitive portion of the human retina, the fovea centralis, the visual purple is wanting; it is also found to be completely absent from the retine of many animals possessing keen sight.

(2), Electrical theory.--The second, or electrical, theory supposes that the visual impulse is the conconitant of an electrical impulse; that an electrical "urrent is generated in the retina under the incilence of light, and that this is transmitted to the brain by the optic nerve. There is much to be said in favour of this view, for it is an undoubted fact, that light gives rise to retinal currents, and that, conversely, an electrical current suitably applied causes the sensation of light.

Retinal currents.-Holmgren, Dewar, IIcKendrick, Kuhne, Steiner, and others have shown that illumination produces electric variation in a freshly excised eye. About this general fact of the electrical response there is a widespread agreement, but there is some difference of opinion as regards the sign of this response immediately on the application, cessation, and during the continuance of light. These slight discrepancies may be partly due to the unsatisfactory nomenclature-as regards use of terms positive and negutire-hitherto in 
vogue and partly also to the differing states of the excised eyes observed.

Waller, in his excellent and detailed work on the retinal currents of the frog, has shown how the sign of response is reversed in the moribund condition of the eye.

As to the confusion arising from our present terminology, we must remember that the term positive or negative is used with regard to a current of reference - the so-called current of injury.

When the two galvanometric contacts are made, one with the cut end of the nerve, and the other on the

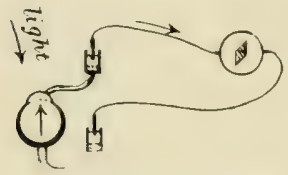

Fig. 95. Retinal Response то Liant

The current of response is from the nerve to the retima. uninjured cornea, a current of injury is found which in the eye is from the nerve to the retina. In the normal freshly excised eye, the current of response due to the action of light on the retina is always from the nerve, which is not directly stimulated by light, to the retiua, that is, from the less excited to the more excited (fig. 9.j). This current of response flows, then, in the same direction as the existing current of reference -the current of injury-and may therefore be called prositive. Unfortunately the current of injury is very often apt to change its sign; it then flows through the eye from the cornea to the nerve. And now, though the current of response due to light may remain unchanged in direction, still, owing to the reversal of the current of reference, it will appear as negative. That is to say, though its absolute direction is the same as hefore, its relative direction is altered. 
I have already advocated the use of the term positive for currents which flow towards the stimulated, and negative for those whose flow is away from the stimulated. If such a convention be adopted, no confusion can arise, even when, as in the given cases, the currents of injury undergo a change of direction.

Normal response positive.-The normal effect of light on the retina, as noticed by all the observers already mentioned, is a positive variation, during exposure to light of not too long duration. Cessation of light is followed by recovery. On these points there is general agreement amongst investigators. Deviations are regarded as due to abnormal conditions of the eye, owing to rough usage, or to the rapid approach of death. For just as in the dying plant we found occasional reversals from negative to positive response, so in the dying retina the response may undergo changes from the normal positive to negative.

The sign of response, as we have already seen in numerous cases, depends very much on the molecular condition of the sensitive substance, and if this condition be in any way changed, it is not surprising that the character of the response should also undergo alteration.

Unlike muscle in this, successive retinal responses exhibit little change, for, generally speaking, fatigue is very slight, the retina recovering quickly even under strong light if the exposure be not too long. In exceptional cases, howerer, fatigue, or its converse, the staircase effect, may be observed.

Inorganic response under the stimulus of light.It may now be asked whether such a complex rital 
phenomenon as retinal response could have its comnterpart in non-living response. Taking a rod of silver, we may beat out one end into the form of a hollow cup, sensitising the inside by exposing it for a short time to vapour of bromine. The cup may now be filled with water, and comnection made with a galvanometer by non-polarisable electrodes. There will now be a current due to difference between the inner surface and the rod. This may be balanced, however, by a compensating E.M.F.

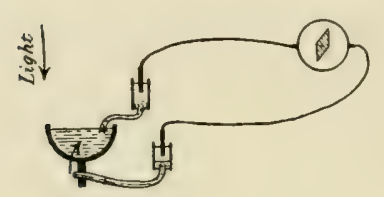

(a)

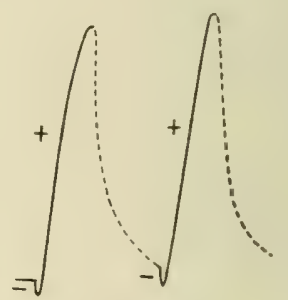

(b)

Fig. 96.-Record of Responses to Light aiven by the Sensitive Cell

Thick lines represent the effect during illumination, dotted lines the recovery

in darkness. Note the preliminary negative twitch, which is sometimes

also observed in responses of frog's retina.

We have thus an arrangement somewhat resembling the eye, with a sensitive layer corresponding to the retina, and the less sensitive rod corresponding to the conducting nerve-stump (fig. 96, a).

The apparatus is next placed inside a black box, with an aperture at the top. By means of an inclined mirror, light may be thrown down upon the sensitive surface through the opening.

On exposing the sensitive surface to light, the balance is at once disturbed, and a responsive current of positive chararter produced. The current, that is to 
say, is from the less to the more stimulated sensitive layer. On the cessation of light, there is fairly quick recovery (fig. $96, b$ ).

The character and the intensity of E.M. variation of the sensitive cell depend to some extent on the process of preparation. The particular cell with which most of the following experiments were carried ont usually gave rise to a positive variation of about .008 volt when acted on for one minute by the light of an incandescent gas-burner which was placed at a distance of $50 \mathrm{~cm}$.

Typical experiment on the electrical effect induced by light.-This subject of the production of an electrical current by the stimulus of light would appear at first sight very complex. But we shall be able to advance naturally to a clear understanding of its most complicated phenomena if we go through a preliminary consicleration of an ideally simple case. We have seen, in our experiments on the mechanical stimulation of, for example, tin, that a difference of electric potential was induced between the more stimulated and less stimulated parts of the same rod, and that an action current could thus be obtained, on making suitable electrolytic connections. Whether the more excited was zincoid or cuproid depended on the substance and its molecular condition.

Let us now imagine the metal rod flattened into a plate, and one face stimulated by light, while the other is protected. Would there be a difference of potential induced between the two faces of this same sheet of metal ? 
Let two blocks of paraffin be taken and a large hole drilled through both. Next, place a sheet of metal between the blocks, and pour melted paraffin round the edge to seal up the junction, the two open ends being also closed by panes of glass. We shall have then two compartments separated by the sheet of metal, and these compartments may be filled with water through the small apertures at the top (fig. 97, a).

The two liquid masses in the separated chambers thus make perfect electrolytic contacts with the two

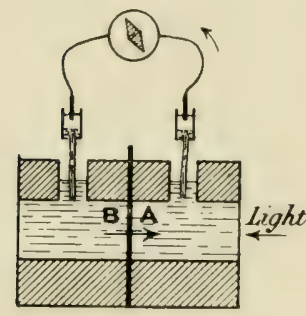

FIG. $97(a)$

A, B are the two faces of a brominated sheet of silver. One face, say $A$, is acted on by light. The current of response is from $\mathrm{B}$ to $\mathrm{A}$, across the plate. faces $\mathrm{A}$ and $\mathrm{B}$ of the sheet of metal. These two faces may be put in connection with a galvanometer by

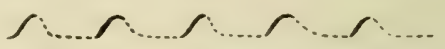

Fig. 97 (b).-Record of Responses obtained Fron the Arove CeLL

Ten seconds' exposure to light followed by fifty seconds' recovery in the dark. Thick lines represent action in light, dotted lines represent recovery.

means of two non-polarisable electrodes, whose ends dip into the two chambers. If the sheet of metal have been properly annealed, there will now be no difference of potential between the two faces, and no current in the galvanometer. If the two faces are not molecularly similar, however, there will be a current, and the electrical effects to be subsequently described will act additively, in an algebraical sense. Let one face now be exposed to the stimulus of light. A responsive current will be found to flow, from the less to the more stimulated face, in some cases, and in others in an opposite direction. 
It appears at first very curious that this difference of electric potential should be maintained between opposite faces of a very thin and lighly conducting sheet of metal, the intervening distance between the opposed surfaces being so extremely small, and the electrical resistance quite infinitesimal. A homogeneous sheet of metal has become by the unequal action of light, molecularly speaking, heterogeneous. The two opposed surfaces are thrown into opposite kinds of electric condition, the result of which is as if a certain
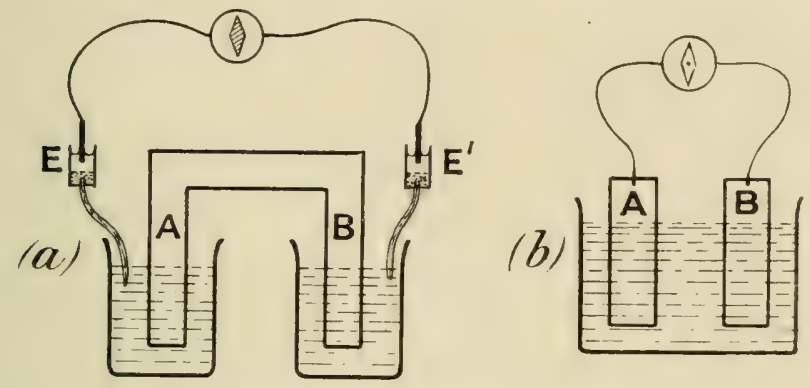

Fig. 98.-Modification of the Sensitive Celi

thickness of the sheet, electrically speaking, were marle zinc-like, and the rest copper-like. From such unfamiliar conceptions, we shall now pass easily to others to which we are more accustomed. Instead of two opposed surfaces, we may obtain a similar response by unequally lighting different portions of the same surface. Taking a sheet of metal, we may expose one half, say $\mathrm{A}$, to light, the other half, B, being screened. Electrolytic contacts are made by plunging the two limbs in two vessels which are in connection with the two nonpolarisable electrodes $\mathrm{E}$ and $\mathrm{E}^{\prime}$ (fig. 98, $a$ ). On 
illumination of A and B alternately, we shall now obtain currents flowing alternately in opposite directions.

Just as in the strain cells the galvanometer contact was transferred from the electrolytic part to the metallic part of the circuit, so we may next, in an exactly similar mamner, cut this plate into two, and connect these directly to the galvanometer, electrolytic connection being made by partially plunging them into a cell

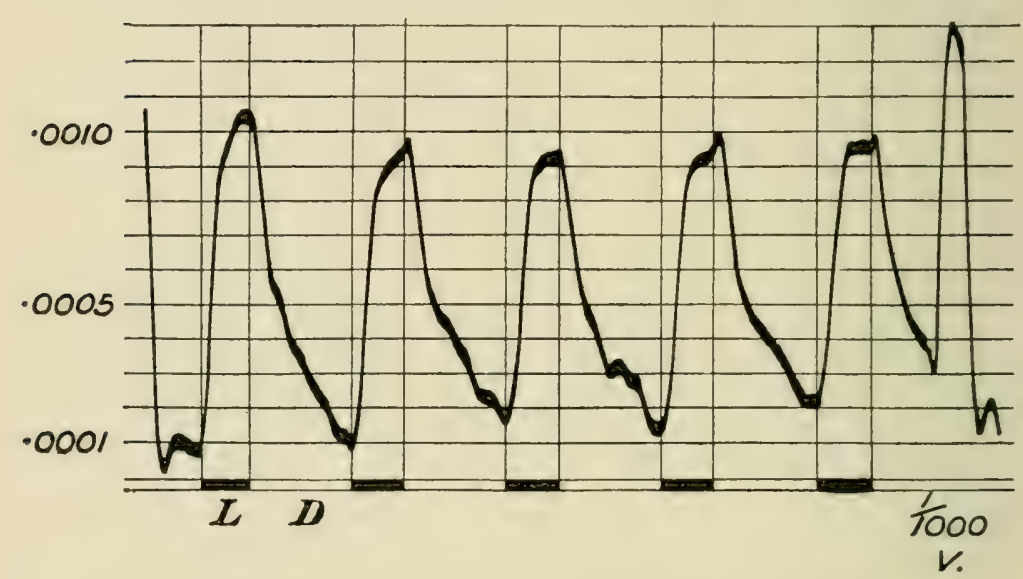

Fig. 99.-Responses to Light in Frog's Retina

Illumination $\mathrm{L}$ for one minute, recovery in dark for two minutes during obscurity $\mathrm{D}$. (Waller.)

containing water. The posterior surfaces of the two half-plates may be covered with a non-conducting coating. And we arrive at a typical photo-electric cell (fig. 98, $b$ ). These considerations will show that the eye is practically a photo-electric cell.

We shall now give detailed experimental results obtained with the sensitive silver-bromide cell, and compare its response-curve with those of the retina. A series of uniform light stimuli gives rise to uniform 
responses, which show very little sign of fatigue. How similar these response-curves are to those of the retina will be seen from a pair of records given below, where fig. 99 shows responses of frog's retina, and fig. 100 gives the responses obtained with the sensitive silver cell (fig. 100).

It was said that the responses of the retina are uniform. This is only approximately true. In addition to numerous cases of uniform responses, Waller finds instances of 'staircase' increase, and its opposite, slight fatigue. In the record here given of the silver cell,

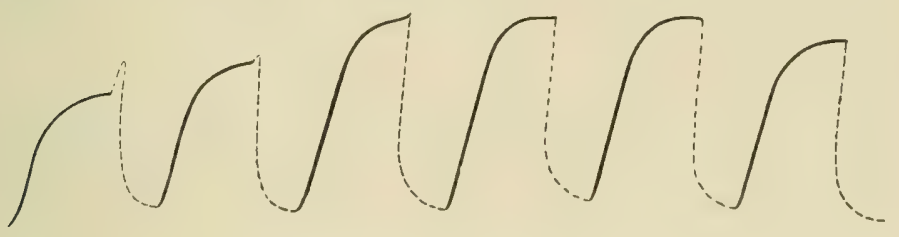

Fif. 100.-Responses in Sensitive Sinver Celit

Illumination for one minute and obscurity for one minute. Thick line represents record during illumination, dotted line recovery during obscurity.

the staircase eflect is seen at the begiming, and followed by slight fatigue. I have other records where for a very long time the responses are perfectly uniform, there being no sign of fatigue.

Another curious phenomenon sometimes observed in the response of retina is an occasional slight increase of response immediately on the cessation of light, after which there is the final recovery. An indication of this is seen in the second and fourth curves in fig. 99. Curiously enough, this abnormality is also occasionally met with in the responses of the silver cell, as seen in the first two curves of fig. 100. Other instances will be given later. 


\section{CHAP'TER XVIII}

INORGANIC RESPONSE-INFLUENCE OF VARIOUS CONDITIONS ON THE RESPONSE TO STIMULUS OF LIGHT

Effect of temperature-Effect of increasing length of exposure-Relation between intensity of light and magnitude of response-After-oscillation -Abnormal effects: (1) preliminary negative twitch; (2) reversal of response; (3) transient positive twitch on cessation of light; (4) decline and reversal-liésumé.

We shall next proceed to study the effect, on the re-sponse of the sensitive cell, of all those conditions which influence the normal response of the retina. We shall then briefly inquire whether even the abnormalities sometimes met with in retinal responses have not their parallel in the responses given by the inorganic.

Effect of temperature.-It has been found that when the temperature is raised above a certain point, retinal response shows rapid diminution. On cooling, however, response reappears, with its original intensity. In the response given by the sensitive cell, the same peculiarity is noticed. I give below (fig. 101, a) a set of responsecurves for $20^{\circ} \mathrm{C}$. These responses, after showing slight fatigue, became fairly constant. On raising the temperature to $50^{\circ} \mathrm{C}$. response practically disappeared $(101, b)$. But on cooling to the first temperature again, it reappeared, with its original if not slightly greater intensity (fig. 101, c). A curious point is that while in 
record $(a)$, before warming, slight fatigue is observed, in (c), after cooling, the reverse, or staircase effect, appears.

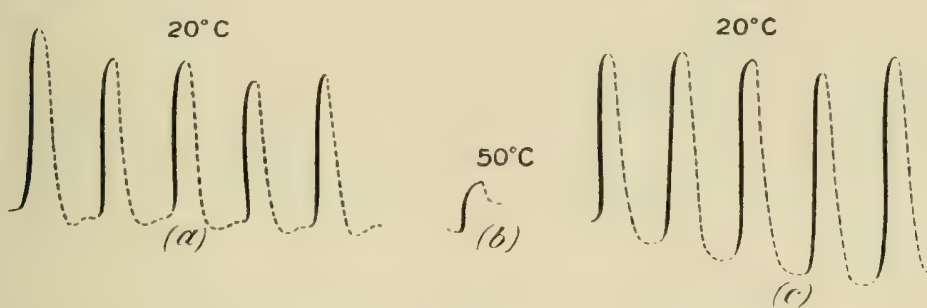

Fig. 101.-Influence of Temperature on Response

Illumination $20^{\prime \prime}$, obscurity $40^{\prime \prime}$.

In $(a)$ is shown a series of responses at $20^{\circ} \mathrm{C}$. - the record exhibits slight fatigue. $(b)$ is the slight irregular response at $50^{\circ} \mathrm{C} . \quad(c)$ is the record on re-cooling; it exhibits 'staircase' increase.

Effect of increasing length of exposure. - If the intensity of light be kept constant, the magnitude of

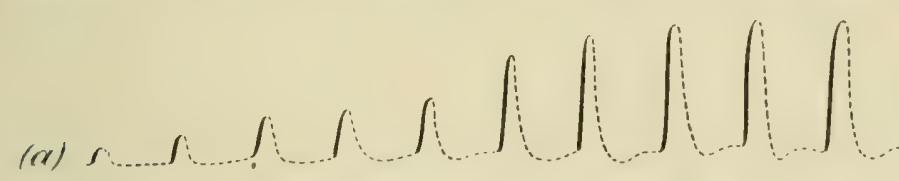

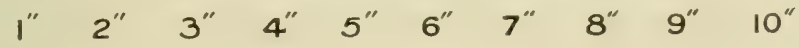

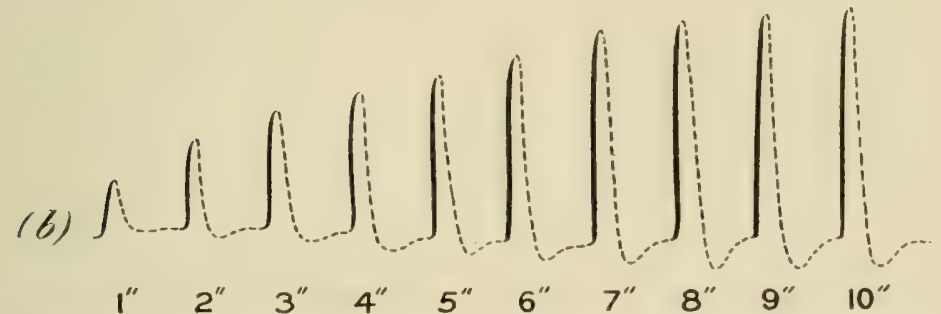

$$
1^{\prime \prime} 2^{\prime \prime} 3^{\prime \prime} 4^{\prime \prime} 5^{\prime \prime} 6^{\prime \prime} 7^{\prime \prime} 8^{\prime \prime} 9^{\prime \prime} 10^{\prime \prime}
$$

Fig. 102.-Response-curves for moreasing Duration of Illumination from $1^{\prime \prime}$ то $10^{\prime \prime}$

In $(a)$ the source of light was at $\Omega$ distance of $50 \mathrm{~cm}$.; in $(b)$ it was at a distance of $25 \mathrm{~cm}$. Note the after-oscillation.

response of the sensitive cell increases with length of exposure. But this soon reaches a limit, after which 
increase of duration does not increase magnitude of effert. Too long an exposure may however, owing to fatigue, produce an actual decline.

I give here two sets of curves (fig. 102) illustrating the effect of lengthening exposure. The intensities of light in the two cases are as 1 to 4 . The incandescent burner was in the two cases at distances 50 and $25 \mathrm{~cm}$. respectively. It will be olserved that beyond eight seconds' exposure the responses are approximately uniform. Another noticeable fact is that with long exposure there is an after-oscillation. This growing effect with lengthening exposure and attainment of limit is exactly paralleled by responses of retina under similar conditions.

Relation between intensity of light and magnitude of response.- In the responses of retina, it is found that increasing intensity of light produces an increasing effect. But the rate of increase is not uniform : increase of effect does not keep pace with increase of stimulus. Thus a curve giving the relation between stimulus and response is concare to the axis which represents the stimulus.

The same is true of the sensation of light. That is to say, within wide limits, intensity of sensation does not increase so rapidly as stimulus.

This particular relation between stimulus and effect is also exhibited in a remarkable manner by the sensitive cell. For a constant source of light I used an incandescent burner, and graduated the intensity of the incident light by varying its distance from the sensitive cell. The intensity of light incident on the cell, when 
the incandescent burner is at a distance of $150 \mathrm{~cm}$., has been taken as the arhitrary unit. In order to make allowance for the possible effects of fatigue I took two
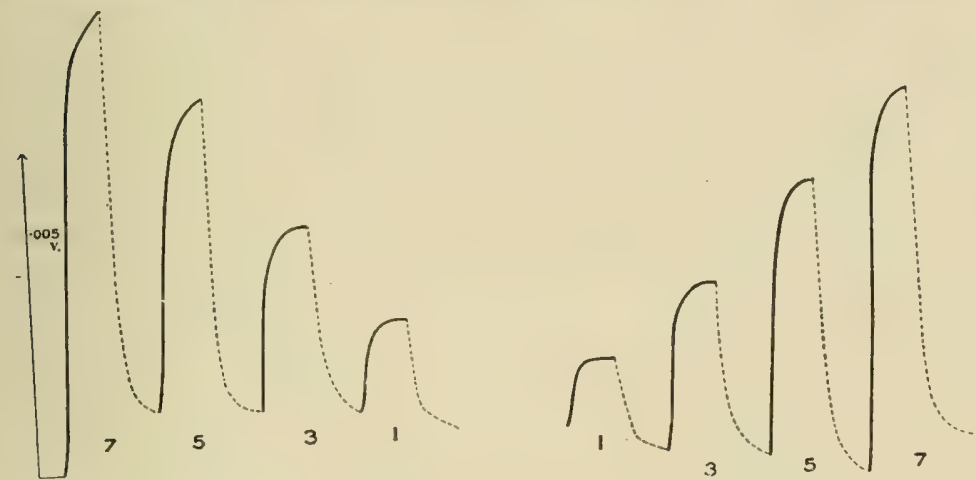

Fir. 103.-Responses of Sensitive Celu to variods Intensities of Light

On the left the responses are for diminishing intensities in the ratios of $7,5,3$, and 1. On the right they are for the increasing intensities $1,3,5$, and 7 . The thick lines are records during exposures of one minute; the dotted lines represent recoveries for one minute.

successive series of responses (fig. 103). In the first, records were taken with intensities diminishing fron 7 to 1 , and immediately afterwards increasing from 1 to 7 , in the second.

Tabie giving Riesponse to varying Intensities of Light (The intensity of an incandescent gas-burner at a distance of $150 \mathrm{~cm}$. is taken as unit.)

\begin{tabular}{|c|c|c|c|c|}
\hline $\begin{array}{l}\text { Intensity } \\
\text { of Light }\end{array}$ & $\begin{array}{c}\text { Response } \\
\text { (Light } \\
\text { diminishing) }\end{array}$ & $\begin{array}{l}\text { Response } \\
\quad \text { (Linht } \\
\text { increasing) }\end{array}$ & Mean & Value in volt \\
\hline 7 & 43 & 39 & 41 & $63.0 \times 10^{-}$volt \\
\hline 5 & 31 & 29 & 30 & $46 \cdot 1 \times$ \\
\hline 3 & $18 \cdot \tilde{5}$ & $17 \cdot 5$ & 18 & $27 \cdot 7 \times$ \\
\hline 1 & 10 & 9 & $9 \cdot 5$ & $14 \cdot 6 \times$ \\
\hline
\end{tabular}

As the zero point was slightly shifted during the 
rourse of the experiment, the deflection in each curve was measured from a line joining the beginning of the response to the eñd of its recovery. A mean deflection, rorresponding to each intensity, was obtained by taking the arerage of the descending and ascending readings. The two sets of readings did not, however, vary to any marked extent.

The deflections corresponding to the intensities 1 , $3,5,7$, are, then, as 9.5 to 18 , to 30 , to 41 . If the deflections had been strictly proportionate to the inten-
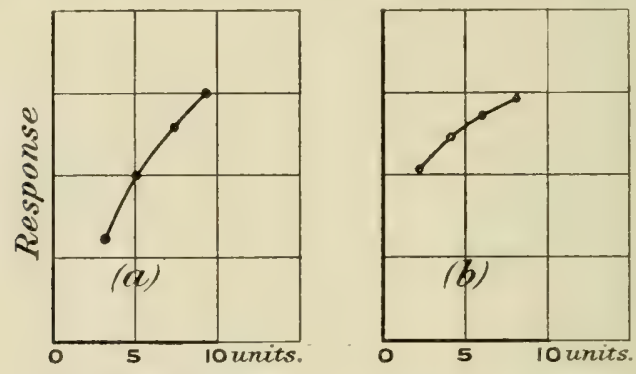

Stimulus

Fig. 104.-Curves giving the Relation between Intenstity of Light and Magnitude of Response

In $(a)$ sensitive cell, (b) in frog's retina.

sities of light stimulus they would have been as $9 \cdot \tilde{\partial}$ to $28 \cdot 5$, to $47 \cdot 5$, to $66 \cdot 5$.

In another set of records, with a different cell, I olstained the deflections of $6,10,13,15$, corresponding to light intensities of $3,5,7$, and 9 .

The two curves in fig. 104, giving the relation between response and stimulus, show that in the case of inorganic substances, as in the retina (Waller), magnitude of response does not increase so rapidly as stimulus.

After-oscillation.-When the sensitive surface is suljected to the continued action of light, the E.IJ. 
effect attains a maximum at which it remains constant for some time. If the exposure be maintained after this for a longer period, there will be a decline, as we found to be the case in other instances of continued stimulation. The appearance of this decline, and its rapidity, depends on the particular condition of the substance.

When the sensitive element is considerably strained by the action of light, and if that light be now cut
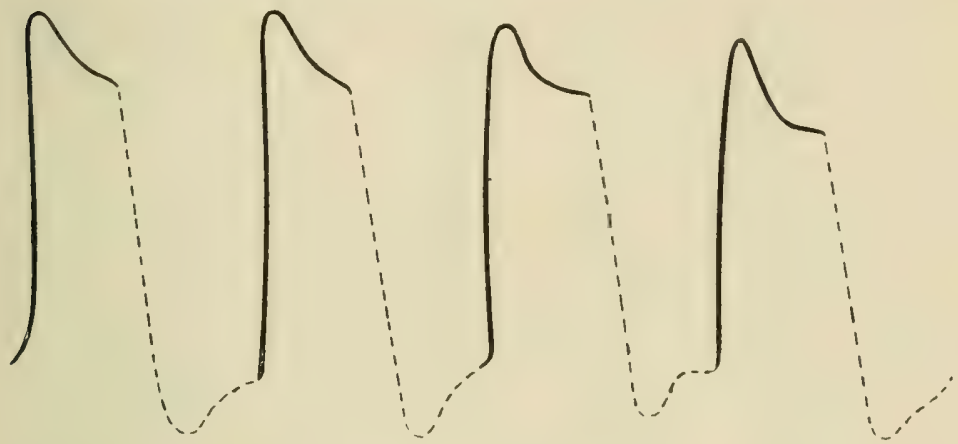

Fig. 105.-After-oscilliatton

Exposure of one minute followed by obscurity of one minute. Note the decline during illumination, and after-oscillation in darkness.

off, there is a rebound towards recovery and a subsequent after-oscillation. That is to say, the curve of recovery falls below the zero point, and then slowly oscillates back to the position of equilibrium. We have already seen an instance of this in fig. 102. Ahove is given a series of records showing the appearance of decline, from too long-continued exposure and recovery, followed by after-oscillation on the cessation of light (fig. 105). Certain visual analogues to this phenomenon will be noticed later. 
Abnormal effects. - We have already treated of all the normal effects of the stimulus of light on the retina, and their counterparts in the sensitive cell. But the retina undergoes molecular changes when injured, stale, or in a dying condition, and under these circumstances various complicated modifications are observed in the response.

I. Preliminary negative twitch.--When the light is incident on the frog's retina, there is sometimes a transitory negative variation, followed by the normal

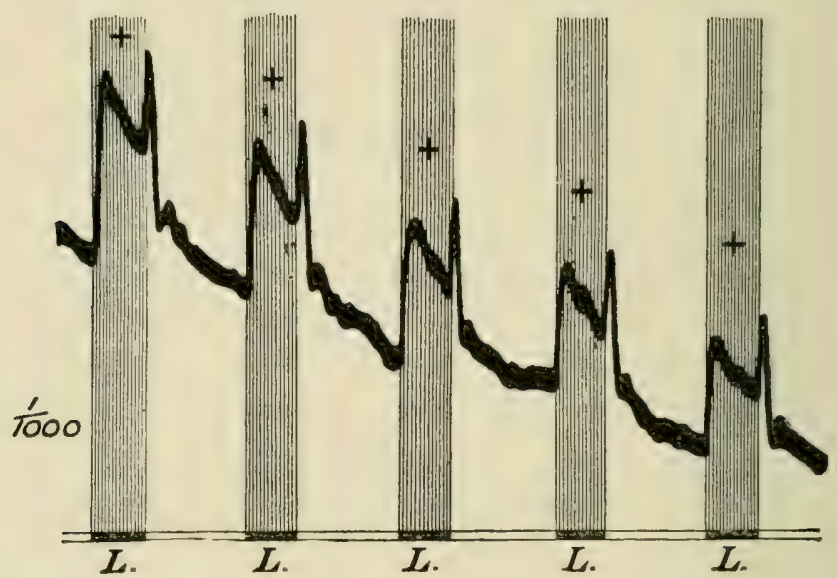

Fig. 106.- Transient Positive Adgmentation given by the Frog's Retixa on the Cessation of Light L (Waller)

positive response. This is frequently observed in the sensitive cell (see fig. 96, b).

2. Reversal of response-Again, in a stale retina, owing to molecular modification the response is apt to undergo reversal (Waller). That is to say, it now becomes negative. In working with the same sensitive rell on different days I have found it occasionally exhibiting this reversed response. 


\section{Transient rise of current on cessation of light.-} Another very curious fact observed in the retina by Kuhne and Steiner is that immediately on the stoppage of light there is sometimes a suctlen increase in the retinal current, before the usual recovery takes place. This is very well shown in the series of records taken by Waller (fig. 106): It will be noticed that on illumination the response-curve rises, that continued illumination produces a decline, and that on the cessation of light there is a transient rise of current. I give here a series of records which will show the remarkable similarity between the responses of the cell and retina, in respect even of abnormalities so marked as those described (fig. 107). I may mention here that some of these curious effects, that is to say, the preliminary negative twitch and sudden augmen-

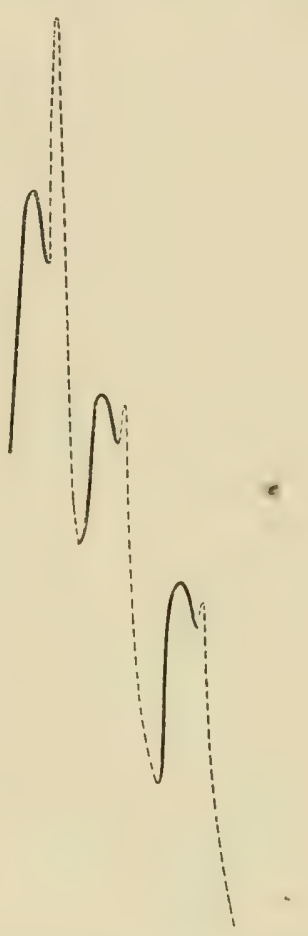

Fig. 107.-Responses in Silver Cell

The thick line represents response during light (half a minute's exposure), and dotted line the recovery during darkness. Note the terminal positive twitch.

tation of the current on the cessation of light, have also been noticed by Minchin in photo-electric cells.

4. Decline and reversal.-We have seen that under the continuous action of light, response begins to 
decline. Sometimes this process is very rapid, and in any case, under continued light, the deflection falls.

(1) The decline may nearly reach zero. If now the light be cut off there is a rebound towards recovery dounwards, which carries it below zero, followed by an after-oscillation (fig. 108, $a$ ).

(2) If the light be continued for a longer time, the decline goes on even below zero; that is to say, the

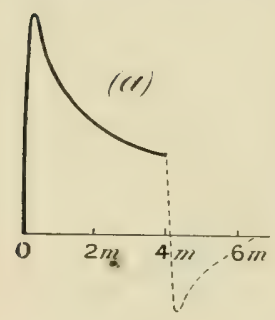

(b)

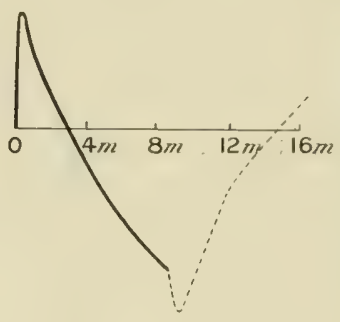

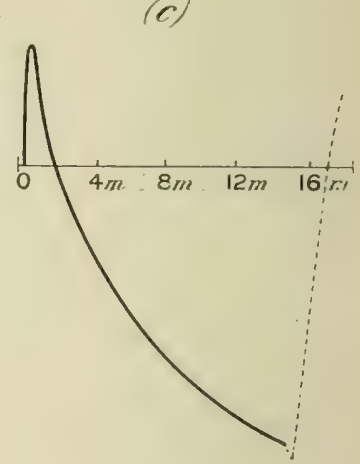

Fig. 108-Dechine under the Continued Action of Light

(a) Decline short of zero; on stoppage of light, rebound downwards to zero; after-oscillation.

(b) Decline below zero; on stoppage of light, rebound towards zero, with preliminary negative twitch.

(c) The same, decline further down; negative twitch almost disappearing.

response now becomes apparently negative. If, now, the light be stopped, there is a rehound upwards to recovery, with, generally speaking, a slight preliminary twitch downwards (fig. 108, l, c). This rebound carries it back, not only to the zero position, but sometimes beyond that position. We have here a parallel to the following observation of Dewar and McKendrick: 
"When diffuse light is allowed to impinge on the eye of the frog, after it has arrived at a tolerably stable condition, the natural E.ML.F. is in the first place increased, then diminished; during the continuance of light it is still slowly diminished to a point where it remains tolerably constant, and on the remoral of light there is a sudden increase of the E.ML. power nearly up to its original position.' 1

(3) I have sometimes obtained the following curious result. On the incidence of light there is a response, say, upward. On the continuation of light the response declines to zero and remains at the zero position, there being no further action during the continuation of stimulus. But on the cessation or 'break' of light stimulus, there is a response downwards, followed by the usual recovery. This reminds us of a somewhat similar responsive action produced by constant electric current on the muscle. At the moment of 'make' there is a responsive twitch, but afterwards the muscle remains quiescent during the passage of the current, but on breaking the current there is seen a second responsive twitch.

Résumé.-So we see that the response of the sensitive inorganic cell, to the stimulus of light, is in every way similar to that of the retina. In both we have, under normal conditions, a positive variation; in both the intensity of response up to a certain limit increases with the cluration of illumination; it is affected, in both alike, by temperature; in both there is comparatirely little fatigue; the increase of response with intensity of 1 Proc. Roy. Suc. Edin. 1873, p. 153. 
stimulus is similar in both; and fually, even in abnormalities_such as reversal of response, preliminary negative twitch on commencement, and terminal positive twitch on cessation of illumination, and decline and reversal under continued action of light-parallel effects are noticed.

We may notice here certain curious relations even in these abnormal responses (fig. 109). If the equilibrium position remain always constant, then it is easy to understand how, when the rising curve has attained

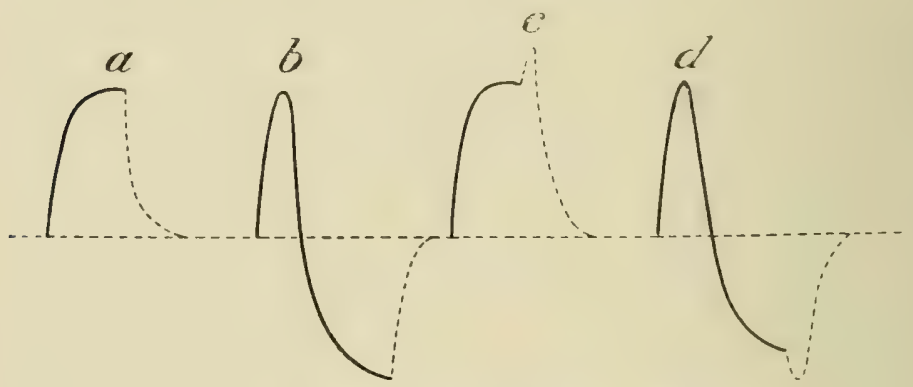

Fig. 109.-Certain After-effects of Light

its maximum, on the cessation of light, recovery should proceed downuards, towards the equilibrium position (fig. 109, a). One can also understand how, after reversal by the continued action of light, there should be a recovery uquards towards the old equilibrium position (fig. 109, b). What is curious is that in certain cases we get, on the stoppage of light, a preliminary twitch away from the zero or equilibrium position, upwards as in (c) (compare also fig. 10 7 ) and downwards as in $(d)$ (compare also fig. $108 \mathrm{~b}$ ).

In making a general retrospect, finally, of the effects 
produced by stimulus of light, we find that there is not a single phenomenon in the responses, normal or abnormal, exhibited by the retina which has not its counterpart in the sensitive cell constructed of inorganic material. 


\section{CHAPTER XIX}

VISUAL ANALOGUES

Effect of light of short duration-After-oscillation-Positive and negative after-images-Binocular alternation of vision-Period of alternation modified by physical condition-After-images and their revival - Cnconscious visual impression.

$\mathrm{W}_{\mathrm{E}}$ have already referred to the electrical theory of the visual impulse. We have seen how a flash of light causes a transitory electric impulse not only in the retina, but also in its inorganic sulstitute. Light thus produces not only a visual but also an electrical impulse, and it is not improbable that the two may be identical. Again, varying intensities of light give rise to corresponding intensities of current, and the curves which represent the relation between the increasing stimulus and the increasing response have a general agreement with the corresponding curve of visual sensation. In the present chapter we shall see how this electrical theory not only explains in a simple mamer ordinary risual phenomena, but is also deeply suggestive with regard to others which are very obscure.

We have seen in our silver cell that if the molecular conditions of the anterior and posterior surfaces were exactly similar, there would be no current. In practice, howerer, this is seldom the case. There is, generally 
speaking, a slight difference, and a feeble current in the circuit. It is thus seen that there may be an existing feeble current, to which the effert of light is added algebraically. The stimulus of light may thus increase the existing current of darkness positive variation). On the cessation of light again, the current of response disippears and there remains only the feeble original current.

In the case of the retina, also, it is curious to note that on closing the eye the sensation is not one of absolute darkness, but there is a general feel le sensation. of light, known as 'the intrinsic light of the retina.' The effert produced by extemal light is superposed on this intrinsic light, and certain curious results of this algebraical summation will be noticed later.

Effect of light of short duration.-If we sulject the sensitive cell to a flash of radiation, the effect is not instantaneous but grows with time. It attains a maximm some little time after the incidence of light, and the effect then gradually passes away. Again, as we have seen previously with regard to mechanical strain, the after-effect persists for a slightly longer time when the stimulus is stronger. The same is true of the after-effect of the stimulus of light. Two "urves which exhibit this are given below (fig. 110). With regard to the first point-that the maximm effect is attained some time after the cessation of a short exposure-the corresponding experiment on the eye may be made as follows: at the end of a tube is fixed a glass disc coated with lampblack, on which, by scratching with a pin, some words are written in transparent characters. 
The length of the tube is so adjusted that the disc is at the distance of most distinct rision from the end of the tube applied to the eye. The blackened dise is turned towards a source of strong light, and a short exposure is given by the release of a photographic shutter interposed between the disc and the eye. On closing the eye, immediately after a short exposure, it will at first be found that there is hardly any well-defined visual sensation; after a short time, however, the writing on

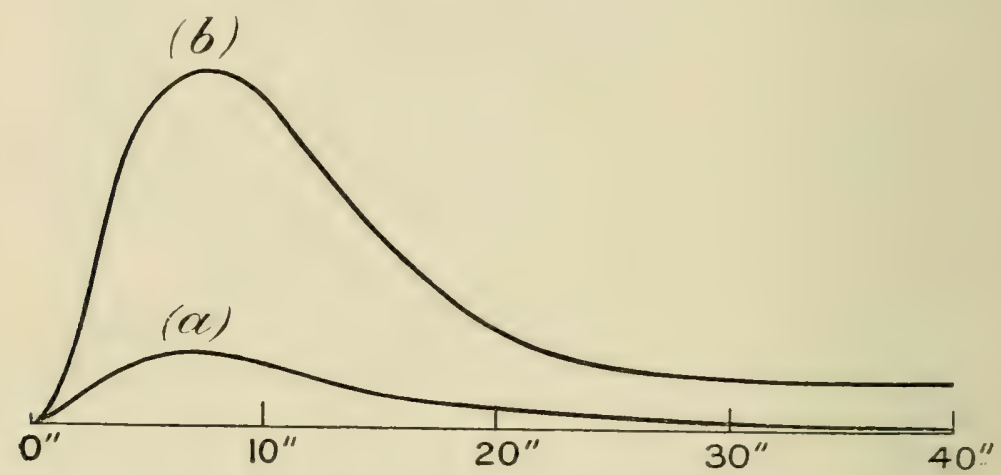

Fig. 110.-Response-corves of the Sensitive Siluet Celi

Showing greater persistence of after-effect when the stimulus is strong.

(a) Short exposure of $2^{\prime \prime}$ to light of intensity $1 ;(b)$ short exposure of $2^{\prime \prime}$ to light nine times as strong.

the blackened disc begins to appear in luminous characters, attains a maximum intensity, and then fades away. In this case the stimulus is of short duration, the light being cut off before the maximum effect is attained. The after-effect here is positive, there being no reversal or interval of darkness between the direct image and the after-image, the one being merely the continuation of the other. But we shall see, if light is cut off after a maximum effect is attained by long 
exposure, that the immediate after-image would be negative (see below). The relative persistence of after-effect of lights of different intensities may be shown in the following manner :

If a bold design be traced with magnesium powder on a blackened board and fired in a dark room, the observer not being acquainted with the design, the instantaneous flash of light, besides being too quick for detailed observation, is obscured by the accompanying smoke. But if the eyes be closed immediately after the flash, the feebler obscuring sensation of smoke will first disappear, and will leave clear the more persistent aftersensation of the design, which can then be read distinctly. In this mamner I have often been able to see distinctly, on closing the eyes, extremely brief phenomena of light which could not otherwise have been observed, owing either to their excessive rapidity or to their dazzling character. ${ }^{1}$

After-oscillation.-In the case of the sensitive silver cell, we have seen (fig. 10.j), when it has been subjected for some time to strong light, that the current of response attains a maximum, and that on the stoppage of the stimulus there is an immediate rebound towards recovery. In this rebound there may be an over-shooting of the equilibrium position, and an after-oscillation is thus produced.

1 As an instance of this I may mention the experiment which I saw on the quick fusion of metals exhibited at the Royal Institution by Sir William Roberts-Austen (1901), where, owing to the glare and the dense fumes, it was impossible to see what happened in the crucible. But I was able to see erery detail on closing the eyes. The effects of the smoke, being of less luminescence, cleared away first, and left the after-image of the molten metal growing clearer on the retina. 
If there has been a feeble initial current, this oscillatory after-current, by algebraical summation, will cause the current in the circuit to be alternately weaker and stronger than the initial current.

Visual recurrence.-Translated into the visual cir'cuit, this would mean an alternating series of after-images. On the cessation of light of strong intensity and long duration, the immediate effect would be a negative rebound, unlike the positive after-effect which followed on a short exposure.

The next rebound is positive, giving rise to a sensation of brightness. This will go on in a recurrent series.

If we look for some time at a very bright object, preferably with one eye, on closing the eye there is an immediate dark sensation followed by a sensation of light. These go on alternating and give rise to the phenomena of recurrent vision. With the eyes closed, the positive or luminous phases are the more prominent.

This phenomenon may be observed in a somewhat different manner. After staring at a bright light we may look towards a well-lighted wall. The dark phases will now become the more noticeable.

If, however, we look towards a dimly lighted wall, both the dark and bright phases will be noticed alternately.

The negative effect is usually explained as due to fatigue. That position of the retina affected by light is supposed to be 'tired,' and a negative image to be formed in consequence of exhaustion. By this exhaus- 
tion is meant either the presence of fatigue-stuffs, or the breaking-down of the sensitive element of the tissue, or both of these. In such a case we should expect that this fatigue, with its consequent negative image, would gradually and finally disappear on the restoration of the retina to its normal condition.

We find, however, that this is not the case, for the negative image recurs with alternate positive. The accepted theory of fatigue is incapable of explaining this phenomenon.

In the sensitive silver cell, we found that the molecular strain produced by light gave rise to a current of response, and that on the cessation of light an oscillatory after-effect was produced. The alternating after-effect in the retina points to an exactly similar process.

Binocular alternation of vision.-It was while experimenting on the phenomena of recurrent vision that I discovered the curious fact that in normal eves the two do not see equally well at a given instant, hut that the visual effect in each eye undergoes fluctuation from moment to monent, in such a way that the sensation in the one is complementary to that in the other, the sum of the two sensations remaining approximately constant. Thus they take up the work of seeing, and then, relatively speaking, resting, alternately. This division of lalbour, in binocular vision, is of obvious advantage.

As regards maximum sensation in the two retina there is then a relative retardation of half a period. This may be seen by means of a stereoscope, carrying, instead of stereo-photographs, incised plates through which we look at light. The design consists of two 
slanting cuts at a suitable distance from each other. One cut, $\mathrm{R}$, slants to the right, and the other, $\mathrm{L}$, to the left (see fig. 111). When the design is looked at through the stereoscope, the right eye will see, say $\mathrm{R}$, and the left $\mathrm{L}$, the two images will appear superimposed, and we see an inclined cross. When the stereoscope is turned towards the sky, and the cross looked at steadily for some time, it will be found, owing to the alternation alrealy referred to, that while one arm of the cross begins to be dim, the other becomes bright, and vice
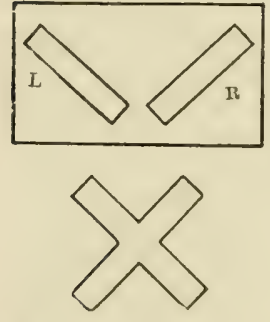

Fic. 111.-STEREกSCOPIC DESIGN versa. The alternate fluctuations become far more conspicuous when the eyes are closed; the pure oscillatory after-effects are then obtained in a most vivid manner. After looking through the stereoscope for ten seconds or more, the eyes are closed. The first effect observed is one of darkness, due to the rebound.

Then one luminous arm of the cross first projects aslant the dark field, and then slowly (lisappears, after which the second (perceived by the other eye) shoots out suclenly in a direction athwart the first. This alternation proceeds for a long time, and produces the curious effect of two luminous blades crossing and recrossing each other.

Another method of bringing out the phenomenon of alternation in a still more striking manner is to look at two different sets of writing, with the two eyes. The resultant effect is a blurr, due to superposition, and the inscription camnot be read with the eyes open. - But on 
closing them, the composite image is analysed alternately into its component parts, and thus we are enabled to read better with eyes shut than open.

This period of altemation is modified by age and by the condition of the eye. It is, generally speaking, shorter in youth. I have seen it rary in different individuals from $1^{\prime \prime}$ to $10^{\prime \prime}$ or more. About $4^{\prime \prime}$ is the most usual. With the same individual, again, the period is somewhat modified by previous conditions of rest or artivity. Very early in the moming, after sleep, it is at its shortest. I give below a set of readings given by an observer:

\begin{tabular}{|c|c|c|}
\hline 8 А.м. .................. & 6 г.м. & $\begin{array}{l}\text { Periolt } \\
.5 . t^{\prime \prime}\end{array}$ \\
\hline 12 noon.................4" & 9 &. $.5 \cdot 6^{\prime \prime}$ \\
\hline 3 г.м. ...............5" & 11 & $.6 \% 5)^{\prime \prime}$ \\
\hline
\end{tabular}

Again, if one eye be cooled and the other warmed, the retinal oscillation in one eye is quicker than in the other. The quicker oscillation overtakes the slower, and we obtain the curious phenomenon of "visual beats.'

After-images and their revival.-In the experiment with the stereoscope and the design of the cross, the after-images of the cross seen with the eyes closed are at first very distinct-so distinct that any unevenness at the edges of the slanting cuts in the design can be distinctly made out. There can thus be no doubt of the 'objective' nature of the strain impression on the retina, which on the cessation of direct stimulus of light gives rise to after-oscillation with the concomitant visual recurrence. This recurrence may therefore be taken as a proof of the pliysical strain produced on the 
retina. The recurrent after-image is very distinct at the begimning and becomes fainter at each repetition; a time comes when it is difficult to tell whether the image seen is the objective after-effect due to strain or merely an effect of 'memory.' In fact there is no line of demarcation between the two, one simply merges into the other. That this 'memory' image is due to objective strain is rendered evident by its recurrence.

In comection with this it is interesting to note that some of the undoubted phenomena of memory are also recurrent. "Certain sensations for which there is no corresponding process outside the body are generally grouped for convenience under this term [memory]. If the eyes be closed and a picture be called to memory, it will be found that the picture camnot be held, but will repeatedly disappear and appear.' 1

The visual impressions and their recurrence often persist for a very long time. It usually happens that owing to weariness the recurrent images disappear; but in some instances, long after this disappearance, they will spontaneously reappear at most unexpected moments. In one instance the recurrence was observed in a dream, about three weeks after the original impression was made. In connection with this, the revival of images, on closing the eyes at night, that have been seen during the day, is extremely interesting.

Unconscious visual impression. - While repeating certain experiments on recurrent rision, the above phenomenon became prominent in an unexpected

' E. W. Scripture, The New Psychology, p. 101. 
manner. I had been intently looking at a particular window, and obtaining the subsequent after-images by closing the eye; my attention was concentrated on the window, and I saw nothing but the window either as a direct or as an after effect. After this had been repeated a number of times, I found on one occasion, after closing the eye, that, owing to weariness of the particular portion of the retina, I could no longer see the after-image of the window; instead of this I however saw distinctly a circular opening closed with slass panes, and I noticed even the jagged edges of a broken pane. I was not aware of the existence of a circular opening higher up in the wall. The image of this had impressed itself on the retina without $11 \mathrm{y}$ knowledge, and had undoubtedly been producing the recurrent images which remained mmoticed because my principal field of after-vision was filled up and my attention directed towards the recurrent inage of the window. When this failed to appear, my field of after-rision was relatively free from distraction, and I could not help seeing what was unnoticed before. It thus appears that, in addition to the images impressed in the retina of which we are conscious, there are many others which are imprinted without our knowledge. We fail to notice them because our attention is directed to something else. But at a subsequent period, when the mind is in a passive state, these impressions may suddenly revive owing to the phenomenon of recurrence. This observation may aftord an explanation of some of the phenomena connected with ocular phantons and hallucinations not traceable to any disease. In these 
I80 RESPONSE IN THE LIVING AND NON-LIVING

(ases the psychical effects produced appear to have no objective cause. Bearing in mind the numerous visual impressions which are being unconsciously made on the retina, it is not, at all unlikely that many of these visual phantoms may be due to objective causes. 


\section{CHAPTER XX}

\section{GENERAL SURVEY AND CONCLUSION}

WE have seen that stimulus produces a certain excitatory change in living substances, and that the excitation produced sometimes expresses itself in a visible change of form, as seen in muscle; that in many other cases, however-as in nerve or retina-there is no visible alteration, but the disturbance produced by the stimulus exhibits itself in certain electrical changes, and that whereas the mechanical mode of response is limited in its application, this electrical form is universal.

This irritability of the tissue, as shown in its capacity for response, electrical or mechanical, was found to depend on its physiological activity. Under certain conditions it could be converted from the responsive to an irresponsive state, either temporarily as by anæsthetics, or permanently as by poisons. When thus made permanently irresponsive by any means, the tissue was said to have been killed. We have seen further that from this observed fact-that a tissue when killed passes out of the state of responsiveness into that of irresponsiveness ; and from a confusion of 'dead' things with inanimate matter, it has been tacitly assumed that inorganic substances, like dead 
animal tissues, must necessarily be irresponsive, or incapalse of being exeited hy stimulus - an assmption which has been shown to be gratuitous.

This ' mexplained conception of irritability became the starting-point,' to quote the words of Terworn, ${ }^{1}$ ' of vitalism, which in its most complete form asserted a dualism of living and lifeless Nature. . . The ritalists soon,' as he goes on to say, 'laid aside, more or less completely, mechanical and chemical explanations of vital phenomena, and introduced, as an explanatory principle, an all-controlling unknown and inscrutible " force hypermécanique." While chemical and physical forces are responsible for all phenomena in lifeless bodies, in living organisms this special force induces and rules all vital actions.

'Tater' ritalists, howerer, attempted no analysis of vital force; they employed it in a wholly mystical form as a convenient explanation of all sorts of vital phenomena. . . In place of a real explanation a simple phrase such as "vital force" was satisfactory, and signified a mystival force belonging to organisms only. Thus it was easy to "explain" the most complex vital phenomena.'

From this position, with its assumption of the superphysical character of response, it is clear that on the discovery of similar effects amongst inorganic sulbstances, the necessity of theoretically maintaining such dualism in Nature must immediately fall to the ground.

In the previous chapters I have shown that not the fact of response alone, but all those modifications in

1 Verworn, General Physiology, p. 18. 
response which occur under rarious conditions, take place in plants and metals just as in animal tissues. It may now be well to make a general survey of these phenomena, as exhibited in the three classes of substances.

We have seen that the wave of molecular disturbance in a living animal tissue under stimulus is accompanied by a wave of electrical disturbance; that in certain types of tissue the stimulated is relatively positive to the less disturbed, while in other's it is the reverse ; that it is essential to the obtaining of electric response to have the contacts leading to the galvanometer mequally affected by excitation ; and finally that this is accomplished either (1) by 'injuring' one contact, so that the excitation produced there would be relatively feeble, or (2) by introlucing a perfect blork between the two contacts, so that the excitation reaches one and not the other.

Further, it has been shown that this characteristic of exhibiting electrical response under stimulus is not confined to animal, but extends also to regetable tissues. In these the same electrical rariations as in nerve and muscle were obtained, by using the method of injury, or that of the block.

Passing to inorganic sulstances, and using similar experimental arrangements, we have found the same electrical responses evoked in metals under stimulus.

Negative variation. - In all cases, animal, regetal)le, and metal, we may obtain response by the method of negative variation, so called, by reducing the excitability of one contact by physical or chemical means. Stimulus causes a transient diminution of the existing current, 
the variation depending on the intensity of the stimulus (figs. 4, 7, 54).

Relation between stimulus and response.-In all three classes we have found that the intensity of response increases with increasing stimulus. At very high intensities of stimulus, however, there is a tendency of the response to rearch a limit (figs. 30, 32, 84). The law that is known as Weber-Fechner's shows a similar characteristic in the relation between stimulus and sensation. And if sensation be a measure of physiological effect we can understand this correspondence

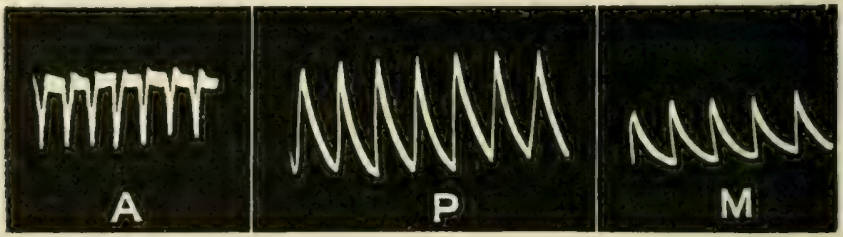

Fig. 112.--Uniforu Responses in (A) Nerve, (P) Plant, and (M) Metal

The normal response in nerve is represented 'down.' In this and following figures, (A) is the record of responses in animal, (P) in plant, and (MI) in metal.

of the physiological and sensation curves. We now see further that the physiological effects themselves are ultimately reducible to simple physical phenomena.

Effects of superposition.-In all three types, ineffective stimuli become effective hy superposition.

Again, rapidly succeeding stimuli produce a maximum effect, kept balanced by a force of restitution, and continuation of stimulus produces no further eflect, in the three cases alike (figs. 17, 18, 86).

Uniform responses.-In the responses of animal, vegetable, and metal alike we meet with a type where the responses are uniform (fig. 112). 
Fatigue.-There is, again, another type where fatigue is exhibited.

The explanation hitherto given of fatigue in animal tissues - that it is due to dissimilation or breakdown of tissue, complicated by the presence of fatigue-products, while recovery is due to assimilation, for which material is brought by the blood-supply-has long been seen to be inadequate, since the restorative effect succeeds a short period of rest even in excised bloodless muscle. But that the phenomena of fatigue and recovery

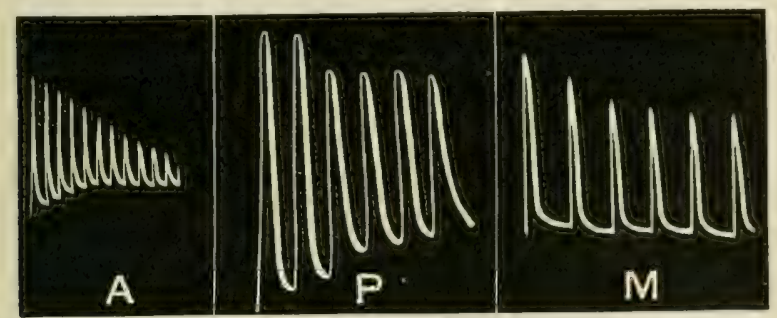

Fig. 113.-Fatigue (A) in Muscle, (P) in Plant, (M) in Metal

were not primarily dependent on dissimilation or assimilation becomes self-evident when we find exactly similan effects produced not only in plants, but also in metals (fig. 113). It has been shown, on the other hand, that these effects are primarily dne to cumulative residual strains, and that a brief period of rest, by removing the overstrain, removes also the sign of fatigue.

Staircase effect.- The theory of dissimilation due to stimulus reducing the functional activity below par, and thus causing fatigue, is directly negatived by what is known as the 'staircase' effect, where successive equal stimuli produce increasing response. We saw an 
I86 RESPONSE IN THE LIVING AND NON-LIVING

exactly similar phenomenon in plants and metals, where successive responses to equal stimuli exhibited an

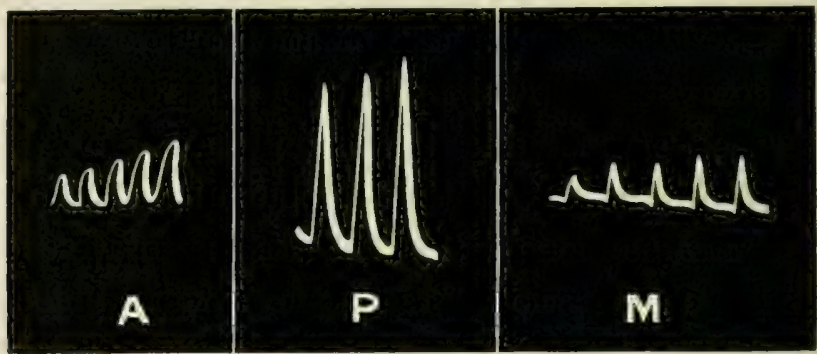

Fig. 114.--STtamcase' in Muscle, Plant, and Metal

increase, apparently by a gradual removal of molecular sluggishness (fig. 114).

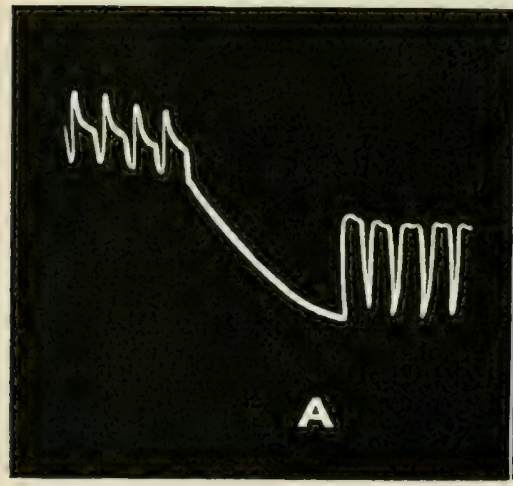

Before

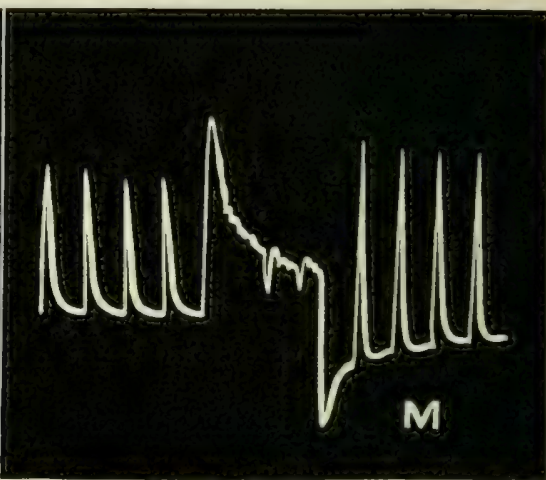

Fig. 115.--Increasen Response after Continuous Stmolation in Nerve AND METAL

The normal response in animal tissue is represented 'down,' in metal ' up.'

Increased response after continuous stimulation.An effect somewhat similar, that is to say, an in rreased response, due to increased molecular mobility, 
is also shown sometimes after continuous stimulation, not only in animal tissues, but also in metals (fig. 115).

Modified response.-In the case of nerve we saw that the normal response, which is negative, sometimes becomes reversed in sign, i.e. positive, when the specimen is stale. In retina again the normal positive response is converted into negative under the same conditions. Similarly, we found that a plant when withering often shows a positive instead of the

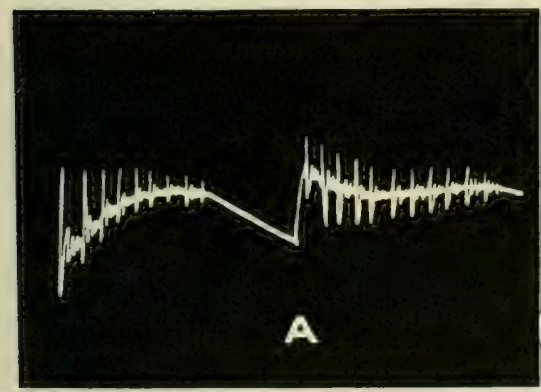

Before

After

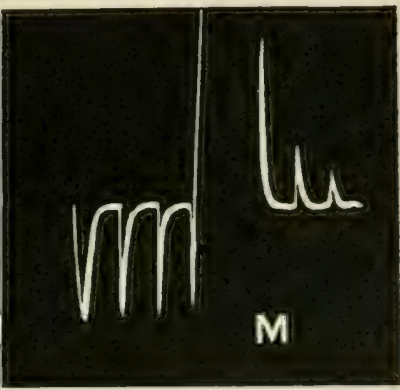

Before

After

Frg. 116.-Modified Abxorial Response iN (A) Nerve and (M) Metal converted into Normal, after Continuods Stimulation

(A) is the record for nerve (recording galvanometer not being dead-beat shows after-oscillation); the abnormal ' up ' is converted into normal 'down' after continuous stimulation. (MI) is the record for metal, the abnormal 'down' being converted into normal ' up' after like stimulation.

usual negative response (fig. 2S). On nearing the cleathpoint, also by subjection to extremes of temperature, the same reversal of response is occasionally observed in plants. This reversal of response due to peculiar molecular modification was also seen in metals.

But these modified responses usually become normal when the specimen is subjected to stimulation either strong or long continued (fig. 116). 
Diphasic variation. $-\Lambda$ diphasic variation is observed in nerve, if the wave of molecular disturbance does not reach the two contacts at the same moment, or if the rate of excitation is not the same at the two points. A similar diphasic variation is also observed in the responses of plants and metals (figs. 26, 68).

Effect of temperature.-In animal tissues response becomes feeble at low temperatures. At an optimum temperature it reaches its greatest amplitucte, and, again, beyond a maximum temperature it is very much reduced.

We have observed the same phenomena in plants. In metals too, at high temperatures, the response is very much diminished (figs. 38, 65).

Effect of chemical reagents.-Finally, just as the response of animal tissue is exalted by stimulants, lowered by depressants, and abolished by poisons, so also we have found the response in plants and metals undergoing similar exaltation, depression, or abolition.

We have seen that the criterion by which vital response is differentiated is its abolition by the action of certain reagents_the so-called poisons. We find, however, that 'poisons' also abolish the responses in plants and metals (fig. 117). Just. as animal tissues pass from a state of responsiveness while living to a state of irresponsiveness when killed by poisons, so also we find metals transformed from a responsive to an irresponsive condition by the action of similar "poisonnus' reagents.

The parallel is the more striking since it has long heen known with regard to animal tissues that the 
same drug, arlministered in large or small doses, might have opposite effects, and in preceding chapter's we have seen that the same statement holds good of plants and metals also.

Stimulus of light.--Eren the responses of such a highly specialised organ as the retina are strictly paralleled by inorganic responses. We have seen how the stimulus of light evokes in the artificial retina responses which coincirle in all their detail with those produced in the real retina. This was seen in ineffective

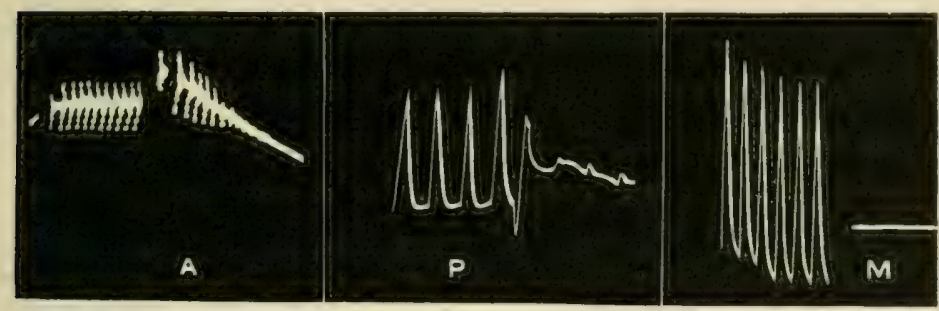

Before $\uparrow$ After Before $\uparrow$ After $\quad$ Before $\uparrow$ After

Fig. 117.-Abolition of Response in Nerve, Plant, and Metal by the Action of the saje 'Poison'

The first half in each set shows the normal response, the second half the abolition of response after the application of the reagent.

stimuli becoming effective after repetition, in the relation between stimulus and response, and in the effects produced by temperature ; also in the phenomenon of afteroscillation. These similarities went even further, the very abnormalities of retinal response finding their reflection in the inorganic.

Thus living response in all its diverse manifestations is found to be only a repetition of responses seen in the inorganic. There is in it no element of mystery or caprice, such as we must admit to be applied in the 
assmmption of a hypermerhanical vital forre, acting in rontradiction or defiance of those physical laws that govern the rorld of matter. Nowhere in the entire range of these response-phenomena-inclusive as that is of metals, plants, and animals-do we detect any breach of continuity. In the study of processes apparently so complex as those of irritability, we must, of course, expect to be confronted with many difficulties. But if these are to be overcome, they, like others, must be faced, and their investigation patiently pursued, without the postulation of special forces whose convenient property it is to meet all emergencies in virtue of their vagueness. If, at least, we are ever to understand the intricate mechanism of the animal machine, it will be granted that we must cease to evade the problems it presents by the use of mere phrases which really explain nothing.

We have seen that anongst the phenomena of response, there is no necessity for the assumption of vital force. They are, on the contrary, physicochemical phenomena, susceptible of a physical inquiry as definite as any other in inorganic regions.

Physiologists have taught us to read in the responsecurves a history of the influence of various external agencies and conditions on the phenomenon of life. By these means we are able to trace the gradual diminution of responsiveness by fatigue, by extremes of heat and cold, its exaltation by stimulants, the arrest of the lifeprocess by poison.

The investigations which have just been described 
may possibly carry us one step further, proving to us that these things are determined, not by the play of an unknowable and arbitrary vital force, but by the working of laws that know no change, acting equally and uniformly throughout the organic and the inorganic worlds. 



\section{INDEX}

Actron current in metal, 88

,$\quad$ in nerve, 8

" $\quad$ in plant, 19

After-images and their revival, 177

After-oscillation in photo-sensitive cell, 159, 163

Anæsthetics, effect on response in nerve, 72

$" \quad " \quad \quad$ in plant, 30, 73, 74, 75

Annealing, effect on response in metal, 101, 138

Binocular alternation of vision, 175

Block method, advantages of, 28, 77

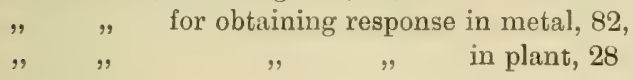

Chloral, effect on plant response, 75

Chloroform, effect on nerre response, 72

Compensator, 22

plant response, 74

Current of injury in nerve, 7

Curves, characteristics of response, 3

Death-pornt, determination of, in plants, 61,63

Depressants, effect on inorganic response, 142

Depression, response by relative, 87

Dewar on retinal current, 149

Diphasic variation in metal, 113, 114, 115, 116, 188
" $\quad$ in nerve, 188
" $\quad$ in plant, 46,188

Dose, effect on inorganic response, 89, 146, 189

" $\quad$ plant response, 79,189

ELectrical recorder, 11

Electrical response. See Response, electrical

Electric tapper, 24

Exaltation, response by relative, 89 
Fatigue, absence of, under certain conditions, in metal, 120

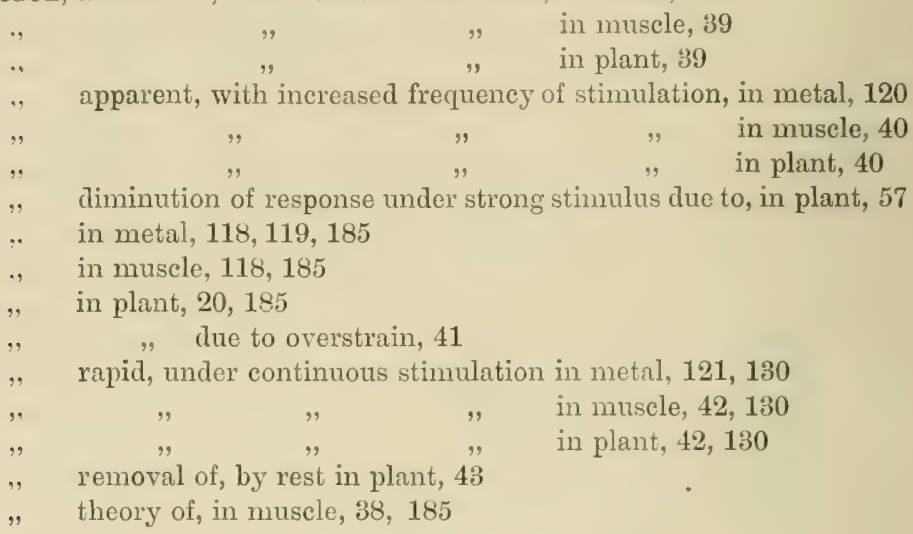

HoLMGREN on retinal current, 149

Hysteresis, 137

INJuRY, eurrent of, in nerve, 7

Inorganic response. See Metal, electrical response in

KuHNe on retinal current, 149

Kunkel on electrical changes by injury or flexion in plant, 14, 70

LiGнт, after-effect of short exposure to, on photo-sensitive cell, 171

\begin{tabular}{|c|c|}
\hline & on retina, 171 \\
\hline & $\begin{array}{r}\text { decline and reversal of response under continuous, in photo- } \\
\text { sensitive cell, } 166\end{array}$ \\
\hline "9 & $" \quad, \quad \begin{array}{cc}166 & \text { continuous, in retina }\end{array}$ \\
\hline & $\begin{array}{l}\text { effect of temperature on response of photo-sensitive cell produced } \\
\qquad \mathrm{by}, 158\end{array}$ \\
\hline , & " $\quad$ retinal response produced by, 158 \\
\hline , & $\begin{array}{c}\text { relation between intensity and response to, in photo-sensitive cell, } \\
161,162\end{array}$ \\
\hline " & " $\quad " \quad$ " in retina, 162 \\
\hline$"$ & response to, after-oscillation in photo-sensitive cell, 159,163 \\
\hline " & $\begin{array}{l}\text { effect of increasing length of exposure in photo-sensi- } \\
\text { tive cell, } 159\end{array}$ \\
\hline " & " in retina, 160 \\
\hline & $1,156,164 ; 166$ \\
\hline & in photo-sensitive cell, $152,153,154,155,157,165,166$ \\
\hline
\end{tabular}


McKendrick on retinal response, 149

Mechanical recorder, 3

", response, 1

" stimulus by electric tapper, 24

$" \quad$ " by spring-tapper, 23

" $\quad$, by vibrator, 24

$" \quad$ conditions of maintaining uniformity of, 26

" " means of graduating intensity of, 22, 24, 96

Metal, electric response in, abnormal, 125

\begin{tabular}{|c|c|c|}
\hline ", & " & abolition of, by 'poison,' 143 \\
\hline , & " & $\begin{array}{l}\text { additive effect of superposition of stimulus on, } \\
135\end{array}$ \\
\hline ", & .. & annealing, effect of, on, 101 \\
\hline ", & .. & by method of block, 82,92 \\
\hline & , & , negative variation, 87,183 \\
\hline & , & depressants, effect of, on, 142 \\
\hline ", & .. & diphasic, $113,114,115,116,188$ \\
\hline ", & ,. & $\begin{array}{l}\text { enhancement of, after continuous stimulation, } \\
127,128,186\end{array}$ \\
\hline " & .. & $\begin{array}{c}\text { fatigue, } 118,119,120,121,185 . \text { See also } \\
\text { Fatigue }\end{array}$ \\
\hline , & .. & $\begin{array}{l}\text { maximum effect due to superposition of } \\
\text { stimuli, } 136\end{array}$ \\
\hline " & , & modified, 129 \\
\hline , & ,. & $\begin{array}{l}\text { 'molecular arrest,' effect of, by 'poison' on, } \\
145\end{array}$ \\
\hline , & .. & molecular friction, effect of, on, 108, 109 \\
\hline " & .. & prolongation of recovery by overstrain, 106 \\
\hline , & .. & ",$\quad$ by 'poison,' 145 \\
\hline$"$ & .. & relation between, and stimulus, 134,135 \\
\hline , & ., & staircase effect, 122,186 \\
\hline " & " & stimulant, effect of, on, 141 \\
\hline , & .. & temperature, effect of, on, 111 \\
\hline & , & uniform, 102,184 \\
\hline
\end{tabular}

Minchin on photo-electric cell, 165

Molecular 'arrest' in metals by ' poison,' 145

$"$ friction, 108, 109

" model, 107

, voltaic cell, 99

Munck on electric response in sensitive plants, 14

Muscle, fatigue in, 38, 39, 40, 42. See also Fatigue

" prolongation of recorery by 'poison' in, 144

" relation between stimulus and response in, 52

" staircase effect in, 122

, stimulus, effect of superposition of, on, 36

Myograph, 2 
Negatrve variation, response by method of, in metal, 87, 183

Nerve, current of injury in, 7

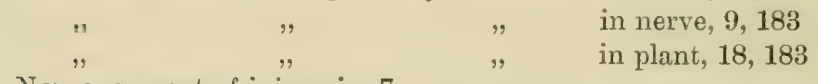

" injured and uninjured contacts corresponding to $\mathrm{Cu}$ and $\mathrm{Zn}$ in voltaic couple, 8

, response in, abnormal, when stale, 124, 187

" $\quad$ " abolition of, by 'poison,' 139,189

", anæesthetics, effect of, on, 72

, $\quad$ by method of negative variation, 9

, $\quad$ current of action of, 8

, " $\quad$ enhancement of, after continuous stimulation, 127

, " $\quad$, modified, 128

, $\quad$ " $\quad$ relation between, and stimulus, 52

, $\quad$ reversed when stale, 11

, $\quad$ uniform, 184

Nomenclature, anomalies of present, 9,85

Photographic recorder, 11, 22

Plant chamber, 64

" electrical response in, abnormal, when stale or dying, 48, 187

\begin{tabular}{|c|c|c|}
\hline ," & " & abolition of, by high temperature, 32,64 \\
\hline " & , & additive effect of stimulus on, 37 \\
\hline ", & ", & anæsthetics, effect of, on, $30,73,74,75$ \\
\hline ", & " & by method of block, 28 \\
\hline ," & ", & " of negative variation, 18,183 \\
\hline ," & $"$ & diphasic, 46 \\
\hline " & " & $\begin{array}{l}\text { fatigue, } 20,39,40,41,42,43,57,185 . \text { See also } \\
\text { Fatigue }\end{array}$ \\
\hline$"$ & " & physiological character of, 30 \\
\hline " & $"$ & 'poison,' effect of, on, $30,32,78,79$ \\
\hline ", & " & relation between, and stimulus, $52,53,54$ \\
\hline " & $"$ & staircase effect, 37,185 \\
\hline " & " & stimulus, effect of single, on, 35 \\
\hline ," & " & " effect of superposition of, on, 35 \\
\hline 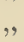 & $"$ & temperature, effect of, on, $32,59-69$ \\
\hline & $M$ & uniform, 36, 184 \\
\hline
\end{tabular}

Poison, effect of, on response in metal, 143, 189

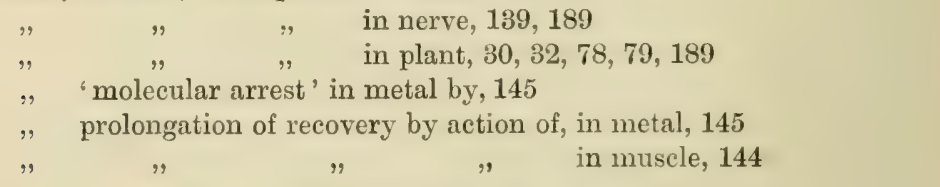

RECORD, simultaneous mechanical and electrical, of response, 13 Recorder, electrical, 11 
Recorder, mechanical, 3

photographic, 11, 22

" response, 19

Response-curve, characteristics of, 3

electrical, abnormal, in metal, 123, 125

\begin{tabular}{|c|c|c|}
\hline & $"$ & in stale nerve, 11,123 \\
\hline & " & in stale or dying plant, 48,187 \\
\hline & " & in stale retina, 11,164 \\
\hline & $"$ & $\begin{array}{l}\text { converted into normal after strong or con- } \\
\text { tinuous stimulation in metal, } 125,187\end{array}$ \\
\hline & $"$ & $\quad \quad \quad \quad \quad \quad$ in nerve, 124,187 \\
\hline & $"$ & $" \quad, \quad, \quad$ in plant, 48 \\
\hline & , & abolition of, by high temperature in plant, 32,64 \\
\hline & " & $" \quad$ by 'poison,' in metal, 143,189 \\
\hline & " &,$\quad$ in nerve, 139,189 \\
\hline & " & $" \quad, \quad$ in plant, $30,32,78,79,189$ \\
\hline & $"$ & additive effect of stimulus on, in metal, 135 \\
\hline & $"$ & $\quad \quad \quad \quad \quad$ on, in plant, 37 \\
\hline & " & anæsthetics, effect of, on, in nerve, 72 \\
\hline & " & $\Rightarrow \quad \quad \quad \quad$ in plant, $30,73,74,75$ \\
\hline & " & annealing, effect of, on, in metal, 101, 138 \\
\hline & " & by method of block, $28,82,92$ \\
\hline & " & by negative variation, $9,18,87,183$ \\
\hline & " & by relative depression, 87 \\
\hline & , & by relative exaltation, 89 \\
\hline t? & " & conditions for obtaining, $6,86,87$ \\
\hline , & $"$ & $\begin{array}{l}\text { continuous transformation from positive to negative } \\
\text { in metal, } 115\end{array}$ \\
\hline ", & " & $\begin{array}{l}\text { decline and reversal of, under continuous light in } \\
\text { photo-sensitive cell, } 166\end{array}$ \\
\hline " & ", & $\begin{array}{l}\text { decline and reversal of, under continuous light in } \\
\text { retina, } 166\end{array}$ \\
\hline , & $"$ & depressants, effect of, on inorganic, 142 \\
\hline ? & " & diminution of. See Fatigue \\
\hline$"$ & " & diphasic in metal, $113,114,115,116,188$ \\
\hline " & , & $" \quad$ in nerve, 188 \\
\hline " & $"$ & $" \quad$ in plant, 46,188 \\
\hline$"$ & $"$ & dose, effect of, on inorganic, 89, 146, 189 \\
\hline. & " & $\quad \quad \quad$ on, in plant, 79,189 \\
\hline " & 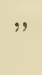 & $\begin{array}{l}\text { enhancement of, after continuous stimulation in } \\
\text { metal, } 127,128,186\end{array}$ \\
\hline ". & $"$ & $\begin{array}{l}\text { enhancement of, after continuous stimulation in } \\
\text { nerve, } 127,186\end{array}$ \\
\hline & $"$ & $\begin{array}{l}\text { maximum effect due to superposition of stimulus, } \\
35,136\end{array}$ \\
\hline & $"$ & measure of physiological activity, 13 \\
\hline
\end{tabular}


Response, electrical, molecular friction, effect of, on, 108, 109

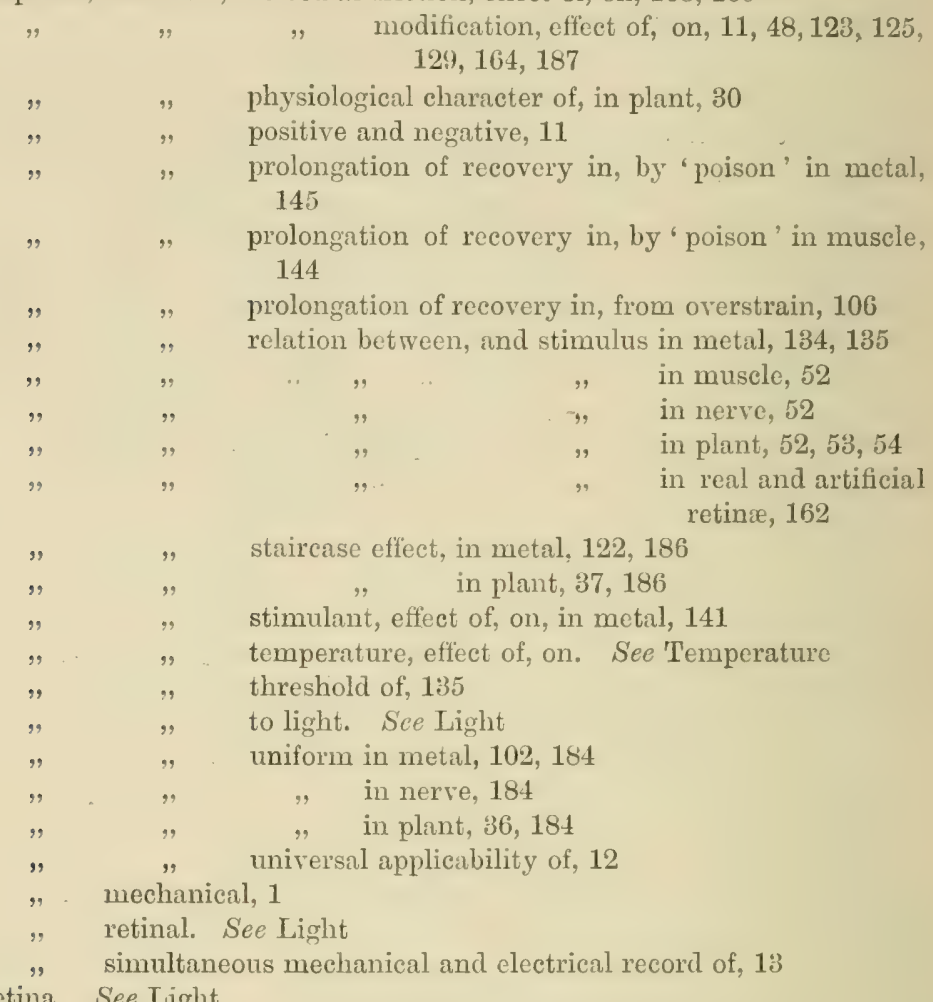

Retina. See Light

Sanderson, Burdon-, on electrical response in sensitive plants, 14 Spring-tapper, mechanical stimulus by, 23

Staircase effect in metal, 122, 186 in muscle, 122, 186

$$
\begin{aligned}
& . . \quad \text { in muscle, } 122,186 \\
& \text { in plant, } 37,186
\end{aligned}
$$

Steiner on retinal response, 149

Stimuli, maximum effect due to superposition of, in metal, 136

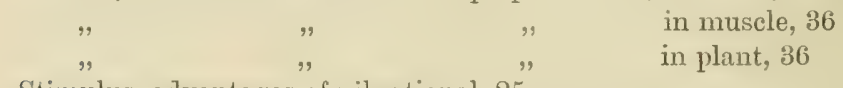

Stimulus, advantages of vibrational, 25

\begin{tabular}{|c|c|c|c|}
\hline " & " & " & in muscle, 52 \\
\hline " & , & , & in nerve, 52 \\
\hline , & , & , & in plant, $52,53,54$ \\
\hline ", & , & , & in real and artificial retinæ, 162 \\
\hline
\end{tabular}


Stimulus, effect of different kinds of, 2

, mechanical, by spring-tapper, 24

" $\quad$ conditions for maintaining uniformity of, 26

" $\quad$ means of graduating intensity of, 22,96

"ribrational, $24,25,26$

TeMPERATURE, death-points in plants, 61,63

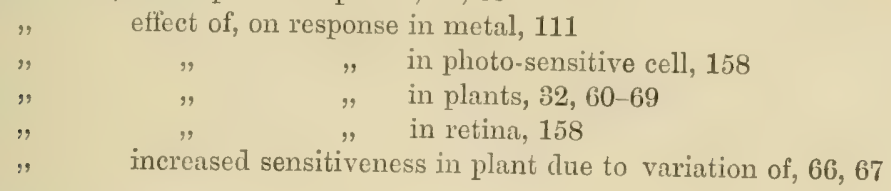

VibrationaL stimulus, 24, 25. 26

Vision, binocular alternation of, 175

$"$ effect of various conditions on the period of binocular alternation of, 177

Visual images, revival of, 177

" impression, unconscious, 178

" impulse, chemical theory of, 148

" . $\quad$ electrical theory of, 149

" phantoms, 179

" recurrence, 174

Vital force, 13

Vitalism, 182

Waller on enhancement of nerve-responseafter continuous stimulation, 127

" on relation between stimulus and response in muscle, nerve, and retina, 52, 162

" on retinal response, $150,156,165$

$" \quad$ on reversal of response in stale nerve and retina, 11, 124, 164

$" \quad$ on transformation from abnormal to normal response in nerve after continuous stimulation, 124 


\section{A SELECT LIST OF BOOKS}

IN

\section{NATURAL AND PHYSICAL SCIENCE MATHEMATICS AND TECHNOLOGY \\ PUBLISHED BY}

Messrs. LONGMANS, GREEN, \& CO.

LONDON : 39 PATERNOSTER ROW, E.C.

NEW YORK : 9I \& 93 FIFTH AVENUE,

BOMBAY : 32 HORNBY ROAD.

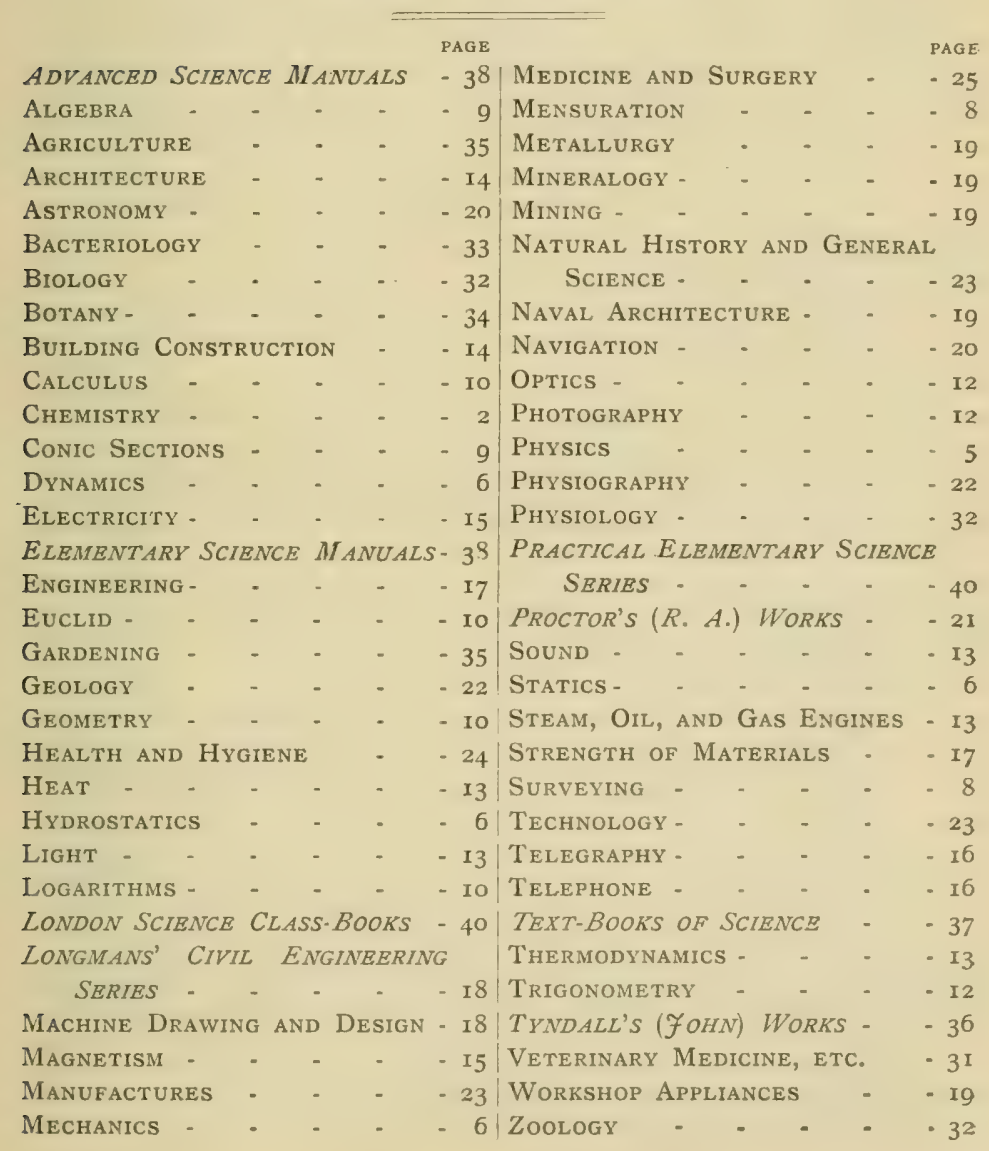




\section{CHEMISTRY.}

ARRHENIUS.-A TEXT-BOOK OF ELECTROCHEMISTRY. By Svante ARrhenius, Professor at the University of Stockholm. Translated from the German Edition by JOHN MCCRAE, Ph.D. With $5^{8}$ Illustrations. $8 \mathrm{vo}, 9$ s. $6 d$. net.

CROOKES.-SELECT METHODS IN CHEMICAL ANALYSIS, chiefly Inorganic. By Sir WILLIAM CrookES, F.R.S., etc. Third Edition, Rewritten and Enlarged. With 67 Woodcuts. 8vo., 2 Is, net.

FUR NEAUX.-ELEMENTARY CHEMISTRY, Inorganic and Organic. By W. FURneAux, F.R.G.S., Lecturer on Chemistry, London School Board. With 65 Illustrations and 155 Experiments. Crown 8vo, , 2s, 6d.

GARRETT AND HARDEN.-AN FLEMENTARY COURSE OF PRACTICAL ORGANIC CHEMISTRY. By F. C. GARRETT, M.Sc. (Vict. et Dunelm.), Assistant Lecturer and Demonstrator in Chemistry, the Durham College of Science, Newcastle-on-Tyne; and ARTHUR HARDEN, M.Sc. (Vict.), Ph.D., Assistant Lecturer and Demonstrator in Chemistry, the Owens College, Manchester. With I4 Illustrations. Crown 8vo., 2 s.

JAGO.-Works by W. JAGO, F.C.S., F.I.C.

INORGANIC CHEMISTRY, THEORETICAL AND PRACTICAL. With an Introduction to the Principles of Chemical Analysis, Inorganic and Organic. With $6_{3}$ Woodcuts and numerous Questions and Exercises. Fcp, 8vo, 2s, 6d.

AN INTRODUCTION TO PRACTICAL INORGANIC CHEMISTRY. Crown 8vo, , $\mathbf{I} s, 6 d$.

INORGANIC CHEMISTRY, THEORETICAL AND PRACTICAL. A Manual for Students in Advanced Classes of the Science and Art Department. With Plate of Spectra and 78 Woodcuts. Crown 8 vo., 4 s. $6 d$.

KLÖCKER. - FERMENTATION ORGANISMS : a Laboratory Handbook. By AlB. KLð̌cker. Translated by G. E. Allan, B.Sc., and J. H. MILLAR, F.I.C. With I46 Illustrations in the text. 8vo., I2s. net.

MELLOR.-HIGHER MATHEMATICS FOR STUDENTS OF CHEMISTRY AND PHYSICS. With Special Reference to Practical Work. By J. W. MELLOR, D.Sc., late Senior Scholar, and I85I Exhibition Scholar, New Zealand University; Research Fellow, the Owens College, Manchester. With 142 Diagrams. 8vo, 12s. 6 \%. net.

MENDELEEEF.-THE PRINCIPLES OF CHEMISTRY. By D. MENDELÉEFF. Translated from the Russian (Sixth Edition) by GeORGE Kamensky, A.R.S.M., of the Imperial Mint, St. Petersburg; and Edited by T. A. LAwson, B.Sc., Ph.D., Fellow of the Institute of Chemistry. With 96 Diagrams and Illustrations. 2 vols. 8 vo., 36 s.

MEYER.-OUTLINES OF THEORETICAL CHEMISTRY. By Lothar MEyer, Professor of Chemistry in the University of Tübingen, Translated by Professors P. Phillips Beoson, D.Sc., and W. Carleton WiLliams, B.Sc. 8vo., 9 s.

MILLER.-INTRODUCTION TO THE STUDY OF INORGANIC CHEMISTRY. By W. ALlen MrLler, M.D., Ll.D. With 7I Illustrations. Fcp. 8vo., 3s. $6 d$. 


\section{CHEMISTRY-Continued.}

MUIR.-A COURSE OF PRACTICAL CHEMISTRY. By M. M. P. MUrR, M.A., Fellow and Prælector in Chemistry of Gonville and Caius College, Cambridge. (3 Parts.)

Part I. Elementary. Crown 8vo., 4s. $6 d$.

Part II. Intermediate. Crown 8vo., $4 s .6 d$.

Part III.

[In preparation.

NEWTH.-Works by G. S. NEWTH, F.I.C., F.C.S., Demonstrator in the Royal College of Science, London.

CHEMICAL LECTURE EXPERIMENTS. With 230

Illustrations. Crown 8vo., 6s.

CHEMICAL ANALYSIS, QUANTITATIVE ANI) QUALITATIVE. With roo Illustrations. Crown 8vo., 6s. 6 .

A TEXT-BOOK OF INORGANIC CHEMISTRY. With I 55 Illustrations. Crown 8vo., 6s, $6 d$.

ELEMENTARY PRACTICAL CHEMISTRY. With Io8 Illustrations and 254 Experiments, Crown 8vo., 2s. $6 d$.

OSTWALD.-SOLUTIONS. By W. Ostwald, Professor of Chemistry in the University of Leipzig. Being the Fourth Book, with some additions, of the Second Edition of Oswald's 'Lebrbuch der allgemeinen Chemie'. Translated by M. M. PATTison Muir, Fellow and Prælector"in Chemistry of Gonville and Caius College, Cambridge. 8vo., ros. $6 d^{\text {. }}$

PERKIN.-QUALITATIVE CHEMICAL ANALYSIS (ORGANIC AND INORGANIC). By F. Mollwo PERkin, Ph.D., Head of the Chemistry Department, Borough Polytechnic Institute, London. With 9 Illustrations and Spectrum Plate. 8vo., 3s. $6 d$.

PLIMMER. - THE CHEMICAL CHANGES AND PRODUCTS RESULTING FROM FERMENTATIONS. By R. H.|ADER. PlimMer. 8vo, 6s, net.

REYNOLDS.-EXPERIMENTAL CHEMISTRY FOR JUNIOR STUDENTS. By J. EMERSON REYNoldS, M.D., F.R.S., Professor of Chemistry, University of Dublin. Fcp. 8vo., with numerous Woodcuts.

Part I. Introductory. Fcp. 8vo, is. $6 d$.

Part II. Non-Metals, with an Appendix on Systematic Testing for Acids. Fcp. 8vo., 2s, $6 d$.

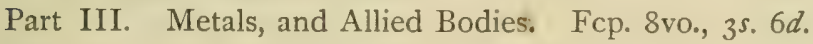

Part IV. Carbon Compounds. Fcp. 8vo., 4s.

SHENSTONE.-Works by IV. A. SHENSTONE, F.R.S., Lecturer on Chemistry in Clifton College.

THE METHODS OF GLASS-BI.OWING AND OF WORKING SILICA IN THE OXY-GAS FLAME. For the Use of Physical and Chemical Students, With 43 Illustrations. Crown 8vo., 2s, 6d.

A PRACTICAL INTRODUCTION TO CHEMISTRY. Intended to give a Practical acquaintance with the Elementary Facts and Principles of Chemistry. With 25 Illustrations. Crown 8vo., $2 s$. 


\section{CHEMISTRY-Contimer?.}

SMITH AND HALL.-THE TEACHING OF CHEMISTRY AND PHYSICS IN THE SECONDARY SCHOOL. By ALEXANDER Smith, B.Sc., Ph.D., Associate Professor of Chemistry in the University of Chicago, and Edwin H. Hall, Ph. D., Professor of Physics in Harvard University. With 2 r Woodcuts, Bibliographies, and Index. Crown 8vo., 6s, net.

THORNTON AND PEARSON.-NOTES ON VOLUMETRIC ANALYSiS. By Arthur Thornton, M.A., and Marchant Pearson, B.A., Assistant Science Master, Bradford Grammar School, Medium 8vo., 2s.

THORPE.—Works by T. E. THORPE, C.B., D.Sc. (Vict.), Ph.D., F.R.S., Principal of the Government Laboratory, London. Assisted by Eminent Contributors.

A DICTIONARY OF APPLIED CHEMISTRY. 3 vols. 8vo. Vols. I. and II., 42s, each. Vol. III., 63s.

QUANTITATIVE CHEMICAL ANALYSIS. With 88 Woodcuts. Fcp. 8vo., 4s. $6 d$.

THORPE AND MUIR.-QUALITATIVE CHEMICAL ANALYSIS AND LABORATORY PRACTICE. By T. E. THORPE, C. B., Ph.D., D.Sc., F.R.S., and M. M. PATTison MUiR, M.A. With Plate of Spectra and 57 Illustrations. Fcp. 8vo., 3s. $6 d$.

TILDEN.-Works by WILLIAM A. TILDEN, D.Sc. London, F.R.S., Professor of Chemistry in the Royal College of Science, South Kensington.

A SHORT HISTORY OF THE PROGRESS OF SCIENTIFIC CHEMISTRY IN OUR OWN TIMES. Crown 8vo., 5s, net.

INTRODUCTION TO THE STUDY OF CHEMICAL PHILOSOPHY. The Principles of Theoretical and Systematic Chemistry. With 5 Illustrations. Fep, 8vo., 5s. With ANSWERS to Problems. Fep. 8vo., 5s. $6 d$.

PRACTICAL CHEMISTRY. The principles of Qualitative Analysis. Fcp. 8vo., Is, $6 d$.

WATTS DICTIONARY OF CHEMISTRY. Revised and entirely Rewritten by H. Forster MORLEY, M.A., D.Sc., Fellow of, and lately Assistant Professor of Chemistry in, University College, London; and M. M. PATtison Muir, M.A., F.R.S.E., Fellow, and Prælector in Chemistry, of Gonville and Caius College, Cambridge. Assisted by Eminent Contributors. 4 vols. 8 vo., $£ 5$ net.

IIHITELEY.-Works by R. LLOYD WHITELEY, F.I.C., Principal of the Municipal Science School, West Bromwich.

CHEMICAL CALCULATIONS. With Explanatory Notes, Problems and Answers, specially adapted for use in Colleges and Science Schools. With a Preface by Professor F. Clowes, D.Sc. (Lond.), F.I.C. Crown 8vo, 2 s.

ORGANIC CHEMISTRY: the Fatty Compounds. With 45 Illustrations. Crown 8vo., 3s. $6 d$. 


\section{PHYSICS, ETC.}

\section{BIDGOOD.-ELEMENTARY PHYSICS AND CHEMISTRY} FOR THE USE OF SCHOOLS. (In Three Books.) By JOHN BIDGOOD, B.Sc., Headmaster of the Gateshead School of Science.

Book I. Elementary Physics. IVith 120 Illustrations. Crown 8 vo., $\mathbf{I s}, 6 d$.

Book II. Physics and Chemistry. With ${ }_{22}$ Illustrations. Crown 8vo., Is. $6 d$.

BOSE.-RESPONSE IN THE LIVING AND NON-LIVING.

B By Jagadis Chunder Bose, M.A. (Cantab.), D.Sc. (Lond.), Professor, Presidency College, Calcutta. With $\mathrm{II} 7$ Illustrations. 8vo., Ios. $6 d$.

$i_{*}^{*}$ * This volume describes experimental investigations on animal; vegetable and inorganic substances regarding their response to stimulus. These researches show that the effects of fatigue, stimulants, depressants and poisons are alike in the organic and inorganic, and demonstrate that the response phenomena in the 'living' have been foreshadowed in the "non-living'.

GANOT.-Works by PROFESSOR GANO'T. Translated and Edited by E. Atkinson, Ph.D., F.C.S., and A. W. Reinold, M.A., F.R.S.

ELEMENTARY TREATISE ON PHYSICS, Experimental and Applied. With 9 Coloured Plates and Maps, and roł8 Woodcuts, and Appendix of Problems and Examples with Answers. Crown 8vo., I5s.

NATURAL PHILOSOPHY FOR GENERAL READERS AND YOUNG PEOPLE. With 7 Plates, 632 Woodcuts, and an Appendix of Questions. Crown 8vo., 7s. 6d.

GLAZEBROOK AND SHAW.-PRACTICAL PHYSICS. By R. T. GLazebrook, M.A., F.R.S., and W. N. Shaw, M.A. With I34 Illustrations. Fcp. 8vo., 7s. 6d.

GUTHRIE.-MOLECULAR PHYSICS AND SOUND.

By

F. Guthrie, Ph. D. With gi Diagrams. Fcp. 8vo., Is. 6d.

HELMHOLTZ.-POPULAR LFCTURES ON SCIENTIFIC SUBJEC'TS. By HeRMANN yon HELMHOLTZ. Translated by E. ATKinson, Ph.D., F.C.S., formerly Professor of Experimental Science, Staft College. Witb 68 Illustrations. 2 vols., crown 8 vo., 3 s. 6 . each.

HENDERSON.-ELEMENTARY PHYSICS. By JoHN Henderson, D.Sc. (Edin.), A.I.E.E., Physics Department, Borough Road Polytechnic. Crown 8vo, $2 s, 6 d$.

MACLEAN.EXERCISES IN NATURAL PHILOSOPHY. By Magnus MaClean, D.Sc., Professor of Electrical Engineering at the Glasgow and West of Scotland Technical College. Crown 8vo., 4 s. $6 d$.

MEYER.-THE KINETIC THEORY OF GASES. Elementary Treatise, with Mathematical Appendices. By Dr. Oskar EMIL Meyer, Professor of Physics at the University of Breslau. Second Revised Edition. Translated by RoBERT E. BAYNES, M.A., Student of Christ Church, Oxford, and Dr. Lee's Reader in Physics. 8vo., I5s. net.

$V A N$ 'THOFF.-THE ARRANGEMENT OF ATOMS IN SPACE. By J. H. VAN T'HOFF. Second, Revised, and Enlarged Edition. With a Preface by Johannes Wislicenus, Professor of Chemistry at the University of Leipzig; and an Appendix 'Stereo-chemistry among Inorganic Substances,' by ALFRED WERNER, Professor of Chemistry at the University of Zürich. Translated and Edited by ARNOLd ElloART. Crown 8vo., 6s. $6 d$. 


\section{PHYSICS, ETC.-Continued.}

WATSON.-Works by W. WATSON, A.R.C.S., F.R.S., D.Sc., Assistant Professor of Physics at the Royal College of Science, London.

ELEMENTARY PRACTICAL PHYSICS: a Laboratory Manual for Use in Organised Science Schools. With I2o Illustrations and 193 Exercises. Crown 8vo., 2s. 6d.

A TEXT-BOOK OF PHYSICS. With 568 Diagrams and Illustrations, and a Collection of Examples and Questions with Answers. Large crown 8vo., ros. $6 d$.

WORTHINGTON.-A FIRST COURSE OF PHYSICAL LABORATORY PRACTICE. Containing 264 Experiments. By A. M. Worthington, M.A., F.R.S. With Illustrations. Crown 8vo., 4 s. $6 d$.

WRIGHT.-ELEMENTARY PHYSICS. By MARK R. WRIGHT, M.A., Professor of Normal Education, Durham College of Science. With 242 Illustrations. Crown 8 vo., 2s. $6 d$.

\section{MECHANICS, DYNAMICS, STATICS, HYDRO- STATICS, ETC.}

BALL.-A CLASS-BOOK OF MECHANICS. By Sir R. S. BALL, LL.D. 89 Diagrams. Fcp. 8vo., 1s. $6 d$.

GOODEVE.-Works by T. M. GOODEVE, M.A., formerly Professor of Mechanics at the Normal School of Science, and the Royal School of Mines.

THE ELEMENTS OF MECHANISM. With 357 Illustrations. Crown 8vo., 6s.

PRINCIPLES OF MECHANICS. With 253 Illustrations and numerous Examples. Crown 8vo., 6s.

A MANUAL OF MECHANICS: an Elementary Text-Book for Students of Applied Mechanics. With I38 Illustrations and Diagrams, and 188 Examples taken from the Science Department Examination Papers, with Answers. Fcp. 8vo., $2 s, 6 d$.

GOODMAN.-MECHANICS APPLIED TO ENGINEERING. By JoHn Goodman, Wh.Sch., A.M.I.C.E., M. I. M.E., Professor of Engineering in the Yorkshire College, Leeds (Victoria University). W1th 620 Illustrations and numerous examples. Crown 8vo., $7 s .6 d$. net.

GRIEVE.-LESSONS IN ELEMENTARY MECHANICS.

By W. H. GRIEVE, late Engineer, R.N., Science Demonstrator for the London School Board, etc.

x. With 165 Illustrations and a large number of Examples. Fcp. 8vo., Is. $6 d$.

Stage 2. With 122 Illustrations. Fcp. 8vo., Is, $6 d$.

Stage 3. With 103 Illustrations. Fcp. 8vo., is. $6 d$. 
Scientific Works published by Longmans, Green, \& Co.

MECHANICS, DYNAMICS, STATICS, HYDROSTATICS, ETC.continued.

MAGNUS.-Works by SIR PHILIP MAGNUS, B.Sc., B.A.

LESSONS IN ELEMENTARY MECHANICS. Introductory to the study of Physical Science. Designed for the Use of Schools, and of Candidates for the London Matriculation and other Examinations. With numerous Exercises, Examples, Examination Questions, and Solutions, etc., from 1870-1895. With Answers, and I3I Woodcuts. Fcp. 8vo., 35. 6d.

Key for the use of Teachers only, price 5 s. $3 \frac{1}{2} d$.

HYDROSTATICS AND PNEUMATICS. Fcp. 8vo., 1s. 6d.; or, with Answers, 2s. The Worked Solutions of the Problems, 2s.

PULLEN.-MECHANICS: Theoretical, Applied, and Experimental. By W. W. F. Pullen, Wh.Sch., M.I.M.E., A.M.I.C.E. With 318 Diagrams and numerous Examples. Crown 8vo., 4s. 6d.

ROBINSON.-ELEMENTS OF DYNAMICS (Kinetics and Statics). With numerous Exercises. A Text-book for Junior Students. By the Rev. J. L. Robinson, M.A. Crown 8vo., $6 s$.

SMITH.-Works by J. HAMBLIN SMITH, M.A.

ELEMENTARY STATICS. Crown 8vo, $3^{\text {s. }}$

ELEMENTARY HYDROSTATICS. Crown 8vo., 3 s.

KEY TO STATICS AND HYDROSTATICS. Crown 8vo., 6s.

TARLETON-AN INTRODUCTION TO THE MATHEMATICAL THEORY OF ATTRACTION. By FRANCIS A. TARLETON, LL.D., Sc.D., Fellow of Trinity College, and Professor of Natural Philosophy in the University of Dublin. Crown 8vo., ros. 6\%.

TAYLOR.-Works by J. E. TAYLOR, M.A., B.Sc. (Lond.).

THEORETICAL MECHANICS, including Hydrostatics and Pneumatics. W'ith 175 Diagrams and Illustrations, and 522 Examination Questions and Answers. Crown 8vo., 2s, 6d.

THEORETICAL MECHANICS-SOLIDS. With 163 Illustrations, I20 Worked Examples and over 500 Examples from Examination Papers, etc. Crown 8vo., 2s, 6d.

THEORETICAL MECHANICS.-FLUIIS. With I2 2 Illustrations, numerous Worked Examples, and about 500 Examples from Ex. amination Papers, etc. Crown 8vo., 2s, $6 d$.

THORNTON.-THEORETICAL MECHANICS-SOLIDS. Including Kinematics, Statics and Kinetics. By ARTHUR THORNTON, M.A., F.R.A.S. With 200 Illustrations, I30 Worked Examples, and over 900 Examples from Examination Papers, etc. Crown 8vo., 4s. 6d. 
Scientific Works published by Longmans, Green, \& Co.

\section{MECHANICS, DYNAMICS, STATICS, HYDROSTATICS, ETC.- continued.}

TWISDEN.-Works by the Rev. JOHN F. TWISDEN, M.A.

PRACTICAL MECHANICS; an Elementary Introduction to their Study. With 855 Exercises, and 184 Figures and Diagrams. Crown 8 vo., Ios. $6 d$.

THEORETICAL MECHANICS. With 172 Examples, numerous Exercises, and $\mathbf{5} 54$ Diagrams. Crown 8vo., 8s, 6d.

WILLIAMSON.-INTRODUCTION TO THE MATHEMATICAL THEORY OF THE STRESS AND STRAIN OF ELASTIC SOLIDS. By Benjamin Williamson, D.Sc., F.R.S. Crown 8vo., 5 s.

WILLIAMSON AND TARLETON.-AN ELEMENTARY TREATISE ON DYNAMICS. Containing Applications to Thermodynamics, with numerous Examples. By BenJAMin WILLIAMSON, D.Sc., F. R.S., and FRANCIS A. TARLETON, LL.D. Crown 8vo., ros. $6 d$.

WORTHINGTON.-DYNAMICS OF ROTATION: an Elementary Introduction to Rigid Dynamics. By A. M. WorTHINGTON, M.A., F.R.S. Crown 8vo., 4s. $6 d$.

\section{MENSURATION, SURVEYING, ETC.}

$B R A B A N T$.-THE ELEMENTS OF PLANE AND SOLID MENSURATION. With Copious Examples and Answers. By F. G. BRABANT, M.A. Crown 8vo., 3s. $6 d$.

GRIBBLE.-PRELIMINARY SURVEY AND ESTIMATES. By Theodore Graham Gribble, Civil Engineer. Including Elementary Astronomy, Route Surveying, Tacheometry, Curve Ranging, Graphic Mensuration, Estimates, Hydrography and Instruments. With I33 Illustrations, Quantity Diagrams, and a Manual of the Slide-Rule. Fcp. 8vo., 7s. 6d.

LODGE.-MENSURATION FOR SENIOR STUDENTS. By ALFRED LODGE, M.A., late Fereday Fellow of St. John's College, Oxford; Professor of Pure Mathematics at the Royal Indian Engineering College, Cooper's Hill. With Answers. Crown 8vo., 4s, 6d.

LUPTON.-A PRACTICAL TREATISE ON MINE SURVEYING. By ARNold Lupton, Mining Engineer, Certificated Colliery Manager, Surveyor, Member of the Institution of Civil Engineers, etc. With 216 Illustrations. Medium 8 vo., I2s, net.

NESBIT.-Works by A. !NESBIT.

PRACTICAL IIENSURATION. Illustrated by 700 Practical Examples and 700 Woodcuts. r2mo., 3s. 6d. KEY, 5 .

PRACTICAL LAND-SURVEYING, for the Use of Schools and Private Students. Edited by W. BURNESs, F.R.A.S. With I4 Plates, $22 \mathrm{~T}$ Figures, and a Field-Book. 8vo., I2s.

SMITH.-CIRCULAR SLIDE RULE. By G. L. Smith. Fcp. 8vo., Is, net. 


\section{ALGEBRA, ETC.}

* * For other Books, see Longmans \& Co.'s Catalogue of Educational and School Books. ANNALS OF MATHEMATICS. (PUBLISHED UNDER THE AUSPICES OF HARVARD UNIVERSITY.) Issued Quarterly. 4to., 2s, net.

BURNSIDE AND PANTON.-Works by WILLIAM SNOW BURNSIDE, M.A., Fellow of Trinity College, Dublin ; and ARTHUR WIILIAM PANTON, M.A., Fellow and Tutor of Trinity College, Dublin.

THE THEORY OF EQUATIONS. With an Introduction to the Theory of Binary Algebraic Forms. 2 vols. 8vo., 9s. $6 d$. each.

AN INTRODUCTION TO DETERMINANTS: being a Chapter from the Theory of Equations (being the First Chapter of the Second Volume of 'The Theory of Equations'). 8vo, sewed, $25.6 \mathrm{~d}$.

CRACKNELL.-PRACTICAL MATHEMATICS. By A. G. CR.ACKNelL, M.A., B.Sc., Sixth Wrangler, etc. With Answers to the Examples. Crown 8vo., 3s. $6 d$.

GRIFFIN.-Works by Rev. WIILIAM NATHANIEL GRIFFIN,

B.D., sometime Fellow of St. John's College, Cambridge.

THE ELEMENTS OF ALGFBRA INI) TRIGONONETRY. Fcp, 8vo., 3s. $6 d$.

NOTES ON THE ELEMENTS OF ALGEBRA AND TRIGONOMETRY. With Solutions of the more Difficult Questions.

Fcp. 8vo., 3s. 6d.

MELLOR.-HIGHER MATHEMATICS FOR STUDENTS OF CHEMISTRY AND PHYSICS. With special reference to Practical Work. By J. W. MELlor, D.Sc., Research Fellow, The Owens College, Manchester. With 142 Diagrams. 8vo., 12s. 6d. net.

WELSFORD AND MAYO-ELEMENTARY ALGEBRA. By J. W. WelsFord, M.A., formerly Fellow of Gonville and Caius College, Cambridge, and C. H. P. MAYO, M.A., formerly Scholar of St. Peter's College, Cambridge; Assistant Masters at Harrow School. Crown 8vo., 3s. 6d., or with Answers, 4s. 6d.

\section{CONIC SECTIONS, ETC.}

CASEY.-A TREATISE ON THE ANALYTICAI, GEOMETRY OF THE POINT, LINE, CIRCLE, AND CONIC SECTIONS. By JOHN CASEY, LL.D., F.R.S. Crown 8vo., I2s.

RICHARDSON.GEOMETRICAL, CONIC SECTIONS. By G. Richardson, M.A. Crown 8vo., 4s. $6 d$.

SALMON.-A TREATISE ON CONIC SECTIONS, containing an Account of some of the most Inportant Modern Algebraic and Geometric Methods. By G. Salmon, D.D., F.R.S. 8vo., I2s.

SMITH.-GEOMETRICAL CONIC SECTIONS. By J. Hamblin Smith, M.A. Crown 8vo., 3s. 6 . 


\section{THE CALCULUS, LOGARITHMS, ETC,}

BARKER. - GRAPHICAL CAICULUS. By ARTHur H. BARKER, B A., B.Sc. With an Introduction by JOHN GoOdMAN, A.M.I.C.E. With 6I Diagrams. Crown 8vo., 4s. $6 d$.

MURRAY. - AN INTRODUCTORY COURSE IN DIF. FERENTIAL EQUATIONS. By DANIEL ALEXANDER MURRAY, Ph.D. Crown 8vo., 4s. 6 d.

TATE.-PRINCIPLES OF THE DIFFERENTIAL AND INTEGRAL CALCULUS. Applied to the Solution of Useful Problems in Mathematics and Mechanics. By Thomas TATE. r2mo., 4 s. $6 d$.

TAYLOR.-Works by F. GLANVILLE TAYLOR.

AN INTRODUCTION TO THE DIFFERENTIAL AND INTEGRAL CALCULUS AND DIFFERENTIAL EQUATIONS. Crown 8vo., 9s.

AN INTRODUCTION TO THE PRACTICAL USE OF LOGARITHMS, WITH EXAMPLES IN MENSURATION. With Answers to Exercises. Crown 8vo., Is. $6 d$.

WILLIAMSON.-Works by BENJAMIN WILLIAMSON, D.Sc.

AN ELEMENTARY TREATISE ON THE DIFFERENTIAL CALCULUS; containing the Theory of ${ }_{\alpha i}^{1}$ Plane Curves with numerous Examples. Crown 8vo., Ios. $6 d$.

AN ELEMENTARY TREATISE ON THE INTEGRAL CALCULUS; containing Applications to Plane Curves and Surfaces, and also a Chapter on the Calculus of Variations, with numerous Examples. Crown 8vo., Ios. $6 d$.

\section{GEOMETRY AND EUCLID.}

* * For other Works, see Longmans \& Co.'s Catalogue of Educational and School Books. ALLMAN. - GREEK GEOMETRY FROM THALES TO EUClid. By G. J. Allman. 8vo, ros, 6d.

C ASEY.-Works by JOHN CASEY, LL.D., F.R.S.

THE ELEMENTS OF EUCLID, BOOKS I.-VI. and Propositions, I.-XXI. of Book XI., and an Appendix of the Cylinder, Sphere, Cone, etc. With Cnpious Annotations and numerous Exercises. Fcp. 8vo., 4s. 6d. KeY to Exercises. Fcp. 8vo., 6s,

A SEQUEL 'TO THE ELEMENTS OF EUCLID. Part I. Books I.-VI. With numerous Examples. Fcp. 8vo., 3s. $6 d$.

A TREATISE ON THE ANALYTICAL GEOMETRY OF THE POINT, LINE, CIRCLE AND CONIC SECTIONS. Containing an Account of its most recent Extension. Crown 8vo., I2s. 
GEOIMETRY AND EUCLID-Continuer.

HAMILTON.-ELEMENTS OF QUATERNIONS. By the late Sir William Rowan Hamilton, LL.D., M.R.I.A. Edited by Charles JASPER Joly, M.A., Fellow of Trinity College, Dublin. 2 vols, 4to, 2 Is. net each.

HIME.-THE OUTLINES OF QUATERNIONS. By Lieut.Colonel H. W. L. Hime, late Royal Artillery. Crown 8vo, ros.

LOW-TEXT-BOOK ON PRACTICAL, SOLID, AND DESCRIP'TIVE GEOMETRY. By DAVID ALLAN Low, Professor of Engineering, East London Technical College. Crown 8 vo.

Part I. With II4 Figures, 2s.

Part II. With 64 Figures, $3^{s}$.

MORRIS.-Works by I. HAMMOND MORRIS.

PRACTICAL PLANE AND SOLID GEOMETRI, including Graphic Arithmetic fully Illustrated with Drawings prepared specially by the Author. Crown 8vo., 2s. $6 d$.

GEOMETRICAL DRAIVING FOR ART STUDENTS. Embracing Plane Geometry and its Applications, the Use of Scales, and the Plans and Elevations of Solids as required in Section I. of Science Subjects. Crown 8vo., 2 .

SMTTH.-ELEMENTS OF GEOMETRY. By J. HAMBLIN SMITH, M.A. Containing Books I to 6 , and portions of Books II and I2, of Euclid, with Exercises and Notes. Crown 8vo., 3s. 6d. KEY, crown 8vo., 8 s. 6 d.

Books I and 2, limp cloth, Is. $6 d .$, may be had separately.

SPOONER.-THE EIEMENTS OF GEOMETRICAI, I)RAI'ING : an Elementary Text-book on Practical Plane Geometry, including an Introduction to Solid Geometry. Written to include the requirements of the Syllabus of the Board of Education in Geometrical Drawing and for the use of Students preparing for the Military Entrance Examinations. By HENRY J. Spooner, C. E., M.Inst.M.E. ; Director of the Polytechnic School of Engineering, etc. Crown 8 vo., $3^{s .}$. 6 .

WATSON.-ELEMENTS OF PLANE ANI) SOIID GEOMETRY. By H. W. Watson, M.A. Fcp. 8vo., $3 s .6 \%$.

WILSON.-GEOMETRICAL. DRAWING. For the use of Candidates for Army Examinations, and as an Introduction to Mechanical Drawing. By W. N. WILson, M. A. Parts I. and II. Crown 8vo., 4 s. $6 d$. each

\section{WINTER. - EIENENTARY GEOMETRICAI DRAWING.} By S. H. WINTER.

Part I. Including Practical Plane Geometry, the Construction of Scales, the Use of the Sector, the Marquois Scales, and the Protractor. With 3 Plates and rooo Exercises and Examination Papers. Post 8vo., 5 s. 


\section{TRIGONOMETRY,}

\section{CASEY. - A TREATISE ON ELEMENTARY TRIGONO-} METRY. By JOHN CASEY, LL. D., F.R.S., late Fellow of the Royal University of Ireland. 'With numerous Examples and Questions for Examination. I2mo., $3^{s}$.

CLARKE.-PLANE TRIGONOMETRY. Containing the more advanced Propositions, Solution of Problems and a complete Summary of Formulæ, Bookwork, etc., together with recent Examination Papers for the Army, Woolwich, etc. With Answers. By the Rev. A. Dawson Clarke, M.A., St. John's College, Cambridge. Crown 8vo, 5 s.

GOODWIN.-Works by H. B. GOODWIN, M.A.

PLANE AND SPHERICAL TRIGONOMETRY. In Three Parts, comprising those portions of the subjects, theoretical and practical, which are required in the Final Examination for Rank of Lieutenant at Greenwich. 8vo., $8 s, 6 \%$.

ELEMENTARY PLANE TRIGONOMETRY. With numerous Examples and Examination Papers set at the Royal Naval College in recent years. With Answers. 8vo., $5^{s}$.

JONES.-THE BEGINNINGS OF 'TRIGONOMETRY. By A. Clement Jones, M.A., Ph.D., late Open Scholar and Senior Hulme Exhibitioner of Brasenose College, Oxford; Senior Mathematical Master of Bradford Grammar School, Crown 8vo., $2 s$.

MURRAY.PLANE TRIGONOMETRY FOR COLLEGES AND SECONDARY SCHOOLS. By DANiel A. MURRAY, B.A., Ph.D., Instructor in Mathematics in Cornell University. Crown 8vo., $35.6 d$. With Logarithmic and Trigonometric Tables. Crown 8vo., $5 s$.

SMITH.-ELEMENTARY TRIGONOMETRY. By J. HAMBLIN Sмiтh, M.A. Crown 8vo., 4s. 6d. Key, 7s. $6 d$.

\section{OPTICS, PHOTOGRAPHY, ETC.}

$A B N E Y$. A TREATISE ON PHOTOGRAPHY. By Sir WILLIAM DE Wiveleslite ABNeY, K.C.B., F.R.S., Principal Assistant Secretary of the Secondary Department of the Board of Education. With r34 Illustrations. Fcp. 8vo., $5^{s .}$

DRUDE.-THE THEORY OF OPTICS. By PAUL IRUdE, Professor of Physics at the University of Giessen. Translated from the German by C. Riborg Mann and Robert A. Millikan, Assistant Professors of Physics at the University of Chicago. With Iro Diagrams. 8vo., 15s. net.

GLAZEBKOOK.-PHYSICAL OPTICS. By R. T. GLAZEBROOK, M.A., F.R.S., Principal of University College, Liverpool. With $\mathrm{I}_{3}$ Woodcuts of Apparatus, etc. Fcp. 8vo., $6 \mathrm{~s}$.

VANDERPOEL.-COLOR PROBLEMS: a Practical Manual for the Lay Student of Color. By EMILY Noves VANDRRPOEL. With II7 Plates in Color. Square 8vo., 2Is. net.

WRIGHT.-OPTICAL PROJECTION : a Treatise on the Use of the Lantern in Exhibition and Scientific Demonstration. By LEWIS WRIGHT, Author of 'Light : a Course of Experimental Optics'. With 232 Illustrations. Crown 8vo., 6s. 
Scientific Works published by Longmans, Green, \& Co.

\section{SOUND, LIGHT, HEAT, AND THERMODYNAMICS.}

\section{DEXTER.-ELEMENTARY PRACTICAL SOUND, LIGHT} AND HEAT. By Joseph S. Dexter, B.Sc. (Lond.), Physics Master, Technical Day School, The Polytechnic Institute, Regent Street. With ${ }^{5}{ }^{2}$ Illustrations. Crown 8vo., 2s. $6 d^{d}$.

EMTAGE.-LIGHT. By W. T. A. EmTaGe, M.A., Director of Public Instruction, Mauritius. With 232 Illustrations. Crown 8vo., 6 s.

HELMHOLTZ-ON THE SENSATIONS OF TONE AS A PHYSIOLOGICAL BASIS FOR THE THEORY OF MUSIC. By HERMANN VON HELMHOLTz. Royal 8vo., 28s.

MAXWELL.-THEORY OF HEAT. By J. Clerk MAXwell, M.A., F.R.SS., L. and E. With Corrections and Additions by Lord RAY LEIGH. With 38 Illustrations. Fcp. 8vo., 4s. $6 d$.

SMITH.-THE STUDY OF HEAT. By J. Hamblin Smith, M.A., of Gonville and Caius College, Cambridge. Crown 8vo., $3^{s .}$

TYNDALL.-Works by JOHN TYNDALL, D.C.L., F.R.S. See p. 36 .

WORMELL. - A CLASS-BOOK OF THERMODYNAMICS. By RICHARD WORMELl, B.Sc., M.A. Fcp. 8vo., Is, $6 d$.

WRIGHT.-Works by MARK R. WRIGHT, M.A.

SOUND, LIGHT, AND HEAT. With I60 Diagrams and Illustrations. Crown 8vo, $2 s .6 d$.

ADVANCED HEAT. With I36 Diagrams and numerous Examples and Examination Papers. Crown 8vo., 45.6d.

\section{STEAM, OIL, AND GAS ENGINES.}

BALE.-A HAND-BOOK FOR STEAM USERS; being Rules for Engine Drivers and Boiler Attendants, with Notes on Steam Engine and Boiler Management and Steam Boiler Explosions. By M. Powis BALE, M.I.M.E., A.M.I.C.E. Fcp. 8vo., 2s. 6d.

CLERK.-THE GAS AND OIL ENGINE. By Dugald CLERK, Member of the Institution of Civil Engineers, Fellow of the Chemical Society, Member of the Royal Institution, Fellow of the Institute of Patent Agents. With 228 Illustrations. 8vo., I5s. 


\section{STEAM, OIL, AND GAS ENGINES-Continued.}

HOLMES.-THE STEAM ENGINE. By George C. V. HoLMEs, Chairman of the Board of Works, Ireland. With 212 Illustrations. Ficp. 8vo., 6s.

NEILSON.-THE STEAM TURBINE. By ROBERT M. NEILson, Whitworth Exhibitioner, Associate Member of the Institute of Mechanical Engineers, Lecturer on Steam and the Steam Engine at the Heginbottom Technical School, Ashton-under-Lyne, With I45 Illustrations. 8 vo., 75, 6d. net.

NORRIS.-A PRACTICAL TREATISE ON THE 'OTTO' CYCLE GAS ENGINE. By William NORris, M.I.Mech.E. With 207 Illustrations. 8 vo., Ios. $6 d$.

RIPPER.-Works by WILLIAM RIPPER, Professor of Engineering in the Technical Department of University College, Sheffield.

STEAM. With I 85 Illustrations. Crown 8vo., 2s. 6 .

STEAM ENGINE THEORY AND PRACTICE. With 438 Illustrations. 8vo., 9s.

SENNETT AND ORAM.THE MARINE STEAM ENGINE: A Treatise for Engineering Students, Young Engineers and Officers of the Royal Navy and Mercantile Marine. By the late RICHARD SENNETT, Engineer-in-Chief of the Navy, etc. ; and HENRY J. Oram, Senior Engineer Inspector at the Admiralty, Inspector of Machinery in H.M. Fleet, eto. With 4 I4 Diagrams, 8vo., 2Is.

STROMEYER.-MARINE BOILER MANAGEMENT AND CONSTRUCTION. Being a Treatise on Boiler Troubles and Repairs, Corrosion, Fuels, and Heat, on the properties of Iron and Steel, on Boiler Mechanics, Workshop Practices, ana Boiler Design. By C. E. STRomeyer, Chief Engineer of the Manchester Steam Users' Association, Member of Council of the Institution of Naval Architects, etc. With $45^{2}$ Diagrams, etc. 8 vo., I2s, net.

\section{ARCHITECTURE, BUILDING CONSTRUCTION, ETC.}

\section{ADVANCED BUILDING CONSTRUCTION. By the Author} of 'Rivingtons' Notes on Building Construction'. With 385 Illustrations. Crown 8vo., 4s. 6d.

BURRELL.-BUILDING CONSTRUCTION. By EDWARD J. Burrell, Second Master of the People's Palace Technical School, London. With 303 Working Drawings. Crown 8vo., 2s. $6 d$.

GIVILT.-AN ENCYCLOPADIA OF ARCHITECTURE. By JosePH GwILT, F.S.A. Revised (1888), with Alterations and Considerable Additions by Wyatt PAPWORTH. With I7oo Engravings. 8vo., 2 Is. net.

PARKER AND UNWIN.-THE ART OF BUILDING A HOME : A Collection of Lectures and Illustrations. By BARRY PARKER and RAYMOND UNWin. With 68 Full-page Plates. 8vo,, Ios. 6d. net.

RICHARDS.-BRICKLAYING AND BRICKCUTTING. By H. W. RICHARDS, Examiner in Brickwork and Masonry to the City and Guilds of London Institute, Head of Building Trades Department, Northern Polytechnic Institute, London, N. With over 200 Illustrations. 8vo., $3 s^{5} 6$. 
ARCHITECTURE, BUILDING CONSTRUCTION, ETC.-Contimer.

SEDDON.-BUILDER'S IVORK AND THE BUILDING TRADES. By Col. H. C. SEDDON, R.E. With numerous Illustrations. Medium 8vo., $16 s$.

THOMAS-THE VENTILATION, HEATING AND MANAGEMENT OF CHURCHES AND PUBLIC BUILDINGS. By J. W. Thomas, F.I.C., F.C.S., Author of 'Coal, Mine-Gases, and Ventilation,' etc. With 25 Illustrations. Crown 8 vo., $2 s, 6 d$.

$V A L D E R$.-BOOK OF TABLES, giving the Cubic Contents of from One to Thirty Pieces Deals, Battens and Scantlings of the Sizes usually imported or used in the Building Trades, together with an Appendix showing a large number of sizes, the Contents of which may be found by referring to the aforesaid 'Tables. By ThOMAS VAlder. Oblong 4to., 6s. net.

\section{RIVINGTONS' COURSE OF BUILDING CONSTRUCTION.}

NOTES ON BUILDING CONSTRUCTION. Medium Sro.

Part I. With $55^{2}$ Illustrations, 9s. net.

Part II. With 479 Illustrations, 9 s. net.

Part III. Materials. With I 88 Illustrations, I8s. net.

Part IV. Calculations for Building Structures. With 55 I Illustrations, 13s, net.

\section{ELECTRICITY AND MAGNETISM.}

ARRHENIUS.-A TEXT-BOOK OF EIECTROCHEMISTRY. By Svante ARrhenius, Professor at the University of Stockholm. Translated from the German Edition by JOHN MCCRAE, Ph.D. With $5^{8}$ Illustrations. 8 vo., $9 s, 6 d$. net.

CARUS-IVILSON-ELECTRO-DYNAMICS : the DirectCurrent Motor. By Charles Ashley Carus-Wilson, M.A. Cantab. With 7I Diagrams, and a Series of Problems, with Answers. Crown 8vo., 7s. 6d.

$C U M M I N G$-ELECTRICITY TREATED EXPERIMEN. TALLY. By Linn eus Cumming, M.A. With 242 Illustrations. Cr. 8vo., 4 s, 6 d.

$D A Y$.-EXERCISES IN ELECTRICAL AND MAGNETIC MEASUREMENTS, with Answers. By R. E. DAY, I2mo., 3s, $6 d$.

FITZGERALD.-THE SCIENTIFIC WRITINGS OF THE LATE GEORGE FRANCIS FITZGERALD, Sc.D., F.R.S., F.R.S.E., Fellow of Trinity College, Dublin. Collected and Edited, with an Historical Introduction, by JOSEPH LARMOR, Sec.R.S., Fellow of St. John's College, Cambridge. With Portiait. 8vo., I5s.

GORE.-THE ART OF ELECTRO-METALLURGY, including all known Processes of Electro-Deposition. By G. GORE, LL.D., F.R.S. With 56 Illustrations. Fep. 8vo., $6 s$.

HENDERSON.-Works by JOHN HENDERSON,D.Sc., H.R.S.E.

PRACTICAL ELECTRICITY AND MAGNETISM. With I59 Illustrations and Diagrams. Crown 8vo., 6s. $6 d$.

PRELIMINARY PRACTICAL MAGNETISM AND EIEC. TRICITY. Crown 8vo., Is. 


\section{ELECTRICITY AND MAGNETISIM-Continued.}

$J E N K I N$.-ELECTRICITY AND MAGNETISM. By F LEEMING JENkIN, F.R.S., M.I.C.E. With 177 Illustrations. Fcp. 8vo., 3s. $6 d$.

JOUBERT.-ELEMENTARY TREATISE ON ELECTRICITY AND MAGNETISM. By G. CAREY Foster, F.R.S., Fellow and Emeritus Professor of Physics in University College, London; and ALFRED W. PORTER, B.Sc., Fellow and Assistant Professor of Physics in University College, London. Founded on JOUBERT's 'Traité Elémentairé d'Electricité'. Second Edition. With 374 Illustrations and Diagrams. 8vo., Ios, $6 d$. net.

JO YCE.-EXAMPLES IN ELECTRICAL ENGINEERING. By Samuel Joyce, A.I.E.E. Crown 8 vo., 5 s.

MACLEAN AND MARCHANT.EIEMENTARY QUESTIONS IN ELECTRICITY AND MAGNETISM. With Answers. Compiled by Magnus Maclean, D.Sc., M.I.E.E., and E. W. MARChANT, D.Sc., A.I.E.E. Crown 8vo., Is.

MERRIFIELD.-MAGNE'TISM AND DEVIATION OF THE COMPASS. By JOHN MERRIFIELD, LL.D., F.R.A.S., I8mo, $2 s, 6 d$.

PARR.-PRACTICAL ELECTRICAL TESTING IN PHYSICS AND ELECTRICAL ENGineEring. By G. D. Aspinall Parr, Assoc. M.I.E.E. With 23 r Illustrations. 8vo., 8s. $6 d$.

POYSER.-Works by A. W. POYSER, M.A.

MAGNETISM AND ELECTRICITY. With 235 Illustrations. Crown 8vo, 2 s. $6 d$.

ADVANCED ELECTRICITY AND MAGNETISM. With $3^{\text {II }}$ Illustrations. Crown 8vo., 4s, 6d.

RHODES.-AN ELEMENTARY TREATISE ON ALTERNATING CURRENTS. By W. G. RHODES, M.Sc. (Vict.), Consulting Engineer. With 80 Diagrams. 8vo., 7s. $6 d$. net.

SLINGO AND BROOKER.-Works by W. SLINGO and A. BROOKER.

ELECTRICAL ENGINEERING FOR ELECTRIC LIGHT ARTISANS AND STUDENTS. With $3^{8} 3$ Illustrations. Crown 8vo., 12s.

PROBLEMS AND SOLUTIONS IN ELEMENTARY ELECTRICITY AND MAGNETISM. With 98 Illustrations. Cr. 8vo., 2s.

TYNDAL.L._Works by JOHN TYNDALI, D.C.L., F.R.S. Seep. 36 .

\section{TELEGRAPHY AND THE TELEPHONE.}

HOPKINS. - TELEPHONE LINES AND THEIR PROPERTIES. By William J. Hopkins, Professor of Physics in the Drexel Institute, Philadelphia. Crown 8 vo., $6 s$.

PREECE AND SIVEWRIGHT.-TELEGRAPHY. By Sir W. H. PREECE, K.C.B., F.R.S., V.P.Inst., C.E., etc., Consulting Engineer and Electrician, Post Office Telegraphs; and Sir J.SivEWRIGHT, K.C.M.G., General Manager, South African Telegraphs. With 267 Illustrations. Fep. 8vo., 6s. 
Scientific Works published by Longmans, Green, \& Co.

\section{ENGINEERING, STRENGTH OF MATERIALS, ETC.}

ANDERSON.THE STRENGTH OF MATERIALS AND STRUCTURES : the Strength of Materials as depending on their Quality and as ascertained by Testing Apparatus. By Sir J. ANDERson, C.E., LL.D., F.R.S.E. With 66 Illustrations. Fcp. 8vo., 3s. $6 d$.

$B A R R Y$.-RAILIVAY APPLIANCES : a Description of Details of Railway Construction subsequent to the completion of the Earthworks and Structures. By Sir JoHn WOLFE BARRY, K.C.B., F.R.S., M.I.C.E. With 218 Illustrations. Fcp. 8vo., $4 s .6 d$.

DIPLOCK.-A NEIV SYSTEM OF HEAVY GOODS TRANSPORT ON COMMON ROADS. By BRAHAM JOSEPH DIPLOCK. With 27 Illustrations. 8vo.

GOODMAN.-MECHANICS APPLIED TO ENGINEERING. By John Goodman, Wh.Sch., A.M.I.C. E., M.I.M.E., Professor of Engineering in the Yorkshire College, Leeds (Victoria University). With 620 Illustrations and numerous Examples. Crown 8vo., 7s. 6d. net.

$L O W$ - A POCKET-BOOK FOR MECHANICAL EN. GINEERS. By DAvid ALlan Low (Whitworth Scholar), M.I.Mech.E., Professor of Engineering, East London Technical College (People's Palace), London. With over Iooo specially prepared Illustrations. Fcp. 8vo., gilt edges, rounded corners, $7 s_{0} 6 d$.

PARKINSON-LIGHT RAIIWAY CONSTRUCTION. By RICHARD Marion PARKinson, Assoc.M.Inst.C.E. With 85 Diagrams. 8 vo., ros. 6 d. net.

SMITH.-GRAPHICS, or the Art of Calculation by Drawing Lines, applied especially to Mechanical Engineering. By ROBERT H. SMITH, Professor of Engineering, Mason College, Birmingham. Part I. With separate Atlas of 29 Plates containing 97 Diagrams. 8vo., 15s.

STONEY.-THE THEORY OF STRESSES IN GIRDERS AND SIMILAR STRUCTURES; with Practical Observations on the Strength and other Properties of Materials. By BINDON B. STONEY, LL.D., F.R.S., M.I.C.E. With 5 Plates and I43 Illust. in the Text. Royal 8vo., $36 s$.

UNWIN.-THE TESTING OF MATERIALS OF CONSTRUCTION. A Text-book for the Engineering Laboratory and a Collection of the Results of Experiment. By W. CAWTHORNE UNWIN, F.R.S., B.Sc. With 5 Plates and 188 Illustrations and Diagrams. 8vo., I6s, net.

WARREN.-ENGINEERING CONSTRUCTION IN IRON, STEEL, AND TIMBER. By William HeNry WARRen, Challis Professor of Civil and Mechanical Engineering, University of Sydney. With 13 Folding Plates and 375 Diagrams. Royal 8vo., r6s. net.

WHEELER.—THE SEA COAST: Destruction, Littoral Drift, Protection. By W. H. WheEler, M.Inst, C. E. With 38 Illustrations and Diagram. Medium 8vo,, ros, $6 d$. net, 


\section{LONGMANS' CIVIL ENGINEERING SERIES.}

CIVIL ENGINEERING AS APPLIED TO CONSTRUCTION. By Leveson Francis Vernon-Harcourt, M.A., M.Inst.C.E. With 368 Illustrations. Medium 8vo., i4s, net.

Contents-Materials, Preliminary Works, Foundations and Roads-Railway Bridge and Tunnel Engineering-River and Canal Engineerıng-Irrigation Works-Dock Works and Maritime Engineering-Sanitary Engineering.

NOTES ON DOCKS AND DOCK CONSTRUCTION. By C. Colson, C.B., M.Inst.C.E. With 365 Illustrations. Medium 8vo., 21s. net.

CALCULATIONS IN HYDRAULIC ENGINEERING: a Practical Text-Book for the use of Students, Draughtsmen and Engineers. By T. Claxton Fidler, M.Inst.C.E.

Part I. Fluid Pressure and the Calculation of its Effects in Engineering Structures. With numerous Illustns, and Examples. 8vo, $6 \mathrm{~s}$. $6 d_{\text {。 }}$. net.

Part II. Calculations in Hydro-Kinetics. With numerous Illustrations and Examples. 8vo., 7s, 6d. net.

RAILWAY CONSTRUCTION. By W. H. Mills, M.I.C.E., Engineer-in-Chief of the Great Northern Railway of Ireland. With 516 Illustrations and Diagrams. 8vo., $18 s$, net.

PRINCIPLES AND PRACTICE OF HARBOUR CONSTRUCTION. By William SHield, F.R.S.E., M.Inst.C.E. With 97 Illustrations. Medium 8vo., I5s. net.

TIDAL RIVERS: their (I) Hydraulics, (2) Improvement, (3) Navigation. By W. H. WHEELER, M.Inst.C.E. With 75 Illustrations. Medium 8vo., I6s. net.

\section{MACHINE DRAWING AND DESIGN.}

LOW.-Works by DAVID ALLAN LOW, Professor of Engineering, East London 'Technical College (People's Palace).

IMPROVED DRAWING SCALES. $6 d$. in case.

AN INTRODUCTION TO MACHINE DRAWING AND DESIGN. With $\mathrm{r}_{53}$ Illustrations and Diagrams. Crown 8vo, 2s, 6d.

LOW AND BEVIS.-A MANUAL OF MACHINE DRAWING AND DESIGN. By David Allan Low and Alfred William Bevis M.I. Mech.E. With 700 Illustrations, 8vo, $7 s, 6 d$.

UNWIN.-THE ELEMENTS OF MACHINE DESIGN. BY W. CAWTHORNe UnWin, F.R.S.

Part I. General Principles, Fastenings, and Transmissive Machinery. With 345 Diagrams, etc. Fcp. 8vo., 7s. 6d.

Part II. Chiefly on Engine Details, Witt 259 Illustrations. Fcp. 8vo., 6s, 


\section{NAVAL ARCHITECTURE.}

ATTWOOD.-TEXT-BOOK OF THEORETICAL NAVAL ARCHITECTURE : a Manual for Students of Science Classes and Draughtsmen Engaged in Shipbuilders' and Naval Architects' Drawing Offices. By EDWARD Lewis ATtwood, Assistant Constructor, Royal Navy. With II4 Diagrams. Crown 8vo., 7s. $6 d$.

WATSON.-NAVAL ARCHITECTURE: A Manual of Layingoff Iron, Steel and Composite Vessels. By Thomas H. WATson, Lecturer on Naval Architecture at the Durham College of Science, Newcastle-upon-Tyne. With numerous Illustrations. Royal 8vo., I5s. net.

\section{WORKSHOP APPLIANCES, ETC.}

NORTHCOTT.-LATHES AND TURNING, Simple, Mechanical and Ornamental. By W. H. NORTHCOTT. With $33^{8}$ Illustrations. 8vo., r8s.

SHELLEY.-WORKSHOP APPLIANCES, including Descriptions of some of the Gauging and Measuring Instruments, Hand-cutting Tools, Lathes, Drilling, Planeing, and other Machine Tools used by Engineers. By C. P. B. SHELLEY, M.I.C.E. With an additional Chapter on Milling by R. R. LISTER. With 323 Illustrations. Fcp. 8vo., $5^{5}$.

\section{MINERALOGY, MINING, METALLURGY, ETC.}

BAUERMAN.-Works by HILARY BAUERMAN, F.G.S.

SYSTEMATIC MINERALOGY. With 373 Illustrations. Fcp. 8vo., 6s.

DESCRIPTIVE MINERALOGY. With 236 Illustrations. Fcp. 8vo, 6s.

BREARLEY AND IBBOTSON. - THE ANALYSIS OF SIEEL-WORKS MATERIALS. By HARRY BREARLEY and FRED IBBOTSON, B.Sc. (Lond.), Demonstrator of Micrographic Analysis, University College, Sheffield. With 85 Illustrations. 8vo., I4s. net.

GORE.-THE ART OF ELECTRO-METALLURGY. By G. GORE, LL.D., F.R.S. With 56 Illustrations. Fcp. 8vo., 6 s.

HUNTINGTON AND M'MILLAN.-METALS: their Properties and Treatment. By A. K. Huntington, Professor of Metallurgy in King's College, London, and W. G. M'MiLLAN, Lecturer on Metallurgy in Mason's College, Birmingham. With 122 Illustrations, Fcp. 8vo., 7s, 6d.

LUPTON.-Works by ARNOLD LUPTON, M.I.C.E., F.G.S., etc.

MINING. An Elementary 'Treatise on the Getting of Minerals. With 596 Diagrams and Illustrations. Crown 8vo., 9 s. net.

A PRACTICAL 'TREATISE ON MINE SURVEYING. With 209 Illustrations. 8vo., I2s, net.

RHEAD.-METALLURGY. By E. L. RHEAD, Lecturer on Metallurgy at the Municipal Technical School, Manchester, With 94 Illustrations. Fcp. 8vo., 3s. $6 d$.

RHEAD AND SEXTON.-ASSAYING AND METALLURGICAL ANALYSIS for the use of Students, Chemists and Assayers. By E, L. RHEAD, Lecturer on Metallurgy, Municipal School of 'Technology, Manchester; and A. Humboldt Sexton, F.I.C., F.C.S., Professor of Metallurgy, Glasgow and West of Scotland Technical College. 8vo., 10s. $6 \mathrm{~d}$. net.

RUTLEY.-THE STUDY OF ROCKS: an Elementary Textbook of Petrology. By F. RutLey, F.G.S. With 6 Plates and 88 other Illustrations. Fep. 8vo., 4 s. $6 d$. 


\section{ASTRONOMY, NAVIGATION, ETC.}

ABBOTT.ELEMENTARY THEORY OF THE TIDES : the Fundamental Theorems Demonstrated without Mathematics and the Influence on the Length of the Day Discussed. By T. K. ABBOTT, B.D., Fellow and Tutor, Trinity College, Dublin. Crown 8vo., $2 s$.

BALL.-Works by Sir ROBERT S. BALL, LL.U., F.R.S.

ELEMENTS OF ASTRONOMY. With I 30 Figures and Diagrams. Fcp. 8vo, 6s. 6d.

A CLASS-BOOK OF ASTRONOMY. With 4 I Diagrams. Fcp. 8vo., is. 6d.

GILL.-TEXT-BOOK ON NAVIGATION AND NAUTICAL ASTRONOMY. By J. GILL, F.R.A.S., late Head Master of the Liverpool Corporation Nautical College. 8 vo., Ios, $6 d$.

GOODWIN.-AZIMUTH TABLES FOR 'THE HIGHER DECLINATIONS. (Limits of Declination $24^{\circ}$ to $30^{\circ}$, both inclusive.) Between the Parallels of Latitude $0^{\circ}$ and $60^{\circ}$. With Examples of the Use of the Tables in English and French. By H. B. GoodwiN, Naval Instructor, Royal Navy, Royal 8vo., 7s, 6d.

HERSCHEL.-OUTLINES OF ASTRONOMY. By Sir JoHN F. W. Herschel, Bart., K.H., etc. With 9 Plates and numerous Diagrams. 8 vo., I2s.

\section{LAUGHTON.-AN INTROIUCTION TO THE PRAC-} TICAL AND THEORETICAL STUDY OF NAUTICAL SURVEYING. By John Knox Laughton, M.A., F. R.A.S. With 35 Diagrams. Crown 8vo., 6s.

LOWELL.-MARS. By Percival Lowell, Fellow American Academy, Member Royal Asiatic Society, Great Britain and Ireland, etc. With 24 Plates. 8vo., $125.6 d$.

MARTIN.-NAVIGATION AND NAUTICAL ASTRONOMY. Compiled by Staff Commander W. R. MARTIN, R.N. Royal 8vo., I8s.

MERRIFIELD.-A TREATISE ON NAVIGATION. For the Use of Students. By J. Merrifield, LL.D., F.R.A.S., F.M.S. With Charts and Diagrams. Crown 8 vo., 5 s.

PARKER.-ELEMENTS OF ASTRONOMY. With Numerous Examples and Examination Papers. By GEORGE W. PARKER, M.A., of Trinity College, Dublin. With 84 Diagrams. 8 vo., $5 s$. $6 d$, net.

WEBB.-CELESTIAL OBJECTS FOR COMMON TELESCOPES. By the Rev, T. W. WEBB, M.A., F.R.A.S. Fifth Edition, Revised and greatly Enlarged by the Rev. T. E. EspiN, M.A., F. R.A.S. (Two Volumes.) Vol. I., with Portrait and a Reminiscence of the Author, 2 Plates, and numerous Illustrations. Crown 8 vo., $6 s$. Vol. II., with numerous Illustrations. Crown 8 vo., $6 s, 6 d$. 


\section{WORKS BY RICHARD A. PROCTOR.}

THE MOON : Her Motions, Aspect, Scenery, and Physical Condition. With many Plates and Charts, Wood Engravings, and 2 Lunar Photographs. Crown 8vo, 3 s. $6 d$.

OTHER WORLDS THAN OURS: the Plurality of Worlds Studied Under the Light of Recent Scientific Researches. With I4 Illustrations; Map, Charts, etc. Crown 8vo., 3s. $6 d$.

OUR PLACE AMONG INFINITIES: a Series of Essays contrasting our Little Abode in Space and Time with the Infinities around us. Crown 8 vo., 3 s. $6 d$.

MYTHS AND MARVEI.S OF ASTRONOMY. Crown 8vo., 3. $6 d$.

LIGHT SCIENCE FOR LEISURE HOURS: Familiar Essays on Scientific Subjects, Natural Phenomena, etc. Crown 8vo., 35. $6 d$.

THE ORBS AROUND US; Essays on the Moon and Planets, Meteors and Comets, the Sun and Coloured Pairs of Suns. Crown 8 vo., $3^{\text {s. }} 6 d$.

THE EXPANSE OF HEAVEN : Essays on the Wonders of the Firmament. Crown 8vo., 3s. 6d.

OTHER SUNS THAN OURS: a Series of Essays on Suns-OId, Young, and Dead. With other Science Gleanings. Two Essays on Whist, and Correspondence with Sir John Herschel. With 9 Star-Maps and Diagrams. Crown 8vo., 35. $6 d$.

HALF-HOURS WITH THE TELESCOPE: a Popular Guide to the Use of the Telescope as a means of Amusement and Instruction. With 7 Plates. Fcp. 8vo., 2s, 6 .

NEW STAR ATLAS FOR THE I,IBRARY, the School, and the Observatory, in Twelve Circular Maps (with Two Index-Plates). With an Introduction on the Study of the Stars. Illustrated by 9 Diagrams. $\mathrm{Cr}$. 8vo., ${ }^{5}$.

THE SOUTHERN SKIES: a Plain and Easy Guide to the Constellations of the Southern Hemisphere. Showing in 12 Maps the position of the principal Star-Groups night after night throughout the year. With an Introduction and a separate Explanation of each Map. True for every Year. $4^{\text {to. }}, 5^{5}$,

HALF-HOURS WITH THE STARS: a Plain and Easy Guide to the Knowledge of the Constellations. Showing in 12 Maps the position of the principal Star-Groups night after night throughout the year. With Introduction and a separate Explanation of each Map. True for every Year.

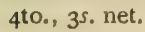

LARGER STAR ATLAS FOR OBSERVERS AND STUI)ENTS. In 'Twelve Circular Maps, showing 6000 Stars, 1500 Double Stars, Nebulæ, etc. With 2 Index-Plates. Folio, ${ }^{5}$. 
Scientific Works published by Longmans, Green, \& Co.

\section{WORKS BY RICHARD A. PROCTOR-Continued.}

THE STARS IN THEIR SEASONS: an Easy Guide to a Knowledge of the Star-Groups. In 12 Large Maps. Imperial 8vo., $5^{5 .}$

ROUGH WAYS MADE SMOOTH. Familiar Essays on Scientific Subjects. Crown 8vo., 3s. $6 d$.

PLEASANT WAYS IN SCIENCE. Crown 8vo., $3^{s .} 6 d$.

NATURe studies. By R. A. Proctor, Grant Allen, A. Wilson, T. Foster, and E. Clodo. Crown 8vo., 3s. 6d.

LEISURE REAdings. By R. A. Proctor, F. Clodd, A. Wilson, T. Foster, and A. C. RANyARd. Crown 8 vo, , $3^{s .} 6 d$.

\section{PHYSIOGRAPHY AND GEOLOGY.}

BIRD.-Works by CHARLES BIRD, B.A.

ELEMENTARY GEOLOGY. With Geological Map of the British Isles, and 247 Illustrations. Crown 8vo., 2s. 6d.

ADVANCED GEOLOGY. A Manual for Students in Advanced Classes and for General Readers. With over 300 Illustrations, a Geological Map of the British Isles (coloured), and a set of Questions for Examination. Crown 8vo., $7 s, 6 d$.

GREEN.-PHYSICAL GEOLOGY FOR STUDENTS AND GENERAL READERS. By A. H. GREen, M.A., F.G.S. With 236 Illustrations. 8vo., 2IS。

MORGAN.-Works by ALEX. MORGAN, M.A., D.Sc., F.R.S.E.

ELEMENTARY PHYSIOGRAPHY. Treated Experimentally. With 4 Maps and 243 Diagrams. Crown 8vo., 2s. 6d.

ADVANCED PHYSIOGRAPHY. With 2r5 Illustrations. Crown 8 vo., $45^{5} 60^{\circ}$

THORNTON.-Works by J. THORNTON, M.A.

ELEMENTARY PRACTICAL PHYSIOGRAPHY.

Part I. With 2 I 5 Illustrations. Crown 8vo., 2s. $6 d$.

Part II. With 98 Illustrations. Crown 8vo., 2s, $6 d$.

ELEMENTARY PHYSIOGRAPHY : an Introduction to the Study of Nature. With 13 Maps and 295 Illustrations. With Appendix on Astronomical Instruments and Measurements. Crown 8vo., 2s. 6d.

ADVANCED PHYSIOGRAPHY. With II Maps and 255 Illustrations. Crown 8vo., 4s. $6 d$. 
NATURAL HISTORY AND GENERAL SCIENCE.

BEDDARD.-THE STRUCTURE AND CLASSIFICATION

OF BIRDS. By FRANK E. BEDDARD, M.A., F.R.S., Prosector and Vice-

Secretary of the Zoological Society of London. With 252 Illus. 8vo., 2 Is, net.

FURNEAUX.-Works by WILLIAM FURNEAUX, F.R.G.S.

THE OUTDOOR IVORLD; or, The Young Collector's Handbook. With 18 Plates, 16 of which are coloured, and 549 Illustrations in the Text. Crown 8vo., 6s, net.

LIFE IN PONDS AND STREAMS. With 8 Coloured Plates and 33 Illustrations in the Text. Crown 8vo., $6 s$, net.

BUTTERFLIES AND MOTHS (British). WVith I 2 Coloured Plates and 24I Illustrations in the Text. Crown 8vo., 6s, net.

HUDSON.-BRITISH BIRDS. By W. H. HuDSON, C.M.Z.S.

With 8 Coloured Plates from Original Drawings by A. THORBURN, and 8 Plates and 100 Figures by C. E. LODGE, and 3 Illustrations from Photographs. Crown 8vo., 6s, net.

MILLAIS.-THE NATURAI, HISTORY OF THE BRITISH SURFACE-FEEDING DUCKS. By JoHN Guille Millais, F.Z.S., etc. With 6 Photogravures and 66 Plates ( 4 I in colours) from Drawings by the Author, ARCHIBALD THORBURN, and from Photographs. Royal 4to., \&6 6s. net.

$N A N S E N$. - THE NORIVEGIAN NORTH POLAR EXPEDITION, 1893-I896: Scientific Results. Edited by FRIDTJOF NANSEN. Volume I. With 44 Plates and numerous Illustrations in the Text. Demy 4to., 40 s. net.

Contents: The Fran-The Jurassic Fauna of Cane Flora. With a Geological Sketch of Cape Flora and its Neighbourhood-Fossil Plants from Franz' Josef Land-An Account of the Birds-Crustacea.

Volume II. With 2 Charts and 17 Plates. Demy 4to., 3os, net.

Contents: Astronomical Observations-Terrestrial Magnetism-Results of the Pendulum -Observations and some Remarks on the Constitution of the Earth's Crust.

Volume III. With 33 Plates. Demy 4to., 32s, net.

Contents: The Oceanography of the North Polar Basin-On Hydrometers and the Surface Tension of Liquids.

STANLEY.-A FAMILIAR HISTORY OF BIRISS. By E. STANLEY, D.D., formerly Bishop of Norwich. With I6o Illustrations. Crown 8vo., 3s. $6 d$.

\section{MANUFACTURES, TECHNOLOGY, ETC.}

$B E L L$. JACQUARD IVEAVING AND DESIGNING. By F. T. BELL. With 199 Diagrams. 8vo, 12s. net.

CROSS AND BEVAN.-Works by C. F. CROSS and E. J. BEVAN.

CELLUI_OSE: an Outline of the Chemistry of the Structural Elements of Plants. With reference to their Natural History and Industrial Uses, (C. F. Cross, E. J. Bevan and C. BEAdLe.) With I4 Plates. Crown 8vo., I2s. net.

RESEARCHES ON CELLULOSE, r895-I9oo. Crown 8vo., 6s, net.

DODSON.-THE DOUBLING ANI MANUFACTLRE OF THREADS. By JoHN DODSON, Vice-President of the Bolton and District Mills Managers' Technical Association. With 134 Illustrations. 8vo, , ros, 6d. net, 


\section{MANUFACTURES, TECHNOLOGY, ETC.-Conlimer?.}

MORRIS AND WILKINSON.-THE ELEMENTS OF COT. TON SPINNING. By JOHN MORRIS and F. WIL"KINSON. With a Preface by Sir B. A. DOBSon, C.E., M.I.M.E. With 169 Diagrams and Illustrations. Crown 8 vo., $7 s, 6 d$. net.

RICHARIS.-BRICKLAYING AND BRICK-CUTTING. By H. W. Richards, Examiner in Brickwork and Masonry to the City and Guilds of London Institute, Head of Building Trades Department, Northern Polytechnic Institute, London, N. With over 200 Illustrations. Med. 8vo., 35. 6d.

TAYLOR.-COTTON WEAVING AND DESIGNING. By JoHN T. TAYLOR. With 373 Diagrams. Crown 8vo., $7 s, 6 d$. net.

WATTS.-AN INTRODUCTORY MANUAL FOR SUGAR GROWERS. By FRANCIS WATTS, F.C.S., F.I.C. With 20 Illustrations. Crown 8vo., $6 s$.

\section{HEALTH AND HYGIENE.}

$A S H B Y$.-HEAI,TH IN THE NURSERY. By Henry Ashby, M.D., F.R.C.P. With 25 Illustrations. Crown 8vo., $3^{\text {s. net. }}$

BUCKTON.-HEALTH IN THE HOUSE. By Mrs. C. M. Buckton. With $4 \mathrm{I}$ Woodcuts and Diagrams. Crown 8vo,, 2s.

CORFIELD.-THE LAWS OF HEALTH. By W. H. CORFIELD, M.A., M.D. Fcp. 8vo., Is. $6 d$.

FURNEAUX.-ELEMEN'TARY PRACTICAL HYGIENE.Section I. By William S. FurneauX. With 146 Illustrations. Cr. 8vo., 2s. $6 d$.

NOTTER AND FIRTH.-Works by J. L. NOTTER, M.A., M.D., and R. H. FIRTH, F.R.C.S.

HYGIENE. With 95 Illustrations. Crown 8vo., 3 s. $6 d$.

PRACTICAL DOMESTIC HYGIENE. With 83 Illustrations. Crown 8vo., 2s, $6 d$.

POORE.-Works by GEORGE VIVIAN POORE, M.D.

ESSAYS ON RURAL HYGIENE. Crown 8vo., 6s. $6 d$.

THE DWELLING-HOUSE. With 36 Illustrations. Crown 8 vo., 3s. $6 \pi$.

COLONIAL AND CAMP SANITATION. With I I Illustrations. Crown 8vo., 2s, net.

THE EARTH IN RELATION TO THE PRESERVATION AND DESTRUCTION OF CONTAGIA: being the Milroy Lectures delivered at the Royal College of Physicians in 1899, together with other Papers on Sanitation. With 13 Illustrations. Crown 8 vo., $5^{5 .}$

WILSON.-A MANUAL OF HEALTH-SCIENCE. By ANDREW WILSON, F.R.S.E., F.L.S., etc. With 74 Illustrations, Crown 8 vo.. 2s. $6 \%$. 


\section{MEDICINE AND SURGERY.}

ASHB Y AND WRIGHT.-THE DISEASES OF CHILDREN, MEDICAL AND SURGICAL. By HeNry Ashby, M.D., Lond., F.R.C.P., Physician to the General Hospital for Sick Children, Manchester; and G. A. WRIGHT, B.A., M.B. Oxon., F.R.C.S., Eng., Assistant-Surgeon to the Manchester Royal Infirmary, and Surgeon to the Children's Hospital. Enlarged and Improved Edition. With r92 Illustrations. 8vo., 25 s.

BENNETT.-Works by Sir WILLIAM BENNETT, K.C.V.O., F.R.C.S., Surgeon to St. George's Hospital; Member of the Board of Examiners, Royal College of Surgeons of England.

CLINICAL LECTURES ON VARICOSE VEINS OF THE LOWER EXTREMITIES. With 3 Plates. 8vo, 6 s.

ON VARICOCELE; A PRACTICAL TREATISE. With 4 Tables and a Diagram. 8vo., $5^{5}$.

CLINICAL LECTURES ON ABDOMINAL HERNIA: chiefly in relation to Treatment, including the Radical Cure. With I2 Diagrams in the Text. 8 vo., $8 s, 6 d$.

ON VARIX, ITS CAUSES AND TREATMENT, IVITH ESPECIAL REFERENCE TO THROMBOSIS. 8vo., 3s. 6d.

THE PRESEN'T POSITION OF THE TREATMENT OF SIMPLE FRACTURES OF THE LIMBS. 8vo, $2 s, 6 d$.

LECTURES ON THE USE OF MASSAGE AND EARLY PASSIVE MOVEMEN'TS IN RECENT FRACTURES AND O'THER COMMON SURGICAL INJURIES : The Treatment of Internal Derangements of the Knee Joint and Management of Stiff Joints. With I7 Illustrations. 8vo., 6s.

BENTLEY.-A TEXT-BOOK OF ORGANIC MATERIA MEDICA. Comprising a Description of the Vegetable and Animal Drugs of the British Pharmacopœia, with some others in common use. Arranged Systematically, and Especially Designed for Students. By ROBERT BENTLEY, M.R.C.S. Eng., F.L.S. With 62 Illustrations on Wood. Crown 8vo., 7s, $6 d$.

$C A B O T$-A GUIDE TO THE CLINICAL EXAMINATION OF THE BLOOD FOR DIAGNOSTIC PURPOSES. By RICHARD C. Савот, M.D., Physician to Out-patients, Massachusetts General Hospital. With 3 Coloured Plates and 28 Illustrations in the Text. 8vo., $16 s$.

CARR, PICK, DORAN, AND DUNCAN.-THE PRACTITIONER'S GUIDE. By J. WALTER CARR, M.D. (Lond.), F.R.C.P. ; T. PICKERING PICK, F.R.C.S. ; AlBAN H. G. DORAN, F.R.C.S. ; ANDREW DunCaN, M.D., B.Sc. (Lond.), F.R.C.S., M.R.C.P. 8vo., 21s. net.

CELLI.-MALARIA, ACCORDING TO THE NEIV RESEARCHES. By Prof. ANGELo CELLI, Director of the Institute of Hygiene, University of Rome. Translated from the Second Italian Edition by JoHN JOSEPH EYRE, M.R.C.P., L.R.C.S. Ireland, D.P.H. Cambridge. With an Introduction bv Dr. PATRICK MANSON, Medical Adviser to the Colonial Office. 8 vo., ros. $6 \dot{a}$. 


\section{MEDICINE AND SURGERY-Continued.}

CHE YNE AND BURGHARD.-A MANUAL OF SURGIGAL TREATMENT. By W. WATSON CHEYNe, C.B.. M.B., F.R.C.S., F.R.S., Professor of Surgery in King's College, London, Surgeon to King's College Hospital, etc. ; and F. F. BURGHARD, M.D. and M.S., F.R.C.S., Teacher of Practical Surgery in King's College, London, Surgeon to King's College, Hospital (Lond.), etc.

Part I. The Treatment of General Surgical Diseases, including Inflammation, Suppuration, Ulceration, Gangrene, Wounds and their Complications, Infective Diseases and Tumcurs; the Administration of Anæsthetics. With 66 Illustrations, Royal 8vo., Ios. $6 d$.

Part II. The Treatment of the Surgical Affections of the Tissues, including the Skin and Subcutaneous Tissues, the Nails, the Lymphatic Vessels and Glands, the Fasciæ, Bursæ, Muscles, Tendons and Tendonsheaths, Nerves, Arteries and Veins. Deformities. With I4r Illustrations. Royal 8vo, i iss.

Part III. The Treatment of the Surgical Affections of the Bones. Amputations. With Ioo Illustrations. Royal 8vo., 12s.

Part IV. The Treatment of the Surgical Affections of the Joints (including Excisions) and the Spine. With 138 Illustrations. Royal 8 vo., I 4 s.

Part V. The Treatment of the Surgical Affections of the Head, Face, Jaws, Lips, Larnyx and Trachea; and the Intrinsic Diseases of the Nose, Ear and Larynx, by H. LAMBERT LACK, M.D. (Lond.), F.R.C.S., Surgeon to the Hospital for Diseases of the Throat, Golden Square, and to the 'Throat and Ear Department, The Children's Hospital, Paddington Green. With 145 Illustrations. Royal 8vo, I8s.

Part VI. Section I. The Treatment of the Surgical Affections of the Tongue and Floor of the Mouth, the Pharynx, Neck, Esophagus, Stomach and Intestines. With I24 Illustrations. Royal 8vo., I8s.

Section II. The Treatment of the Surgical Affections of the Rectum, Liver, Spleen, Pancreas, Throat, Breast and Genito-urinary Organs. With II 3 Illustrations. Royal 8vo,, 2Is.

CLARKE.-POST-MORTEM EXAMINATIONS IN MEDICOLEGAL AND ORDINARY CASES. With Special Chapters on the Legal Aspects of Post-mortems, and on Certificates of Death. By J. JACKSON Cl.ARKE, M.B. Lond., F.R.C.S., Assistant Surgeon at the North-west London and City Orthopæedic Hospitals, etc. Fcp. 8vo., 2s. 6d.

COATS.-A MANUAL OF PATHOLOGY. By JOSEPH CoAts, M.D., late Professor of Pathology in the University of Glasgow. Fourth Edition. Revised throughout and Edited by LEwis R. SUTHERLAND, M. D., Professor of Pathology, University of St. Andrews.

[Nerv Edition in the press.

COOKE.-Works by THOMAS COOKE, F.R.C.S. Eng., B.A., B.Sc., M.D., Paris.

TABLETS OF ANATOMY. Being a Synopsis of Demonstrations given in the Westminster Hospital Medical School. Eleventh Edition in Three Parts, thoroughly brought up to date, and with over 700 Illustrations from all the best Sources, British and Foreign. Post 4 to.

Part I. The Bones. 7s. $6 d$. net.

Part II. Limbs, Abdomen, Pelvis. Ios. $6 d$. net.

Part III. Head and Neck, Thorax, Brain. Ios. 6d. net. 
Scientific Works published by Longmans, Green, \& Co.

MEDICINE AND SURGERY-Continued.

COOKE.-Works by THOMAS COOKE (continued).

APHORISMS IN APPLIED ANATOMY AND OPERATIVE

SURGERY. Including Ioo Typical vivâ voce Questions on Surface Marking, etc. Crown 8 vo., $3^{s .} 6 d$.

DAKIN.-A HANDBOOK OF MIDWIFERY. By William RADFORD DAKIN, M.D., F.R.C.P., Obstetric Physician and Lecturer on Midwifery at St. George's Hospital, etc. With 394 Illustrations. Large crown 8 vo., 18 s.

DICKINSON.--Works by W. HOWSHIP DICKINSON, M.D. Cantab., F.R.C.P.

ON RENAL AND URINARY AFFECTIONS. With I 2 Plates and 222 Woodcuts. Three Parts. 8vo., 634 s. $6 d$.

THE TONGUE AS AN INDICATION OF DISEASE : being the Lumleian Lectures delivered March, I888, 8vo., 7s, $6 d$.

OCCASIONAL PAPERS ON MEDICAL SUBJECTS, IS55I8g6. 8 vo., I2S.

MEDICINE OLD AND NEW. An Address Delivered on the Occasion of the Opening of the Winter Session, r899-1900, at St. George's Hospital Medical School, on 2nd October, I8gg. Crown 8vo., 2s. $6 d$.

DUCKIVORTH.-Works by SIR DYCE DUCKWOR'TH, M.D.,

LL.D., Fellow and Treasurer of the Royal College of Physicians, etc.

THE SEQUELS OF DISEASE : being the Lumleian Lectures, 1896. 8vo., ros. $6 d$.

THE INFLUENCE OF CHARACTER AND RIGHT JUDGMENT IN MEDICINE: the Harveian Oration, 1898. Post 4to., 2s. $6 d$.

ERICHSEN.-THE SCIENCE AND ART OF SURGERY; a Treatise on Surgical Injuries, Diseases, and Operations. By Sir JOHN ERIC ERICHSEN, Bart., F.R.S., LL.D. Edin., Hon. M.Ch. and F.R.C.S. Ireland. Illustrated by nearly rooo Engravings on Wood. 2 vols. Royal 8vo., 48 s.

FOIVLER AND GODLEE.THE IDISEASES OF THE LUNGS. By JAMES Kingston Fowler, M.A., M.D., F.R.C.P., Physician to the Middlesex Hospital and to the Hospital for Consumption and Diseases of the Chest, Brompton, etc. ; and RICKMAN JoHN GODLEE, Honorary Surgeon in Ordinary to His Majesty, M.S., F.R.C.S., Fellow and Professor of Clinical Surgery, University College, London, etc. With 160 Illustrations. 8vo., 25 s. 


\section{MEDICINE AND SURGERY-Contimeed.}

GARROD.-Works by SIR ALFRED BARING GARROD, M.D., F.R.S., etc.

A TREATISE ON GOUT AND RHEUMATIC GOUT (RHEUMATOID ARTHRITIS). With 6 Plates, comprising 2 I Figures. (14 Coloured), and 27 Illustrations engraved on Wood. 8vo., 21 s.

THE ESSENTIALS OF MATERIA MEDICA AND THERAPEUTICS. Crown 8vo, , I2s. 6 d.

GOADBY.-THE MYCOLOGY OF THE MOUTH : a TextBook of Oral Bacteria. By KENNETH W. GOADBY, L.D.S. (Eng.), D.P.H. (Camb.), L.R.C.P., M.R.C.S., Bacteriologist and Lecturer on Bacteriology, National Dental Hospital, etc. With 82 Illustrations. 8 vo., $8 s, 6 d$. net..

GOODSALL AND MILES.-DISFASES OF THE ANUS AND RECTUM. By D. H. Goodsall, F.R.C.S., Senior Surgeon, Metropolitan Hospital; Senior Surgeon, St. Mark's Hospital; and W. ERneST Miles, F.R.C.S., Assistant Surgeon to the Cancer Hospital, Surgeon (out-patients), to the Gordon Hospital, etc. (In Two Parts.) Part I. With gr Illustrations. 8 vo., $75.6 d$. net.

GRAY.-ANATOMY, DESCRIPTIVE AND SURGICAL. By HENRY GRAY, F.R.S., late Lecturer on Anatomy at St. George's Hospital. Medical School. The Fifteenth Edition Enlarged, edited by T. PICKERING PICK, F.R.C.S., Consulting Surgeon to St. George's Hospital, etc., and by ROBERT HOWDEN, M.A., M.B., C.M., Professor of Anatomy in the University of Durham, etc. With 772 Illustrations, a large proportion of which are Coloured, the Arteries being coloured red, the Veins blue, and the Nerves yellow. The attachments of the muscles to the bones, in the section on Osteology, arealso shown in coloured outline. Royal 8 vo., 325 . net.

HALLIBURTON.-Works by W. D. HALLIBURTON, M.D., F.R.S., Professor of Physiology in King's College, London.

A TEXT-BOOK OF CHEMICAL PHYSIOLOGY AND. PATHOLOGY. With I04 Illustrations. 8vo., $28 s$.

ESSENTIALS OF CHEMICAL PHYSIOLOGY. . With 77 Illustrations. 8 vo., $5^{5}$.

LANG.-THE METHODICAL EXAMINATION OF THE EYE. Being Part I. of a Guide to the Practice of Ophthalmology for Students and Practitioners. By William LANG, F.R.C.S. Eng., Surgeon to the Royal London Ophthalmic Hospital, Moorfields, etc. With I5 Illustrations. Crown 8vo., $3^{s .} 6 d$.

LUFF-TEXT-BOOK OF FORENSIC MEDICINE AND TOXICOLOGY. By ARTHur P. LUFF, M.D., B.Sc. (Lond.), Physician in Charge of Out-Patients and Lecturer on Medical Jurisprudence and Toxicology in St. Mary's Hospital. With $I_{3}$ full-page Plates ( $I$ in colours) and 33 Illustrations in the Text. 2 vols. Crown 8 vo., 245. 
MEDICINE AND SURGERY-contimeed.

LIVERPOOL UNIVERSITY PRESS PUBLICATIONS, THE.

The Thomson Yates Laboratories Reports. Physiology; Path-. ology; Bacteriology; Tropical Medicine; Hygiene. Edited by RUPERT BOYCE and C. S. SHERRINGTON. With Plates and Illustrations in the text. Demy 4to. Vol I., I898-9, Ios. 6d.; Vol. II., I898-9, 255.; Vol. III., Part I., I900, $7 s .6$. ; Vol. III., Part II., I901, I2s. 6d. ; Vol. IV., Part I., I901, 20s. ; Vol. IV., Part II., I902, 21s.

\section{THE LIVERPOOL SCHOOL OF TROPICAL MEDICINE MEMOIRS.}

With Plates and Illustrations in the text. Demy 4 !o.

I. Malarial Fever: Its Cause, Prevention and Treatment. Containing full details for the use of Travellers, Sportsmen, Soldiers, and Residents. in Malarious Places. By RonALD Ross, C.B., F.R.S., F.R.C.S. With Frontispiece. 8vo., 2s. 6 d.

II. Report of the Malaria Expedition to West Africa, August, I899. By Ronald Ross, C.B., F.R.S., F.R.C.S., H. E. AnnetT, M.D., D.P.H. and E. E. Austen. With Supplementary Reports by Major G. M. Giles, M. B. and R. FIELDING-OULD, M.B. 2Is.

III. Report of the Malaria Expedition to Nigeria. Part I. Malarial Fever, etc. By H. E. ANNETt, M.D., J. Everett Dutton, M.B. and J. H. ELliotT, M.D. Ios. 6 .

IV. Report of the Malaria Expedition to Nigeria. Part II: Filariasis. By H. E. Annett, M.D., J. Everett Dutton, M.B. and J. H. ELLIOTT, M.D. I5.

V. Part I. First Progress Report of the Campaign against Mosquitoes in Sierra Leone (rgor). By Ronald Ross, C.B., F.R.C.S., F.R.S. 8vo, is.

V. Part II. Second Progress Report of the Campaign against Mosquitoes in Sierra Leone. By M. Logan TAYLOR, M.B. 8vo., Is.

VII. Report of the Yellow Fever Expedition to Pará (I900). By H. E. Durham, M.B., F.R.C.S., and the late Walter Myers, M.B. 4 to., $7 s, 6 d$.

VIII. Report on the Sanitary Conditions of Cape Coast Town, with Suggestions as to Improvement of same. By M. LOGAN TAYLOR, M. B. 8vo., sewed, $\mathbf{s}$.

IX. Report on Malaria at Ismailia and Suez. By Ronald Ross, C.B., F.R.C.S. 8vo., sewed, Is.

$$
\text { MIISCELLANEOUS. }
$$

Notes on Sanitary Conditions obtaining in Pará. By the Members. OF THE Yellow FEVER EXPEDITION. 8vo., Is.

PAGET.-Edited by STEPHEN PAGET.

SELECTED ESSAYS AND ADIRRESSES. By Sir JAMES PAGET. 8vo., I2s, $6 d$. net

MEMOIRS AND LETTERS OF SIR JAMES PAGET, BART., F.R.S., D.C.L., late Sergeant-Surgeon to Her Majesty Queen Victoria. With. Portrait. 8vo., 6s. net.

PICK.-SURGERY : a Treatise for Students and Practitioners. By T. PICKERING PICK, Consulting Surgeon to St. George's Hospital; Senior Surgeon to the Victoria Hospital for Children; H.M. Inspector of Anatomy in England and Wales. With 44r Illustrations. Medium 8vo., 25 s.

POOLE.COOKERY FOR THE DIABETIC. By W. H. and Mrs. Poole. With Preface by Dr. PAvy. Fcap. 8vo., 2s. $6 d$. 


\section{MEDICINE AND SURGERY-continued.}

PROBYN-WILLIAMS.-A PRACTICAL GUIDE TO THE ADMINISTRATION OF ANÆSTHETICS. By R. J. PROBYN-WILLIAMS, M.D., Anæsthetist and Instructor in Anæsthetics at the London Hospital ; Lecturer in Anæsthetics at the London Hospital Medical College, etc. With 34 Illustrations. Crown 8vo., 4s. 6d. net.

QUAIN.-QUAIN'S (SIR RICHARD) DICTIONARY OF MEDICINE. By Various Writers. Third Edition. Edited by H. Montague Murray, M.D., F.R.C.P., Joint Lecturer on Medicine, Charing Cross Medical School, and Physician to Out-Patients, Charing Cross Hospital ; assisted by John HARold, M.B., B.Ch., B.A.O., Physician to St. John's and St. Elizabeth's Hospital; and W. Cecil Bosanquer, M.A., M.D., M.R.C.P., Physician to Out-Patients, Victoria Hospital for Children, Chelsea. With 2I Plates (I4 in Colour) and numerous Illustrations in the Text. 8vo., 2Is. net, buckram; or 30 s. net, half-morocco.

QUAIN.-QUAIN'S (JONES) ELEMENTS OH ANATOMY. The Tenth Edition. Edited by EdWARd Albert Schäfer, F.R.S., Professor of Physiology in the University of Edinburgh; and GEORGE DANCER THANE, Professor of Anatomy in University College, London.

VOL. I., PART I, EMBRYOLOGY. By E. A. SCHÄFER, F.R.S. With 200 Illustrations. Royal 8vo., 9s.

VOL. I., PART II. GENERAL ANATONY OR HISTOLOGY. BY E. A. SCHÄFER, F.R.S. With $29 \mathrm{I}$ Illustrations. Royal 8vo., I2s. 6 d.

VOL. II., PART I. OSTEOLOGYARTHROLOGY. By G. D. Thane. With 224 Illus, Royal 8vo., IIs.

VOL. II., PART II. MYOLOGYANGEIOLOGY. By G. D. THANE. With I9g Illustrations. Royal 8vo. x6s.

VOL. III, PART I. THE SPINAL CORD AND BRAIN. By E. A. SCHÄFER, F.R.S. With I39 Illustrations. Royal 8vo., I2s. $6 d$.
VOL. III., PART II. THE NERVES. By G. D. THANE. With IO2 Illustrations. Royal 8vo., gs.

VOL. III., PART III. THE ORGANS OF THE SENSES. By E. A. SCH ÄFER, F.R.S. With 178 Illustrations. Royal 8vo., 9s.

VOL. III., PART IV. SPLANCHNOLOGY. By E. A. SCHĀFER, F.R.S., and JOHNSON SYMINGTON, M.D. With 337 Illustrations. Royal 8vo., I6s.

APPENDIX, SUPERFICIAL AND SURGICAL ANATOMY. By Professor G. D. THANE and Professor R. J. GODLEE, M.S. With 29 Illustrations. Royal 8vo., $6 s, 6 d$.

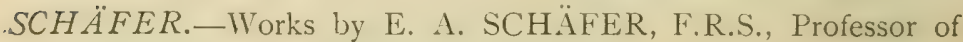
Physiology in the University of Edinburgh.

THE ESSENTIALS OF HISTOLOGY. Descriptive and Practical. For the Use of Students. With 463 Illustrations. 8 vo., gs, net.

\section{DIRECTIONS FOR CLASS WORK IN PRACTICAL} PHYSIOLOGY : Elementary Physiology of Muscle and Nerve and of the Vascular and Nervous Systems. With 48 Diagrams and 24 pages of plain paper at end for Notes. 8 vo., 3 s. net.

SMALE AND COLYER.-DISEASES AND INJURIES OF THE TEETH, including Pathology and Treatment. By MORTON SMALE, M.R.C.S., L.S.A., L.D.S., Dental Surgeon to St. Mary's Hospital, Dean of the School, Dental Hospital of London, etc. ; and J. F. COLYER, L.R.C.P., M.R.C.S., L.D.S., Dental Surgeon to Charing Cross Hospital and to the Dental Hospital of London. Second Edition Revised and Enlarged by J. F. COLYER. With 640 Illustrations. Large crown 8 vo., 2Is, net. 
Scientific Works published by Longmans, Green, \&o Co.

MEDICINE AND SURGERY-continned.

SMITH (H. F.).-THE HANDBOOK FOR MIDIVIVES By HeNRY Fly SMith, B.A., M.B. Oxon., M.R.C.S. 4I Woodcuts. Cr. 8vo., 5s.

STEVENSON.-WOUNDS IN WAR : the Mechanism of their Ploduction and their Treatment. By Surgeon-Colonel W. F. STEvenson

(Army Medical Staff), A.B., M.B., M.Ch. Dublin University, Professor of Military Surgery, Army Medical School, Netley. With 86 Illustrations, 8vo , I8s.

TAPPEINER. - INTRODUCTION TO CHEMICAL METHODS OF CLINICAL DIAGNOSIS. By Dr. H. TAPPEINER, Professor of Pharmacology and Principal of the Pharmacological Institute of the University of Munich. Translated by EDMOND J. MCWEENEY, M.A., M.D. (Royal Univ. of Ireland), L.R.C.P.I., etc. Crown 8vo., 3s. $6 d$.

WALLER.-Works by AUGUSTUS D. WALLER, M.U., Lecturer on Physiology at St. Mary's Hospital Medical School, London; late External Examiner at the Victorian University.

AN INTRODUCTION TO HUMAN PHYSIOLOGY. Third Edition, Revised. With 3 I 4 Illustrations. 8vo., I8s.

LECTURES ON PHYSIOLOGY. First Series. On Animal Electricity. 8vo, 5s, net.

\section{VETERINARY MEDICINE, ETC.}

FITZWYGRAM.-HORSES AND STABLES. By Lieut.General Sir F. FItzWYGram, Bart. With 56 pages of Illustrations. $8 \mathrm{vo}, 35$, net.

STEEL.-Works by JOHN HENRY STEEL, F.R.C.T.S., F.Z.S., A.V.D., late Professor of Veterinary Science and Principal of Bombay Veterınary College.

A TREATISE ON THE DISEASES OF THE DOG; being a Manual of Canine Pathology. Especially adapted for the use of Veterinary Practitioners and Students. With 88 Illustrations. $8 \mathrm{vo}$, , $10 \mathrm{~s} 6$.

A TREATISE ON THE DISEASES OF THE OX; being a Manual of Bovine Pathology. Especially adapted for the use of Veterinary Practitioners and Students. With 2 Plates and II 7 Woodcuts. 8vo. I 5 s.

A TREATISE ON THE DISEASES OF THE SHEEP ; being a Manual of Ovine Pathology for the use of Veterinary Practitioners and Students. With Coloured Plate and 99 Woodcuts. 8vo., I2s.

YOUATT.-Works by WILLIAM YOUATT.

THE HORSE. With 52 Wood Engravings. 8vo., 7s. 6d.

THE DOG. With 33 Wood Engravings. 8vo., 6s. 


\section{PHYSIOLOGY, BIOLOGY, ZOOLOGY, ETC.}

(And see MEDICINE AND SURGERY, page 25.)

$A N N A N D A L E$ AND ROBINSON. - FASCICULI MALAY ENSES: Anthropological and Zoological Results of an Expedition to Perak and the Siamese Malay States, Igor-2. Undertaken by NELSON ANNANDALE and HERBERT C. ROBINSON, under the auspices of the University of Edinburgh and University College, Liverpool. With 17 Plates and I 5 Illustrations in the text. Part I. 4to., $15^{s}$. net.

$A S H B Y$.-NOTES ON PHYSIOLOGY FOR THE USE OF STUDENTS PREPARING FOR EXAMINATION. BY HENRY ASHBY, M.D. Lond., F.R.C.P., Physician to the General Hospital for Sick Children, Manchester. With 148 Illustrations. I8mo., 5 s.

BARNETT.-THE MAKING OF THE BODY : a Children's Book on Anatomy and Physiology. By Mrs. S. A. BARnetT. With Ir3 Illustrations. Crown 8vo, is. 9d.

$B E D D A R D .-$ Works by FRANK E. BEDDARD, M.A. Oxon.

ELEMENTARY PRACTICAL ZOOLOGY. With 93 Illustrations. Crown 8 vo, , 2s, $6 d$.

THE STRUCTURE AND CLASSIFICATION OF BIRDS. With 252 Illustrations. 8vo., 2Is, net.

BIDGOOD.-A COURSE OF PRACTICAI, EI.EMENTARY BIOLOGY. By JOHN BIDGOOD, B.Sc., F.L.S. With 226 Illustrations. Crown 8vo., $4 s .6 d$.

BOSE.-RESPONSE IN 'THE LIVING'AND NON-LIVING. By J AGadis Chunder Bose, M.A. (Cantab.), D.Sc. (Lond.), Professor, Presidency College, Calcutta. With II7 Illustrations. 8vo, Ios. $6 d$.

BRODIE. - THE ESSENTIAIS OF EXPERIMENTAL PHYSIOLOGY. For the Use of Students. By T. G. Brodie, M.D., Lecturer on Physiology, St. Thomas's Hospital Medical School. With 2 Plates and 177 Illustrations in the Text. 8vo., $6 s .6 d$.

CHAPMAN.-THE FORAMINIFERA: An Introduction to the Study of the Protozoa. By FREDERICK CHAPMAN, A.L.S., F.R.M.S. With I4 Plates and 42 Illustrations in the Text. 8vo., 9s. net.

FURNEAUX.-HUMAN PHYSIOLOGY. By W. FurNEAUX, F.R.G.S, With 218 Illustrations, Crown 8 vo., $25.6 d$.

HUDSON AND GOSSE.-THE ROTIFERA, Or 'WHEELANIMACUlES'. By C. T. Hudson, LL.D., and P. H. Gosse, F.R.S. With 30 Coloured and 4 Uncoloured Plates. In 6 Parts. 4 to., Ios, $6 d$. each.

Supplement 12s, $6 d$. Complete in 2 vols., with Supplement, 4to., $6_{0} 44$.

MACALISTER. - Works by ALEXANDER MACALISTER, M.D.

AN INTRODUCTION TO THE SYSTEMATIC ZOOLOGY AND MORPHOLOGY OF VERTEBRATE ANIMALS. With 4I Diagrams. 8vo., Ios. $6 d$.

ZOOLOGY OF THE INVERTEBRATE ANIMALS. With 77 Diagrams. Fcp. 8vo., is. 6d.

ZOOLOGY OF THE VERTEBRATE ANIMALS. With 59 Diagrams. Fcp. 8vo., is. $6 d$. 
PHYSIOLOGY, BIOLOGY, ZOOLOGY, ETC.-Contimeer.

MACDOUGAL. - Works by DANIEL TREMBLY MAC-

DOUGAL, Ph.D., Director of the Laboratories of the New York Botanical Garden.

PRACTICAL TEXT-BOOK OF PLANT PHYSIOLOGY. With I59 Illustrations. 8vo., 7s, 6 $d$. net:

ELEMENTARY PLANT PHYSIOLOGY. With Io8 Illustrations. Crown 8 vo., $3^{\text {s. }}$.

MOORE.-ELEMENTARY PHYSIOLOGY. By BENJAMIN Moore, M.A., Lecturer on Physiology at the Charing Cross Hospital Medical School. With 125 Illustrations. Crown 8 vo., 3s. $6 d$.

MORGAN.-ANIMAL BIOLOGY : an Elementary Text-Book. By C. Lloyd MoRgan, F.R.S., Principal of University College, Bristol. With. Io3 Illustrations. Crown 8vo., 8s. $6 d$.

SCHÄFER.-DIRECTIONS FOR CLASS WORK IN PRACTICAL PHYSIOLOGY : Elementary Physiology of Muscle and Nerve and of the Vascular and Nervous Systems. By E. A. SCHÄFER, LL.D., F.R.S., Professor of Physiology in the University of Edinburgh. With 48 Diagrams. 8 vo., 3s, net.

THORNTON.-Works by JOHN THORNTON, M.A.

HUMAN PHYSIOLOGY: With 267 Illustrations, some Coloured. Crown 8vo., 6s.

ELEMENTARY BIOLOGY, Descriptive and Experimental. With numerous Illustrations. Crown 8 vo., $3^{s}$. $6 d$.

\section{BACTERIOLOGY.}

CURTIS.THE ESSENTIALS OF PRACTICAL BACTERIOLOGY : An Elementary Laboratory Book for Students and Practitioners. By H. J. CuRTiS, B.S. and M.D. (Lond.), F.R.C.S. With I33 Illustrations. 8vo., gs.

DHINGRA.-AAN INTRODUCTION TO BACTERIOLOGY. (Specially designed for Indian Medical Students.) By M. L. DHingra, M. D.D.P.H.

FRANKLAND.-MICRO-ORGANISMS IN WATER. TOgether with an Account of the Bacteriological Methods involved in their Investigation. Specially designed for the use of those connected with the Sanitary Aspects of Water-Supply. By PERCY Frankland, Ph.D., B.Sc. (Lond.), F.R.S., and Mrs. PERCy FrankLand. With 2 Plates and Numerous Diagrams, 8vo., $16 s$, net.

FRANKLAND.-BACTERIA IN DAILY LIFE. By Mrs. Percy Frankland, F.R.M.S. Crown 8vo., 5s. net.

GOADBY.THE MYCOLOGY OF THE MOUTH : A TextBook of Oral Bacteria. By KeNNETH W. GoAdBy, L.D.S. Eng., etc.; Bacteriologist and Lecturer on Bacteriology, National Dental Hospital, etc. With 82 Illustrations, 8 vo., $8 s .6 d$. net. 
34 Scientific Works published by Longmans, Grcen, \& Co.

\section{BACTERIOLOGY-Continzed.}

PLIMMER. - THE CHEMICAL CHANGES AND PRODUCTS RESULTING FROM FERMENTATION. By R. H. ADERS Plimmer, D.Sc., Lond, Grocers' Research Student, Jenner Institute of Preventive Medicine. 8 vo., $6 s$. net.

\section{BOTANY.}

AITKEN. - ELEMENTARY TEXT-BOOK OF BOTANY. By EDITH AITKEN, late Scholar of Girton College. With 400 Diagrams. Crown 8vo., 4s, 6d.

BENNETT AND MURRAY.-HANDBOOK OF CRYPTOGAMIC BOTANY. By ALFRED W. BENNETT, M.A., B.Sc., F.L.S., Lecturer on Botany at St. Thomas's Hospital ; and GEORGE MURRAY, F.L.S., Keeper of Botany, British Museum. With 378 Illustrations. 8vo., I6s.

CROSS AND BEVAN.-Works by C. F. CROSS, E. J. BEVAN and $\mathrm{C} . \mathrm{BEADJ} \mathrm{E}$.

CELLULOSE : an Outline of the Chemistry of the Structural Elements of Plants. With Reference to their Natural History and Industrial Uses, With 14 Plates. Crown 8vo., I2s, net.

RESEARCHES ON CELLULOSE, I895-I90o. Cr. 8vo., 6s, net.

EDMONDS.-Works by HENRY EDMONDS, B.Sc., London.

ELEMENTARY BOTANY. With 342 Illustrations. Cr.8vo., 2s.6d. BOTANY FOR BEGINNERS. With 85 Illustrations. Fcp. $8 \mathrm{vo}$, Is. 6 d.

FARMER.-A PRACTICAL INTRODUCTION TO THE STUDY OF BOTANY : Flowering Plants. By J. BRETLAND FARMER, F.R.S., M.A., Professor of Botany in the Royal College of Science, London. With I2I Illustrations. Crown 8vo., 2s, 6d.

HOFFMANN.-ALPINE FlORA: for Tourists and Amateur Botanists. By Dr. Julius Hoffmann. Translated by E. S. Barton (Mrs. A. GEPP). With 40 Plates, containing 250 Coloured Figures, from Water-Colour Sketches by HERMANN FRIESE. With Text descriptive of the most widely distributed and attractive of Alpine Plants. 8vo, $7 s, 6 d$. net.

KITCHENER. -A YEAR'S BOTANY. Adapted to Home and School Use. By Frances A. Kitchener. With I95 Illustrations. Cr. 8vo., $5^{s}$.

LINDLEY AND MOORE.-THE TREASURY OF BOTANY. Edited by J. LiNDLEY, M.D., F.R.S., and T. MOORE, F.L.S. With 20 Steel Plates and numerous Woodcuts. Two parts. Fcp. 8vo., I2s.

MCNAB.-CLASS-BOOK OF BOTANY. By IV. R. MCNAB. MORPHOLOGY AND PHYSI- CLASSIFICATION OF PLANTS. OLOGY. With 42 Diagrams. With 1I8 Diagrams. Fcp. 8vo., Fcp. 8vo., Is. 6d.

SORAUER.-A POPULAR TREATISE ON THE PHYSIOLOGY OF PLANTS. By Dr. PAUl SORAuER. Translated by F. E. Weiss, B.Sc., F.L.S. With 33 Illustrations. 8vo., 9s. net. 


\section{BOTANY-Continued.}

THOMÉ AND BENNETT.-STRUCTURAL AND PHYSIOLOGICAL BOTANY. By OtTo Wilhelm Thomé and by ALFRED W. BenNetT, B.Sc., F.L.S. With Coloured Map and 600 Woodcuts. Fcp. 8vo., 6s.

$T U B E U F$-DISEASES OF PLANTS INDUCED BY CRYPTOGAMIC PARASITES. Introduction to the Study of Pathogenic Fungi, Slime Fungi, Bacteria and Algæ. By Dr. KARL FrEIHERR VON TUBEUF, Privatdocent in the University of Munich. English Edition by William G. Smith, B.Sc., Ph.D., Lecturer on Plant Physiology, University of Edinburgh. With 330 Illustrations. Royal 8vo., r8s, net.

WATTS.-A SCHOOL FLORA. For the use of Elementary Botanical Classes. By W. MARshall. WAtts, D.Sc, Lond. Cr, 8vo, 2s, 6d.

\section{AGRICULTURE AND GARDENING.}

ADD YMAN.-AGRICULTURAL ANALYSIS. A Manual of Quantitative Analysis for Students of Agriculture. By FrANK T. ADDYMAN, B.Sc. (Lond.), F.I.C. With 49 Illustrations. Crown 8vo., 5 s. net.

COLEMAN AND ADDYMAN.-PRACTICAL AGRICULTURAL CHEMISTRY. By J. BERNARD COLEMAN, A.R.C.Sc., F.I.C., and FRANK T. ADDYMAN, B.Sc. (Lond.), F.I.C. With 24 Illustrations. Crown 8 vo., Is $6 d$. net.

HAGGARD.-Works by H. RIDER HAGGARD.

A FARMER'S YEAR : being his Commonplace Book for 1898 . With 36 Illustrations by G. LEON LITTLE and three others. Crown 8vo., $7 s .6 d$. net.

RURAL ENGLAND : being an Account of Agricultural and Social Researches carried out in the years I90r and 1902. With 23 Agricultural Maps and 75 Illustrations from Photographs. 2 vols. 8vo., 36 s. net.

$J E K Y L L .-W o r k s$ by GERTRUDE JEKYLL.

HOME AND GARDEN : Notes and Thoughts, Practical and Critical, of a Worker in both. With 53 Illustrations from Photographs. 8vo., Ios. 6 d. net.

WOOD AND GARDEN : Notes and Thoughts, Practical and Critical, of a Working Amateur. With 7I Photographs. 8vo., Ios. $6 d$. net.

WEATHERS. - A PRACTICAL GUIDE TO GARDEN PLANTS. Containing Descriptions of the Hardiest and most Beautiful Annuals and Biennials, Hardy Herbaceous and Bulbous Perennials, Hardy Water and Bog Plants, Flowering and Ornamental Trees and Shrubs, Conifers, Hardy Ferns, Hardy Bamboos and other Ornamental Grasses; and also the best kinds of Fruit and Vegetables that may be grown in the Open Air in the British Islands, with Full and Practical Instructions as to Culture and Propagation. By JOHN WEATHERS, F.R.H.S., late Assistant Secretary to the Royal Horticultural Society, formerly of the Royal Gardens, Kew, etc. IVith 163 Diagrams. 8vo., 2IS. net.

WEBB.--IVorks by HENRY J. WEBB, Ph.U., B.Sc. (Lond.).

ELEMENTARY AGRICULTURE. A Text-Book specially adapted to the requirements of the Board of Education, the Junior Examination of the Royal Agricuitural Society, and other Elementary Examinations. With 34 Illustrations. Crown 8vo., 2s. $6 d$.

AGRICULTURE. A Manual for Advanced Science Students. With roo Illustrations. Crown 8vo., 7s. 6d. net. 


\section{WORKS BY JOHN TYNDALL, D.C.L., LL.D., F.R.S.}

LECTURES ON SOUND. With Frontispiece of Fog-Syren, and 203 other Woodcuts and Diagrams in the Text. Crown 8vo, Ios. $6 d$.

HEAT, A MODE OF MOTION. With 125 Woodcuts and Diagrams. Crown 8vo., r2s.

LECTURES ON LIGHT DELIVERED IN THE UNITED STATES IN 1872 AND 1873 . With Portrait, Lithographic Plate, and 59 Diagrams. Crown 8vo., $5^{s}$.

FRAGMENTS OH SCIENCE: a Series of Detached Essays, Addresses, and Reviews. 2 vols. Crown 8vo., i6s.

Vol. I. - The Constitution of Nature-Radiation-On Radiant Heat in Relation to the Colour and Chemical Constitution of Bodies-New Chemical Reactions produced by Light-On Dust and Disease-Voyage to Algeria to observe the Eclipse-Niagara-

The Parallel Roads of Glen Roy-Alpine Sculpture-Recent Experiments on FogSignals-On the Study of Physics-On Crystalline and Slaty Cleavage-On Paramagnetic and Diamagnetic Forces-Physical Basis of Solar Chemistry-Elementary Magnetism-On Force-Contributions to Molecular Physics-Life and Letters of FARADAY - The Copley Medallist of $187 \mathrm{C}$-The Copley Medallist of $1871-$ Death by Lightning-Science and the Spirits.

Vol. II.-Reflections on Prayer and Natural Law-Miracles and Special Providences-On Prayer as a Form of Physical Energy-Vitality-Matter and Force-Scientific Materialism-An Address to Students-Scientific Use of the Imagination-The Belfast Address-Apology tor the Belfast Address-The Rev. JAMES MARTineAu and the Belfast Address-Fermentation, and its Bearings on Surgery and Medicine-Spontaneous Generation-Science and Man-Professor VIRCHOW and Evolution-The Electric Light.

NEW FRAGMENTS. Crown 8vo., Ios. 6 d.

Conrents.-The Sabbath-Goethe's 'Farbenlehre'-Atoms, Molecules, and Ether Waves - Count Rumford-Louis Pasteur, his Life and Labours-The Rainbow and its CongenersAddress delivered at the Birkbeck Institution on October 22, $188_{4}$-Thomas Young-Life in the Alps-About Common Water-Personal Recollections of Thomas Carlyle-On Unveiling the Statue of Thomas Carlyle-On the Origin, Propagation, and Prevention of Phthisis-Old Alpine Jottings-A Morning on Alp Lusgen.

ESSAYS ON THE FLOATING MATTER OF THE AIR IN RELATION TO PUTREFACTION AND INFECTION. With 24 Woodcuts. Crown 8vo., 7s. 6d.

RESEARCHES ON DIAMAGNETISM AND MAGNECRYSTALLIC ACTION; including the Question of Diamagnetic Polarity. Crown 8vo., I2s.

NOTES OF A COURSE OF NINE LECTURES ON LIGHT. delivered at the Royal Institution of Great Britain, r869. Crown 8vo., rs. $6 d$.

NOTES OF A COURSE OF SEVEN LECTURES ON ELECTRICAL PHENOMENA AND THEORIES, delivered at the Royal Institution of Great Britain, 1870 . Crown 8vo, is. $6 d$.

LESSONS IN ELECTRICITY AT THE ROYAL INSTITUTION 1875-1876. With 58 Woodcuts and Diagrams. Crown 8vo, 2s. $6 d$.

THE GLACIERS OF THE ALPS: being a Narrative of Excursions and Ascents. An Account of the Origin and Phenomena of Glaciers, and an Exposition of the Physical Principles to which they are related. With 7 Illustrations. Crown 8vo., $6 s .6 d$. net.

HOURS OF EXERCISE IN THE ALPS. With 7 Illustrations. Crown 8 vo., 6s. 6d. net.

FARADAY AS A DISCOVERER. Crown 8vo., 3s. $6 d$. 


\section{TEXT-BOOKS OF SCIENCE.}

PHOTOGRAPHY. By Sir WilliaM DE WIVEleslie ABNey, K.C.B., F.R.S. With I 34 Illustrations. Fcp. 8vo., $5^{s}$.

THE STRENGTH OF MATERIALS AND STRUCTURES. By Sir J. ANDERson, C.E. With 66 Illustrations. Fcp. 8vo., 35. 6d.

RAILWAY APPLIANCES. By Sir JOHN WOLFE BARRY, K.C.B., F.R.S., M.I.C.E. With 218 Illustrations. Fcp. 8vo., 4s. 6d.

INTRODUCTION TO THE STUDY OF INORGANIC CHEMISTRY. By William Allen Miller, M.D., LL.D., F.R.S. With 72 Illustrations. 3s. $6 d$.

QUANTITATIVE CHEMICAL ANALYSIS. By T. E. THORPE, C.B., F.R.S., Ph.D. With 88 Illustrations. Fcp. 8vo., 4s. 6d.

QUALITATIVE ANALYSIS AND LABORATORY PRACTICE. By T. E. ThORPE, C.B., Ph.D., F.R.S., and M. M. PATTISON Muir, M.A. and F.R.S.E. With Plate of Spectra and .57 Illustrations. Fcp. 8vo., $3^{s}, 6 d$.

INTRODUCTION TO THE STUDY OF CHEMICAL PHILOSOPHY. By William A. Tilden, D.Sc., London, F.R.S. With Illustrations. Fcp. 8vo., 5s. With Answers to Problems. Fcp. 8vo., 5s.6d.

ELEMENTS OF ASTRONOMY. By Sir R. S. BALL, LL.D., F.R.S. With I30 Illustrations. Fcp. 8vo., 6s. 6d.

SYSTEMATIC MINERALOGY. By HILARY BAuERMAN, F.G.S. With 373 Illustrations, Fcp. 8vo,, 6s.

DESCRIPTIVE MINERALOGY. By Hilary BAUERMAN, F.G.S., etc. With 236 Illustrations, Fcp. 8vo, 6 s.

METALS : THEIR PROPERTIES AND TREATMENT. BY A. K. HuNTINGTON and W. G. MCMiLLAN. With I22 lllustrations. Fcp. 8vo., 75. $6 d$.

THEORY OF HEAT. BY J. CLERK MAXWELL, M.A., LL.D., Edin., F.R.SS., L. \& E. With 38 Illustrations. Fcp. 8vo., 4s. 6 d.

PRACTICAL PHYSICS. By R. T. GLAZEBROOK, M.A., F.R.S., and W. N. SHAW, M.A. With I $_{34}$ Illustrations. Fcp. 8vo., 7s. 6d.
PRELIMINARY SURVEY AND ES. TIMATES. By THEODORE GRAHAM GRIBBLE, Civil Engineer. Including Elementary Astronomy, Route Surveying, Tacheometry, Curve-ranging, Graphic Mensuration, Estimates, Hydrography and Instruments. With r33 Illustrations. Fcp. 8vo., 7s, 6d.

ALGEBRA AND TRIGONOMETRY. By William Nathaniel Griffin, B.D. 3s. 6 . Notes on, with Solutions of the more difficult Questions. Fcp. 8vo., 3s. 6d.

THE STEAM ENGINE. By GEORGE C. V. Holmes, Secretary of the Institution of Naval Architects. With 212 Illustrations, Fcp. 8vo., 6s.

ELECTRICITY AND MAGNETISM. By FleEMING JENKIN, F.R.SS., L. \& E. With I77 Illustrations. Fcp. 8vo., 3s. $6 d$.

THE ART OF ELECTRO-METALLURGY. By G. GORE, LL.D., F.R.S. With 56 Illus. Fcp. 8vo., 6s, TELEGRAPHY. By Sir W. H. PREECE, K.C.B., F.R.S., M.I.C.E., and Sir J. Sivewright, M.A., K.C.M.G. With 267 Illustrations. Fcp. 8vo., $6 s$.

PHYSICAL OPTICS. By R. T. GLAZEBROOK, M.A., F.R.S. With I83 Illustrations. Fcp. 8vo, $6 s$.

TECHNICAL ARITHMETIC AND MENSURATION. By CHARLES W. MERRIEFIELD, F.R.S. 3s. $6 d$. Key, by the Rev. JOHN HUNTER, M.A. Fcp. 8vo., 3s. $6 d$.

THE STUDY OF ROCKS. By FRANK Rutley, F.G.S. With 6 Plates and 88 Illustrations Fcp. 8vo., 4s, $6 d$.

WORKSHOP APPLIANCES, including Descriptions of some of the Machine Tools used by Engineers. By C. P. B. Shelley, MiI.C.E. With 323 Illustrations. Fcp. 8vo., 5s.

ELEMEN'TS OF MACHINE DESIGN. By W. CAWTHORNE UNwIN, F.R.S., B.Sc., M.I.C.E.

PART I. General Principles, Fastenings and Transmissive Machinery. With 345 Illustrations. Fcp. 8vo., 7s. 6d.

PART II. Chiefly on Engine Details. With 259 Illustrations. Fcp. 8vo., 6s,

STRUCTURAL AND PHYSIOLOGICAL BOTANY. BY OTTO WILHELM Thomé, and A. W. BENNETt, M.A., B.Sc, , F.L.S. With 600 Illustrations. Fcp. 8vo., 6s.

PLANE AND SOLID GEOMETRY. By H.W.WAtson, M.A. Fcp.8vo, 3s.6d. 


\section{ADVANCED SCIENCE MANUALS.}

BUILDING CONSTRUCTION. By the Author of 'Rivington's Notes on Building Construction'. With 385 Illustrations and an Appendix of Examination Questions. Crown 8vo., 4s. 6d.

THEORETICAL MECHANICS. Solids, including Kinematics, Statics, and Kinetics. By A. THORNTON, M.A., F.R.A.S. With 220 Illustrations, I30 Worked Examples, and over goo Examples from Examination Papers, etc. Crown 8vo, $4 s, 6 d$.

HEAT, By MARK R, Wright, Hon. Inter. B.Sc. (Lond.). With 136 Illustrations and numerous Examples and Examination Papers. Crown 8vo., 4s. $6 d$.

Light. By W. J. A. Emtage, M.A. With 232 Illustrations. Cr. 8vo., $6 s$.

MAGNETISM AND ELECTRICITY. By ARThur William Poyser, M.A. With 317 Illustrations. Crown 8vo., 4s. $6 d$.

INORGANIC CHEMISTRY, THEORETICAL AND PRACTICAL. By William JAGo, F.C.S., F.I.C. With Plate of Spectra and 78 Woodcuts, Crown 8 vo., $45.6 d$.
GEOLOGY : a Manual for Students in Advanced Classes and for General Readers, By Charles Bird, B.A. (Lond.), F.G.S. With over 300 Illustrations, a Geological Map of the British Isles (coloured), and a set of Questions for Examination. Crown 8vo., 7s. $6 d^{\circ}$.

HUMAN PHYSIOLOGY : a Manual for Students in advanced Classes of the Science and Art Department. By JOHN THORNTON, M.A. With 268 . Illustrations, some of which are Coloured, and a set of Questions for Examination. Crown 8vo., $6 s$.

PHYSIOGRAPHY. By JOHN THORNTON, M.A. With II Maps, 255 Illustrations, and Coloured Map of Ocean Deposits. Crown 8vo., 4s. $6 d$.

AGRiCUlture. By Henry J. WebB, $\mathrm{Ph} . \mathrm{D}$., B.Sc. With roo Illustrations. Crown 8vo., $7 s$. $6 d$. net.

HYGIENE. By J. LANE NoTTER, M.A., M.D., Professor of Hygiene in the Army Medical School, Netley, Colonel, Royal Army Medica Corps; and R. H. FIRTH, F.R.C.S., late Assistant Professor of Hygiene in the Army Medical School, Netley, Major, Royal Army Medical Corps. With 95 Illustrations. Crown 8 vo., $3^{s .6 d \text {. }}$.

\section{ELEMENTARY SCIENCE MANUALS.}

PRACTICAL, PLANE, AND SOLID GEOMETRY, including Graphic Arithmetic. By I. H. MORRIS, Fully Illustrated with Drawings. Crown 8 vo., 2s. $6 d$,

GEOMETRICAL DRAWING FOR ART STUDENTS, Embracing Plane Geometry and its Applications, the Use of Scales, and the Plans and Elevations of Solids. By I. H. MCRRIS. Crown 8vo., $2 s$.

'TEXT-BOOK ON PRACTICAL, SOLID, OR DESCRIP'TIVE GEOMETRY. By DAvid Allan Low (Whitworth Scholar). Part I. Crown 8vo., 2s. Part II. Crown 8vo., 3 s.
AN INTRODUCTION TO MACHINE DRAWING AND DESIGN. By DAVID ALLAN LOW. With I53 Illustrations. Crown 8vo., 2s. $6 d$.

BUILDING CONSTRUCTION AND DRAWING. By EDWARD J. BURRELL. With 308 Illustrations and Working Drawings. Crown 8vo., $2 s, 6 d$.

AN ELEMENTARY COURSE OF MATHEMATICS. Containing Arithmetic; Euclid (Book I., with Deductions and Exercises); and Algebra. Crown 8vo., 2s. $6 d$. 


\section{ELEMENTARY SCIENCE MANUALS-Continzed.}

THEORETICAL MECHANICS. Including Hydrostatics and Pneumatics. By J. E. TAYLOR, M.A., B.Sc. With numerous Examples and Answers, and 175 Diagrams and Illustrations. Crown 8vo., 2s, $6 d$.

THEORETICAL MECHANICS-SOLIDS. By J, E. TAYLOR, M.A., B.Sc. (Lond.). With 163 Illustrations, r20 Worked Examples, and over 500 Examples from Examination Papers, etc. Crown 8vo., 2s, $6 d$.

THEORETICAL MECHANICSFLUIDS. By J. E. TAYLOR, M.A., B.Sc. (Lond.). With 122 Illustrations, numerous Worked Examples, and about 500 Examples from Examination Papers, etc. Crown 8vo., 2s. $6 d$.

A MANUAL OF MECHANICS. With ${ }_{3} 8$ Illustrations and Diagrams, and I88 Examples taken from Examination Papers, with Answers. By T. M. GoOdeve, M.A. Crown 8vo., 25. 6d.

SOUND, LIGHT, AND HEAT. By MARK R. WRIGHT, M.A. With I6o Diagrams and Illustrations. Crown 8vo., 2s, 6d.

METALLURGY : an Elementary 'TextBook. By E. L. RHEAD. With 94 Illustrations. Crown 8 vo., $3^{s}$. $6 d$.

PHYSICS. Alternative Course. By MARK R. WRIGHT, M.A. With 242 Illustrations. Crown 8 vo., $2 s, 6 d$.

MAGNETISM AND ELECTRICITY. By A. W. POYSER, M.A. With 235 Illustrations. Crown 8vo, 2s. $6 d$.

PROBLEMS AND SOLUTIONS IN ELEMENTARY ELECTRICI'TY AND MAGNETISM. By W. SLINGo and A. BROOKER. Embracing a Complete Set of Answers to the South Kensington Papers for the years 1885-1899, and a Series of Original Questions. With 67 Original Illustrations. Crown 8vo., 25 .
ELEMENTARY PHYSIOGRAPHY. By J. Thornton, M.A. With I3 Maps and 295 Illustrations. With Appendix on Astronomical Instruments and Measurements. Crown 8 vo., 2s. $6 d$.

ORGANIC CHEMISTRY : the Fatty Compounds. By R. Lloyd WhitFLEX, F.I.C., F.C.S. With 45 Illustrations. Crown 8vo., 3s. $6 d$.

INORGANIC CHEMISTRY, THEO. RETICAL AND PRACTICAL By William Jago, F.C.S., F.I.C. With 63 Illustrations and numerous Questions and Exercises. Fcp. 8vo., 2s. 6d.

AN INTRODUCTION TO PRACTICAL INORGANIC CHEMISTRY. By William Jago, F.C.S., F.I.C. Crown 8 vo., is. $6 d$.

PRACTICAL CHEMISTRY : the Principles of Qualitative Analysis. By WILLIAM A. TILDEN, D.Sc. Fcp. 8 vo., is. $6 d$.

ELEMENTARY INORGANIC CHEMISTRY. By WILLIAM FURNEAUX, F.R.G.S. Crown 8vo, $2 s, 6 d$.

ELEMENTARY GEOLOGY. By ChARLES BIRD, B.A. F.G.S. With Coloured Geological Map of the British Islands, and 247 Illustrations. Crown 8vo., 2s, 6d.

HUMAN PHYSIOLOGY. By William FurneauX, F.R.G.S. With 218 Illustrations. Crown 8vo., 2s. $6 d$.

A COURSE OF PRACTICAL ELEMENTARY BIOLOGY. BY J. BIDGOOD, B.Sc. With 226 Illustrations. Crown 8vo., $4 s, 6 d$.

ELEMENTARY BOTANY, THEORETICAL AND PRACTICAL. By HENRY EDMONDS, B.Sc. With 342 Illustrations. Crown 8vo., 2s. $6 d$.

STEAM. By William Ripper, Member of the Institution of Civil Engineers. With 185 Illustrations. Crown 8vo., 2s. $6 d$.

AGRICULTURE. By HENRY J. WEBB, $\mathrm{Ph}$.D. With 34 Illustrations. Crown 8vo., 2s. 6t. 


\section{THE LONDON SCIENCE CLASS-BOOKS.}

Edited by G. Carey Foster, F.R.S., and by Sir Philip Magnus, B.Sc., B.A., of the City and Guilds of London Institute.

ASTRONOMY. By Sir ROBERT STAWELL BALL, LL.D., F.R.S With 4r Diagrams. Fcp. 8vo., rs. 6d.

MECHANICS. BY SIR ROBERT STAWELL BALL, LL.D., F.R.S. With 89 Diagrams. Fcp. 8vo., rs. 6d.

THE LAWS OF HEALTH. By W. H. CORFIELD, M A., M.D., F.R.C.P. With 22 Illustrations. Fcp.8vo., Is.6d.

MOLECULAR PHYSICS AND SOUND. By FREDERICK GUTHRIE, F.R.S. With gI Diagrams. Fcp. 8vo., Is. 6d.

GEOMETRY, CONGRUENT FIGURES. By O. HenRICI, Ph.D., F.R.S, With 4 I Diagrams. Fcp. 8vo., Is. 6d.

ZOOLOGY OF THE INVERTEBRATE ANIMALS. By ALEXANDER MACAlisteR, M.D. With 77 Diagrams. Fcp. 8vo., is. $6 d$.

\section{PRACTICAL ELEMENTARY SCIENCE SERIES.}

ELEMENTARY PRACTICAL PHYSIOGRAPHY. (Section I.) By JOHN THORNTON, M.A. With 2I5 Illustrations and a Coloured Spectrum. Crown 8vo., 2s. $6 d$.

ELEMENTARY PRACTICAL PHYSIOGRAPHY. (Section II.). A Course of Lessons and Experiments in Elementary Science for the King's Scholarship Examination. By JOHN ThORnTON, M.A. With 98 Illustrations and a Series of Questions. Crown 8vo., 2s. 6d.

PRACTICAL DOMESTIC HYGIENE. By J. LANE NOTTER, M.A., M.D., and R.H. FIRTH, F.R.C.S. With 83 Illustrations. Crown 8vo., 2s. $6 d$.

A PRACTICAL IN'TRODUC'TION TO THE STUDY OF BOTANY : Flowering Plants. By J. BRETLAND FARMER, F.R.S., M.A. With I2I Illustrations. Crown 8vo., 2s, $6 d$.

ELEMENTARY PRACTICAL HYGIENE. Section I. By William S. FURNEAUX. With Appendix to meet the requirements of the 1902 Syllabus of the Board of Education. With 146 Illustrations. Crown 8vo., 2s. $6 d$.
ZOOLOGY OF THE VERTEBRATE ANIMALS. BY ALEXANDER MACALISTER, M.D. With 59 Diagrams. Fcp. 8vo., is. 6d.

HYDROSTATICS AND PNEUMATICS, By Sir PhILIP MAgNus, B.Sc., B.A. With 79 Diagrams. Fcp. 8vo., Is, 6d. (To be had also with Answers, 2s.) The Worked Solutions of the Problems. 2s.

BOTANY. Outlines of the Classification of Plants. By W. R. MCNAB, M.D. With 118 Diagrams. Fcp. 8vo., Is, 6d.

BOTANY. Outlines of Morphology and Physiology. By W. R. MCNAB, M.D. With 42 Diagrams. Fcp. 8 vo., Is. $6 d$.

THERMODYNAMICS. By RICHARD WORMELL, M.A., D.Sc. With 4 I Diagrams. Fcp. 8vo, is. 6d.

ELEMENTARY PRACTICAL SOUND, LIGHT, AND HEAT. By JOSEPH S. DEXTER. With $1_{52}$ Illustrations. Crown 8vo., 2s. $6 d$.

PRACTICAL MATHEMATICS. By A. G. CRACKNell, M.A., B.Sc. Crown 8vo., 3s. $6 d$.

ELEMENTARY PRACTICAL CHEMISTRY. By G. S. NEwTh, F.I.C., F.C.S. With 108 Illustrations and 254 Experiments. Crown 8vo., 2s. 6d.

ELEMENTARY PRACTICAL PHYSICS. By W. WATSON, D.Sc. With I20 Illustrations and 193 Exercises. Crown 8vo., 2s. $6 d$.

ELEMENTARY BIOLOGY. By JOHN Thornton, M.A. With I08 Illustrations. Crown 8vo., 3s. $6 d$.

THE ELEMENTS OF GEOMETRICAL DRAWING : an Elementary Text-book on Practical Plane Geometry, including an Introduction to Solid Geometry. By HeNry J. SPOONER, C.E., M.Inst.M.E. Crown 8 vo., $3^{\text {s. } 6 d \text {. }}$ 

Bose Jagadis Chund/Response in the livi

|| ||| ||||||||||||| || || || |||||||||||||||||||||||| 
